DAYENE DRUSIAN GOMES

\title{
USO DO DILATÔMETRO DE MARCHETTI PARA A PREVISÃO DA CAPACIDADE DE CARGA E DOS RECALQUES ELÁSTICOS DE ESTACAS
}

\begin{abstract}
Dissertação apresentada à Escola Politécnica da Universidade de São Paulo para obtenção do Título de Mestre em Engenharia.
\end{abstract}

São Paulo 
DAYENE DRUSIAN GOMES

\section{USO DO DILATÔMETRO DE MARCHETTI PARA A PREVISÃO DA CAPACIDADE DE CARGA E DOS RECALQUES ELÁSTICOS DE ESTACAS}

Dissertação apresentada à Escola Politécnica da Universidade de São Paulo para obtenção do Título de Mestre em Engenharia.

Área de Concentração:

Engenharia Geotécnica

Orientador:

Prof. Dr. Faiçal Massad 
Este exemplar foi revisado e alterado em relação à versão original, sob responsabilidade única do autor e com a anuência de seu orientador.

São Paulo, 30 de outubro de 2007.

Assinatura do autor

Assinatura do orientador

FICHA CATALOGRÁFICA

Gomes, Dayene Drusian

Uso do dilatômetro de Marchetti para a previsão da capacidade de carga e dos recalques elásticos de estacas: fundações / D.D. Gomes. -- ed.rev. -- São Paulo, 2007.

$145 \mathrm{p}$.

Dissertação (Mestrado) - Escola Politécnica da Universidade de São Paulo. Departamento de Engenharia de Estruturas e Geotécnica.

1.Dilatômetro de Marchetti 2.Estacas 3.Capacidade de carga 4.Recalques (Previsão) 5.Mecânica dos solos I.Universidade de São Paulo. Escola Politécnica. Departamento de Engenharia de Estruturas e Geotécnica II.t. 
A Deus pelo conforto nas horas difíceis. A minha família pelo incentivo e compreensão. 


\section{AGRADECIMENTOS}

Agradeço em especial ao meu orientador Prof. Dr. Faiçal Massad pelas horas despendidas nos seus atendimentos e pela importância da sua orientação e ensinamentos que muito contribuíram para o meu aprendizado.

Ao meu chefe e professor da graduação, Prof. Dr. Antônio Sérgio Damasco Penna, que muito me incentivou, auxiliou na escolha do tema deste trabalho e que tornou possível o meu contato com os ensaios dilatométricos e a realização dos ensaios feitos no Campo Experimental da USP.

Aos funcionários da Damasco Penna, que contribuíram com desenhos, relatórios entre outros e em especial ao Técnico da empresa José Simões o qual realizou o ensaio de DMT no Campo Experimental da USP e muito me explicou sobre o funcionamento do equipamento.

A minha família e namorado por me confortar e dar incentivo e em especial ao meu irmão Deyvis que me ajudou na digitalização das figuras e na elaboração das listas.

Agradeço a Deus pela força nos momentos difíceis e a todos que em geral conviveram comigo nestes 2 últimos anos, os quais de alguma forma contribuíram para esta dissertação ou apenas souberam compreender esta fase que passei. 


\section{SUMÁRIO}

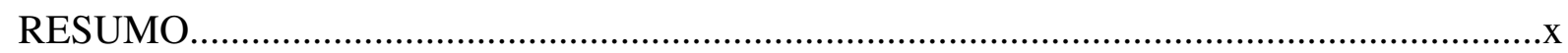

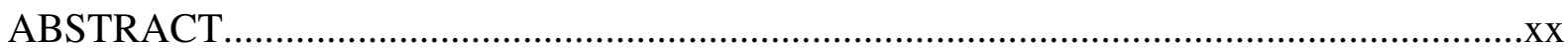

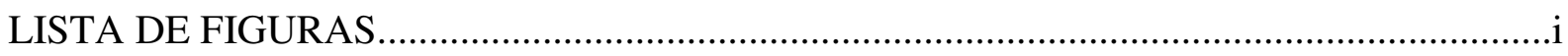

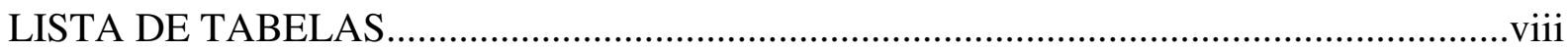

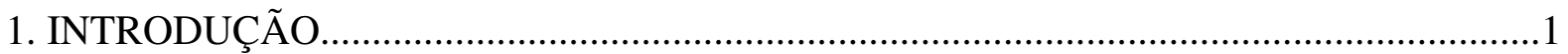

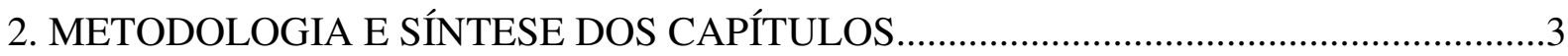

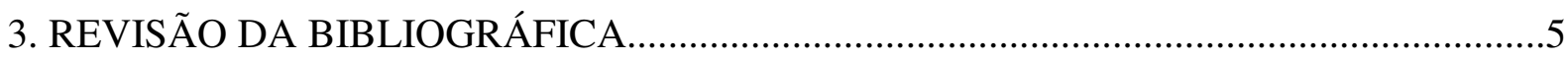

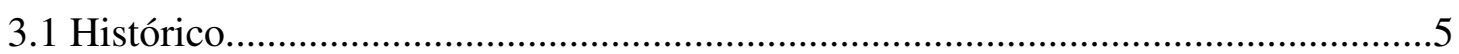

3.2. Apresentação dos componentes do equipamento................................................5

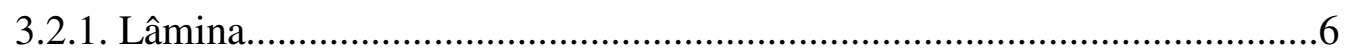

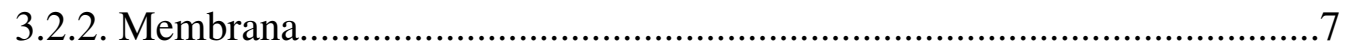

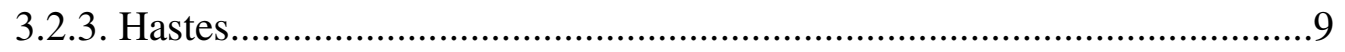

3.2.4. Cabo elétrico-pneumático.................................................................10

3.2.5. Unidade de controle de leituras e pressões...........................................10

3.2.6. Cilindro de gás de nitrogênio extra-seco..............................................11

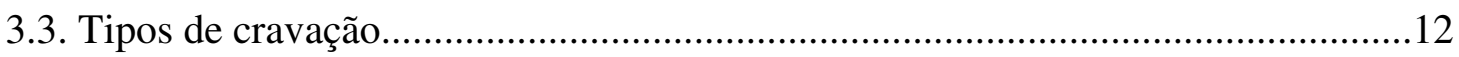

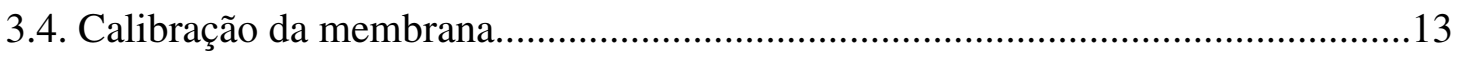

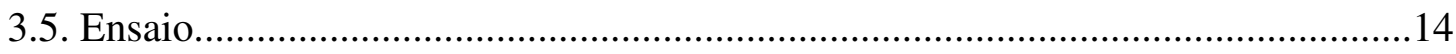

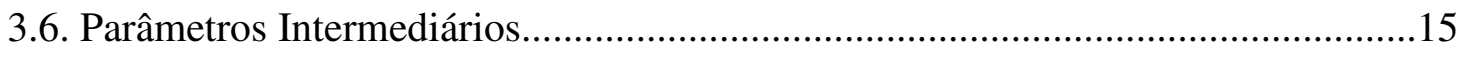

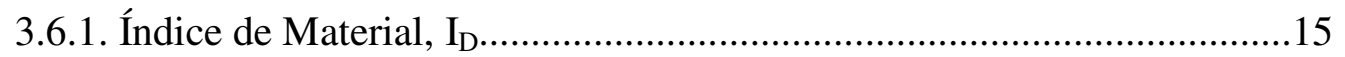

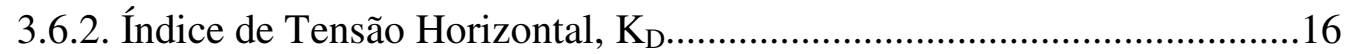

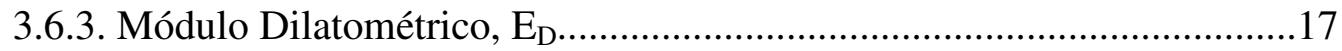

3.6.4 O Dilatômetro testado em solos tropicais brasileiros - Heraldo L.

Giacheti \& Anna S. P. Peixoto e Giuliano De Mio e David de Carvalho.........19

3.7. Correlações para obtenção de parâmetros geotécnicos..........................................23

3.7.1 Parâmetros relacionados ao histórico de tensões.....................................23

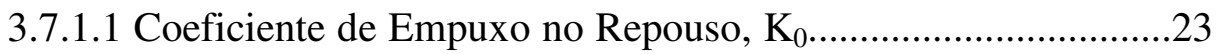




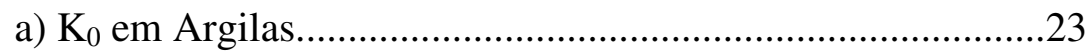

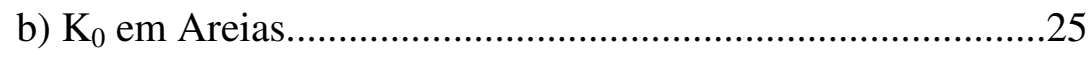

c) Exemplo de validação destas equações...............................27

3.7.1.2 Razão de sobre-adensamento (OCR) .....................................27

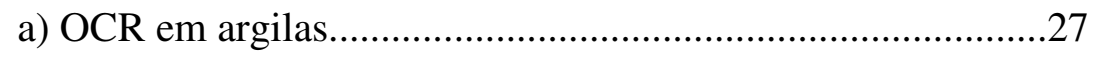

b) OCR em Areias.............................................................29

3.7.2 Parâmetros relacionados à resistência do solo..........................................30

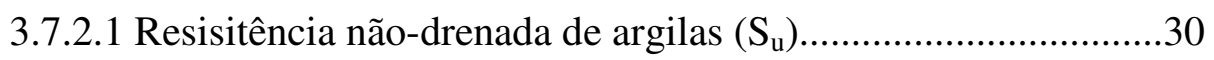

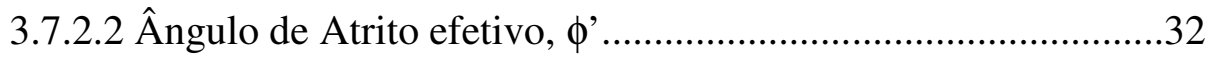

3.7.3 Parâmetros relacionados à deformabilidade...........................................34

3.7.3.1 Módulo edométrico (M) .......................................................34

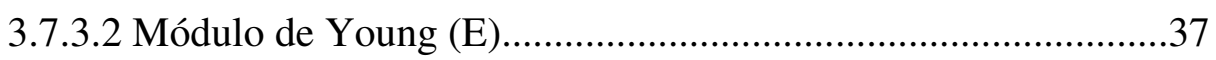

3.7.3.3 Módulo de Deformação Cisalhante $(\mathrm{G})$....................................38

3.7.4 Síntese das correlações apresentadas...........................................41

4. MÉTOdOS TEÓRICOS APLICADOS PARA A OBTENÇÃO DA ESTIMATIVA DE RECALQUES E CARGAS ADMISSÍVEIS EM ESTACAS............................................42

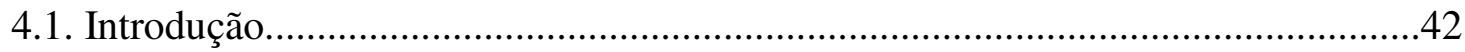

4.2. Métodos para a obtenção das capacidades de carga................................................42

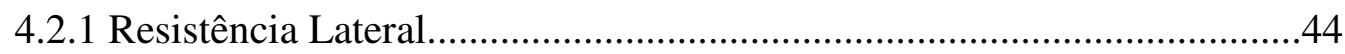

4.2.1.1 Método $\alpha$ (Tensões Totais) .................................................44

4.2.1.2 Método $\beta$ (Tensões Efetivas) …...........................................46

4.2.1.3 Método $\lambda$ (Misto)..............................................................4

4.2.2 Resistência de Ponta........................................................................49

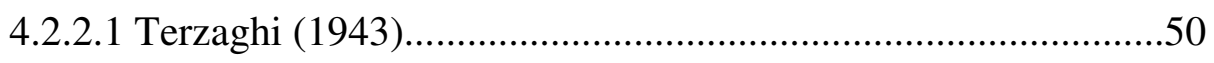

4.2.2.2 Meyerhof (1953)........................................................... 51

4.2.2.3 Berezantzev (1961).......................................................53

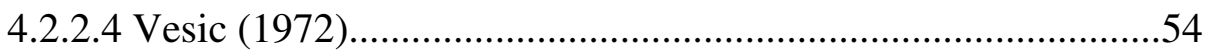

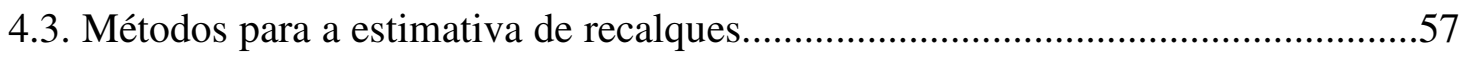


4.3.2 Método de Randolph e Wroth.

4.4. Métodos empíricos para a previsão da capacidade de carga em estacas utilizando o DMT.

4.4.1. Método de Marchetti et al para estacas cravadas em argila. .67

4.4.2. Método de Powell et al. (2001) para estacas cravadas em argila.. 68

5. CAMPO EXPERIMENTAL DE FUNDAÇÃO DA USP/ABEF - COMPARAÇÕES DE RESULTADOS OBTIDOS NO CAMPO x PREVISÕES UTILIZANDO O DMT. .70

5.1. Introdução. .70

5.2. Caracterização Geológica e Geotécnica .70

5.3. Execução dos ensaios dilatométricos. .73

5.4. Análise dos ensaios de DMT. .77

5.5. Análise das provas de carga publicadas na ABEF em comparação com os resultados dos DMT's. .85

5.5.1 Tipos de fundação e Provas de Cargas executadas no Campo Experimental da USP. 85

5.5.2 Análise comparativa da capacidade de carga em estacas. .86

5.5.2.1 Método de Powell et al. .87

5.5.2.2 Combinação da resistência de atrito lateral (método $\beta$ ) e de ponta (Terzaghi).

5.5.2.3Combinação da resistência de atrito lateral (método $\beta$ ) e ponta (Berezantzev) 1961. .90

5.5.2.4 Combinação da resistência de atrito lateral (método $\beta$ ) e de ponta (Vesic, 1972). .91

5.5.2.5 Análise das parcelas de atrito e ponta. .92

5.5.3 Análise comparativa dos recalques nas estacas. .95

5.5.3.1 Método de Poulos e Davis, 1980. .96

a) Módulo Young (E) segundo Robertson et al (1989) . .96

b) Módulo Young (E) segundo Marchetti (1997). 102

5.5.3.2 Método de Randolph e Wroth $(1977,1978)$. 109

5.5.3.3 Comparação entre os Métodos de cálculo. 116 


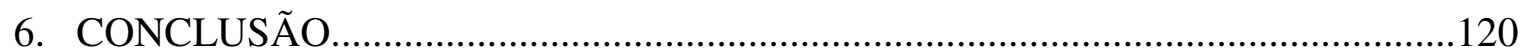

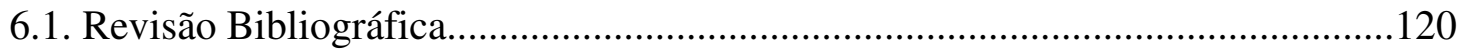

6.2. Classificação e parâmetros dos solos.................................................................120

6.3. Previsão da Capacidade de Carga em estacas.......................................................121

6.4. Estimativa dos recalques elásticos em estacas........................................................123

6.5. Conclusão geral quanto ao uso do DMT para fundações em estacas...................124

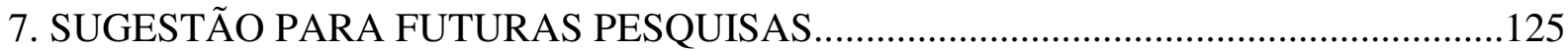

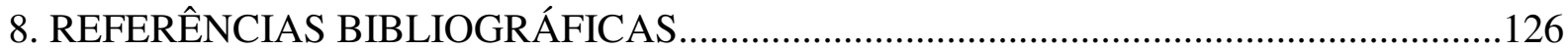

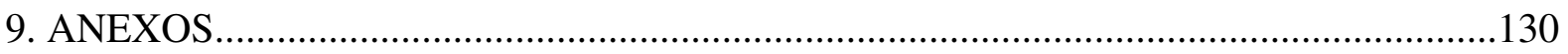




\section{RESUMO}

No Brasil emprega-se, quase que exclusivamente, o $\mathrm{N}$ do SPT para o cálculo e estimativa da capacidade de carga e recalques em estacas. Os ensaios de campo fornecem estimativas rápidas dos parâmetros geotécnicos para o dimensionamento das fundações, sendo que seu uso tem crescido lentamente em algumas empresas da construção civil. A utilização do Dilatômetro de Marchetti no país ainda não é muito difundida, esperando-se, com a apresentação desse trabalho, poder contribuir para tornar a técnica mais utilizável no meio técnico nacional.

O trabalho mostra que uma melhor caracterização do local pode ser obtida com o uso do DMT. Com os dados do ensaio dilatométrico os projetos de fundação ficam mais precisos ocorrendo em alguns casos economias na execução da fundação.

O presente trabalho apresenta uma revisão bibliográfica do ensaio dilatométrico, contemplando publicações recentes sobre o assunto. A obtenção de parâmetros geotécnicos do solo, fornecidos por intermédio de ensaios de DMT, permitiu o emprego dos conceitos clássicos da Mecânica dos Solos em metodologias teóricas de previsão da capacidade de carga e a estimativa de recalques em estacas ensaiadas no Campo Experimental da USP.

O objetivo desta pesquisa é apresentar uma alternativa de se projetar com auxílio de ensaios dilatométricos e obter resultados tão bons ou melhores do que os obtidos até o presente momento com as sondagens à percussão e, principalmente, com o intuito de apresentar mais uma ferramenta como suporte para os projetistas. 


\begin{abstract}
In Brazil, it is employed almost exclusively the " $\mathrm{N}$ " (number of blows required to drive the sampler the last $30 \mathrm{~cm}$ into the soil) of SPT to calculate and estimate the bearing capacity and settlement in piles. The field tests provide quick estimates of the geotechnical parameters for the foundation designs, this practice has been growing slowly in some of Civil Construction Companies. The use of Flat Dilatometer Test in the country is very rare and it is expected that this work will contribute to increase its use among us.
\end{abstract}

In this work is shown that a better characterization of the site can be obtained with DMT. With the flat dilatometer test, the foundation designs may be carried out within a more precise base and in some cases economy may be achieved.

The current work starts with a bibliography review of the flat dilatometer test. It also contemplates recent papers about the subject. The geotechnical parameters of the soil were supplied through DMT's, allowing the employment of the classical concepts of Soil Mechanics in theoretical methodologies of bearing capacity prediction and the elastic settlements of piles tested in full size at the Foundation Experimental Site of EPUSP.

The aim of this research is to present an alternative to design with the help of dilatometer test, obtaining as good results or even better than the ones achieved so far with the Standard Penetration Test, and mainly to show one more tool as a support to the designers. 


\section{LISTA DE FIGURAS}

Figura 3.1 - Montagem esquemática do dilatômetro - (Marchetti 2001)................................6

Figura 3.2 - Detalhe da lâmina (Marchetti 2001)...................................................................

Figura 3.3 - Detalhes da membrana e sua expansão (USDOT , 1992)....................................

Figura 3.4 - Detalhes de fixação da membrana (Marchetti 2001)............................................

Figura 3.5 - Detalhes da ligação haste/lâmina (Marchetti 2001).............................................

Figura 3.6 - Tipos de cabos elétricos-pneumáticos utilizados no ensaio DMT (Marchetti

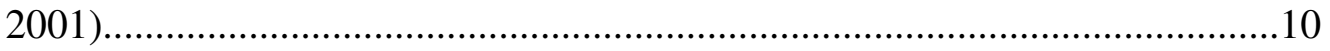

Figura 3.7 - Detalhe da unidade de controle (Marchetti 2001)............................................11

Figura 3.8 - Detalhe da unidade de controle com cilindro de gás (Marchetti 2001)...............11

Figura 3.9 - Equipamentos de cravação estática (Marchetti 2001) ........................................13

Figura 3.10 - Pressão de Contato na interface solo membrana em função do deslocamento da

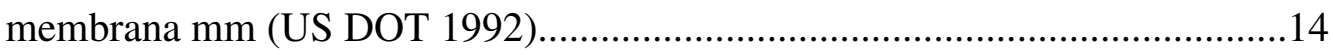

Figura 3.11 - Classificação do tipo de solo, peso específico e consistência ou compacidade obtidos através de $\mathrm{I}_{\mathrm{D}}$ e $\mathrm{E}_{\mathrm{D}}$, (Marchetti e Crapps, 1981).................................18

Figura 3.12 - Resultado dos testes DMT, peso unitário total, distribuição granulométrica, perfil da sondagem (SPT)-Campo Experimental da UNESP-BAURU-SP.. 19

Figura 3.13 - Comparação dos resultados do $\mathrm{E}_{\mathrm{D}}$ do DMT e $\mathrm{E}_{\mathrm{pmt}}$ do pressiômetro de Ménard.Campo Experimental da UNESP - BAURU - SP.

Figura 3.14 - Resultado dos testes DMT, peso unitário total, distribuição granulométrica, perfil da sondagem (SPT) - Campo Experimental da UNICAMP CAMPINAS - SP

Figura 3.15 - Resultado dos testes DMT, peso unitário total, distribuição granulométrica, perfil da sondagem (SPT) - Campo Experimental da USP-SÃO CARLOS.. 22

Figura 3.16 - Classificação do solo proposta por Marchetti e Crapps (1981) para cada Campo Experimental. (a) Bauru (b) Campinas (c) São Carlos. .22

Figura 3.17 - Correlação $K_{0}-K_{D}$ em argilas baseada em Marchetti (1980), Powel \& Uglow (1986) e Lacasse \& Lunne (1988) 
Figura 3.18 - Ábaco para estimativa de $\mathrm{K}_{0}$ a partir de $\mathrm{K}_{\mathrm{D}}(\mathrm{DMT})$ e $\mathrm{q}_{\mathrm{c}}(\mathrm{CPT})$ Marchetti (1985).

Figura 3.19 - Comparação do $\mathrm{K}_{0}$ do DMT (Baldi et al, 1986 e Marchetti, 1980) e $\mathrm{K}_{0}$ do PMT - CE da UNESP - BAURU - SP

Figura 3.20 - Correlação entre KD e OCR para solos coesivos de várias áreas geográficas (Kamei e Iwasaki, 1995).

Figura 3.21 - Ábaco de Marchetti (1985), modificado por Campanella e Robertson (1991) para avaliação de $\phi$ ' através de $\mathrm{K}_{\mathrm{D}}$ em areias não cimentadas, apud (Marchetti, 1997)

Figura 3.22 - Resultados obtidos do ângulo de atrito efetivo do solo( $\phi$ ') calculados com o DMT em comparação com o mesmo parâmetro obtido em laboratório. 34

Figura 3.23 - Correlação entre $R_{M}$ e $K_{D}$ Marchetti (1980). 35

Figura 3.24 - Comparação entre os valores dos módulos edométrico (M) obtidos com o DMT e com ensaios edométricos em amostras indeformadas. $\left(\mathrm{a}_{1}\right)$ e $\left(\mathrm{a}_{2}\right)$ UNICAM $\left(b_{1}\right)$ e $\left(b_{2}\right)$ USPSC .36

Figura 3.25 - Curva típica de carregamento e definição dos módulos de elasticidade (Pinto, 1998 apud Siviero, 2003).

Figura 3.26 - Comparação dos Valores de $\mathrm{G}_{0}$ para os Campos Experimentais. (a) UNESP (b) UNICAMP e (c) USPSC

Figura 3.27 - Comparação entre o $\mathrm{G}_{0}$ previsto e $\mathrm{G}_{0}$ medido em laboratório (Hryciw, 1990) apud Jardim, 1998.

Figura 4.1 - Modelo da expressão de equilíbrio de uma estaca sujeita à compressão.

Figura 4.2 - Curvas para determinação do coeficiente $\alpha$ - sendo L o comprimento da estaca embutido em argila média a rija (Tomlinson 1994, apud Velloso e Lopes 2002).

Figura 4.3 - Determinação do coeficiente $\lambda$ de acordo com o comprimento da estaca (Viajayergiva e Focht, 1972 apud Poulos 1980).

Figura 4.4 - Mecanismo de ruptura de diversas soluções teóricas. a)Terzaghi (1943) b) Meyerhof (1953) c)Berezantzev (1961) d) Vesic (1972) apud Velloso e Lopes 2002). 
Figura 4.5 - Fatores de capacidade de carga (Meyerhof, 1953).

Figura 4.6 - Fatores de capacidade de carga Berezantzev et al (1961).

Figura 4.7 - Elementos do mecanismo de transferência de carga da estaca para o solo. a) cargas e tensões na estaca, b) diagrama carga-profundidade, c) recalques e d) diagramas de atrito lateral e de carga axial - (Vesic, 1977 apud Velloso e Lopes 2002).

Figura 4.8 - a) problema analisado b) elemento de estaca c) ação da estaca sobre os solo e d) ação do solo sobre a estaca (Poulos e Davis 1974)

Figura 4.9 - Fatores para o cálculo de recalque de estacas: a) fator $\mathrm{I}_{\mathrm{o}}$, b) Influência da compressibilidade da estaca, c) da espessura "finita" do solo compressível, d) do coeficiente de Poisson do solo (Poulo e Davis, 1974).

Figura 4.10 - Fator de correção para a base da estaca em solo mais rígido: a) para L/B=75, b) para $L / B=50$, c) para $L / B=25$, d) para $L / B=10$ e e) para $L / B=5$ (Poulos e Davis, 1980). .61

Figura 4.11 - Deformação das camadas (Randolph, 1977 apud Velloso e Lopes 2002)..... .62

Figura 4.12 - Previsão versus medidas da capacidade de carga de estaca usando o método de compressão via DMT (Powell et al. 2001 apud Marchetti, 2001).....

Figura 5.1 - Perfil ilustrativo de amostras indeformadas retirada do CEUSP... .71

Figura 5.2 - Croquis da locação dos ensaios e das estacas executados no Campo Experimental da USP (ABEF, 1989 e Souza, 2001) modificado. .72

Figura 5.3 - Vista do caminhão na execução da cravação do DMT no CEUSP. .73

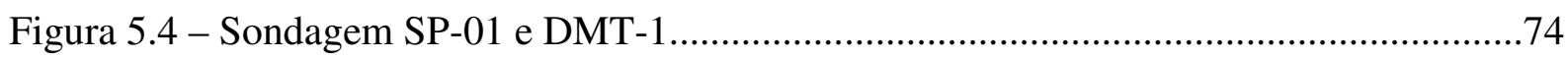

Figura 5.5 - Sondagem SP-02 e DMT-2 .................................................................... 75

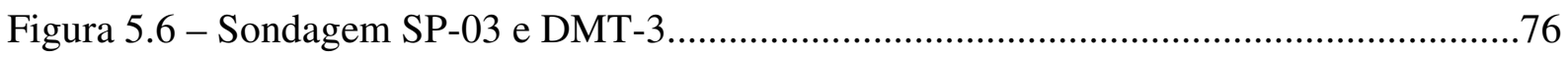

Figura 5.7 - Medida da pressão $\mathrm{p}_{0} \mathrm{x}$ profundidade - Contendo os 3 ensaios de DMT.............77

Figura 5.8 - Medida da pressão $\mathrm{p}_{1} \mathrm{x}$ profundidade - Contendo os 3 ensaios de DMT.............77

Figura $5.9-\mathrm{I}_{\mathrm{D}} \mathrm{x}$ profundidade - Nos 3 ensaios indicando o material como silte arenoso, conforme sondagem local. .78

Figura $5.10-\mathrm{K}_{\mathrm{D}} \mathrm{x}$ profundidade - Solo identificado como sobre-adensado por possuir valores 
Figura 5.11 - $\mathrm{E}_{\mathrm{D}} \mathrm{x}$ Profundidade. .79

Figura $5.12-\gamma \times$ Profundidade

Figura 5.13 - Módulo Edométrico do DMT $\left(\mathrm{M}_{\mathrm{DMT}}\right)$ variando com a profundidade, calculado segundo Marchetti (1980), Eq. 3.39 e Tabela 3.5. 80

Figura 5.14 - Módulo de deformação cisalhante $\left(\mathrm{G}_{0}\right)$ proposta de Hryciw (1990) - Eq. 3.50 . .81

Figura 5.15 - Módulo de Young (E) variando com a profundidade, Robertson et al. (1989)

Figura 5.16 - Módulo de Young (E) variando com a profundidade, Marchetti (1997). 82

Figura 5.17 - Valores de OCR variando com a profundidade, Schmertmann (1988), Eq. 3.23 . .82

Figura 5.18 - Valores de $\mathrm{K}_{0}$ variando com a profundidade, Schmertmann (1983). .83

Figura 5.19 - Comparação da estimativa do ângulo de atrito através dos ensaios de DMT por Marchetti e Crapps (1981), eq. 3.33. e os ensaios de laboratório). 84

Figura 5.20 - Comparação da estimativa do ângulo de atrito através dos ensaios de DMT por Marchetti (1997), eq. 3.37 e os ensaios de laboratório. .84

Figura 5.21 - Carga de ruptura medida versus calculada utilizando oS DMT's (Powell et al..

Figura 5.22 - Comparação entre a resistência de ponta calculada ao longo da profundidade e resistência de ponta medida (Powell et al, 2001). 88

Figura 5.23 - Comparação entre atrito lateral unitário médio calculado e medido (Powell et al)

Figura 5.24 - Carga de ruptura medida versus calculada ( " $\beta$ " + Terzaghi, 1943) .89

Figura 5.25 - Carga de ruptura medida versus calculada utilizando a média dos DMT's (Método das Tensões Efetivas “ $\beta$ " + Critério de Ponta por Berezantzev, 1961) .90

Figura 5.26 - Carga de ruptura medida versus calculada utilizando o DMT-1 (Método das Tensões Efetivas “ $\beta$ ” + Critério de Ponta por Vesic, 1972).

Figura 5.27 - Comparação entre atrito lateral unitário médio calculado e medido (Método $\beta)$

Figura 5.28 - Comparação entre a resistência de ponta calculada e resistência de ponta medida (Método Terzaghi 1943). 
Figura 5.29 - Comparação entre a resistência de ponta calculada e resistência de ponta medida (Método Berezantzev, 1961).

Figura 5.30 - Comparação entre a resistência de ponta calculada ao longo da profundidade e resistência de ponta medida (Método Vesic 1972).

Figura 5.31 - Gráfico de carga versus recalque para estaca hélice contínua (HLC-4), método de Poulos e Davis, utilizando expressão 3.42 e F=4 96

Figura 5.32 - Gráfico de carga versus recalque para estaca hélice contínua (HLC-6), método de Poulos e Davis, utilizando expressão 3.42 e F=4. .97

Figura 5.33 - Gráfico de carga versus recalque para estaca franki (FRA-1), método de Poulos e Davis, utilizando expressão 3.42 e F=4.

Figura 5.34 - Gráfico de carga versus recalque para estaca franki (FRA-2), método de Poulos e Davis, utilizando expressão 3.42 e F=4. .98

Figura 5.35 - Gráfico de carga versus recalque para estaca escavada com lama bentonítica (EST-2), método de Poulos e Davis, utilizando expressão 3.42 e F=4. .98

Figura 5.36 - Gráfico de carga versus recalque para estaca barrete (BAR-1), método de Poulos e Davis, utilizando expressão 3.42 e F=4.

Figura 5.37 - Gráfico de carga versus recalque para estaca pré-moldada (PRE-2), método de Poulos e Davis, utilizando expressão 3.42 e F=4..

Figura 5.38 - Gráfico de carga versus recalque para estaca pré-moldada (PRE-4), método de Poulos e Davis, utilizando expressão 3.42 e F=4 100

Figura 5.39 - Gráfico de carga versus recalque para estaca strauss (STR-1), método de Poulos e Davis, utilizando expressão 3.42 e $\mathrm{F}=4$.

Figura 5.40 - Gráfico de carga versus recalque para estaca metálica (MET-1), método de Poulos e Davis, utilizando expressão 3.42 e F=4.

Figura 5.41 - Gráfico de carga versus recalque para micro-estaca (M-4), método de Poulos e Davis, utilizando expressão 3.42 e $\mathrm{F}=4$. 101

Figura 5.42 - Gráfico de carga versus recalque para estaca hélice contínua (HLC-4), método de Poulos e Davis, utilizando expressão 3.43. 103

Figura 5.43 - Gráfico de carga versus recalque para estaca hélice contínua (HLC-6), método de Poulos e Davis, utilizando expressão 3.43. 103

Figura 5.44 - Gráfico de carga versus recalque para estaca franki (FRA-1), método de Poulos e Davis, utilizando expressão 3.43. 104

Figura 5.45 - Gráfico de carga versus recalque para estaca franki (FRA-2), método de Poulos e Davis, utilizando expressão 3.43. .104 
Figura 5.46 - Gráfico de carga versus recalque para estaca estacão (EST-2 método de Poulos e Davis, utilizando expressão 3.43. .105

Figura 5.47 - Gráfico de carga versus recalque para estaca barrete (BAR-1), método de Poulos e Davis, utilizando expressão 3.43. 105

Figura 5.48 - Gráfico de carga versus recalque para estaca pré-moldada (PRE-2), método de Poulos e Davis, utilizando expressão 3.43. 106

Figura 5.49 - Gráfico de carga versus recalque para estaca pré-moldada (PRE-4), método de Poulos e Davis, utilizando expressão 3.43. 106

Figura 5.50 - Gráfico de carga versus recalque para estaca strauss (STR-1), método de Poulos e Davis, utilizando expressão 3.43. 107

Figura 5.51 - Gráfico de carga versus recalque para estaca metálica (MET-1), método de Poulos e Davis, utilizando expressão 3.43. 107

Figura 5.52 - Gráfico de carga versus recalque para micro-estaca (M-4), método de Poulos e Davis, utilizando expressão 3.43. 108

Figura 5.53 - Gráfico de carga versus recalque para estaca hélice (HLC-4), método de Randolph e Wroth $(1977,1978)$ utilizando a expressão 3.50. 110

Figura 5.54 - Gráfico de carga versus recalque para estaca hélice (HLC-6), método de Randolph e Wroth $(1977,1978)$ utilizando a expressão 3.50. 110

Figura 5.55 - Gráfico de carga versus recalque para estaca franki (FRA-1), método de Randolph e Wroth $(1977,1978)$ utilizando a expressão 3.50. 111

Figura 5.56 - Gráfico de carga versus recalque para estaca franki (FRA-2), método de Randolph e Wroth $(1977,1978)$ utilizando a expressão 3.50. 111

Figura 5.57 - Gráfico de carga versus recalque para o estacão (EST-2), método de Randolph e Wroth $(1977,1978)$ utilizando a expressão 3.50.

Figura 5.58 - Gráfico de carga versus recalque para estaca barrete (BAR-1), método de Randolph e Wroth $(1977,1978)$ utilizando a expressão 3.50. 112

Figura 5.59 - Gráfico de carga versus recalque para estaca pré-moldada (PRE-2), método de Randolph e Wroth $(1977,1978)$ utilizando a expressão 3.50. 113

Figura 5.60 - Gráfico de carga versus recalque para estaca pré-moldada (PRE-4), método de Randolph e Wroth $(1977,1978)$ utilizando a expressão 3.50)..... .113

Figura 5.61 - Gráfico de carga versus recalque para estaca strauss (STR-1), método de Randolph e Wroth $(1977,1978)$ utilizando a expressão 3.50. 114

Figura 5.62 - Gráfico de carga versus recalque para estaca metálica (MET-1), método de Randolph e Wroth (1977, 1978) utilizando a expressão 
Figura 5.63 - Gráfico de carga versus recalque para micro-estaca (M-4), método de Randolph e Wroth $(1977,1978)$ utilizando a expressão 3.50.

Figura 5.64 - Comparação entre recalques medidos no ensaio lento e recalques calculados.

Figura 5.65 - Comparação entre recalques medidos no ensaio rápido e recalques calculados

Figura 5.66 - Comparação entre recalques medidos no ensaio lento e recalques calculados

Figura 5.67 - Comparação entre recalques medidos no ensaio rápido e recalques calculados

Figura 5.68 - Comparação entre recalques medidos no ensaio lento e recalques calculados 118

Figura 5.69 - Comparação entre recalques medidos no ensaio rápido e recalques calculados

Figura 6.1 - Comparação da capacidade de carga medida nas provas de carga das estacas executadas no CEUSP e as capacidades de carga previstas por diferentes métodos 


\section{LISTA DE TABELAS}

Tabela 3.1 - Classificação do tipo de solo baseada no $I_{D}$ (Marchetti, 1980)...........................16

Tabela 3.2 - Correlações para obtenção do OCR segundo Marchetti e Crapps (1981)............28

Tabela 3.3 - Valores médios de OCR em areia..............................................................29

Tabela 3.4 - Valores de $\mathrm{N}_{\mathrm{c}}$ sugeridos por Roque et al. (1988)...............................................31

Tabela 3.5 - Cálculo de $\mathrm{R}_{\mathrm{M}}$ em função de $\mathrm{I}_{\mathrm{D}}$ e $\mathrm{K}_{\mathrm{D}}$ (Marchetti, 1980).....................................35

Tabela 3.6 - Sugestão para o Fator de Correção F segundo alguns autores...............................38

Tabela 3.7 - Parâmetros obtidos com o emprego do dilatômetro (baseado na ASTM,

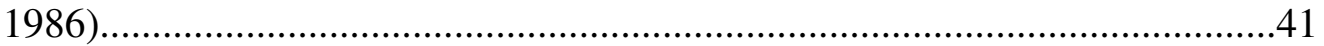

Tabela 4.1 - Valores aproximados do coeficiente $\beta$ segundo Fellenius (1996).......................47

Tabela 4.2 - Valores aproximados do coeficiente $\lambda$ segundo Fellenius (1996)......................49

Tabela 4.3 -Fatores de capacidade de carga (Bowles, 1968) apud Velloso e Lopes

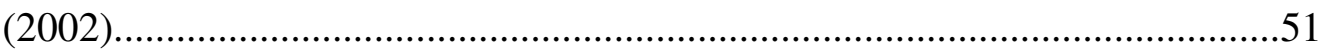

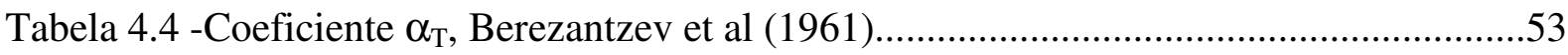

Tabela 4.5 -Fatores de capacidade de carga $\mathrm{N}_{\mathrm{c}}$ e $\mathrm{N}_{\sigma}$, (Vesic, 1972)......................................56

Tabela 4.6 -Valores de E, v (Poulos e Davis, 1980 apud Velloso e Lopes, 2002)..................62

Tabela 5.1 -Resumo das características das estacas e dos resultados de prova de carga de

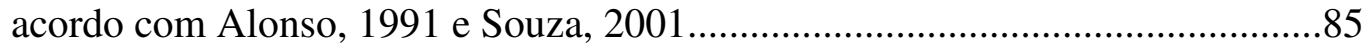

Tabela 5.2 - Arupamento de estacas segundo proximidade aos ensaios de DMT...................86

Tabela 5.3 - Tabela resumo de recalques calculados pelo método de Poulos e Davis utilizando

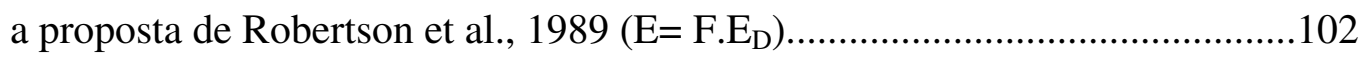

Tabela 5.4 - Tabela resumo de recalques calculados pelo método de Poulos e Davis utilizando

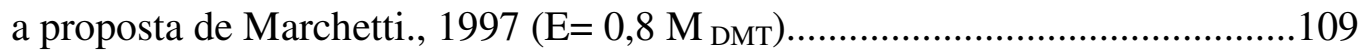

Tabela 5.5 - Tabela resumo de recalques calculados pelo método de Randolph e Wroth (1977, 1978) utilizando o $\mathrm{G}_{0}$ proposto por Hryciw, 1990 (expressão 3.50)................115

Tabela 5.6 - Indicação de parâmetros utilizados..................................................................116 


\section{INTRODUÇÃO}

A segurança e a economia de um projeto de fundações estão sempre atrelados a um bom reconhecimento das condições do subsolo. É fato que a investigação geotécnica no Brasil ficou resumida, durante muito tempo, na execução dos ensaios de Sondagem à Percussão (SPT). Apenas em alguns projetos grandiosos era possível testar outros métodos geotécnicos de investigação do subsolo. O custo envolvido no Brasil na execução de sondagens à percussão varia entre $0,2 \%$ e $0,5 \%$ do custo total da obra, sendo estas informações obtidas de suma importância para a elaboração da solução técnica, à previsão do seu desempenho e à garantia de sua segurança e economia.

Os ensaios de campo fornecem estimativas rápidas dos parâmetros geotécnicos para o dimensionamento das fundações. Dentre os ensaios hoje disponíveis em nível nacional estão a Sondagem de Simples Reconhecimento (SPT), o Ensaio de Penetração de Cone (CPT), o Ensaio Dilatômetro de Marchetti (DMT), os Ensaios Pressiométricos tipo Ménard entre outras técnicas (PMT), o Ensaio de Palheta (Vane Test) e o Ensaio de Placa (PLT). Escolheu-se o DMT para realização do presente trabalho.

De acordo com Penna (2006a), o dilatômetro de Marchetti é um instrumento poderoso para prever recalques de edifícios apoiados em solos nos quais o adensamento primário ou secundário não é relevante. Penna tem usado, com sucesso, o DMT em vários projetos de fundação direta em edifícios na cidade de São Paulo, pois este ensaio tem possibilitado boas estimativas do Módulo de Deformabilidade dos solos e, conseqüentemente, dos recalques.

Segundo Marshall e Berry (2006), para edifícios altos e de elevadas cargas, o projeto da fundação, baseado em metodologias que utilizam apenas o ensaio de SPT, limita muitas vezes o solo a baixas capacidades de suporte. A execução do DMT no mesmo local permite o uso de capacidades significativamente mais altas; assim a possibilidade da utilização de uma maior capacidade de suporte do solo justifica o custo adicional da execução do teste. Apesar dos ótimos resultados obtidos quando utilizaram o DMT, esses autores lembram que uma das desvantagens deste ensaio é que ele não retira amostra do solo, o que quase sempre torna indispensáveis sondagens de simples reconhecimento no local. Outro problema é em situações de solos muito duros, onde as hastes do DMT não conseguem penetrar, comprometendo a análise, visto que naquela determinada profundidade, na qual não foi possível executar o ensaio, a fundação ainda teria influência. 
Na Segunda Conferência Internacional de DMT que foi realizada em Washington, em Abril de 2006, Failmezger e Till (2006) apresentou cinco estudos de casos em que os projetos de fundação foram inicialmente elaborados com base no SPT e posteriormente reprojetados com base no DMT e a economia variou de 200 a 800 mil dólares.

O Dilatômetro de Marchetti pode ser utilizado em vários tipos de solos, tais como: coesivos e não coesivos, saturados e não saturados, normalmente adensados e sobre adensados, naturais e compactados. Pode ser aplicado para obtenção de parâmetros do solo, para realização de projetos em fundação rasa, submetida a esforços verticais, fundações profundas com cargas verticais e horizontais, no controle de compactação, previsão de recalque de fundação de edifício (aterro, tanque, piso), avaliação do módulo de deformabilidade edométrica (de adensamento) dos solos, avaliação da resistência de argilas saturadas solicitadas em condições não drenadas (rápidas), identificação estratigráfica do subsolo, detecção de superfícies de escorregamento em taludes instáveis, identificação da potencialidade de liquefação de massas arenosas entre outros usos.

O procedimento consiste em cravar verticalmente no terreno, mediante uma força do tipo estática ou dinâmica, uma lamina de aço com uma membrana circular, também de aço localizada em um dos lados. Ao ser atingida a profundidade do ensaio, a membrana é expandida medindo-se as pressões que provocam deslocamentos de 0,05mm (pressão A) e 1,10mm (pressão B). Na deformação de 1,10mm, a pressão é reduzida, registrando-se seu valor quando o deslocamento de $0,05 \mathrm{~mm}$ é atingido (pressão C).

Este ensaio é, de certa forma, uma prova de carga horizontal em uma área reduzida, onde são registrados apenas dois dados de carregamento e um de descarregamento. A investigação do terreno prossegue cravando a lamina no solo com o incremento de profundidade entre 0,15 e $0,30 \mathrm{~m}$, sendo mais utilizado o incremento de $0,20 \mathrm{~m}$. É feita uma calibração na membrana antes do início e ao término de todo ensaio.

O resultado deste ensaio envolve primeiramente a identificação de três parâmetros do DMT chamados intermediários, que são o Índice de Material $\left(\mathrm{I}_{\mathrm{D}}\right)$, o Índice de Tensão Horizontal $\left(\mathrm{K}_{\mathrm{D}}\right)$, e o Módulo Dilatométrico $\left(\mathrm{E}_{\mathrm{D}}\right)$. Estes parâmetros têm sido utilizados na prática da engenharia internacional e, recentemente, nacional. 
Os ensaios de DMT serão utilizados nesta pesquisa como meio de obtenção dos parâmetros geotécnicos do solo, procurando-se contribuir para que os conceitos clássicos da Mecânica dos Solos e os avanços dos conhecimentos, somados com a pratica de projetos, permitam que metodologias racionais de análise sejam mais precisas nos projetos de fundações.

O presente trabalho tem como principal objetivo determinar parâmetros da Mecânica dos Solos através do ensaio de DMT e empregá-los em algumas metodologias teóricas de previsão de capacidade de carga e recalques em estacas, comparando-os com os resultados das provas de carga já realizadas no Campo Experimental da USP (CEUSP).

\section{METODOLOGIA E SÍNTESE DOS CAPÍTULOS}

A metodologia deste trabalho envolve basicamente três etapas, descritas a seguir.

1 Execução de ensaios dilatométricos no Campo Experimental da USP de São Paulo (CEUSP) para a obtenção dos parâmetros intermediários do solo: Índice de Material $\left(\mathrm{I}_{\mathrm{D}}\right)$, o Índice de Tensão Horizontal $\left(\mathrm{K}_{\mathrm{D}}\right)$, e o Módulo Dilatométrico $\left(\mathrm{E}_{\mathrm{D}}\right)$.

2 Com os valores de $\left(\mathrm{I}_{\mathrm{D}}\right),\left(\mathrm{K}_{\mathrm{D}}\right)$ e $\left(\mathrm{E}_{\mathrm{D}}\right)$, obtidos nos ensaios, foram empregadas algumas correlações semi-empíricas e empíricas propostas por diversos autores para a determinação de parâmetros da Mecânica dos Solos (ângulo de atrito, coesão, coeficiente de empuxo no repouso, módulo de elasticidade e módulo de cisalhamento), comparando-os com resultados disponíveis de ensaios de laboratório já executados.

3 Aplicação destes parâmetros da Mecânica dos Solos em metodologias teóricas de previsão de capacidade de carga vertical e estimativa dos recalques elásticos, comparando-os com os resultados das provas de carga já executadas em estacas no Campo Experimental da USP.

Com um estudo detalhado sobre o ensaio dilatométrico, e de posse dos resultados da comparação das etapas 2 e 3, foram extraídas as conclusões. As provas de carga referem-se a estacas em verdadeira grandeza do tipo: Hélice Contínua, Franki, Estacão, Strauss, MicroEstaca injetada e Pré-moldada de concreto, pré-moldada metálica (ABEF, 1989); e a Estaca Piloto Instrumentada (Souza, 2001). 
No Capítulo 1 foi apresentada uma breve introdução do uso do DMT e os objetivos da dissertação. No Capítulo 2 relatou-se a metodologia empregada.

No Capítulo 3 expõe-se a revisão bibliográfica contendo a apresentação do equipamento, descrição do ensaio, obtenção dos parâmetros do solo com correlações sugeridas por diversos autores. No Capítulo 4 apresentam-se algumas metodologias de previsão de capacidade de carga vertical e métodos de estimativas de recalques em estacas.

O Capítulo 5 apresenta as características geológicas e geotécnicas do Campo Experimental da USP (CEUSP), os ensaios de SPT e DMT executados para a realização desta dissertação, os parâmetros do solo obtidos via DMT comparados com valores obtidos em laboratório realizados anteriormente e publicados pela ABEF (1989) e com dados de Siviero (2003), resultados da previsão de capacidade de carga e estimativa de recalques comparados com os resultados medidos em provas de carga fornecidas pela ABEF (1989) e Souza (2001).

O Capítulo 6 mostra a conclusão revelada na análise de resultados do Capítulo 5 e no Capítulo 7 são apresentadas sugestões para pesquisas futuras. 


\section{REVISÃO BIBLIOGRÁFICA}

\subsection{Histórico}

O dilatômetro e o ensaio dilatométrico foram criados a partir do equipamento desenvolvido em 1975 pelo Engenheiro Silvano Marchetti, professor da Universidade L'Aquila, em Roma, na Itália, para a determinação das deformabilidades do solo em estacas cravadas, carregadas lateralmente. Posteriormente, Marchetti ampliou seus estudos e correlacionou resultados dos ensaios dilatométricos com diversos parâmetros geotécnicos.

Marchetti se correspondia com o Dr. John H. Schmertmann (na época professor de Engenharia Geotécnica na Universidade da Florida) o qual o encorajou para incluir o dilatômetro em suas pesquisas e práticas de consultoria. $\mathrm{O}$ ensaio foi introduzido nos Estados Unidos pela empresa Schmertmann \& Crapps Inc. em 1978 , onde ganhou destaque e reconhecimento internacional, estando atualmente em uso em 40 países.

As normas para a utilização do ensaio são: a) ASTM "Standard Test Method for Performing the Flat Plate Dilatometer Test" -D6635-01 nos Estados Unidos; e b) Eurocode 7 Geotechinical Design - Part 3 - "Design assisted by field testing" - Section 9 - "Flat Dilatometer Test (DMT)" na Europa.

\subsection{Apresentação dos componentes do equipamento}

O equipamento necessário à realização do ensaio é basicamente: lâmina dilatométrica, hastes, cabo elétrico-pneumático, unidade de controle de leituras e pressões, cabo pneumático e cilindro de gás (nitrogênio extra-seco), conforme esquema geral da Figura 3.1.

O funcionamento do equipamento consiste em aplicar pressões ao solo, através de uma membrana metálica de $6,0 \mathrm{~cm}$ de diâmetro, instalada na face lateral de uma lâmina muito delgada, em aço inoxidável de altíssima resistência.

É aplicada uma pressão na membrana, exercida pela introdução de gás nitrogênio extra-seco, inserido nas costas dessa membrana, fazendo com que se expanda contra o terreno, atingindo um valor máximo de deslocamento de $1,10 \mathrm{~mm}$ em seu centro. As leituras das pressões inicial e final dessa expansão são feitas por meio de 2 manômetros, de alta precisão, disponíveis na unidade de controle do equipamento, que é instalada na superfície do terreno.

O gás nitrogênio extra-seco fica disponível na superfície, em cilindro blindado, de alta 
pressão, com limite superior de até $800 \mathrm{KPa}$, assegurado pelo uso de uma válvula reguladora de pressão. A membrana é ligada por uma fiação elétrica, instalada na lâmina do "DMT", à unidade de controle.

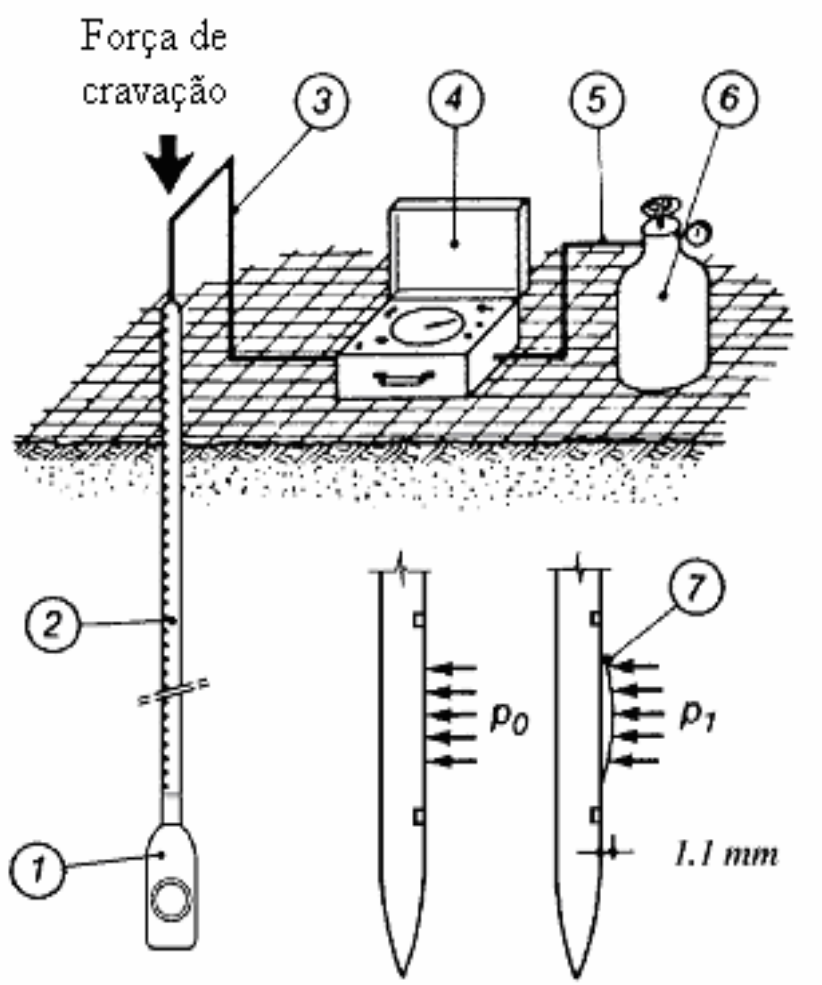
1. Lâmina dilatométrica
3. Cabo elétrico pneumático
5. Cabo pneumático
7. Expansão da membrana
6. Cilindro de gás

Figura 3.1 - Montagem esquemática do dilatômetro - (Marchetti 2001)

\subsubsection{Lâmina}

A lâmina é produzida em aço inox, ou em liga especial, ainda mais resistente, podendo penetrar em terreno de alta compacidade, ou alta consistência, alcançando em princípio, profundidades atingidas em sondagens à percussão (Penna, 2005). As dimensões da lâmina podem ser vistas na Figura 3.2.a e 3.2.b.

Para a execução do ensaio a lâmina deve estar em boas condições como: não haver curvaturas superiores a $0,5 \mathrm{~mm}$, não desviar, durante a cravação, de mais de $2 \mathrm{~mm}$ do eixo das hastes, não haver arranhões, dobras ou fissuras. 


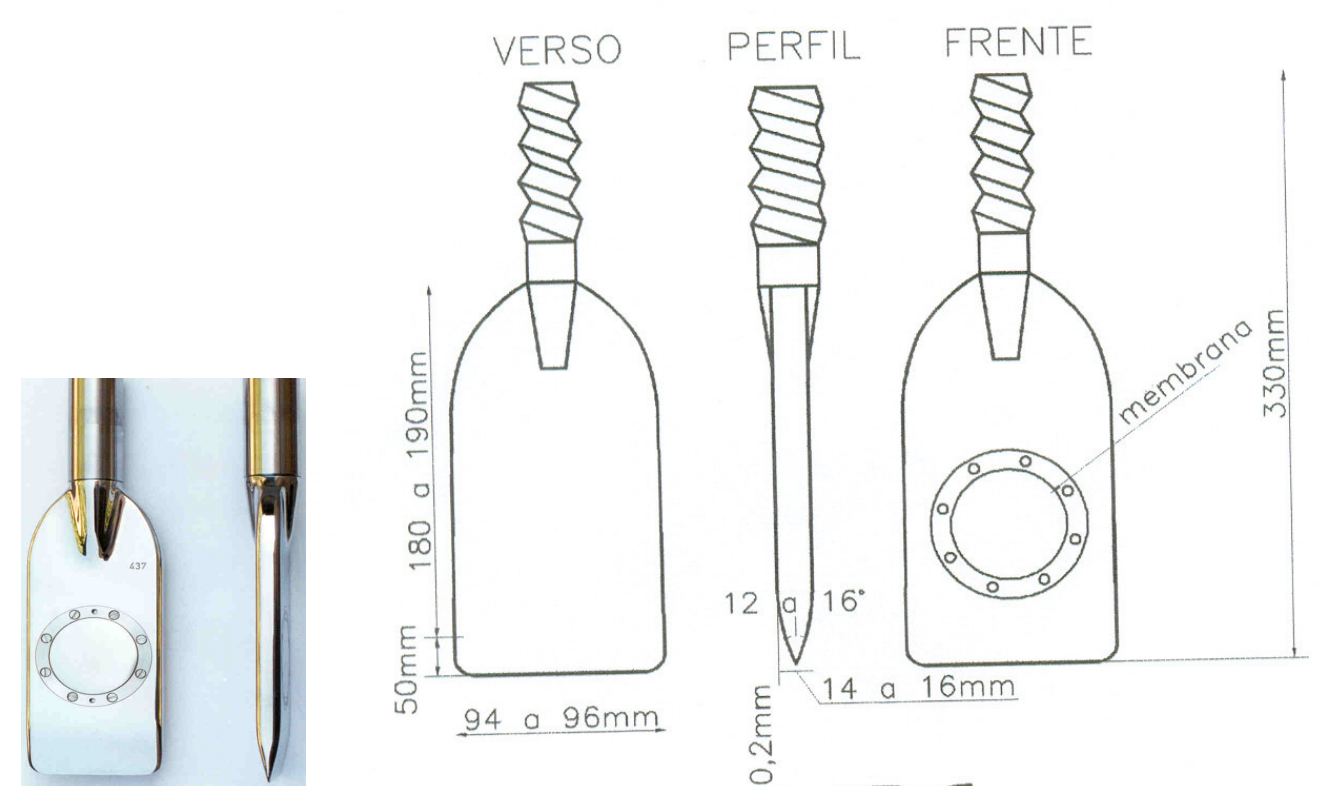

a)

b)

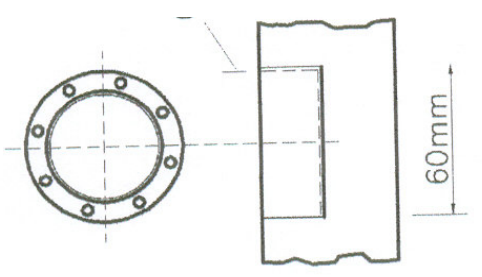

c)

Figura 3.2 - Detalhe da lâmina (Marchetti 2001)

\subsubsection{Membrana}

A membrana tem formato circular, constituída de aço e situada de um lado da lâmina, a qual fica presa por meio de parafusos (Figura 3.3 e 3.4), aplicados sobre um anel vedante de borracha, conforme figura 3.2.c. A membrana é apenas um separador passivo, entre o solo e o gás, não sendo um dispositivo de medição, mas sim um interruptor, do tipo"liga-desliga", onde a precisão dos resultados é governada pela precisão dos manômetros localizados na unidade de controle.

A membrana, quando expandida por meio do gás, gera três fases, onde cada fase é percebida pelo sinal sonoro de uma campainha na unidade de controle:

a) Membrana em repouso (expansão $<0,05 \mathrm{~mm}$ ) - sinal sonoro acionado 
b) Membrana em expansão $(0,05 \mathrm{~mm}$ a $1,10 \mathrm{~mm})$ - sinal sonoro em silêncio

c) Membrana totalmente expandida (expansão > que $1,10 \mathrm{~mm}$ ) - sinal sonoro volta a ser acionado

\section{DETALHES DA MEMBRANA}
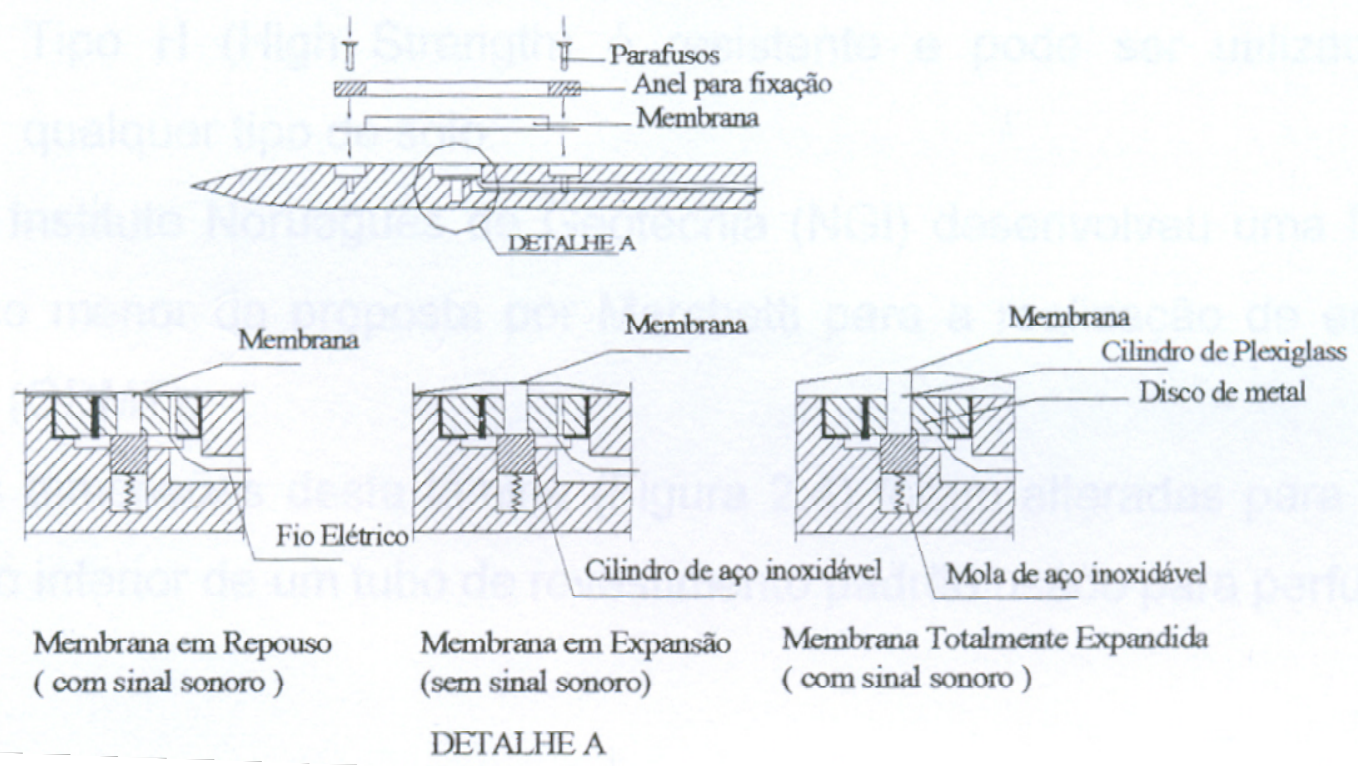

Figura 3.3 - Detalhes da membrana e sua expansão (USDOT , 1992)

Há no mercado dois tipos de membrana:

a)Tipo S - Standard - relativamente frágil, por ser muito delgada, podendo ser utilizada quando a força de cravação da lâmina for inferior a $20 \mathrm{KN}$.

b)Tipo $\mathrm{H}$ - High Strength - resistente, podendo ser utilizada em qualquer tipo de solo.

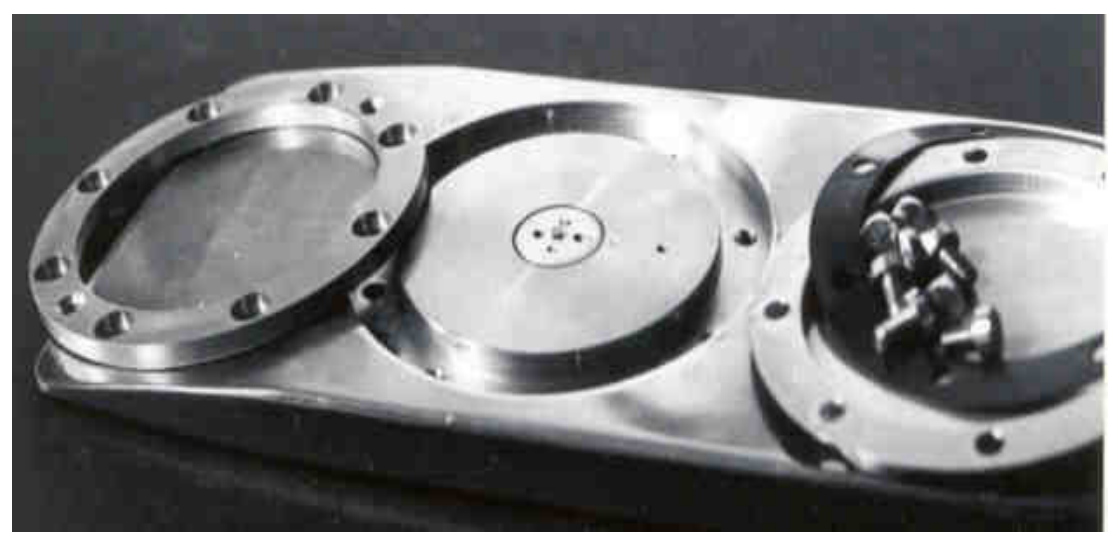

Figura 3.4- Detalhes de fixação da membrana (Marchetti 2001) 


\subsubsection{Hastes}

As hastes são conectadas à lâmina e ao dispositivo de cravação (ou extração), transferindo os esforços reativos, Figura 3.5. A hastes utilizadas na cravação estática são geralmente as mesmas do ensaio do Cone (CPT e CPTU) (ASTM D 3441, ASTM D 5778 e NBR-12069), com diâmetro de 36mm, roscas macho/fêmea e com segmentos de $1 \mathrm{~m}$, existindo hastes mais resistente de 44 a $55 \mathrm{~mm}$.

Segundo Marchetti (2001), o caminhão que executa o ensaio de CPT pode ser equipado com uma série de hastes muito mais resistentes do que a haste comum de $36 \mathrm{~mm}$. Tais hastes foram introduzidas pelo reconhecimento de que os caminhões suportam de 200 a $240 \mathrm{KN}$. Quando se usa hastes de $36 \mathrm{~mm}$, mais frágeis, o operador do caminhão freqüentemente interrompe o teste quando atinge 100 a $150 \mathrm{KN}$ com receio de fraturá-las.

As hastes reforçadas têm muitas vantagens:

- melhor estabilidade lateral contra flambagem nos primeiros poucos metros, no caso de solo mole;

- melhor estabilidade lateral quando as hastes são empurradas dentro de um furo de sondagem vazio;

- possibilidade de usar completamente a capacidade de carga do caminhão e alta resistência decorrente das lâminas do DMT (trabalhando na capacidade de carga de $240 \mathrm{KN})$;

- capacidade de penetração através de camadas cimentadas; e

- redução drástica do risco de perder as hastes.

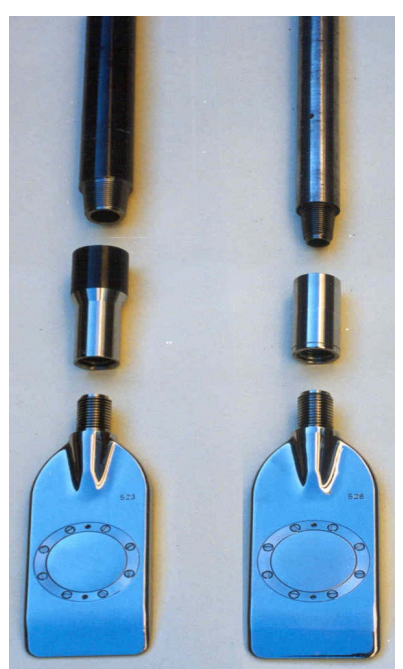

Figura 3.5- Detalhes da ligação haste/lâmina (Marchetti 2001) 


\subsubsection{Cabo elétrico-pneumático}

Com a dupla função de fornecer o gás sob pressão, para a expansão da membrana, e de servir de ligação do circuito elétrico entre a unidade de controle e a lâmina, o cabo elétrico pneumático é constituído de fio de aço inoxidável envolto por um tubo de nylon com conectores em sua extremidade (Figura 3.6). São muito resistentes e não devem ser torcidos.

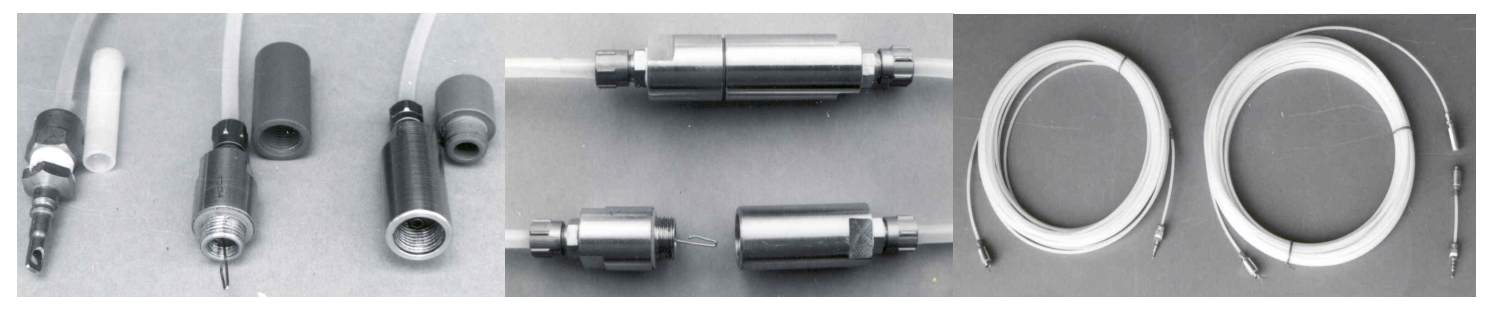
a) tipos de cabo
b) extensão
c) tubo de nylon

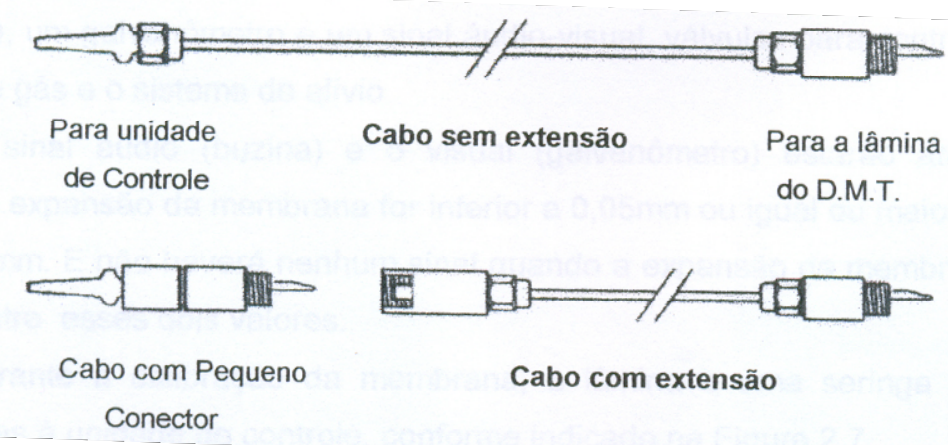

Figura 3.6- Tipos de cabos elétrico-pneumáticos utilizados no ensaio DMT (Marchetti 2001)

\subsubsection{Unidade de controle de leituras e pressões}

O operador faz as leituras A, B e C na unidade de controle mediante os sinais sonoros emitidos pela unidade, para determinada profundidade. Estas leituras devem ser corrigidas levando-se em conta a rigidez da membrana e uma eventual diferença na leitura dos manômetros (Figura 3.7). Depois de corrigidas, têm-se as pressões $\mathrm{p}_{0}, \mathrm{p}_{1}$ e $\mathrm{p}_{2}$. A pressão $\mathrm{p}_{0}$ é a pressão requerida para iniciar o movimento da membrana; $\mathrm{p}_{1}$ é a pressão necessária para mover o centro da membrana em 1,10 mm dentro do solo, e $\mathrm{p}_{2}$ é considerada a leitura da poro pressão (Schmertmann, 1986). 

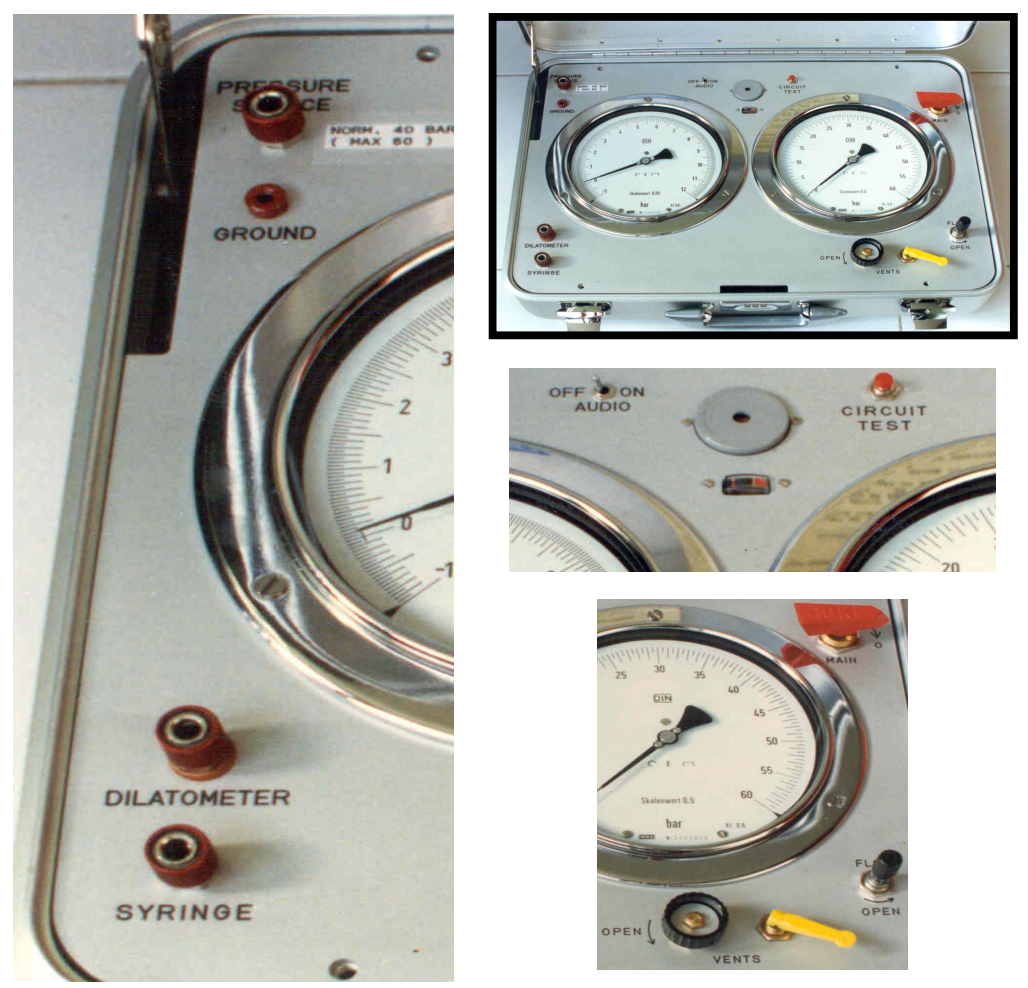

Figura 3.7 - Detalhe da unidade de controle (Marchetti 2001)

\subsubsection{Cilindro de gás de nitrogênio extra-seco}

Sua função é fornecer pressão para a expansão da membrana. Esse cilindro deve possuir uma válvula e deve estar conectado à unidade pelo cabo pneumático (Figura 3.8).

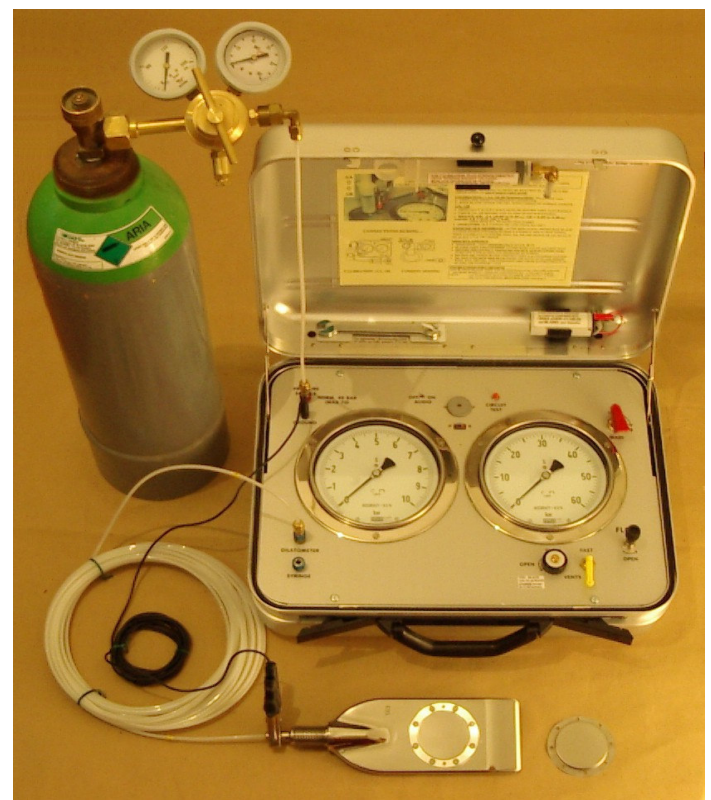

Figura 3.8 - Detalhe da unidade de controle com cilindro de gás (Marchetti 2001) 


\subsection{Tipos de cravação}

A escolha do equipamento e da haste para teste de DMT é muito significativa. A cravação pode ser dinâmica ou estática. Pode-se executar a cravação dinâmica utilizando o mesmo equipamento de sondagem à percussão (SPT) ou, se se optar por cravação estática, pode-se empurrar a lâmina utilizando o equipamento de penetração do cone (CPT) ou o equipamento da sonda rotativa, conforme está mostrado na Figura 3.9.

Segundo Marchetti (2001), caminhões pesados, como os utilizados no CPT, são incomparavelmente mais eficientes do que equipamentos de perfuração. Equipamentos de perfuração ou equipamentos leves são quase sempre inadequados em solos duros e freqüentemente criam problemas.

Ainda de acordo com o autor acima, há outras desvantagens de se utilizar o equipamento do SPT para se executar o DMT:

- muitos equipamentos não possuem um colarinho na superfície do terreno para guiar a haste;

- permite excessiva liberdade de oscilações e vibrações da haste dentro do furo;

- a distância entre a superfície do terreno e a lâmina pode ser de vários metros, portanto a liberdade de flambagem da haste é alta. Em alguns casos, as hastes quando carregadas têm-se observado tomar uma forma de "Z" ou "zigue-zague";

- oscilações da haste podem causar erros nos resultados, em casos de pequena penetração; isto pode ser observado, em camadas duras, que a forma de " $Z$ " das hastes, de repente inverte a posição do lado. Este é um dos poucos casos em que a leitura do DMT pode ser incorreta. No caso dessa oscilação da lâmina, a membrana é pressionada sem controle se está perto ou longe do solo.

A velocidade de cravação deve ser de 1 a $10 \mathrm{~cm} / \mathrm{s}$ em areias e 1 a $3 \mathrm{~cm} / \mathrm{s}$ em siltes ou argilas segundo a ASTM D18.02 e de $1 \mathrm{a} 3 \mathrm{~cm} / \mathrm{s}$ em qualquer tipo de solo, de acordo com a EUROCODE7.

Em caso de areias fofas e argilas sensitivas, por serem solos sensíveis a impactos e vibrações, é mais indicada a cravação estática (Marchetti, 2001). Estudos mostraram que a cravação dinâmica pode alterar significativamente os resultados do ensaio. 


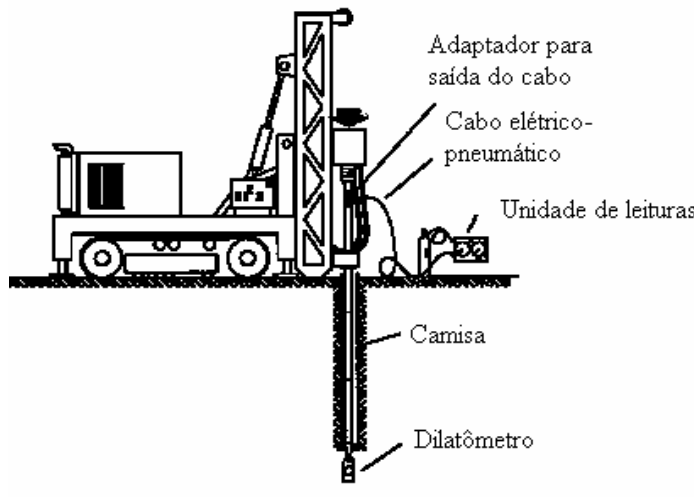

Cravação estática

Sonda rotativa

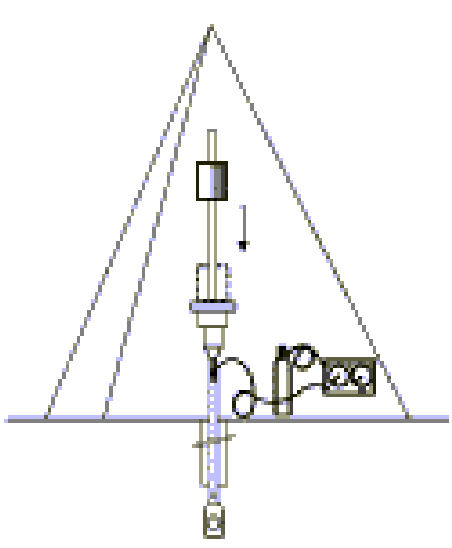

Cravação dinâmica

(equipamento de SPT)

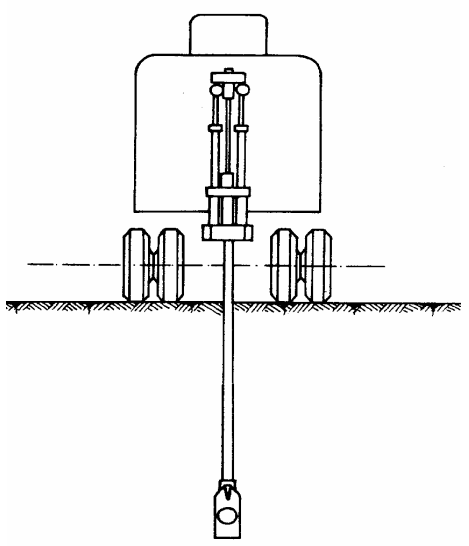

Cravação estática

(caminhão do CPT)

Figura 3.9 - Equipamentos de cravação estática (Marchetti 2001)

\subsection{Calibração da membrana}

Antes da cravação da membrana no solo, e após o término do ensaio, deve-se calibrar a membrana. Esta calibração é efetuada determinando-se as pressões necessárias para vencer a rigidez da membrana ao ar livre.

As pressões A e B, lidas nos manômetros durante a execução do ensaio, definidas mais adiante, são corrigidas através da subtração das pressões necessárias para vencer essa rigidez da membrana $(\Delta \mathrm{A}$ e $\Delta \mathrm{B})$.

Para a obtenção de $\Delta \mathrm{A}$, aplica-se um vácuo atrás da membrana por intermédio de uma seringa, quando a expansão da membrana atingir $0,05 \mathrm{~mm}$ soa um alarme sonoro (bip) na unidade de controle, essa pressão lida será $\Delta \mathrm{A}$. A pressão $\Delta \mathrm{A}$ é negativa, porém é anotada positiva, porque nas fórmulas, como será mostrado a diante, esse sinal é considerado implicitamente. De modo análogo obtém-se o $\Delta \mathrm{B}$, empurrando-se o êmbolo da seringa até a membrana expandir 1.10 mm, soando novamente um "bip", lê-se então a pressão $\Delta \mathrm{B}$.

Sendo a membrana nova, este procedimento deverá ser repetido diversas vezes para se ter consistência nos valores das pressões de calibração. Através deste procedimento pode-se também verificar se há danos na membrana. Para estar em perfeitas condições de uso, a membrana deverá apresentar valores de $\Delta \mathrm{A}$ e $\Delta \mathrm{B}$ ligeiramente constantes. A recomendação é que os valores de $\Delta \mathrm{A}$ fiquem em torno de 5 a 30 (geralmente $15 \mathrm{KPa}$ ), e para $\Delta \mathrm{B}, 5$ a $80 \mathrm{KPa}$ (geralmente $40 \mathrm{kPa}$ ), Marchetti et all, 2001. 


\subsection{Ensaio}

Inicia-se o ensaio cravando a lâmina do DMT no solo, ligada à unidade de controle de superfície por uma fiação elétrica disposta no interior de uma mangueira de gás nitrogênio extra seco. O avanço no terreno é feito em estágios, com intervalos de $20 \mathrm{~cm}$, com o estacionamento da lâmina, na profundidade do ensaio, e com as realizações manuais das leituras das pressões "A", "B" "C".

Sendo:

“A” - pressão necessária para um deslocamento horizontal, do centro da membrana, de 0,05mm, (

"B" - pressão necessária para um deslocamento radial da membrana de 1,10mm, (sinal sonoro é acionado novamente para que o operador registre manualmente a pressão correspondente a tal deslocamento); e

"C" - pressão interna no diafragma durante a despressurização do sistema, quando a membrana retorna ao deslocamento correspondente a $0,05 \mathrm{~mm}$.

De posse das três leituras e das correções devido à rigidez da membrana e de eventuais imprecisões no sistema de medição, determinam-se as pressões $\mathrm{p}_{0}, \mathrm{p}_{1}$ e $\mathrm{p}_{2}$. O valor de $\mathrm{p}_{0}$ corresponde a um deslocamento nulo da membrana e é obtido por extrapolação, como está indicado na Figura 5.10. Por semelhanças de triângulos, Marchetti chegou à expressão 3.1. As demais pressões $\left(\mathrm{p}_{1}\right.$ e $\mathrm{p}_{2}$ ) são calculadas pelas expressões 3.2 e 3.3, com suas respectivas correções.

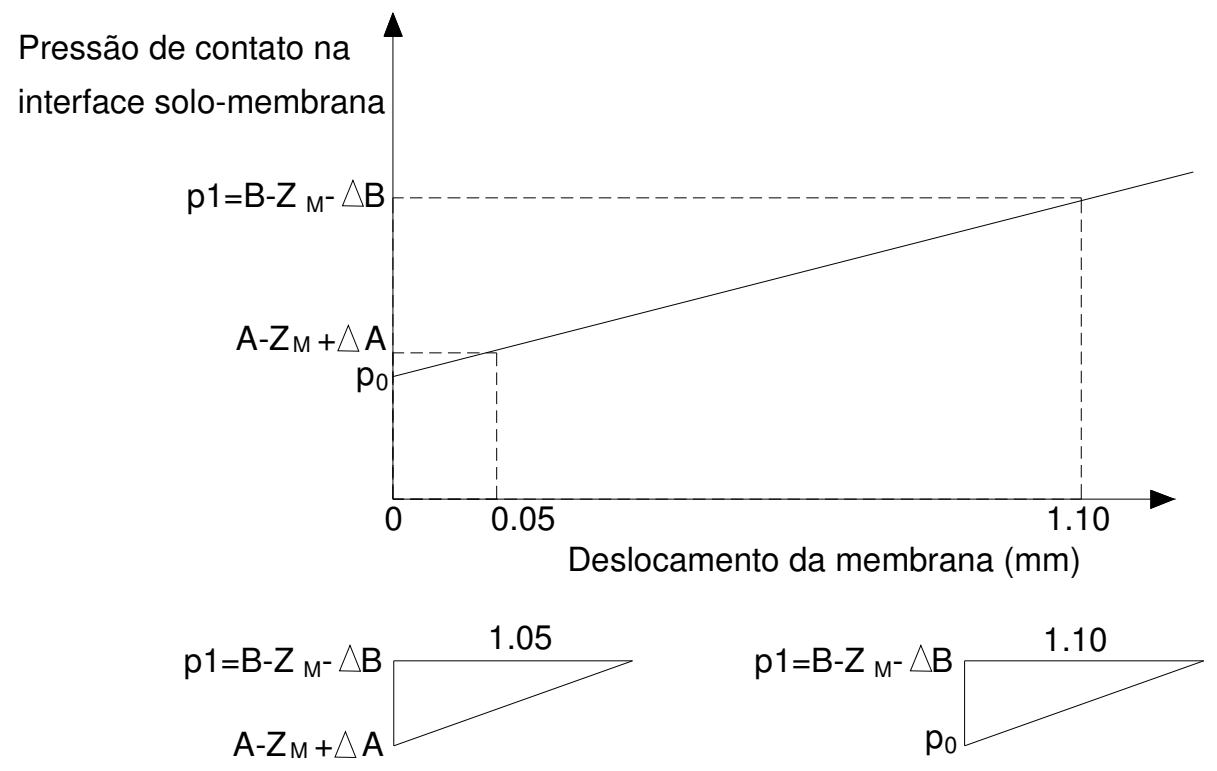

Figura 3.10 - Pressão de Contato na interface solo membrana em função do deslocamento da membrana mm (US DOT 1992) 
$\mathrm{p}_{0}=1,05\left(\mathrm{~A}-\mathrm{Z}_{\mathrm{M}}+\Delta \mathrm{A}\right)-0,05\left(\mathrm{~B}-\mathrm{Z}_{\mathrm{M}}-\Delta \mathrm{B}\right)$

$\mathrm{p}_{1}=\mathrm{B}-\mathrm{Z}_{\mathrm{M}}-\Delta \mathrm{B}$

$\mathrm{p}_{2}=\mathrm{C}-\mathrm{Z}_{\mathrm{M}}+\Delta \mathrm{A}$

sendo:

$\Delta \mathrm{A}$ e $\Delta \mathrm{B}=$ correções devidas à rigidez da membrana (calibração)

$\mathrm{Z}_{\mathrm{M}}=$ pressão lida quando o equipamento está à pressão atmosférica.

A pressão $\mathrm{p}_{2}$ em solos não coesivos corresponde à pressão neutra hidrostática inicial atuante na camada. Isto pode ser explicado pelo fato de que no início da descompressão da membrana um pouco do solo tende a se deslocar na mesma direção da membrana e ao final dessa descompressão a única pressão que estará atuando na membrana será a própria pressão neutra $\mathrm{u}_{0}$.

A norma ASTM D 6635-01 recomenda que além das leituras A, B e C seja anotada a força necessária para a cravação da lâmina.

\subsection{Parâmetros Intermediários}

Os parâmetros intermediários do DMT são calculados através das pressões obtidas no ensaio, devidamente corrigidas, e são fundamentais para a determinação dos parâmetros do solo com base nas correlações empíricas propostas por diversos autores. Os parâmetros intermediários são:

a) $\mathrm{I}_{\mathrm{D}}$ - índice de material;

b) $K_{D}$ - índice de tensão horizontal; e

c) $\mathrm{E}_{\mathrm{D}}$ - módulo dilatométrico.

\subsection{1. Índice de Material, $I_{D}$}

O parâmetro intermediário " $\mathrm{I}_{\mathrm{D}}$ " representa uma forma de identificar o comportamento do solo, baseada na amplitude da faixa de diferença entre as pressões $\mathrm{p}_{0}$ e $\mathrm{p}_{1}$, em relação à condição de confinamento horizontal efetivo $\left(\mathrm{p}_{0}-\mathrm{u}_{0}\right)$, ao qual o solo está submetido, "in-situ". Este índice surgiu da observação de que, em solos argilosos, a pressão " $p_{1}$ " é apenas um pouco maior do que a pressão "po", enquanto nos solos arenosos, essa diferença é bem maior. Por definição tem-se: 
$I_{D}=\frac{p_{1}-p_{0}}{p_{0}-u_{0}}$

sendo:

$u_{0}=$ poro pressão in situ ou hidrostática

Em geral este índice pode ser considerado representativo do tipo de solo, mas em solos coesivos, o $I_{D}$ muitas vezes faz uma inversão entre silte e argila e vice-versa. A combinação de argila e areia geralmente é descrita pelo ensaio com valores de $I_{D}$ representando faixas de silte.

Pode-se usar o $I_{D}$ apenas como um parâmetro que reflete o comportamento mecânico do material e não como uma análise granulométrica, ou substituindo a análise tátil visual do material ensaiado. Na Tabela 3.1 é apresentada a classificação do solo conforme o $\mathrm{I}_{D}$ do material.

Argilas que possuem um comportamento muito rígido, terão, provavelmente seu $\mathrm{I}_{\mathrm{D}}$ relacionado a um silte.

Tabela 3.1 - Classificação do tipo de solo baseada no $I_{D}$ (Marchetti, 1980)

\begin{tabular}{|l|c|}
\hline TIPO DE SOLO & $\mathbf{I}_{\mathbf{D}}$ \\
\hline Argila muito mole/turfa & $<0,10$ \\
\hline Argila & 0,10 a 0,35 \\
\hline Argila Siltosa & 0,35 a 0,60 \\
\hline Silte Argiloso & 0,60 a 0,90 \\
\hline Silte & 0,90 a 1,20 \\
\hline Silte Arenoso & 1,20 a 1,80 \\
\hline Areia Siltosa & 1,80 a 3,30 \\
\hline Areia & $>3,30$ \\
\hline
\end{tabular}

\subsection{2. Índice de Tensão Horizontal, $K_{D}$}

Este índice, assemelhado ao coeficiente de empuxo em repouso " $\mathrm{K}_{0}$ ”, relação entre a tensão horizontal efetiva $\left(\sigma^{\prime}{ }_{h}\right)$ e a tensão vertical efetiva $\sigma^{\prime}{ }_{v}$, é obtido pela expressão:

$$
K_{D}=\frac{p_{0}-u_{0}}{\sigma_{v o}^{\prime}}
$$


sendo:

$\mathrm{p}_{0}=$ pressão horizontal inicial do dilatômetro

$\mathrm{u}_{0}=$ poropressão de equilíbrio

$\sigma^{\prime}{ }_{\text {vo }}=$ tensão vertical efetiva

Este parâmetro $\mathrm{K}_{\mathrm{D}}$ deve ser entendido apenas como um índice e não como uma medida direta do coeficiente de empuxo em repouso " $\mathrm{K}_{0}$ ", uma vez que a introdução da lâmina no terreno altera a condição do "verdadeiro repouso" do solo.

Esse índice está associado, também, ao histórico de tensões, e essa é sua maior aplicação. As observações de Marchetti (1980) indicaram que, em solos normalmente adensados, o valor de " $K_{D}$ " é constante com a profundidade e se situa, muito freqüentemente, entre os valores 1,8 e 2,3. Em solos sobreadensados, o valor " $K_{D}$ " é superior a 2,3 e seu valor geralmente diminui com profundidade, do mesmo modo que a razão de sobreadensamento ("RSA").

\subsubsection{Módulo Dilatométrico, $\mathrm{E}_{\mathrm{D}}$}

Esse índice " $E_{D}$ ” permite a determinação das características de compressibilidade do solo através da aplicação da teoria da elasticidade. Assume-se que a expansão da membrana dentro do solo é modelada como um carregamento flexível em uma área circular, na superfície de um espaço semi-elástico, tendo como parâmetros o módulo de Young (E) e o coeficiente de Poison $(v)$. O movimento da membrana $S$, cujo centro está sujeito à pressão normal $\Delta \mathrm{p}$, foi expresso da seguinte forma por Gravesen (1960) apud USDOT (1992).

$S=\frac{4 \cdot R \cdot \Delta p}{\pi} \cdot \frac{\left(1-v^{2}\right)}{E}$

Sendo que:

$\mathrm{S}$ - deslocamento elástico do centro da membrana

$\mathrm{R}$ - raio da membrana $=30 \mathrm{~mm}$

$\Delta \mathrm{p}-$ pressão aplicada $=\mathrm{p}_{1}-\mathrm{p}_{0}$

E - módulo de Young

$v$ - coeficiente de Poison 
O termo E / $\left(1-v^{2}\right)$ é o Módulo Dilatométrico $E_{D}$. Substituindo-se o deslocamento e o raio da membrana que são $S=1,1 \mathrm{~mm}$ e $\mathrm{R}=30 \mathrm{~mm}$, respectivamente, e obtém-se o módulo dilatométrico em função apenas de $\mathrm{p}_{1}$ e $\mathrm{p}_{0}$.

$\mathrm{E}_{\mathrm{D}}=34,7\left(\mathrm{p}_{1}-\mathrm{p}_{0}\right)$

Como esse índice expressa o acréscimo de pressão necessário para que a membrana se desloque $1,1 \mathrm{~mm}$ no seu centro, o seu valor está relacionado com a consistência das argilas e a compacidade das areias e de certo modo com o peso específico dos solos $(\gamma)$.

Marchetti e Craps (1981), através de análise de dados experimentais, propuseram um sistema de classificação em que o tipo de solo é indicado pelo índice do material $\mathrm{I}_{\mathrm{D}}$ e o estado do solo pelo módulo dilatométrico $\mathrm{E}_{\mathrm{D}}$.

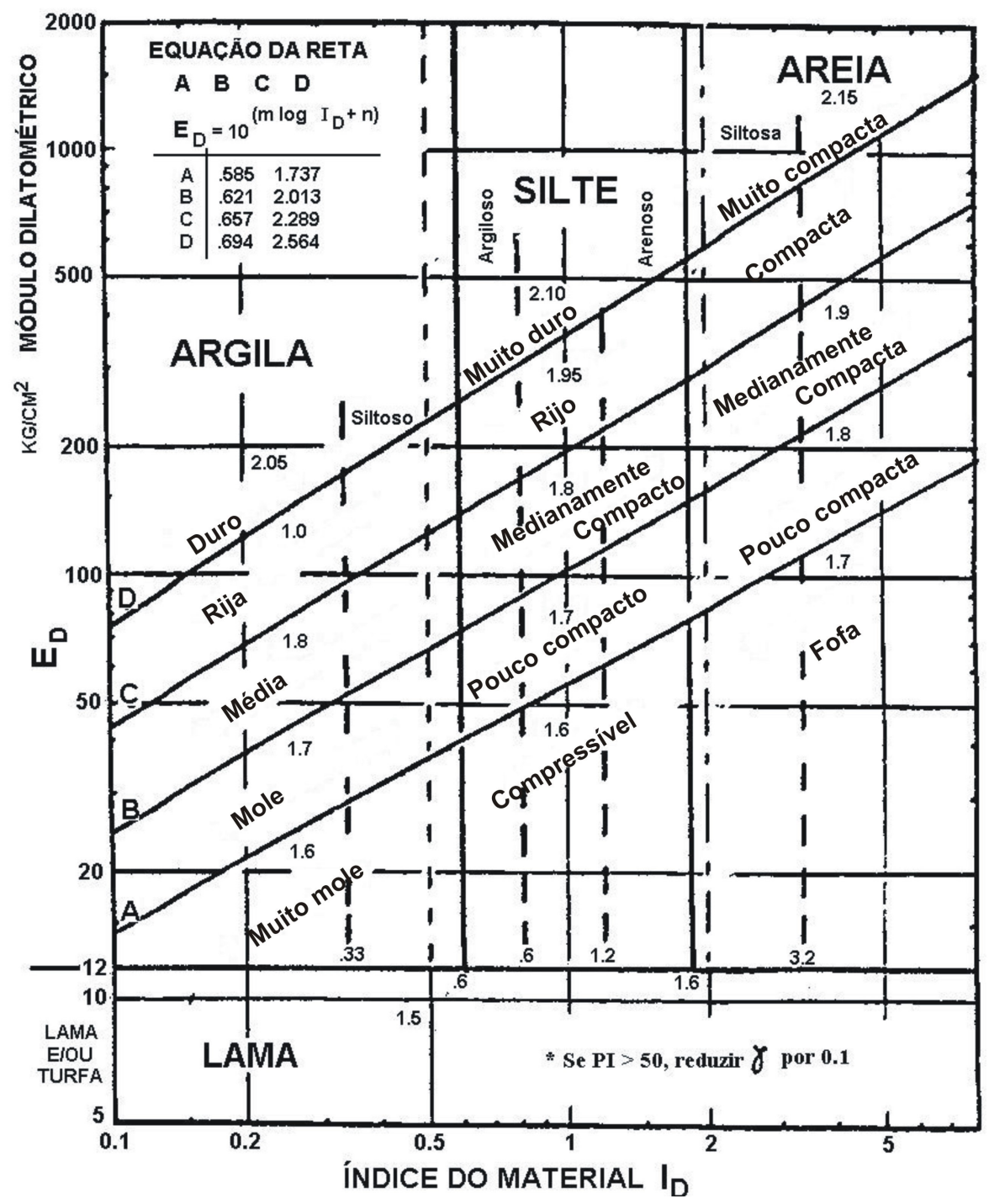

Figura 3.11 - Classificação do tipo de solo, peso específico e consistência ou compacidade obtidos através de $\mathrm{I}_{\mathrm{D}}$ e $\mathrm{E}_{\mathrm{D}}$, (Marchetti e Crapps, 1981). 


\subsubsection{O Dilatômetro testado em solos tropicais brasileiros}

O ensaio de DMT foi testado em três Campos Experimentais distintos, de grande importância no estado de São Paulo: Unesp (Bauru), USP (São Carlos) e Unicamp (Campinas). Os seus resultados foram apresentados, interpretados e comparados com outros ensaios in-situ e ensaios de laboratório por Giacheti et al (2006).

No Campo Experimental da UNESP o solo foi classificado com o $\mathrm{I}_{\mathrm{D}}$ do DMT como silte arenoso até a profundidade de 9,2 m e como areia siltosa entre as profundidades 9,4 e 14,2 m (Fig. 3.12.b e Fig. 3.16.a) A análise granulométrica indicou uma areia fina argilosa obtendo, portanto, uma confirmação sobre a inversão da combinação argila mais areia resultando em faixas de silte (Fig 3.12.f). O DMT permitiu estimar o peso específico $(\gamma)$ através do $I_{D}$ e $E_{D}$ (Figura 3.11) com resultados próximos aos de ensaios de laboratório (Fig 3.12.e).

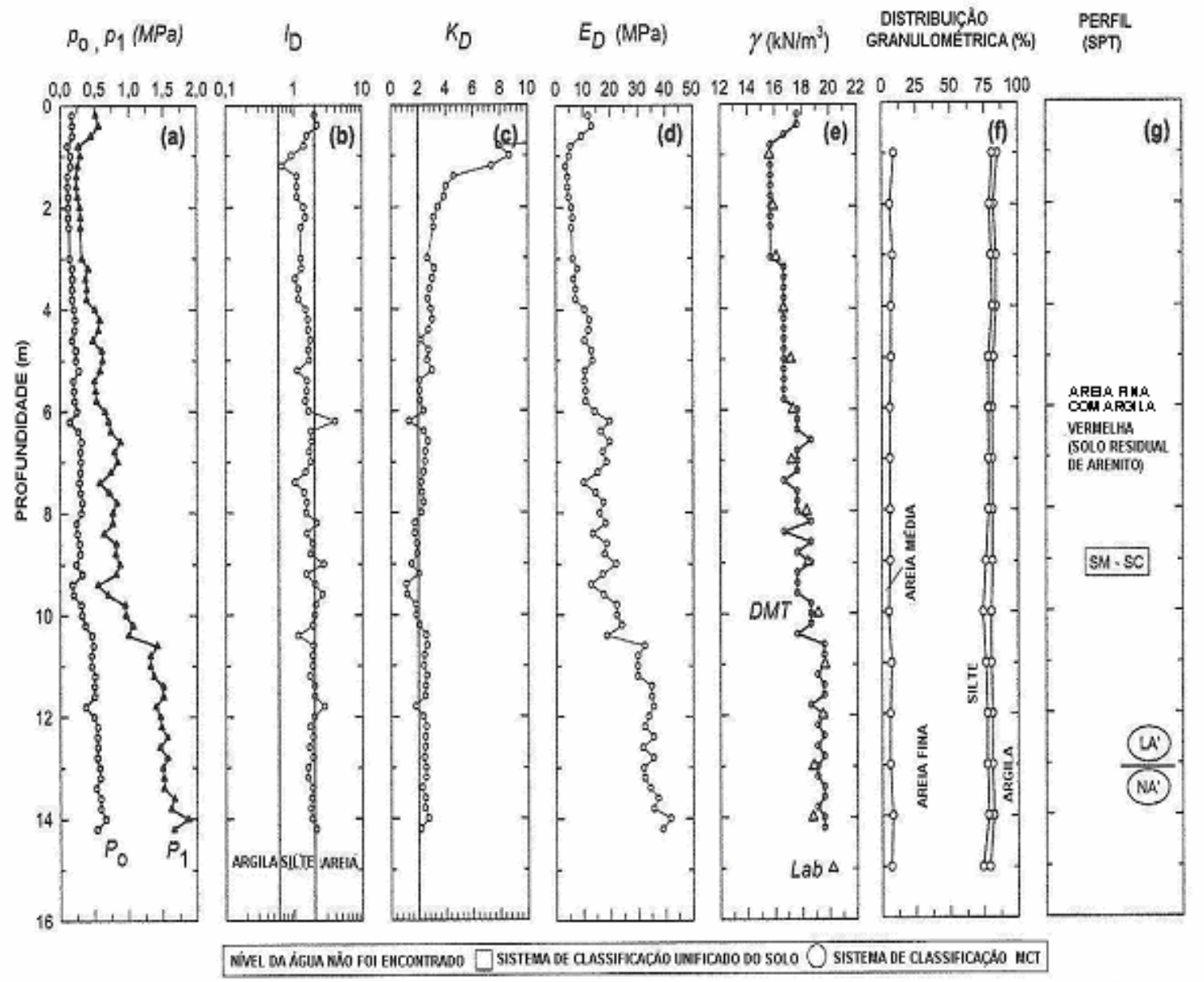

Figura 3.12 - Resultado dos testes DMT, peso unitário total, distribuição granulométrica, perfil da sondagem (SPT) - Campo Experimental da UNESP - BAURU - SP 
Os valores do módulo dilatométrico $\mathrm{E}_{\mathrm{D}}$ foram muito semelhantes aos valores do $\mathrm{E}_{\mathrm{PMT}}$ obtidos através da execução de ensaios com o pressiômetro de Ménard, conforme Figura 3.13.

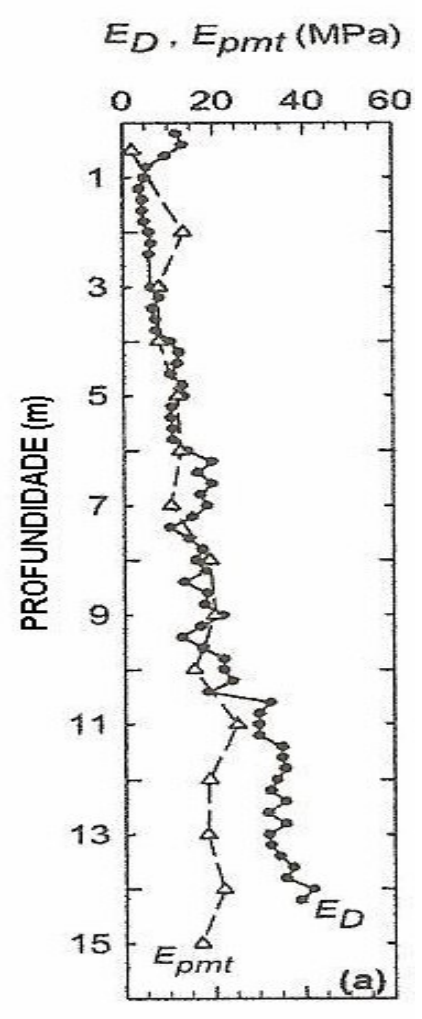

Figura 3.13 - Comparação dos resultados do $\mathrm{E}_{\mathrm{D}}$ do DMT e $\mathrm{E}_{\mathrm{pmt}}$ do pressiômetro de Ménard.Campo Experimental da UNESP - BAURU - SP

No Campo Experimental da UNICAMP o solo foi classificado com o $\mathrm{I}_{\mathrm{D}}$ do DMT como argila siltosa ou silte argiloso até a profundidade de $6 \mathrm{~m}$ (Fig 3.14.b e Fig. 3.16.b) e pela análise granulométrica foi classificado como argila siltosa (Fig 3.14.f). O DMT permitiu identificar uma massa solidificada na profundidade de 6 a $6,5 \mathrm{~m}$, classificada como areia. Entre as profundidades 6,5 e $16 \mathrm{~m}$ o solo foi classificado como silte arenoso, silte e silte argiloso, através do DMT, enquanto pela análise granulométrica o solo foi identificado como silte argiloso. Nos últimos quatro metros houve a maior diferença entre os resultados: argila siltosa pelo DMT e silte areno-argiloso pela granulometria. O DMT super-estimou o peso específico $(\gamma)$, obtido através do $\mathrm{I}_{\mathrm{D}}$ e $\mathrm{E}_{\mathrm{D}}$ (Fig. 3.11), em relação aos valores obtidos em ensaios de laboratório (Fig 3.14.e). 


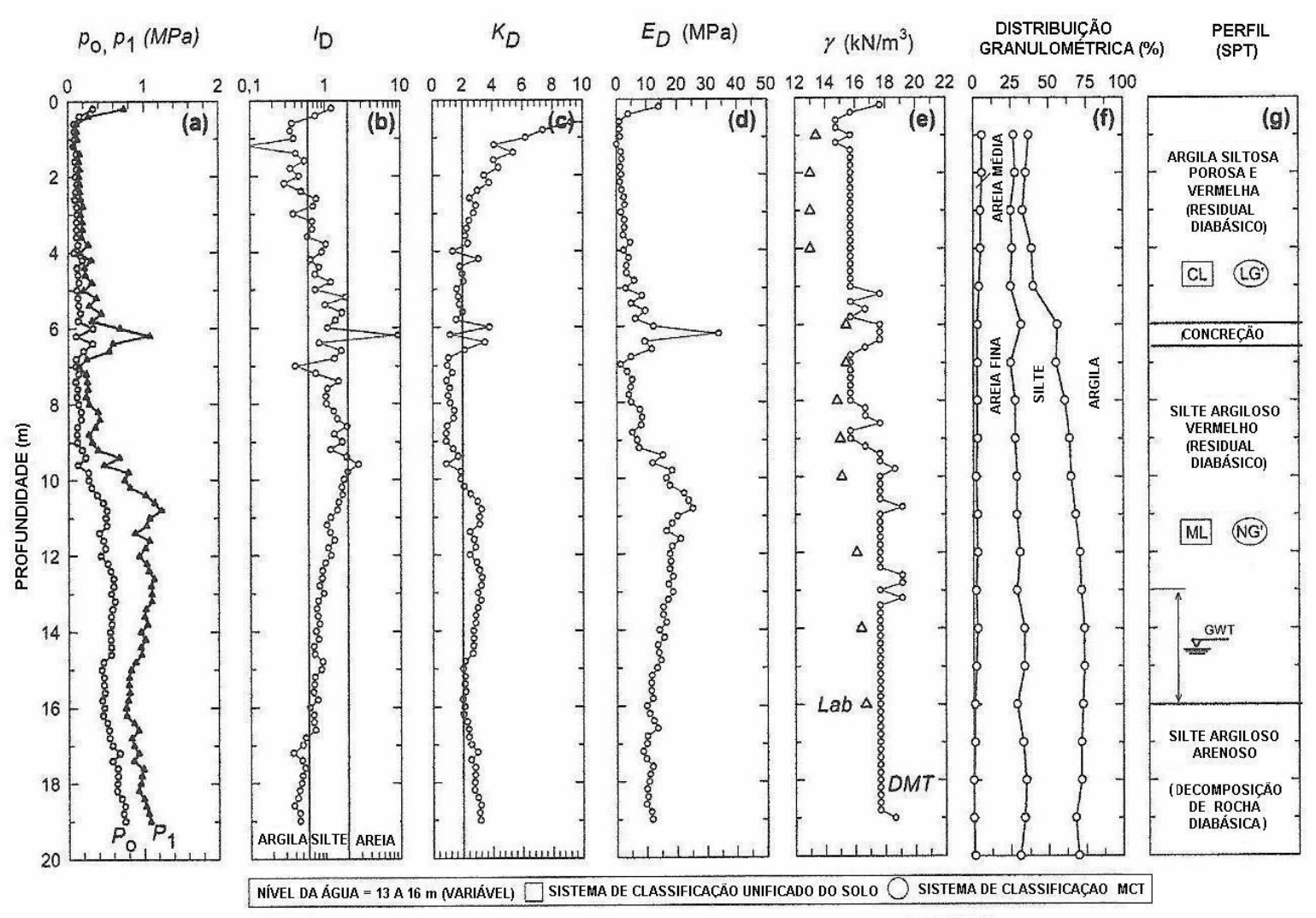

Figura 3.14 - Resultado dos testes DMT, peso unitário total, distribuição granulométrica, perfil da sondagem (SPT) - Campo Experimental da UNICAMP - CAMPINAS - SP

No Campo Experimental da USP de São Carlos o solo foi classificado, com o $I_{D}$ do DMT, na faixa de silte (Fig 3.15.b e Fig. 3.16.c) e, com a análise granulométrica, como areia fina argilosa (Fig 3.15.f). O DMT não possibilitou identificar a camada de seixos na profundidade de 6 a 6,5 m, que foi detectada com o SPT e com o CPT. O DMT permitiu estimar o peso específico $(\gamma)$ obtido através do $I_{D}$ e $E_{D}$ (Figura 3.11), com resultados próximos aos dos ensaios de laboratório até a profundidade de $8 \mathrm{~m}$; após essa profundidade, o DMT sub-estimou o peso específico (Fig 3.15.e). 


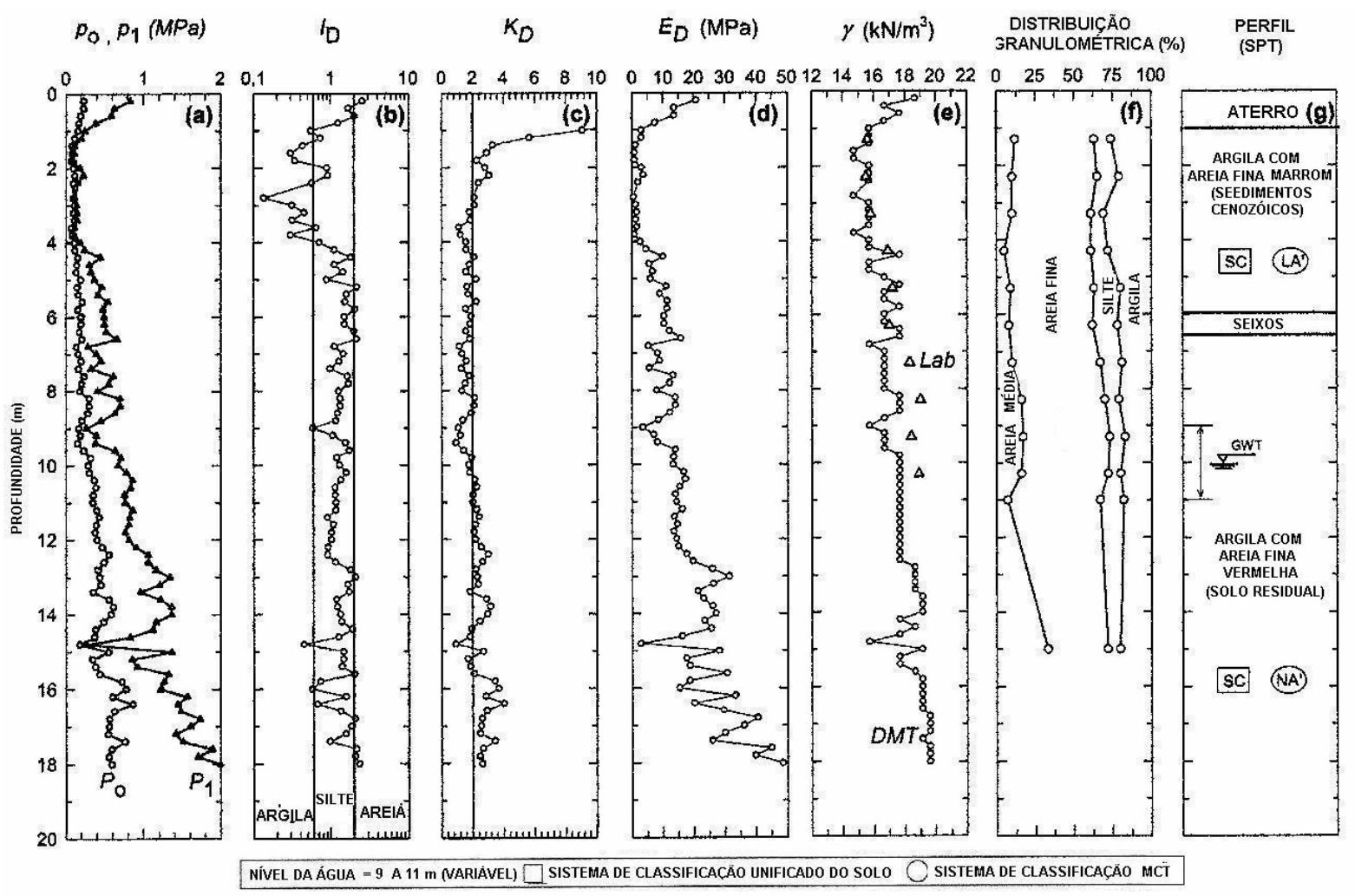

Figura 3.15 - Resultado dos testes DMT, peso unitário total, distribuição granulométrica, perfil da sondagem (SPT) - Campo Experimental da USP - SÃO CARLOS - SP
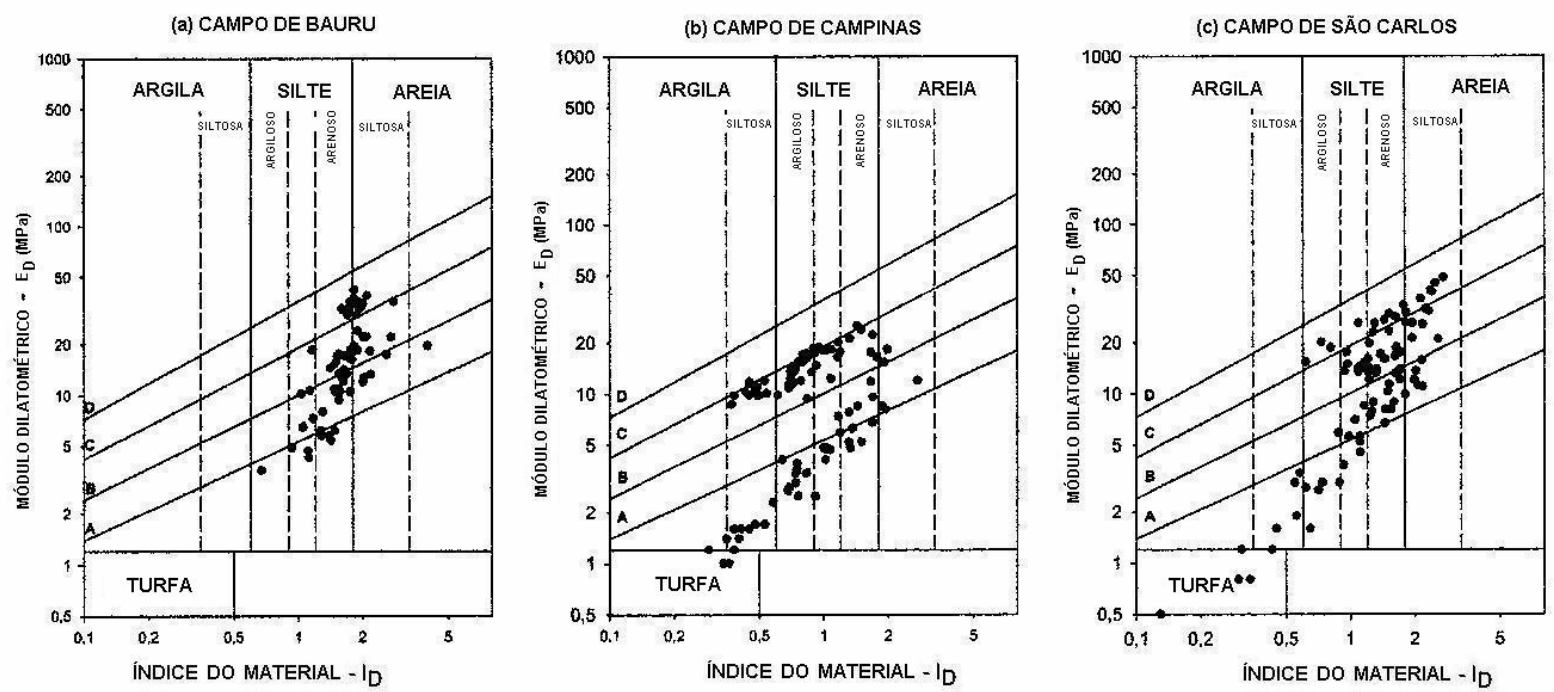

Figura 3.16 - Classificação do solo proposta por Marchetti e Crapps (1981) para cada Campo Experimental. (a) Bauru (b) Campinas (c) São Carlos. 


\subsection{Correlações para a obtenção de parâmetros geotécnicos}

O ensaio de DMT encontra aplicabilidade na Mecânica dos Solos devida às boas correlações que os seus parâmetros intermediários vem mostrando ter com os parâmetros geotécnicos do solo. Segundo Schnaid (2000), com a interpretação dos resultados do ensaio dilatométrico é possível estimar, a partir de correlações semi-empíricas, parâmetros dos solos como: coeficiente de empuxo em repouso $\left(\mathrm{K}_{\mathrm{o}}\right)$, razão de sobre adensamento do solo (OCR), resistência não-drenada de argilas $\left(\mathrm{s}_{\mathrm{u}}\right)$, ângulo de atrito efetivo $\left(\phi^{\prime}\right)$, módulo edométrico $(\mathrm{M})$, módulo de elasticidade (E) e Módulo de Deformação Cisalhante (G).

\subsubsection{Parâmetros relacionados ao histórico de tensões}

\subsubsection{Coeficiente de Empuxo em Repouso, $K_{0}$}

O dilâtometro é reconhecido, entre outras utilizações, como uma ferramenta para estimar o coeficiente de empuxo em repouso $\mathrm{K}_{\mathrm{o}}$. Este coeficiente é a relação entre as tensões efetivas horizontais e verticais "in situ".

Este coeficiente pode ser alterado por variações do estado de tensões ou por efeito de envelhecimento do solo. A impossibilidade de se medir diretamente o $\mathrm{K}_{0}$ é devido à perturbação que a inserção da lâmina causa no solo. Correlações empíricas têm sido propostas através do índice de tensão horizontal $\mathrm{K}_{\mathrm{D}}$.

\section{a) $\mathrm{K}_{0} \mathrm{em}$ Argilas}

A primeira correlação foi apresentada por Marchetti (1980), que propôs a seguinte expressão, baseada em vários ensaios de DMT e de laboratório em argilas na Itália:

$\mathrm{K}_{0}=\left(\mathrm{K}_{\mathrm{D}} / 1,5\right)^{0,47}-0,6$

Jamiolkowski et al. (1988) recomendaram o uso desta equação restritamente a depósitos de argila, de consistência mole a média e não cimentada, que apresentem valores de $\mathrm{I}_{\mathrm{D}} \leq 1,2$. Estudos realizados por diversos autores como Powell e Uglow (1988), Lacasse e Lunne (1988), Lunne et al. (1989) levaram a uma modificação na expressão (3.8), mostrando que a correlação entre $K_{D}$ e $K_{0}$ é função da idade da argila. Foi proposta a separação das argilas em dois grupos: a) as argilas jovens formadas há menos de 70.000 anos; e b) as argilas velhas, formadas há mais de 60 milhões de anos, propondo então que: 
$\mathrm{K}_{0}=0,34 \mathrm{~K}_{\mathrm{D}}^{0,54} \quad\left(\mathrm{~S}_{\mathrm{u}} / \sigma^{\prime}{ }_{\mathrm{vo}} \leq 0,5\right) \quad$ Argilas jovens

$\mathrm{K}_{0}=0,68 \mathrm{~K}_{\mathrm{D}}^{0,54} \quad\left(\mathrm{~S}_{\mathrm{u}} / \sigma^{\prime}{ }_{\mathrm{vo}}>0,8\right) \quad$ Argilas velhas

$\mathrm{Na}$ qual $\mathrm{S}_{\mathrm{u}}$ é a resistência não drenada da argila

A Figura 3.17 apresenta a proposta dos autores citados acima.

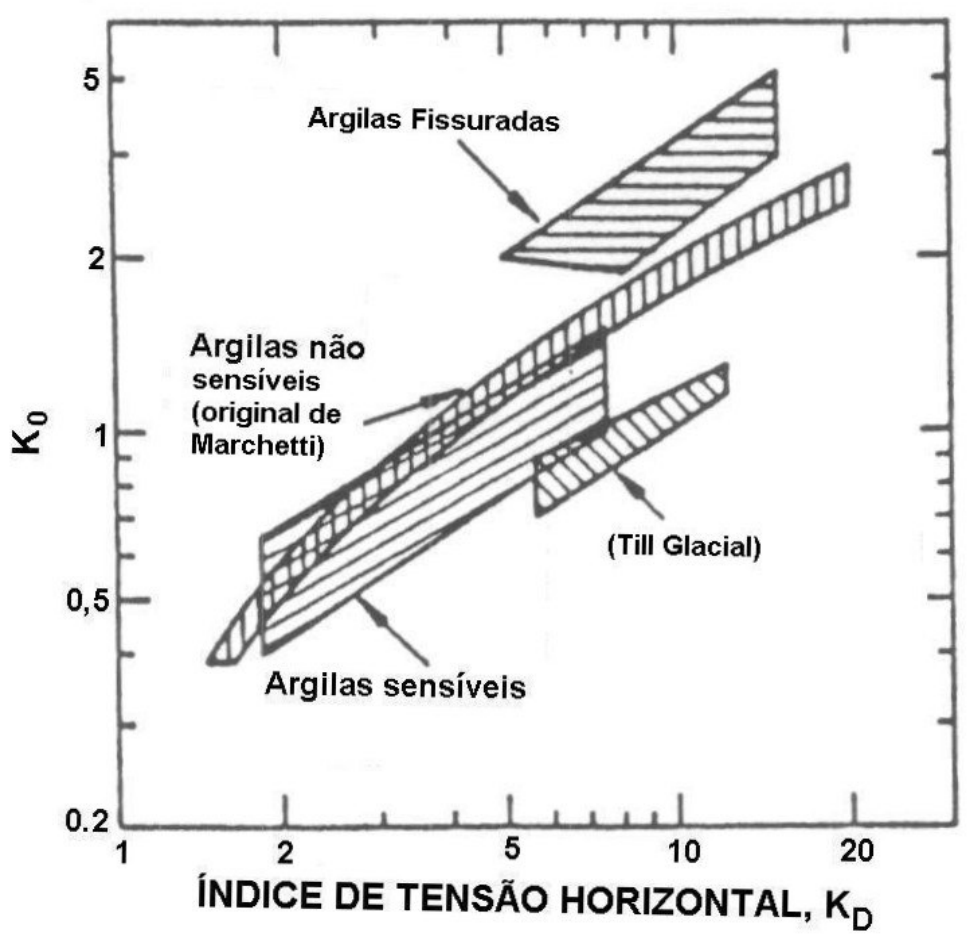

Figura 3.17 - Correlação $\mathrm{K}_{0}-\mathrm{K}_{\mathrm{D}}$ em argilas baseada em Marchetti (1980), Powel \& Uglow (1986) e Lacasse \& Lunne (1988)

Lacasse e Lunne apud Lunne et al. (1990) ainda propuseram a seguinte correlação para argilas jovens em função do índice de plasticidade, com base em ensaios realizados em argilas na Noruega:

$\mathrm{K}_{0}=0,34 \cdot \mathrm{K}_{\mathrm{D}}^{\mathrm{m}} \quad$ para $\mathrm{K}_{\mathrm{D}}<4$

Correlacionaram o expoente " $\mathrm{m}$ " de $\mathrm{K}_{\mathrm{D}}$ à plasticidade da argila, variando entre 0,44 para alta plasticidade e 0,64 para baixa plasticidade.

Ortigão (1994) realizou ensaios pressiométricos (PMT) e dilatométricos (DMT) na argila porosa de Brasília e obteve valores de $\mathrm{K}_{0}$ de grande repetibilidade em todos os furos. A faixa de valores obtida do DMT foi ligeiramente superior aos resultados obtidos do PMT. Isto é devido à variabilidade do depósito considerado como base de dados usado por Lunne et al. 
(1989) para definir a correlação empírica de argilas jovens entre $K_{0}$ e $K_{D}$. Numa profundidade de 3 metro foi retirada uma amostra saturada e através de ensaios de laboratório obteve-se um valor $\mathrm{K}_{0}$ igual a 0,55 , dentro da faixa de valores obtida pelo DMT (na faixa de 0,5 a 0,7 ).

\section{b) $K_{0}$ em Areias}

A correlação para a obtenção de $\mathrm{K}_{0} \mathrm{em}$ areias não é fácil, visto que durante a cravação da lâmina há uma alteração no índice de vazios, que pode provocar um aumento da tensão horizontal e do valor de $p_{0}$. Ensaios executados por Marchetti (1985) em câmaras de calibração indicaram a necessidade de se introduzir outros parâmetros para a obtenção do $\mathrm{K}_{0}$, como a compacidade relativa $\mathrm{C}_{\mathrm{r}}$ ou o ângulo de atrito efetivo ( $\left.\phi^{\prime}\right)$.

Diante deste fato Schmertmann (1983) propôs para estimar o $\mathrm{K}_{0}$ em areias a seguinte equação:

$$
K_{0}=\frac{40+23 \cdot K_{D}-86 \cdot K_{D}\left(1-\sin \phi_{a x}^{\prime}\right)+152\left(1-\sin \phi_{a x}^{\prime}\right)-717\left(1-\sin \phi_{a x}^{\prime}\right)^{2}}{192-717\left(1-\sin \phi_{a x}^{\prime}\right)}
$$

em que:

$\mathrm{K}_{\mathrm{D}}=$ índice de tensão horizontal do dilatômetro

$\phi_{\mathrm{ax}}^{\prime}=$ ângulo de atrito obtido através de ensaios de compressão triaxial - $\left(\phi_{\mathrm{ax}}^{\prime}=\phi^{\prime}\right)$.

A aplicação da equação acima se torna problemática, pois se desconhece $K_{0}$ e $\phi$ ', obtendo-se dessa forma 2 incógnitas. Schmertmann sugeriu a utilização desta expressão em conjunto com a expressão obtida através da teoria de Durgunoglu e Mitchell (1975) para o ensaio de CPT, que expressa $\mathrm{q}_{\mathrm{c}}$ (resistência de ponta obtida através do ensaio de cone) em função de $K_{0}$ e $\phi$ ', obtendo-se, portanto um sistema de duas equações e duas incógnitas.

$\mathrm{K}_{\mathrm{D}}=f_{1}\left(\mathrm{~K}_{0}, \phi^{\prime}\right)$

$\mathrm{q}_{\mathrm{c}}=f_{2}\left(\mathrm{~K}_{0}, \phi^{\prime}\right)$

Através desse sistema Marchetti (1985) construiu um ábaco onde as incógnitas são $\mathrm{K}_{\mathrm{D}}$, $\sigma^{\prime}{ }_{v}$ e $q_{c}$, eliminando a variável desconhecida ( $\phi$ '). Lacasse \& Lunne (1988) recomendam o uso do ábaco de Marchetti, Figura 3.18, para se obter uma primeira estimativa de $\mathrm{K}_{0}$. 


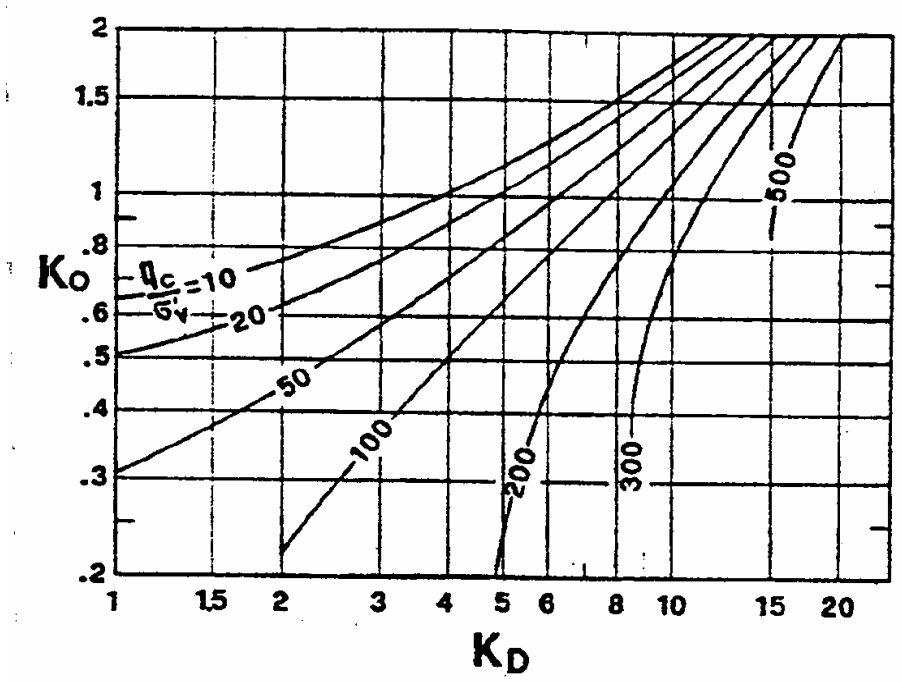

Figura 3.18 - Ábaco para estimativa de $\mathrm{K}_{0}$ a partir de $\mathrm{K}_{\mathrm{D}}$ (DMT) e $\mathrm{q}_{\mathrm{c}}(\mathrm{CPT})$ Marchetti (1985).

Baldi et al. (1986) fizeram uma conversão dos ábacos em equações algébricas, utilizando resultados de 42 ensaios em câmaras de calibração, obtendo-se a seguinte expressão para areias em depósitos recentes:

$\mathrm{K}_{0}=0,376+0,095 \mathrm{~K}_{\mathrm{D}}-0,0017\left(\mathrm{q}_{\mathrm{c}} / \sigma_{\mathrm{v}}^{\prime}\right)$

Estes autores compararam valores resultantes da equação 3.13 e os medidos para as areias do Rio Pó, estudadas por Marchetti (1985), e propuseram a seguinte expressão para as areias não cimentadas com mineral predominante de quartzo:

$\mathrm{K}_{0}=0,376+0,095 \mathrm{~K}_{\mathrm{D}}-0,00461\left(\mathrm{q}_{\mathrm{c}} / \sigma_{\mathrm{v}}^{\prime}\right)$

Marchetti et al (1997) sugerem que se estime $\mathrm{K}_{0}$ em areias pela equação 3.13, obtida por Baldi et al. (1986), para areias depositadas recentemente e pela equação 3.14 para depósitos de areias envelhecidas. A inconveniência do método é que são necessários ensaios de DMT e CPT para cálculo dos parâmetros $K_{D}$ e $q_{c}$. Uma alternativa para se obter o $K_{0}$ é empregar a equação de Schmertmann (1983), com o ângulo de atrito efetivo estimado pelo DMT através da equação 3.37 proposta por Marchetti (1997), que será apresentada adiante. 


\section{c) Exemplo de validação destas equações}

A equação 3.8 proposta por Marchetti (1980) e a equação proposta por Baldi et al (1986) foram testadas no Campo Experimental da UNESP, onde Giacheti et al (2006) obtiveram resultados de $\mathrm{K}_{0}$ semelhantes aos $\mathrm{K}_{0}$ do PMT, conforme Figura 3.19.

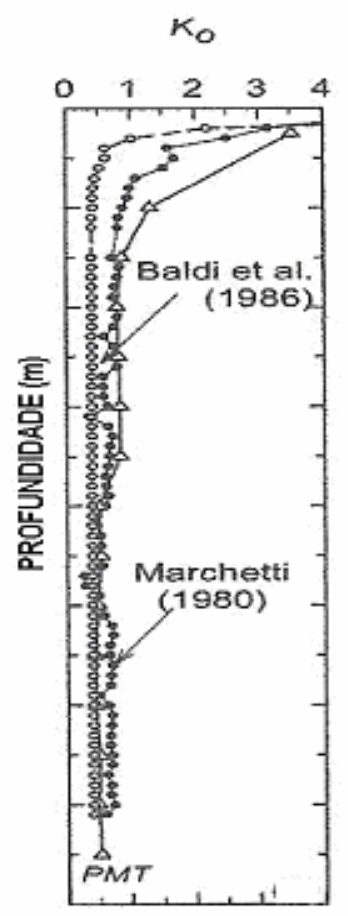

Figura 3.19 - Comparação do $\mathrm{K}_{0}$ do DMT (Baldi et al, 1986 e Marchetti, 1980) e $\mathrm{K}_{0}$ do PMT - CE da UNESP - BAURU - SP

\subsubsection{Razão de sobre-adensamento (OCR)}

A razão de sobre adensamento ou pré-adensamento do solo (RSA ou OCR) é definida como a relação entre a máxima tensão vertical efetiva a que o solo já foi submetido e a tensão vertical efetiva atuante.

\section{a) OCR em argilas}

Marchetti (1980) observou uma semelhança entre os perfis de $K_{D}$ e OCR, com base em dados apenas de argilas não cimentadas. Propôs, então, para essas argilas, uma correlação entre OCR e $\mathrm{K}_{\mathrm{D}}$. Este fato foi posteriormente confirmado em estudos desenvolvidos por 
Jamiolkowski et al. (1988).

Para solos coesivos, que não sofreram cimentação, e possuam $0,2<\mathrm{I}_{D}<2$, Marchetti (1980) sugere a utilização da seguinte equação:

$\mathrm{OCR}=\left(0,5 \mathrm{~K}_{\mathrm{D}}\right)^{1,56}$

Para $K_{D}=2$ tem-se OCR $=1$, ou seja, solo normalmente adensado.

Marchetti e Crapps (1981) restringiram o uso dessa equação apenas para solos com $\mathrm{I}_{\mathrm{D}}<1,2$ e propuseram novas correlações, apresentadas na Tabela 3.2:

Tabela 3.2 - Correlações para obtenção do OCR segundo Marchetti e Crapps (1981).

\begin{tabular}{|c|c|}
\hline $\mathrm{I}_{\mathrm{D}}$ & $\mathrm{OCR}$ \\
\hline $\mathrm{I}_{\mathrm{D}}<1,2$ & $\mathrm{OCR}=\left(0,5 \mathrm{~K}_{\mathrm{D}}\right)^{1,56}$ \\
\hline $\mathrm{I}_{\mathrm{D}}>2$ & $\mathrm{OCR}=\left(0,67 \mathrm{~K}_{\mathrm{D}}\right)^{1,91}$ \\
\hline $1,2<\mathrm{I}_{\mathrm{D}}<2$ & $\mathrm{OCR}=\left(\mathrm{m} \mathrm{K}_{\mathrm{D}}\right)^{\mathrm{n}}$ \\
\hline
\end{tabular}

sendo:

$\mathrm{m}=0,5+0,17 \mathrm{P}$

$\mathrm{n}=1,56+0,35 \mathrm{P}$

$P=\left(\frac{I_{D}-1,2}{0,8}\right)$

Diversos autores propuseram correlações similares, encontradas na literatura internacional, todas correlacionando OCR com $\mathrm{K}_{\mathrm{D}}$. Seguem algumas destas correlações:
$\mathrm{OCR}=\left(0,24 \mathrm{~K}_{\mathrm{D}}\right)^{1,32}$
Powell e Uglow (1988)
OCR $=\left(0,3 \mathrm{~K}_{\mathrm{D}}\right)^{1,17}$ para $\mathrm{S}_{\mathrm{u}} / \sigma^{\prime}{ }_{\mathrm{v}}<0,8 \quad$ Lunne et al (1989)
OCR $=\left(0,27 \mathrm{~K}_{\mathrm{D}}\right)^{1,17}$ para $\mathrm{S}_{\mathrm{u}} / \sigma^{\prime}{ }_{\mathrm{v}}>0,8 \quad$ Lunne et al (1989)
OCR $=0,34 \mathrm{~K}_{\mathrm{D}}{ }^{1,43}=\left(0,47 \mathrm{~K}_{\mathrm{D}}\right)^{1,43} \quad$ Kamei e Iwasaki (1995) - Fig.3.20 


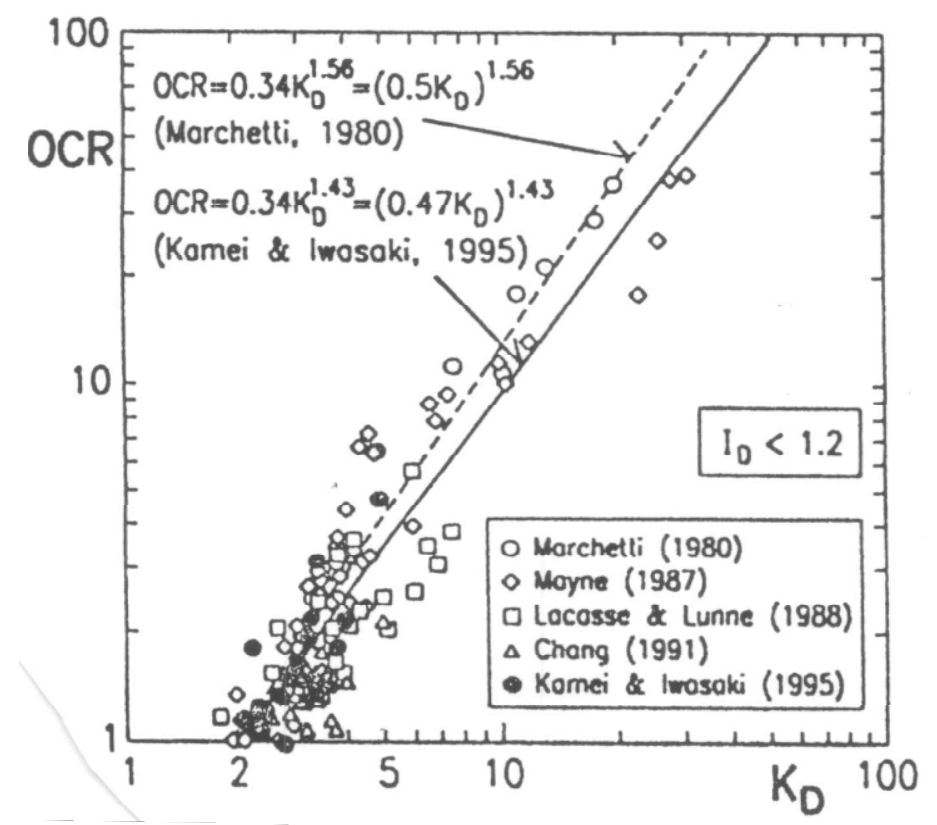

Figura 3.20 - Correlação entre KD e OCR para solos coesivos de várias áreas geográficas (Kamei e Iwasaki, 1995).

A proposta de Kamei e Iwasaki (1995) está ilustrada na Figura 3.20. Como as escalas são logarítmicas, conclui-se que a dispersão de valores é muito grande.

Estudos realizados com argilas estruturadas pré-adensadas mostram que há um incremento no valor de $K_{D}$ devido à cimentação, ou seja, o $K_{D}$ passa a depender do OCR e da cimentação.

\section{b) OCR em Areias}

Uma forma de se obter informações sobre o OCR em areias é usando o coeficiente $\mathrm{M}_{\mathrm{DMT}} / \mathrm{q}_{\mathrm{c}}$, sendo $\mathrm{M}_{\mathrm{DMT}}$, o módulo edométrico obtido através do ensaio dilatométrico, o qual será abordado posteriormente. Na Tabela 3.3 são apresentadas indicações sobre o estado de uma areia, se normalmente (n.a.) ou sobre-adensada (s.a.), em função da relação $\mathrm{M}_{\mathrm{DMT}} / \mathrm{q}_{\mathrm{c}}$.

Tabela 3.3 - Valores médios de OCR em areia.

\begin{tabular}{|l|c|c|}
\hline \multirow{2}{*}{\multicolumn{1}{|c|}{ Autores }} & \multicolumn{2}{c|}{$\mathrm{M}_{\mathrm{DMT}} / \mathrm{q}_{\mathrm{c}}$} \\
\cline { 2 - 3 } & Areias n.a. & Areias s.a. \\
\hline Jendeby (1992) & $7-10$ & $12-24$ \\
\hline Jamiolkowski (1995) & $3-8$ & $10-20$ \\
\hline Baldi et al. (1986) & $4-7$ & $12-16$ \\
\hline
\end{tabular}


Schmertmann (1988) propôs uma correlação para se estimar o OCR partindo do coeficiente de empuxo em repouso $\left(\mathrm{K}_{0}\right)$ e do ângulo de atrito axissimétrico drenado $\left(\phi_{\mathrm{ax}}^{\prime}\right)$, válida apenas para areias com $I_{D} \geq 1,2$ e, não cimentadas, de acordo com a expressão 3.23:

$O C R=\left(\frac{K_{0}}{1-\operatorname{sen} \phi_{a x}^{\prime}}\right)^{\left(\frac{1}{0,8 \operatorname{sen} \phi_{a x}^{\prime}}\right)}$

\subsubsection{Parâmetros relacionados à resistência do solo}

\subsubsection{Resistência não-drenada de $\operatorname{argilas}\left(S_{u}\right)$}

É abordada a seguir a questão da estimativa da resistência não drenada de argilas, importante no estudo de estabilidade de aterros e de fundações diretas em argilas moles a média. A resistência solicitada, no caso de um aterro sobre argila mole, seria a resistência não drenada, de modo análogo ao que ocorre no ensaio dilatométrico, em que a solicitação é aplicada rapidamente, não havendo tempo hábil para que a drenagem ocorra.

Ladd et al (1977), após analisarem dados que mostravam que há um aumento relativo da razão resistência não drenada pela tensão vertical efetiva, em função do OCR, propuseram a expressão:

$\left(\frac{s_{u}}{\sigma_{\text {vo }}^{\prime}}\right)_{\text {s.a. }}=\left(\frac{s_{u}}{\sigma_{\text {vo }}^{\prime}}\right)_{\text {n.a. }} \cdot O C R^{m}$

Com $0,75<\mathrm{m}<0,85$, mais comumente $\mathrm{m}=0,8$, sendo nesta expressão s.a. e n.a., sobre-adensada e normalmente adensada respectivamente.

Mesri (1975), ao retro-analisar rupturas de aterros sobre solos moles, propôs a seguinte expressão para estimar limites inferiores de $S_{u}$ :

$$
\left(\frac{s_{u}}{\sigma_{\mathrm{VM}}^{\prime}}\right) \cong 0,22
$$

sendo: $\sigma_{\mathrm{VM}}^{\prime}=$ tensão efetiva de pré-adensamento

Marchetti (1980), combinou a expressão 3.15, de sua autoria, com as expressões 3.24, de Ladd et al, e 3.25, de Mesri, esta última no formato $\left(\mathrm{S}_{\mathrm{u}} / \sigma^{\prime}{ }_{\mathrm{vo}}\right)$ n.a.=0,22, e propôs para o cálculo da resistência não drenada em argilas a expressão:

$\mathrm{s}_{\mathrm{u}}=0,22 \sigma_{\mathrm{vo}}^{\prime}\left(0,5 \mathrm{~K}_{\mathrm{D}}\right)^{1,25}$ 
Segundo Marchetti (1997) esta expressão tem sido confirmada por vários estudos realizados e publicados posteriormente.

Lacasse e Lunne (1988) apresentaram uma comparação entre o $S_{u}$, obtido de ensaios dilatométricos por intermédio da expressão 3.26, com valores de $S_{u}$ obtidos de ensaios de palheta e de ensaios de compressão triaxial. Para estes autores o coeficiente de $\sigma_{\text {vo }}$ que melhor se ajusta com relação a ensaios de palheta seria 0,17 e para os ensaios triaxiais seria 0,20 .

Roque et al. (1988) propuseram uma analogia da inserção do dilatômetro com a ruptura de uma sapata carregada lateralmente, e propuseram o uso de fórmulas clássicas de capacidade de carga para estimar a resistência não drenada do solo. Estes autores partiram da expressão:

$\mathrm{S}_{u}=\frac{p_{1}-\sigma_{h o}}{N_{c}}$

na qual:

$\mathrm{p}_{1}=$ Pressão de expansão máxima do DMT

$\sigma_{\mathrm{ho}}=$ Tensão horizontal total 'in situ'.

$\mathrm{N}_{\mathrm{c}}=$ Coeficiente de capacidade de carga.

A Tabela 3.4 apresenta os valores de $\mathrm{N}_{\mathrm{c}}$.

Levando-se em conta a expressão 3.8, pode-se escrever:

$$
\begin{aligned}
& \sigma_{h o}^{\prime}=\sigma_{v o}^{\prime} \cdot\left[\left(\mathrm{K}_{\mathrm{D}} / 1,5\right)^{0,47}-0,6\right] \\
& \sigma_{h o}=\sigma_{v o}^{\prime} \cdot\left[\left(\mathrm{K}_{\mathrm{D}} / 1,5\right)^{0,47}-0,6\right]+u_{0} \\
& \mathrm{~s}_{\mathrm{u}}=: \frac{p_{1}-\sigma_{v o}^{\prime} \cdot\left[\left(\mathrm{K}_{\mathrm{D}} / 1,5\right)^{0,47}-0,6\right]+u_{0}}{N_{c}}
\end{aligned}
$$

Tabela 3.4 - Valores de $\mathrm{N}_{\mathrm{c}}$ sugeridos por Roque et al. (1988)

\begin{tabular}{|c|c|}
\hline Tipo de solo & $\mathbf{N}_{\mathbf{c}}$ \\
\hline Argila rija e silte & 5 \\
\hline Argila média & 7 \\
\hline Argila mole & 9 \\
\hline
\end{tabular}


Kamei e Iwasaki (1995) também analisaram a equação 3.26 proposta por Marchetti e propuseram a seguinte correlação:

$\left(\mathrm{s}_{\mathrm{u}} / \sigma_{\mathrm{v} 0}^{\prime}\right)_{\mathrm{NA}}=0,35$

$\left(\mathrm{s}_{\mathrm{u}} / \sigma_{\mathrm{v} 0}^{\prime}\right)=0,35\left(0,47 \mathrm{~K}_{\mathrm{D}}\right)^{1,14}$

\subsubsection{2 Ângulo de Atrito efetivo, $\phi$,}

A estimativa do ângulo de atrito em função do $I_{D}$ e do $E_{D}$, foi feita pela primeira vez por Marchetti e Crapps (1981), ainda em fase experimental, válida para solos com valores de $\mathrm{I}_{\mathrm{D}}>1,2$. A expressão proposta foi:

$$
\phi^{\prime}=25+0.19 \cdot \sqrt{I_{D} \cdot R_{C}-100}
$$

Se $\quad \mathrm{R}>500$ e $\sigma_{{ }_{\mathrm{v}}}<50 \mathrm{kPa} \quad \Rightarrow \quad R_{c}=500+\frac{R-500}{1+\frac{R-500}{1500}}$

Se $\quad R \leq 500$ e $\sigma^{\prime}{ }_{v} \geq 50 \mathrm{kPa} \quad \Rightarrow \quad R_{c}=R$

sendo:

$\mathrm{R}=\frac{\mathrm{E}_{\mathrm{D}}}{\sigma_{\mathrm{v}}^{\prime}}$

Em seguida, Schmertmann (1982 e 1983) apud USDOT (1992) desenvolveu um método iterativo para a determinação do ângulo de atrito efetivo ( $\left.\phi^{\prime}\right)$ tendo por base a teoria de Durgunoglu e Mitchell (1975). Para a obtenção do ф', segundo o autor, precisa-se de uma estimativa simultânea de $\phi$ ' e $\mathrm{K}_{0}$ vindo de $\mathrm{K}_{\mathrm{D}}$ e $\mathrm{q}_{\mathrm{c}}$, novamente recorrendo aos dois ensaios DMT e CPT.

Sendo o método iterativo de Schmertmann não muito prático, Marchetti (1985) propôs um ábaco que permite obter rapidamente $\phi$ '. Este ábaco foi alterado por Campanella e Robertson (1991) apud Marchetti (1997), que adicionaram uma escala à direita da Figura 3.21 , para que se obtenha mais facilmente o $\phi$ ', utilizando apenas a relação $\mathrm{q}_{\mathrm{c}} / \sigma^{\prime}{ }_{\text {vo }}=33 \mathrm{~K}_{\mathrm{D}}$. 


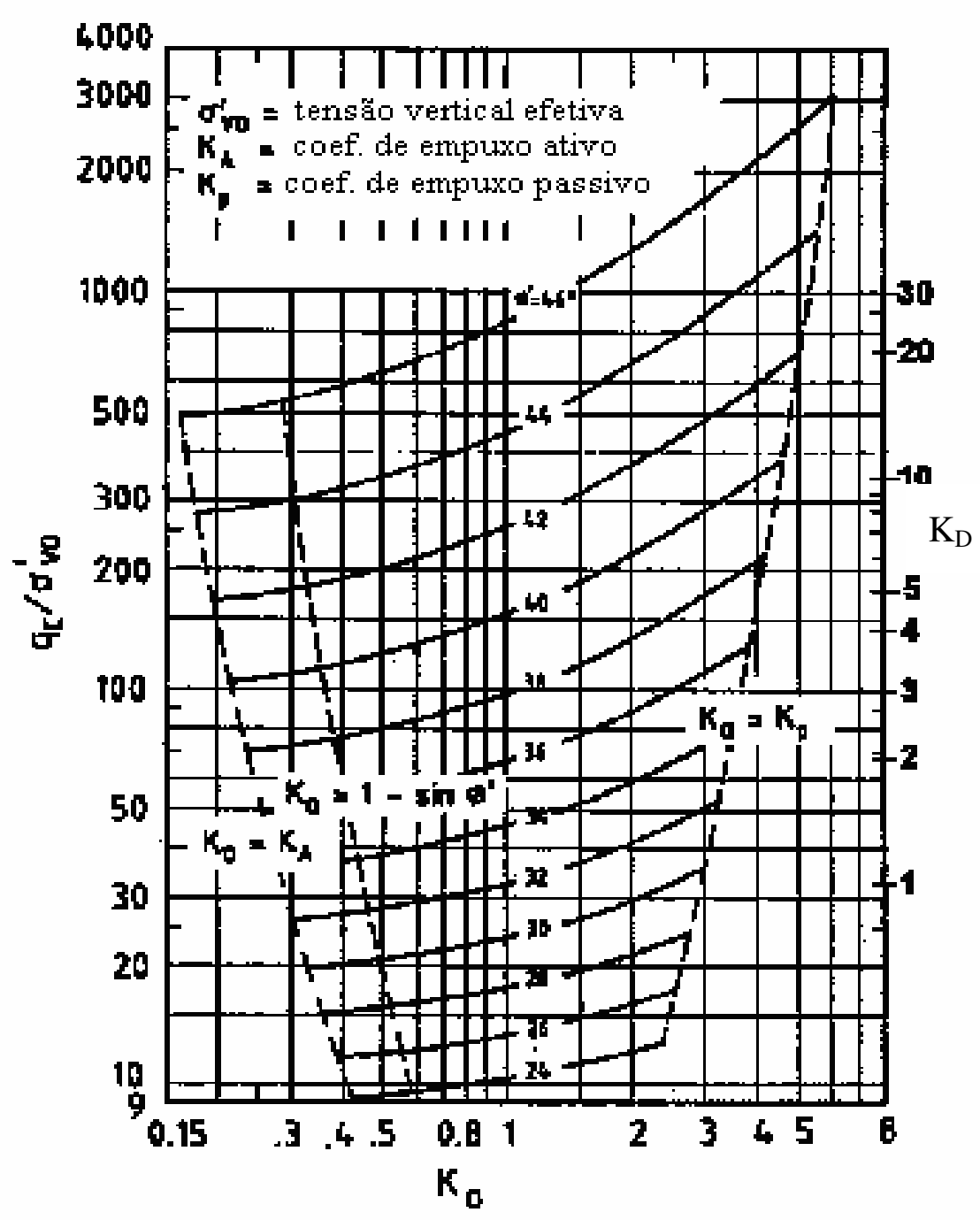

Figura 3.21 -Ábaco de Marchetti (1985), modificado por Campanella e Robertson (1991) para avaliação de $\phi$ ' através de $K_{D}$ em areias não cimentadas, apud (Marchetti, 1997).

Marchetti (1997), ainda propõe, com base nos estudos Campanella e Robertson (1991), uma equação analítica correlacionando o ângulo de atrito efetivo ( $\phi ’$ com $K_{D}$.

$\phi^{\prime}=28+14,6 \log K_{D}-2,1 \log ^{2} K_{D}$

Giacheti et al (2006) aplicaram a equação 3.37 para os Campos Experimentais da UNESP, UNICAMP e USP de São Carlos. No Campo Experimental da UNESP obtiveram com o DMT resultados muito semelhantes aos ensaios em laboratório, conforme mostra a Figura 3.22 (a). No Campo Experimental da UNICAMP, a estimativa do ângulo de atrito efetivo do solo ( $\left.\phi^{\prime}\right)$ pelo DMT foi superestimada (média de $32,5^{\circ}$ ) se comparada aos mesmos parâmetros obtidos em laboratório $\left(20^{\circ}\right)$, apresentados na Figura 3.22 (b). E, por fim, no Campo Experimental da USPSC a comparação da estimativa do ( $\phi$ ') pelo DMT foi ora muito 
semelhante e ora superestimada $\left(30^{\circ}\right)$ se comparada aos mesmos parâmetros obtidos em laboratório $\left(26^{\circ}\right)$, de acordo com a Figura 3.22 (c).
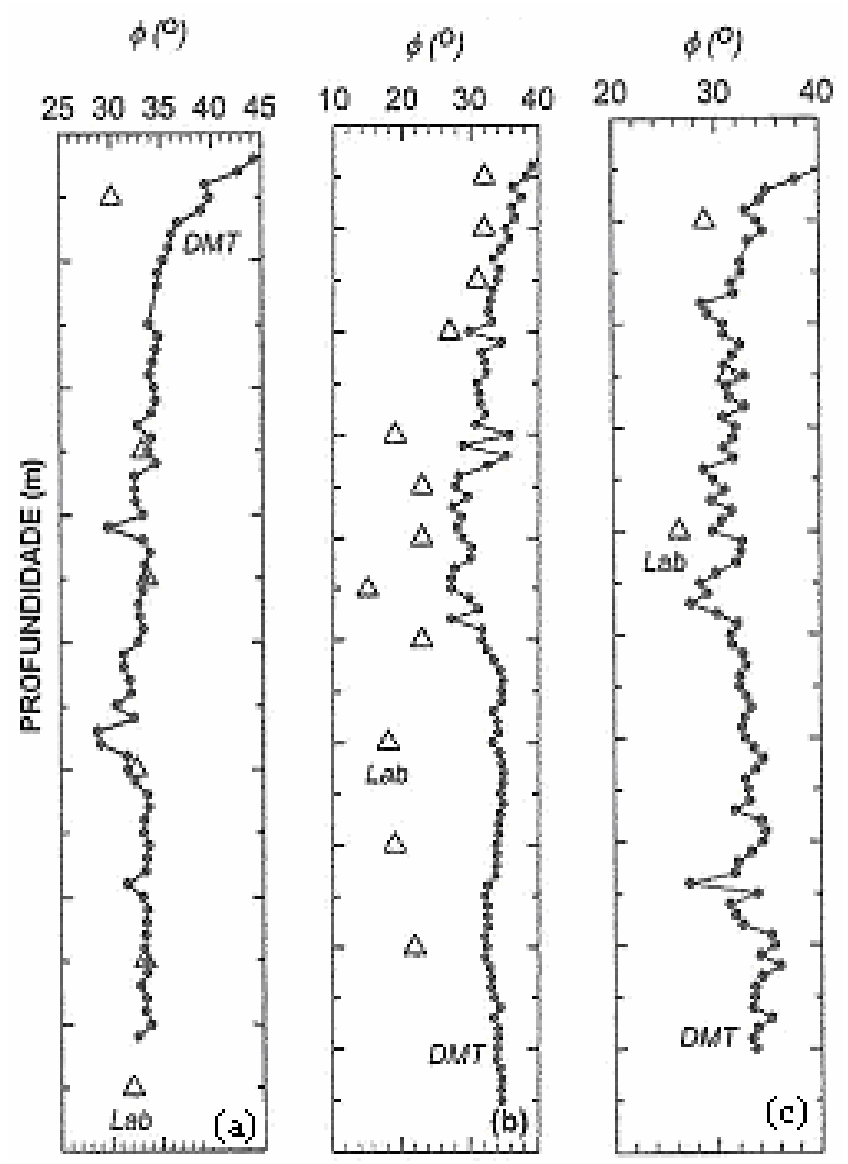

Figura 3.22 - Resultados obtidos do ângulo de atrito efetivo do solo( $\left.\phi^{\prime}\right)$ calculados com o DMT em comparação com o mesmo parâmetro obtido em laboratório.
(a) UNESP
(b) UNICAMP e
(c) USPSC

\subsubsection{Parâmetros relacionados à deformabilidade}

\subsubsection{Módulo edométrico (M)}

O módulo $M$ pode ser expresso através da teoria da elasticidade em função do coeficiente de Poisson (v) e do módulo de elasticidade E.

$$
\mathrm{M}=\frac{1-v}{1-v-2 v^{2}} \cdot \mathrm{E}
$$

Estudos indicaram que há proporcionalidade entre o módulo edométrico $\mathrm{M}$ e $\mathrm{E}_{\mathrm{D}}$. 
Marchetti (1980) verificou que a razão entre $M$ e $E_{D}$, chamada de $R_{M}$, não é constante e que é tanto maior quanto maior o índice de tensão horizontal $\mathrm{K}_{\mathrm{D}}$.

O fator de correção $R_{M}$ varia entre 1 e 3 e experiências em centenas de locais têm mostrado que $\mathrm{M}_{\mathrm{DMT}}$ varia entre 400 e $400.000 \mathrm{kPa}$ conforme Marchetti (1980) o qual determina $R_{M}$ analiticamente. A Figura 3.23 apresenta a correlação entre $R_{M}$ e $K_{D}$

$\mathrm{M}_{\mathrm{DMT}}=\mathrm{R}_{\mathrm{M}} \cdot \mathrm{E}_{\mathrm{D}}$

em que: $\quad R_{M}=$ coeficiente função de $I_{D}$ e $K_{D}$ e sempre $\geq 0,85$

Tabela 3.5 - Cálculo de $\mathrm{R}_{\mathrm{M}}$ em função de $\mathrm{I}_{\mathrm{D}}$ e $\mathrm{K}_{\mathrm{D}}$ (Marchetti, 1980)

\begin{tabular}{|l|c|c|}
\hline \multicolumn{1}{|c|}{ Tipo do Solo } & $\mathrm{I}_{\mathrm{D}}$ & $\mathrm{R}_{\mathrm{M}}$ \\
\hline Argilas e argilas siltosas & $\mathrm{I}_{\mathrm{D}} \leq 0,6$ & $\mathrm{R}_{\mathrm{M}}=0,14+2,36 . \log \cdot \mathrm{K}_{\mathrm{D}}$ \\
\hline $\begin{array}{l}\text { Siltes argilosos, siltes, siltes } \\
\text { arenosos e areias siltosas }\end{array}$ & $0,6<\mathrm{I}_{\mathrm{D}}<3,0$ & $\mathrm{R}_{\mathrm{M}}=\mathrm{R}_{\mathrm{Mo}}+\left(2,5-\mathrm{R}_{\mathrm{Mo}}\right) \log \cdot \mathrm{K}_{\mathrm{D}}$ \\
& & $\mathrm{R}_{\mathrm{Mo}}=0,14+0,15\left(\mathrm{I}_{\mathrm{D}}-0,6\right)$ \\
\hline Areias & $\mathrm{I}_{\mathrm{D}} \geq 3,0$ & $\mathrm{R}_{\mathrm{M}}=0,5+2 . \log . \mathrm{K}_{\mathrm{D}}$ \\
\hline
\end{tabular}

Se $K_{D}>10,0$ deve-se utilizar a expressão: $R_{M}=0,32+2,18 \cdot \log . K_{D}$

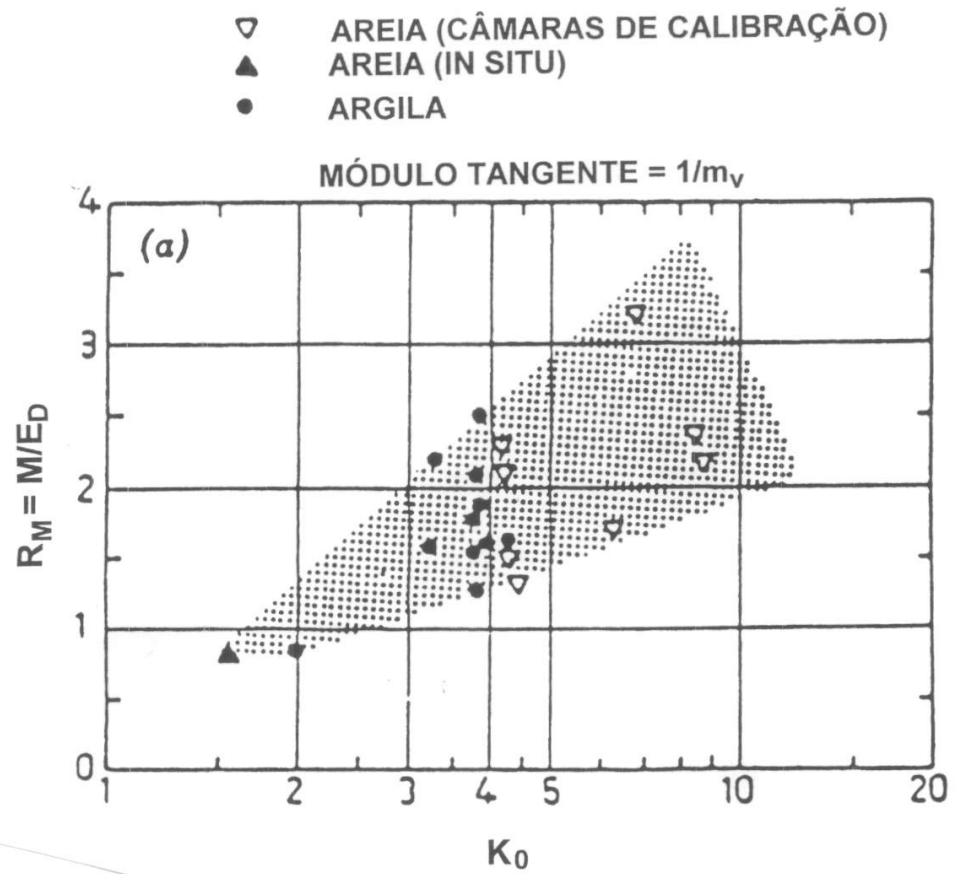

Figura 3.23 - Correlação entre $\mathrm{R}_{\mathrm{M}}$ e $\mathrm{K}_{\mathrm{D}}$ Marchetti (1980). 
$\mathrm{Na}$ literatura é mencionada a necessidade de se corrigir o $\mathrm{E}_{\mathrm{D}}$ através do fator de correção $\mathrm{R}_{\mathrm{M}}$. Tal fato é devido a:perturbação do solo pela penetração da lâmina do dilatômetro;

- o carregamento tem direção horizontal, enquanto que M é vertical;

- $\quad \mathrm{o} \mathrm{E}_{\mathrm{D}}$ não traz informações sobre a história de tensões, e a tensão lateral é refletida até certo ponto pelo $\mathrm{K}_{\mathrm{D}}$. Alguns autores como Leonards e Frost (1988) recomendam o uso de $\mathrm{M}=1,3 \cdot \mathrm{M}_{\mathrm{DMT}}$ para areias normalmente adensadas e $\mathrm{M}=2,4 . \mathrm{M}_{\mathrm{DMT}}$ para areias pré-adensadas; e

- $\quad \mathrm{E}_{\mathrm{D}}$ em argilas refere-se à condição não drenada, enquanto que o $\mathrm{M}$ é o módulo drenado. Em argilas o $\mathrm{E}_{\mathrm{D}}$ é mais próximo do módulo de Young não drenado $\left(\mathrm{E}_{\mathrm{U}}\right)$, de obtenção difícil, pois depende do tipo de ensaio, entre outros fatores. A relação $\mathrm{M}-\mathrm{E}_{\mathrm{D}}$ é uma função complexa de muitos parâmetros, inclusive os parâmetros de poropressão de Skempton. Como estes parâmetros dependem do tipo de solo e da sua história de tensões, de certa forma isto é refletido pelo $\mathrm{I}_{\mathrm{D}}$ e $\mathrm{K}_{\mathrm{D}}$ em termos paramétricos.

Giacheti et al (2006), testou a proposta de Marchetti (1980) para os solos do Campo Experimental da UNICAMP e para a USP de São Carlos. Nos dois Campos, os valores do módulo edométrico do DMT (M) foram muito semelhantes aos valores obtidos através da execução de ensaios edométricos em amostras indeformadas, conforme a Figura 3.24.
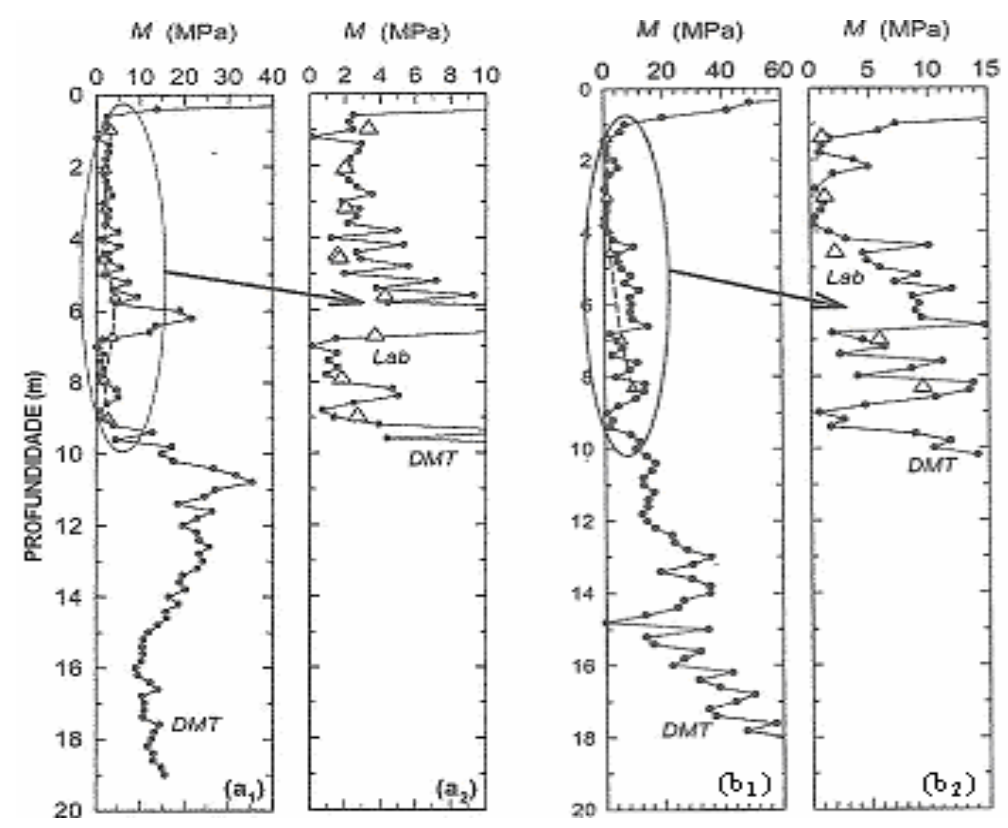

Figura 3.24 - Comparação entre os valores dos módulos edométrico (M) obtidos com o DMT e com ensaios edométricos em amostras indeformadas. $\left(a_{1}\right)$ e $\left(a_{2}\right)$ UNICAM $\left(b_{1}\right)$ e $\left(b_{2}\right)$ USPSC 


\subsubsection{Módulo de Young (E)}

O comportamento dos solos não é elástico e nem linear. Num gráfico tensãodeformação, o que se obtém não é uma reta. Ademais, quando se remove determinada tensão não se verifica o retorno à mesma posição, não podendo ser considerado um material elástico.

Para se levar em conta o efeito da não linearidade, foi associado ao módulo de elasticidade "E" um parâmetro que indica a deformação correspondente. A Figura 3.25 mostra como essa associação é feita. Por exemplo, o módulo $\mathrm{E}_{50}$ corresponde a um acréscimo de tensão igual a $50 \%$ do acréscimo de tensão que provocaria a ruptura.

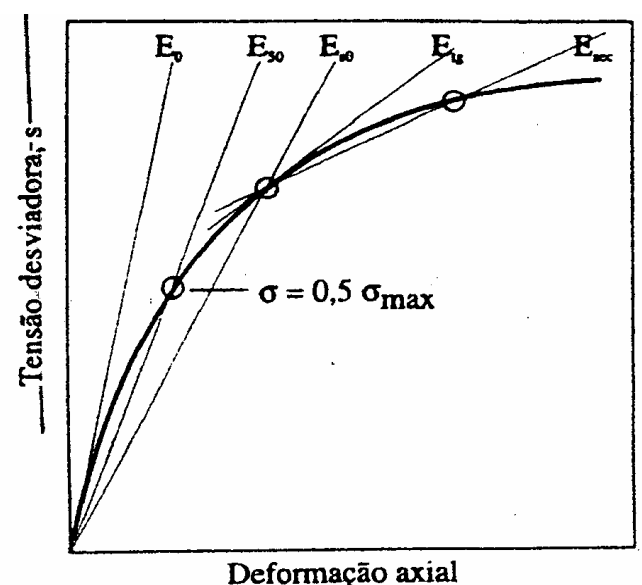

Figura 3.25-Curva típica de carregamento e definição dos módulos de elasticidade (Pinto, 1998 apud Siviero, 2003)

Dois valores de E têm sido investigados, um é o módulo secante a $25 \%$ da tensão de ruptura $\left(E_{25}\right)$ e, o outro, é o módulo tangente inicial $\left(E_{\mathrm{i}}\right)$.

Marchetti (1980) correlaciona o módulo de elasticidade, sem indicar a deformação correspondente, ao módulo dilatométrico $\mathrm{E}_{\mathrm{D}}$, que é dado por:

$\mathrm{E}=\mathrm{E}_{\mathrm{D}} \cdot\left(1-v^{2}\right)$

Alguns autores como Robertson et al. (1989) e Campanella et al. (1985) sugerem simplesmente uma proporcionalidade entre $\mathrm{E}$ e $\mathrm{E}_{\mathrm{D}}$.

$\mathrm{E}=\mathrm{F} \cdot \mathrm{E}_{\mathrm{D}}$

Alguns valores de F estão indicados na Tabela 3.6. 
Tabela 3.6 - Sugestão para o Fator de Correção F segundo alguns autores

\begin{tabular}{|l|c|c|l|}
\hline Tipo de Solo & Módulo & $\mathrm{F}$ & \multicolumn{1}{c|}{ Referência } \\
\hline Coesivos & $\mathrm{E}_{\mathrm{i}}$ & 10 & Robertson et al. (1989) \\
\hline Areia & $\mathrm{E}_{\mathrm{i}}$ & 2 & Robertson et al. (1989) \\
\hline Areia & $\mathrm{E}_{25}$ & 1 & Campanella et al. (1985) \\
\hline Areia n.a. & $\mathrm{E}_{25}$ & 0,85 & Baldi et al. (1986) \\
\hline Areia s.a. & $\mathrm{E}_{25}$ & 3,5 & Baldi et al. (1986) \\
\hline
\end{tabular}

Marchetti (1997) sugere que o módulo de elasticidade, para argilas e areias, seja obtidos a partir do módulo edométrico "M", determinado em função de $\mathrm{E}_{\mathrm{D}}$, $\mathrm{I}_{\mathrm{D}}$ e $\mathrm{K}_{\mathrm{D}}$, conforme a expressão 3.39. O módulo obtido é o correspondente a uma deformação de $0,1 \%$.

$\mathrm{E} \approx 0,8 \mathrm{M}_{\mathrm{DMT}}$

\subsubsection{Módulo de Deformação Cisalhante (G)}

Através da teoria da elasticidade o módulo de cisalhamento ou de deformação cisalhante $(\mathrm{G})$, pode ser obtido pela equação:

$G=\frac{E}{2 \cdot(1+v)}$

O valor máximo de $G\left(G_{0}\right)$ pode ser obtido através de equações de propagação unidimensional de ondas, em função da densidade do solo $(\rho)$ e da velocidade da onda $\left(V_{s}\right)$, a saber:

$\mathrm{G}_{0}=\rho . \mathrm{V}_{\mathrm{s}}$

Para se obter o módulo cisalhante $\mathrm{G}_{0}$, através do DMT, têm sido propostas algumas correlações.

Baldi et al. (1986) introduziram a seguinte relação entre o módulo de cisalhamento máximo $\mathrm{G}_{0}$ e o módulo dilatométrico $\mathrm{E}_{\mathrm{D}}$ para solos não coesivos:

$\mathrm{R}_{\mathrm{G}}=\mathrm{G}_{0} / \mathrm{E}_{\mathrm{D}}$ 
Areias normalmente adensadas do Ticino (Itália) foram estudadas por Baldi et al. (1986). Estes autores realizaram ensaios de coluna ressonante para a determinação do módulo de cisalhamento máximo $\left(\mathrm{G}_{0}\right)$ e ensaios de DMT dentro de câmaras de calibração para a determinação do módulo dilatométrico $\left(\mathrm{E}_{\mathrm{D}}\right)$, encontrando a seguinte expressão:

$\mathrm{R}_{\mathrm{G}}=\mathrm{G}_{0} / \mathrm{E}_{\mathrm{D}}=2,72 \pm 0,59$

Ainda para solos não coesivos, Sully e Campanella (1989) apud Siviero (2003) fizeram ensaios do tipo: DMT, SPT e ensaios de cone sísmicos (SCPT) na Universidade de British Columbia (Canadá) e encontraram uma relação entre os resultados de $E_{D}$ e Go com aplicação na equação 3.46, sendo a expressão proposta:

$\mathrm{R}_{\mathrm{G}}=\mathrm{G}_{0} / \mathrm{E}_{\mathrm{D}}=1,17 \pm 0,15$

Aplicou-se a proposta de Baldi et al. (1986) aos solos dos Campos Experimentais da UNESP, UNICAMP E USPSC e foram comparados estes resultados com o obtidos em ensaios sísmicos (Cross-Hole) e CPT. Os resultados são apresentados na Figura 3.26, extraídos de Giacheti et al (2006).
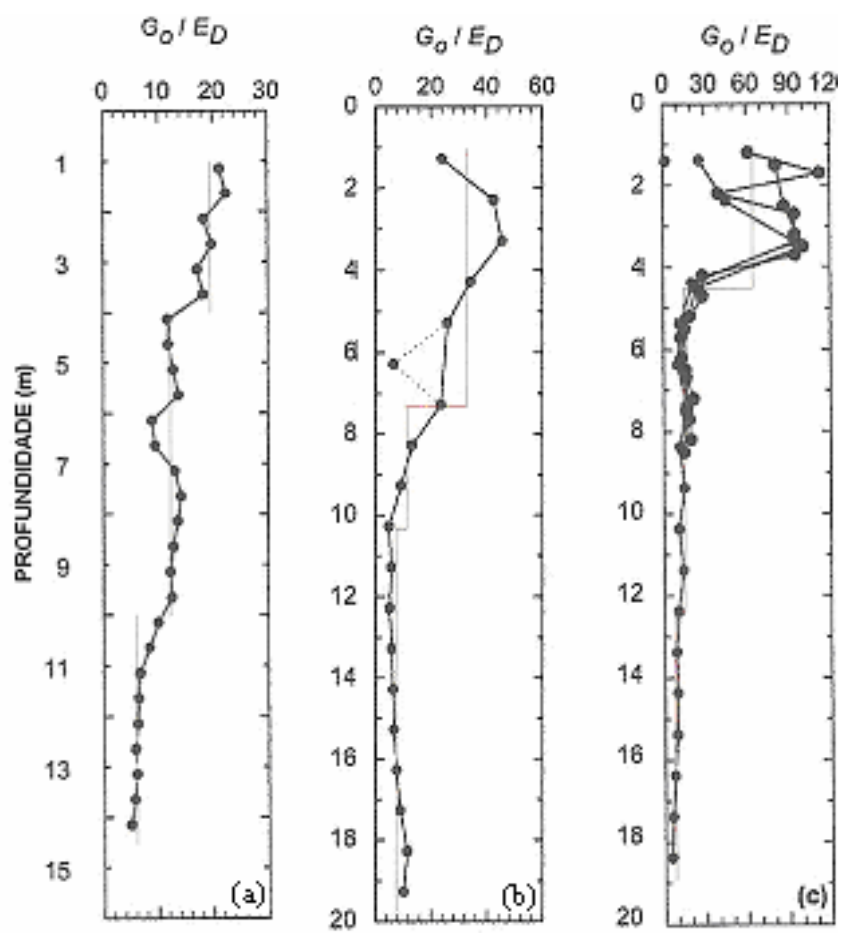

Figura 3.26 - Comparação dos Valores de $\mathrm{G}_{0}$ para os Campos Experimentais.

(a) UNESP (b) UNICAMP e (c) USPSC.

Lunne et al. (1990) propuseram uma correlação para se obter o módulo de cisalhamento máximo $\mathrm{G}_{0}$ para solos coesivos em função de $\mathrm{K}_{\mathrm{D}}$ e de $\sigma^{\prime}{ }_{\text {vo }}$. 
$\mathrm{G}_{0}=\alpha \cdot \mathrm{K}_{\mathrm{D}} \cdot \sigma^{\prime}{ }_{\text {vo }}$

com $\alpha$ variando entre 75 a 150

Hryciw (1990) propôs uma correlação que atenderia tanto solos coesivos como não coesivos. Este método baseou-se em estudos em 9 campos na Itália, Noruega, Canadá e Estados Unidos. Os dados correspondem a diversos tipos de solo, tais como: areia, silte e argila. Na Figura 3.27, Hryciw comparou o $\mathrm{G}_{0}$ obtido de laboratório com o $\mathrm{G}_{0}$ previsto pela expressão 3.50, resultante do estudo destes campos provenientes de vários países. Vê se que a maior parte dos casos revela erros na faixa de $\pm 25 \%$.

$\mathrm{G}_{0}=\frac{530}{\left(\frac{\sigma_{v}^{\prime}}{p_{a}}\right)^{0.25}} \cdot \frac{\frac{\gamma_{d}}{\gamma_{W}}-1}{2,7-\frac{\gamma_{d}}{\gamma_{W}}} \cdot K_{o}^{0.25} \cdot\left(\sigma_{v}^{\prime} \cdot p_{a}\right)^{0.5}$

sendo: $\gamma_{\mathrm{d}}=$ Peso específico seco do solo

$\gamma_{\mathrm{W}}=$ Peso específico da água

$\mathrm{K}_{0}=$ Coeficiente de empuxo no repouso (obtido do DMT)

$\mathrm{p}_{\mathrm{a}}=$ pressão atmosférica (bar)

$\sigma^{\prime}{ }_{\mathrm{v}}=$ Tensão efetiva vertical $\mathrm{G}_{0}$ previsto em bar

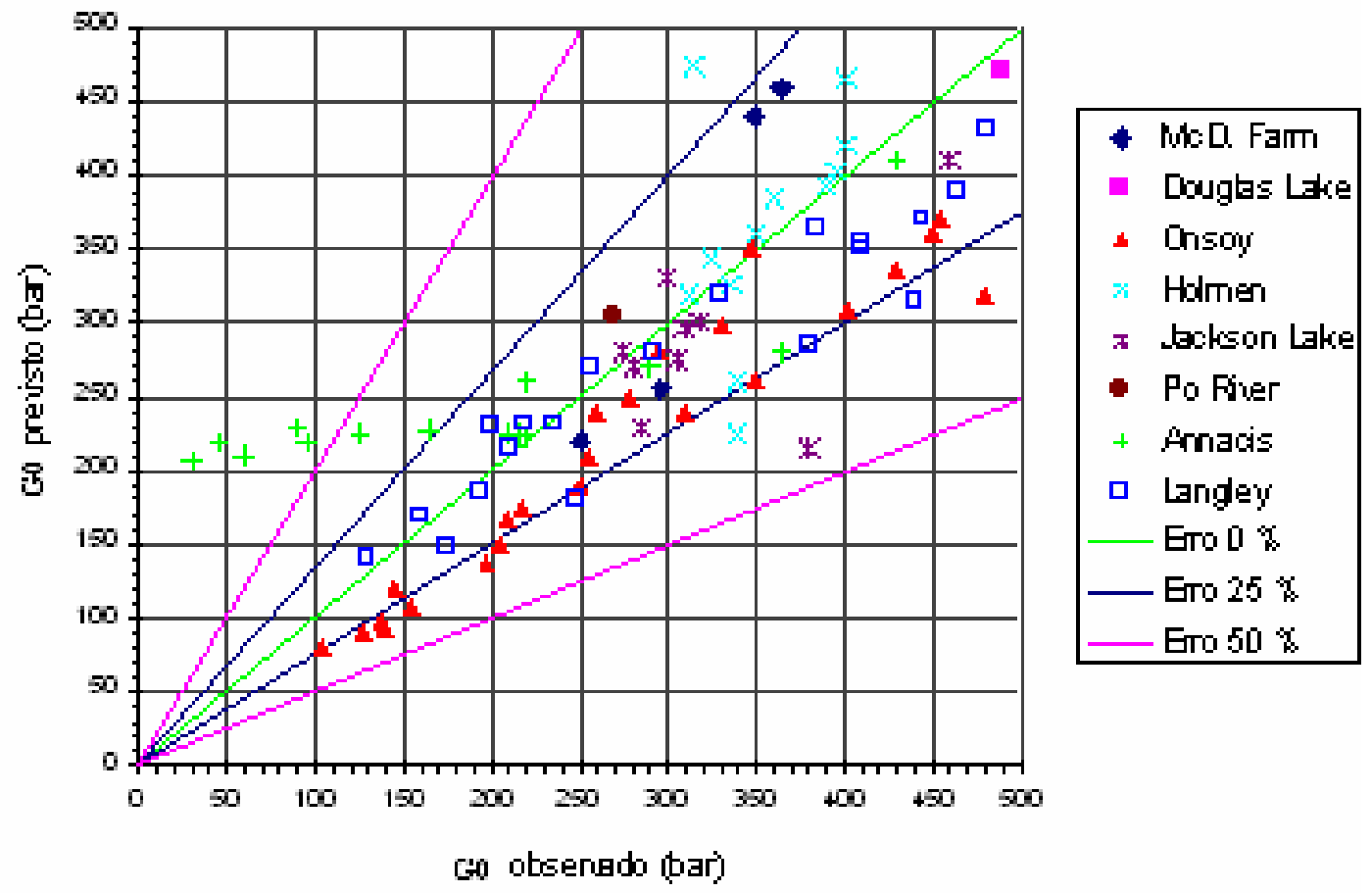

Figura 3.27 - Comparação entre o $\mathrm{G}_{0}$ previsto e $\mathrm{G}_{0}$ medido em laboratório (Hryciw, 1990) apud Jardim, 1998. 


\subsubsection{Síntese das correlações apresentadas}

A Tabela 3.7 lista alguns parâmetros geotécnicos que podem ser obtidos através do ensaio dilatométrico, com indicação:

a) das variáveis intervenientes;

b) do tipo de formulação; e

c) da referência bibliográfica.

Tabela 3.7 - Parâmetros obtidos com o emprego do dilatômetro (baseado na ASTM, 1986)

\begin{tabular}{|c|c|c|c|}
\hline $\begin{array}{l}\text { PARÂMETRO } \\
\text { GEOTÉCNICO }\end{array}$ & VARIÁVEIS & FORMULAÇÃO & REFERÊNCIA \\
\hline $\mathrm{K}_{0}$ (argilas) & $f\left(K_{D}, I_{D}, \sigma_{v}^{\prime}, u_{0}\right)$ & Semi-empírica & $\begin{array}{l}\text { Marchetti (1980) e Jamiolkowski et al. } \\
\text { (1985) }\end{array}$ \\
\hline $\mathrm{K}_{0}$ (areias) & $f\left(K_{D}, \phi^{\prime}, \sigma_{v}^{\prime}, u_{0}, q_{C}\right)$ & Empírica & $\begin{array}{c}\text { Schmertmann (1983) e Baldi et al. } \\
\text { (1986) }\end{array}$ \\
\hline OCR(argilas) & $f\left(K_{D}, I_{D}\right)$ & Empírica & Marchetti (1980) \\
\hline OCR(areias) & $f\left(K_{0}, \phi^{\prime}, \sigma_{v}^{\prime}, u_{0}, q_{c}\right)$ & Empírica & Schmertmann (1988) \\
\hline$\phi^{\prime}$ (areia) & $f\left(K_{0}, \sigma_{v}^{\prime}, u_{0}, q_{c}\right)$ & Teórica & Schmertmann (1983) e Marchetti (1997) \\
\hline $\mathrm{S}_{\mathrm{u}}$ (argila s.a.) & $f\left(K_{D}, \sigma_{v M}^{\prime}, u_{0}\right)$ & Empírica & Marchetti (1980) \\
\hline $\mathrm{S}_{\mathrm{u}}$ (argila n.a.) & $f\left(K_{D}, \sigma_{v}^{\prime}, u_{0}\right)$ & Empírica & Marchetti (1980) \\
\hline$M=1 / m_{v}$ & $f\left(E_{D}, I_{D}, K_{D}\right)$ & Semi-empírica & Marchetti (1980) \\
\hline$E_{25}$ (areia) & $f\left(E_{D}\right)$ & Semi-empírica & Robertson et al. (1985) e Baldi et al. (1986) \\
\hline$E_{i}$ (argila) & $f\left(M, v, E_{D}, I_{D}\right)$ & Semi-empírica & Robertson et al. (1989) \\
\hline $\mathrm{G}_{0}$ & $f\left(K_{D}, \sigma_{v}^{\prime}, p_{a}, \gamma d, \gamma w\right)$ & Semi-empírica & Hryciw (1990) \\
\hline
\end{tabular}




\section{MÉTODOS TEÓRICOS APLICADOS PARA A ESTIMATIVA DA CAPACIDADE DE CARGA E DOS RECALQUES ELÁSTICOS DE ESTACAS}

\subsection{Introdução}

Segundo a Norma Brasileira NBR 6122/96, Carga admissível de uma estaca é a força que aplicada sobre a fundação provoca recalques toleráveis pela construção e segurança satisfatória contra a ruptura ou escoamento do solo ou do elemento de fundação. Um projeto de fundação profunda deve avaliar estes três aspectos. Em geral, a ruptura estrutural de uma estaca é dificilmente o fator limitante, considerada apenas quando se tem solos muito densos ou rochas. Geralmente, a capacidade de carga do solo e o recalque admissível são os fatores determinantes da máxima carga no elemento de fundação.

A estimativa da Capacidade de Carga e dos recalques de uma estaca nem sempre é de fácil obtenção, apesar de haver um grande número de métodos e fórmulas para os cálculos, cuja precisão depende dos parâmetros de entrada utilizados. Os ensaios de campo são muito desejáveis nesta área, apesar de pouco utilizados no Brasil, em comparação ao emprego em outros países. A forma mais precisa de se obter a capacidade de carga e o recalque de uma estaca é através da prova de carga "in loco". Como esta prova de carga nem sempre é viável economicamente, parâmetros dos solos obtidos através de ensaios de campo são cada vez mais requeridos.

\subsection{Métodos para a obtenção das capacidades de carga}

Os métodos estáticos conhecidos para avaliar a capacidade de carga de uma estaca consideram a mobilização de toda a resistência ao cisalhamento ao longo do seu fuste. Estes métodos podem ser classificados em:

- Métodos teóricos - se baseiam em soluções teóricas e utilizam parâmetros básicos do solo, como ângulo de atrito, coesão, módulo de elasticidade, etc, obtidos através de ensaios de laboratório ou "in situ".

- Métodos semi-empíricos - têm como base algum conhecimento teórico-prático e avaliam a capacidade de carga e os recalques com base em correlações empíricas com parâmetros de ensaios "in situ” (SPT, CPT e DMT) 
Nos métodos estáticos imagina-se o equilíbrio entre a carga aplicada, o peso próprio da estaca e a resistência oferecida pelo solo. Uma estaca, quando solicitada por um carregamento vertical, fará com que uma parcela dessa solicitação seja absorvida por atrito lateral, gerado ao longo do fuste, e outra parcela pela ponta da estaca. Isto é:

$\mathrm{Q}+\mathrm{W}=\mathrm{Q}_{\mathrm{p}}+\mathrm{Q}_{1}$

sendo:

$\mathrm{Q}=$ carga total da estaca

$\mathrm{W}=$ peso próprio da estaca

$\mathrm{Q}_{\mathrm{p}}=$ resistência de ponta mobilizada

$\mathrm{Q}_{1}=$ resistência lateral mobilizada

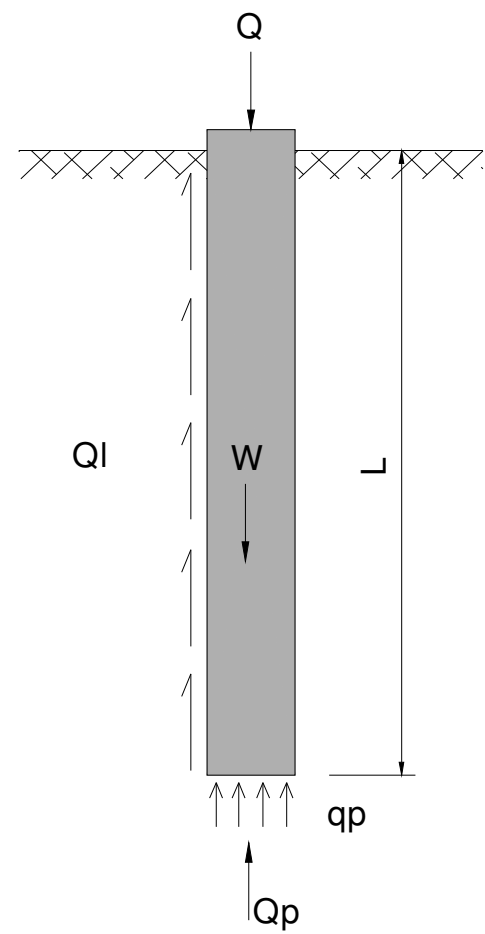

Figura 4.1 - Modelo da expressão de equilíbrio de uma estaca sujeita à compressão

Em geral o peso próprio da estaca é desprezível face às cargas atribuídas a ela.

Como já foi dito, há vários métodos para se obter a capacidade de carga das estacas. Neste trabalho serão focados os métodos teóricos, pois estes dependem de parâmetros de entrada como os parâmetros clássicos de mecânica dos solos, que podem ser obtidos através do DMT. 


\subsubsection{Resistência Lateral}

Como já foi mencionado, uma das componentes da capacidade de carga é a resistência por atrito lateral. O modelo teórico para a determinação do mesmo é análogo à análise da resistência ao deslizamento de um sólido em contato com o solo. A determinação do seu valor inclui a soma de duas parcelas.

$\tau_{\mathrm{a}}=\mathrm{c}_{\mathrm{a}}{ }^{\prime}+\sigma_{\mathrm{n}}{ }^{\prime} \cdot \operatorname{tg} \delta$

em que:

$\tau_{\mathrm{a}}=$ resistência ao cisalhamento solo/estaca ou resistência unitária lateral

$\mathrm{c}_{\mathrm{a}^{\prime}}=$ adesão (aderência entre estaca e solo)

$\sigma_{\mathrm{n}}{ }^{\prime}=$ tensão normal horizontal efetiva média na superfície lateral da estaca

$\delta^{\prime}=$ ângulo de atrito efetivo entre a estaca e o solo

Os valores de $c_{a}, \sigma_{n}$ e $\delta$ podem ser, em alguns casos, determinados a partir de ensaios de laboratório com o material da interface da estaca e do solo. Assim como $\sigma^{\prime}{ }_{n}$, dependem do processo executivo, portanto do tipo de estaca. Daí ser preferível estimá-los com base em dados empíricos, que por sua vez dependem do tipo de solo.

Serão apresentados alguns métodos de obtenção da resistência lateral mais comumente usados. Estes métodos foram formulados, primeiramente, para a utilização em solos argilosos.

\subsubsection{Método $\alpha$ (Tensões Totais)}

Este método surge da necessidade de avaliar a resistência unitária lateral em solos argilosos usando uma análise em tensões totais. A análise em tensões totais é utilizada para argilas sob carregamento rápido devido à dificuldade em se prever os acréscimos de pressão intersticial que permitiriam a utilização de modelos em tensões efetivas. Neste método a resistência lateral é relacionada com a resistência ao cisalhamento (coesão) não drenada do solo, isto é:

$\tau_{\mathrm{a}}=\alpha \cdot \mathrm{s}_{\mathrm{u}}$

na qual:

$\alpha=$ coeficiente determinado pelo tipo de estaca e tipo de solo (determinado empiricamente através de resultados de provas de carga)

$\mathrm{s}_{\mathrm{u}}=$ resistência não drenada das argilas 
Tomlinson (1970) apud Tomlinson (1994) estudou o efeito da camada sobrejacente, visto que onde há a presença de areia acima da camada de argila, o valor da adesão é relativamente maior. Tomlinson (1994) propôs ábacos para a determinação do coeficiente $\alpha$, conforme a Figura 4.2, levando em conta este efeito e, obviamente, a consistência da argila.
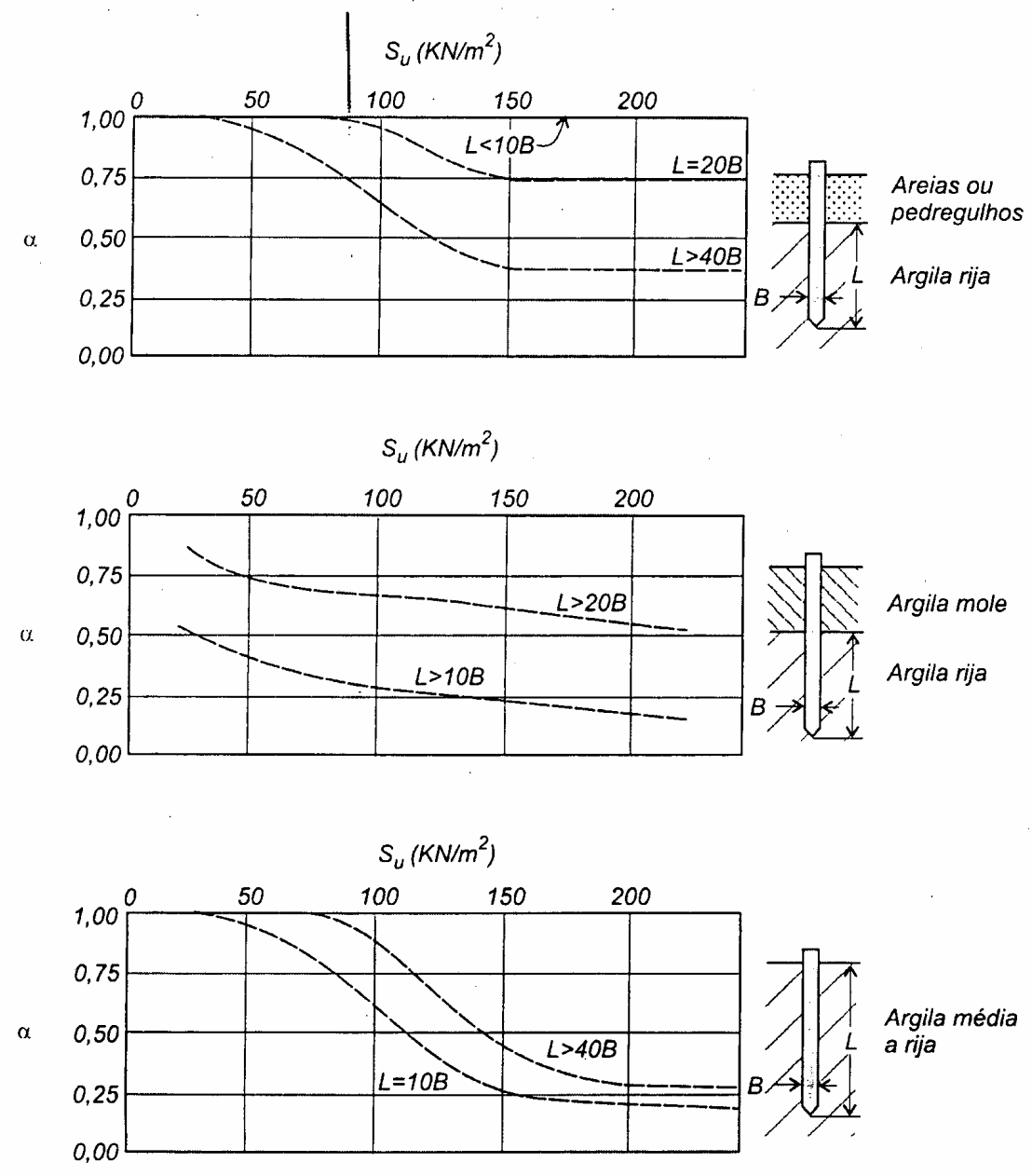

Figura 4.2 - Curvas para determinação do coeficiente $\alpha$ - sendo L o comprimento da estaca embutido em argila média a rija (Tomlinson 1994, apud Velloso e Lopes 2002)

A API (1989) sugere que para valores de $s_{u}$ inferiores a $25 \mathrm{kPa}$, o valor de $\alpha$ seja tomado igual a $1 \mathrm{e}$, para valores superiores a $75 \mathrm{kPa}$, igual a 0,5 . Para valores intermediários, isto é, $25 \mathrm{kPa}<\mathrm{s}_{\mathrm{u}}<75 \mathrm{kPa}$, $\alpha$ pode ser calculado através da expressão (4.4).

$$
\alpha=1-0,5 \cdot\left(\frac{s_{u}-25}{50}\right)
$$




\subsubsection{Método $\beta$ (Tensões Efetivas)}

Diferente do método $\alpha$ este método se baseia nas tensões efetivas do solo. Segundo Burland (1973) apud Poulos e Davis (1980) é fundamental um entendimento dos princípios que regem o comportamento da estaca em termos de tensões efetivas. E isto porque, durante a instalação de uma estaca, o solo, imediatamente adjacente ao fuste, será amolgado e haverá geração de poro-pressões, positivas ou negativas.

Devido ao amolgamento do solo durante a instalação da estaca, Burland considera a coesão efetiva do solo igual a zero, portanto:

$\tau_{\mathrm{a}}=\sigma_{\mathrm{n}}^{\prime} \cdot \operatorname{tg} \delta$

A tensão normal horizontal efetiva $\sigma^{\prime}{ }_{n}$ pode ser expressa em função da tensão vertical efetiva:

$\sigma_{\mathrm{n}}^{\prime}=\mathrm{K}_{\mathrm{s}} \cdot \sigma_{\mathrm{v}}$

sendo:

$\mathrm{K}_{\mathrm{s}}=$ coeficiente de pressão lateral ou coeficiente de empuxo horizontal

Então:

$\tau_{\mathrm{a}}=\mathrm{K}_{\mathrm{s}} \cdot \sigma_{\mathrm{v}} \cdot \tan \delta$

Portanto a resistência acumulada ao longo da profundidade pode ser definida como:

$$
\mathrm{Q}_{1}=\int_{0}^{\mathrm{L}} \mathrm{K}_{\mathrm{s}} \cdot \tan \delta \cdot \sigma^{\prime}{ }_{\mathrm{v}} \mathrm{dz}
$$

ou introduzindo o parâmetro de Burland (1973) apud Poulos e Davis (1980):

$\beta=\mathrm{K}_{\mathrm{s}} \cdot \tan \delta$

pode-se escrever:

$$
\mathrm{Q}_{\mathrm{l}}=\int^{\mathrm{L}} \beta \cdot \sigma^{{ }_{\mathrm{v}}} \mathrm{dz}
$$

Para solos normalmente adensados, costuma se tomar $\mathrm{K}_{\mathrm{s}}=\mathrm{K}_{0}$ e utiliza-se a formula de Jaky $\mathrm{K}_{0}=1$-sen $\phi$ '. Para solos sobre-adensados, esta expressão necessita sr corrigida pelo RSA. 
Admitindo-se que a ruptura ocorra no solo, junto ao fuste, pode-se tomar $\delta=\phi^{\prime}$, onde $\phi '$ é o ângulo de atrito do solo amolgado e drenado. Tem-se, portanto:

$\beta=\left(1-\operatorname{sen} \phi^{\prime}\right) \tan \phi^{\prime}$

Segundo Fellenius (1996) o coeficiente $\beta$ varia com o tipo de solo dentro de uma faixa razoavelmente estreita de valores, como indica a Tabela 4.1.

Tabela 4.1 - Valores aproximados do coeficiente $\beta$ segundo Fellenius (1996)

\begin{tabular}{|c|c|c|}
\hline Solo & $\boldsymbol{\phi}$ & $\boldsymbol{\beta}$ \\
\hline Argila & $25-30$ & $0,25-0,35$ \\
\hline Silte & $28-34$ & $0,27-0,50$ \\
\hline Areia & $32-40$ & $0,30-0,60$ \\
\hline Pedregulho & $35-45$ & $0,35-0,80$ \\
\hline
\end{tabular}

\subsubsection{Método $\lambda$ (Misto)}

Neste método, proposto por Viajayergiva e Focht (1972) apud Poulos e Davis (1980), consideram que a resistência lateral seja função da tensão efetiva e da resistência não drenada da argila. Isto é:

$\tau_{\mathrm{a}}=\lambda\left(\sigma_{\mathrm{v}}+2 \mathrm{~s}_{\mathrm{u}}\right)$

Este é um método híbrido, pois trabalha com tensões efetivas e totais, proposto para estacas cravadas, cilíndricas e de aço. Viajayergiva e Focht obtiveram, a partir de provas de carga, uma curva média com valores para esse coeficiente denominado $\lambda$, conforme Figura 4.3. Este coeficiente $\lambda$ varia com comprimento da estaca, podendo ser 0,1 para estacas com comprimento superior a 50 metros e 0,3 para estacas com 10 metros. 
$\lambda$

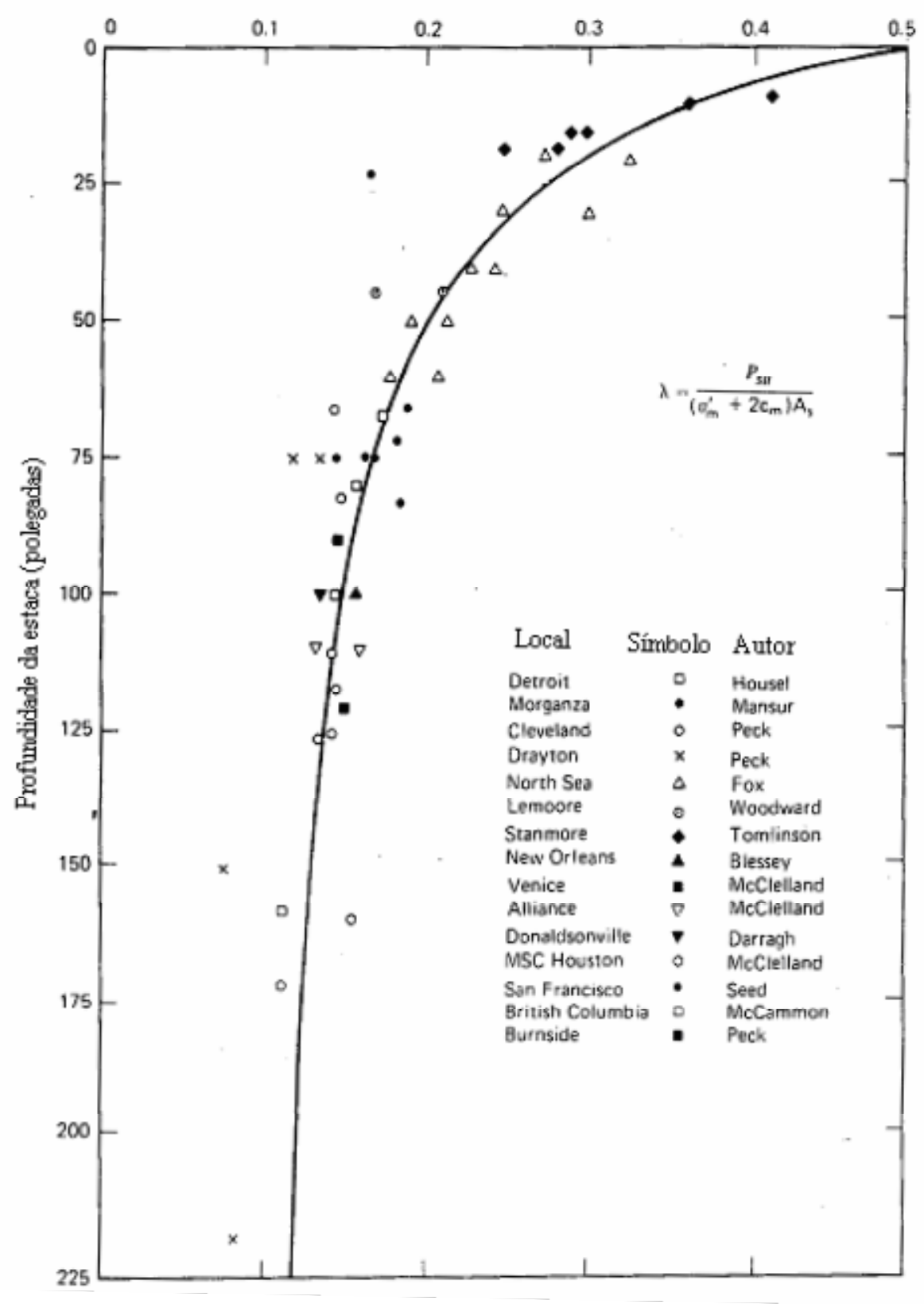

Figura 4.3 - Determinação do coeficiente $\lambda$ de acordo com o comprimento da estaca (Viajayergiva e Focht, 1972 apud Poulos e Davis, 1980)

Segundo Felleniuss (1996) o coeficiente $\lambda$ é função do engastamento da estaca com a profundidade e se reduz com o aumento da profundidade, conforme a Tabela 4.2. Este autor defende a aplicabilidade desse coeficiente quase que exclusivamente para estacas tubulares para estruturas de off-shore em solos relativamente uniformes.

No Brasil Teixeira (1988), aplicou este método a estacas flutuantes da Baixada Santista e obteve bons resultados. 
Tabela 4.2 - Valores aproximados do coeficiente $\lambda$ segundo Fellenius (1996)

\begin{tabular}{|c|c|}
\hline $\begin{array}{c}\text { Profundidade } \\
\text { da estaca }(\mathbf{m})\end{array}$ & $\boldsymbol{\lambda}$ \\
\hline 0 & 0,50 \\
\hline 3 & 0,36 \\
\hline 7 & 0,27 \\
\hline 15 & 0,22 \\
\hline 23 & 0,17 \\
\hline 30 & 0,15 \\
\hline 60 & 0,12 \\
\hline
\end{tabular}

\subsubsection{Resistência de Ponta}

A resistência de ponta de uma estaca foi objeto de estudo de diversos autores, os quais se basearam na Teoria da Plasticidade. As soluções propostas por tais autores diferem entre si pelo mecanismo de ruptura, conforme a Figura 4.4.

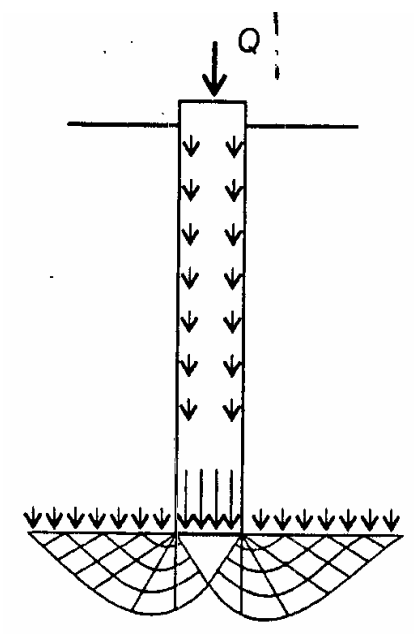

(a)

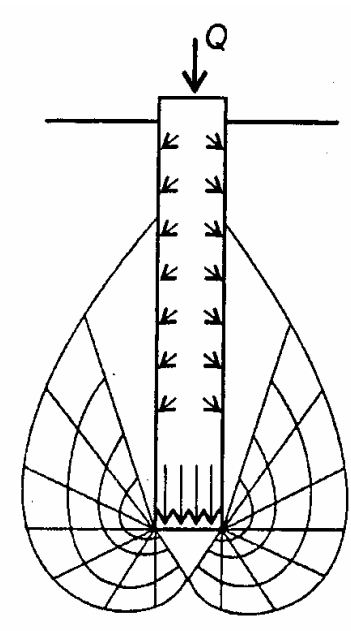

(b)

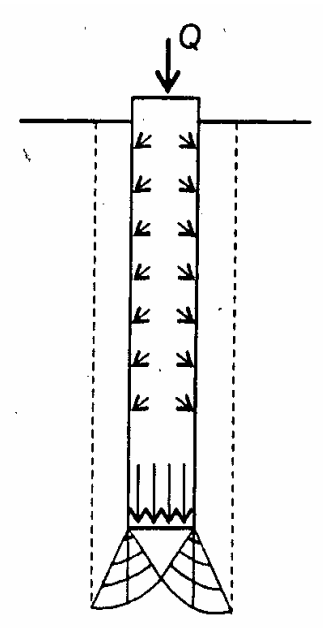

(c)

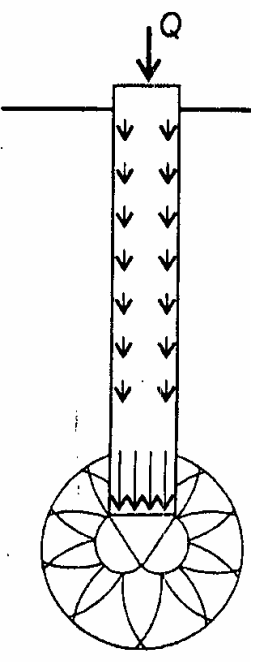

(d)

Figura 4.4 - Mecanismo de ruptura de diversas soluções teóricas. a)Terzaghi (1943) b) Meyerhof (1953) c)Berezantzev (1961) d) Vesic (1975) apud Velloso e Lopes 2002) 


\subsubsection{Terzaghi (1943)}

Admitindo que o solo ao longo do comprimento L da estaca é mais compressível do que na base da estaca, os deslocamentos produzem tensões cisalhantes desprezíveis ao longo de L. E portanto, a influência do solo que envolve a estaca é idêntica à de uma sobrecarga $\gamma . \mathrm{L}$ e a resistência de ponta da estaca pode ser calculada pela equação 4.13.

$q_{p-u l t}=1,2 c \cdot N_{c}+\gamma \cdot L \cdot N_{q}+0,6 \gamma \cdot \frac{B}{2} \cdot N_{\gamma}$-para estacas circulares de diâmetro B

$\mathrm{ou}$

$q_{p-u l t}=1,2 c \cdot N_{c}+\gamma \cdot L \cdot N_{q}+0,8 \gamma \cdot \frac{B}{2} \cdot N_{\gamma}$ - para estacas quadradas de lado B

em que:

$q_{p-u l t}=$ capacidade de carga última

$\mathrm{c}=$ coesão do solo

$\mathrm{N}_{\mathrm{c}} \mathrm{N}_{\gamma} \mathrm{N}_{\mathrm{q}}$ = fatores de capacidade de carga

$\gamma=$ peso específico do solo

$\mathrm{L}=$ profundidade da ponta da estaca

$\mathrm{B}=$ largura da estaca

Para solos homogêneos, percebe-se que existem tensões cisalhantes ao longo do comprimento e neste caso não só altera o mecanismo de ruptura como também a intensidade da tensão vertical no solo junto à base.

Terzaghi e Peck (1948), referindo-se às experiências em modelos de grandes dimensões realizadas por Kerisél (1961), Kerisél e Adam (1962) e Vesic(1963), constataram que quando $\mathrm{L} / \mathrm{D}>5$, a resistência da base não cresce mais com a profundidade de acordo com

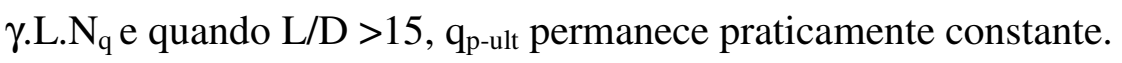

Na Tabela 4.3 são fornecidos os fatores de capacidade de carga $\mathrm{N}_{c}, \mathrm{~N}_{\gamma}$ e $\mathrm{N}_{\mathrm{q}}$ (ruptura geral para solos de elevada resistência) e $\mathrm{N}^{\prime}{ }_{c}, \mathrm{~N}_{\gamma}{ }_{\gamma}$ e $\mathrm{N}_{\mathrm{q}}$ (ruptura local para solos de baixa resistência) apresentados por Bowles (1968) apud Velloso e Lopes (2002) de acordo com o ângulo de atrito do solo. 
Tabela 4.3 - Fatores de capacidade de carga (Bowles, 1968) apud Velloso e Lopes (2002).

\begin{tabular}{|c|c|c|c|c|c|c|}
\hline $\boldsymbol{\phi}\left(^{\mathbf{0}}\right)$ & $\mathbf{N}_{\mathbf{c}}$ & $\mathbf{N}_{\mathbf{q}}$ & $\mathbf{N}_{\boldsymbol{\gamma}}$ & $\mathbf{N}_{\mathbf{c}}{ }^{\prime}$ & $\mathbf{N}_{\mathbf{q}}{ }^{\prime}$ & $\mathbf{N}_{\boldsymbol{\gamma}}{ }^{\prime}$ \\
\hline 0 & 5,7 & 1 & 0 & 5,7 & 1,0 & 0,0 \\
\hline 5 & 7,3 & 1,6 & 0,5 & 6,7 & 1,4 & 0,2 \\
\hline 10 & 9,6 & 2,7 & 1,2 & 8,0 & 1,9 & 0,5 \\
\hline 15 & 12,9 & 4,4 & 2,5 & 9,7 & 2,7 & 0,9 \\
\hline 20 & 17,7 & 7,4 & 5,0 & 11,8 & 3,9 & 1,7 \\
\hline 25 & 25,1 & 12,7 & 9,7 & 14,8 & 5,6 & 3,2 \\
\hline 30 & 37,2 & 22,5 & 19,7 & 19,0 & 8,3 & 5,7 \\
\hline 35 & 57,8 & 41,4 & 42,4 & 25,2 & 12,6 & 10,1 \\
\hline 40 & 95,7 & 81,3 & 100,4 & 34,9 & 20,5 & 18,8 \\
\hline 45 & 172,3 & 173,3 & 297,5 & 51,2 & 35,1 & 37,7 \\
\hline
\end{tabular}

\subsubsection{Meyerhof (1953)}

O mecanismo de ruptura deste autor difere da solução de Terzaghi. Meyerhof (1953) apud Velloso e Lopes (2002) supôs que as linhas de ruptura do maciço sejam um pouco acima daquelas idealizadas por Terzaghi, que se situavam abaixo da base da estaca, conforme apresentado na Figura 4.4.b.

A parcela de resistência de ponta de acordo com Meyerhof (1953) apud Velloso e Lopes (2002) pode ser obtida através da equação:

$$
q_{p-u l t}=c \cdot N_{c}+K s \cdot \gamma \cdot L \cdot N_{q}+\gamma \cdot \frac{B}{2} \cdot N_{\gamma}
$$

sendo:

$\mathrm{K}_{\mathrm{s}}=$ coeficiente de empuxo do solo contra o fuste na zona de ruptura próxima à ponta $\mathrm{N}_{\mathrm{c}}, \mathrm{N}_{\gamma}$ e $\mathrm{N}_{\mathrm{q}}=$ fatores de capacidade de carga, que dependem do ângulo de atrito e de L/B Quando a relação L/B for elevada, despreza-se a última parcela. 
Os valores dos fatores de capacidade de carga $\mathrm{N}_{\mathrm{c}}, \mathrm{N}_{\gamma}$ e $\mathrm{N}_{\mathrm{q}}$ para fundações profundas, são apresentados graficamente, como mostra a Figura 4.5.

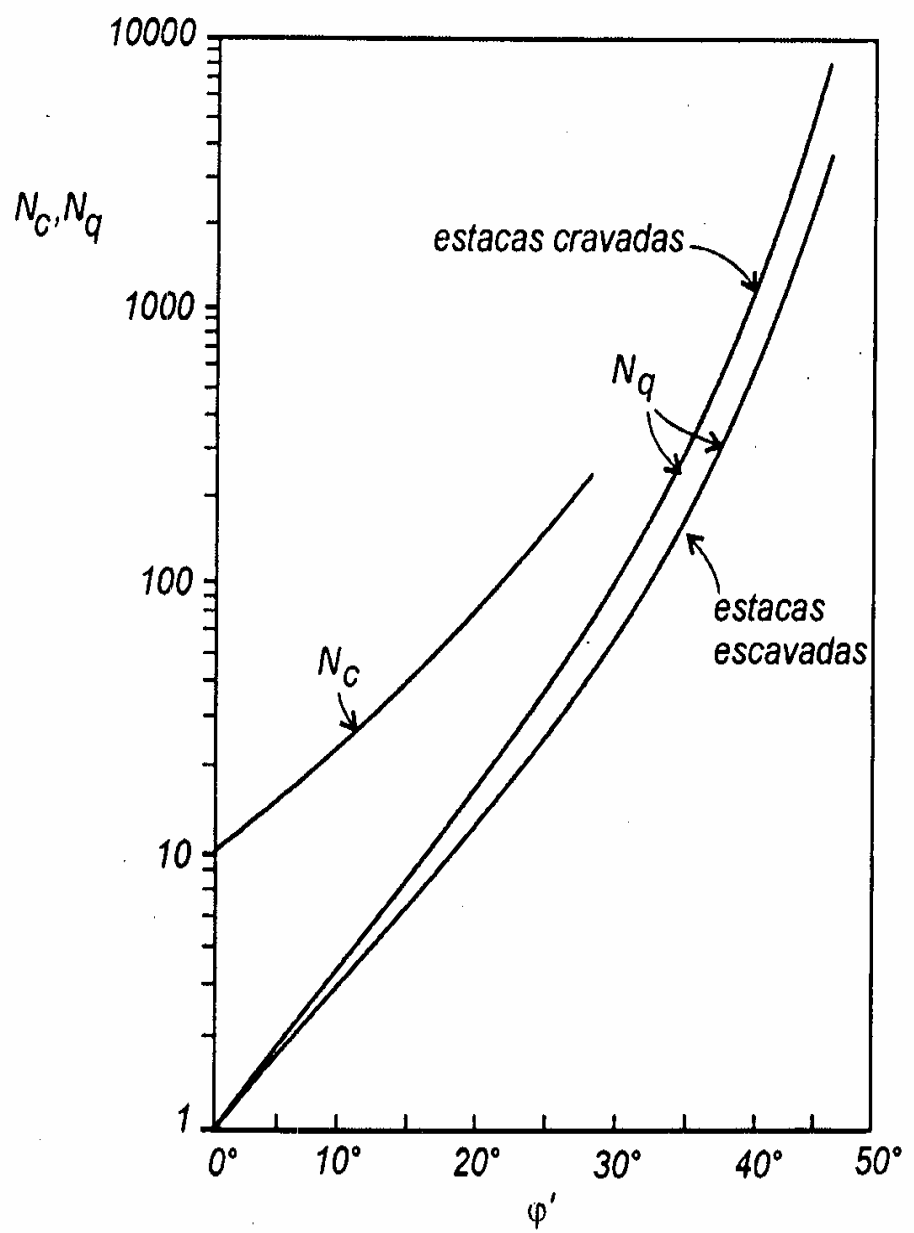

Figura 4.5 - Fatores de capacidade de carga (Meyerhof, 1953) apud Velloso e Lopes (2002).

Para solos argilosos e saturados $(\phi=0)$, este autor propôs a seguinte equação para resistência de ponta das estacas:

$q_{p-u l t}=9,5 \cdot s u+\gamma \cdot L$

e para solos granulares:

$q_{p-u l t}=K s \cdot \gamma \cdot L \cdot N_{q}$ 


\subsubsection{Berezantzev (1961)}

A solução deste pesquisador se baseou em análises da capacidade de carga de estacas isoladas e em grupos, em solos arenosos, comparando os resultados de provas de carga com os resultados obtidos da aplicação das teorias do seu mecanismo de ruptura, conforme Figura 4.4.c.

A teoria aplicada pelo autor para a obtenção da resistência de ponta tem como base os problemas axissimétricos da Teoria do Equilíbrio Limite, onde obteve:

$q_{p-u l t}=A k \cdot \gamma \cdot B+B k \cdot q T$

em que:

$A_{k}$ e $B_{k}=$ função de $\phi$, obtidos conforme curvas propostas pelo autor apresentadas na Figura 4.6.

$\mathrm{B}=$ diâmetro da estaca

sendo, $q T=\alpha T \cdot \gamma \cdot L$

na qual:

$\alpha_{T}=$ função da relação L/B e de $\phi$, obtido da Tabela 4.4.

Tabela 4.4 - Coeficiente $\alpha_{\mathrm{T}}$, Berezantzev et al (1961) apud Velloso e Lopes (2002)

\begin{tabular}{|c|c|c|c|c|c|}
\multicolumn{1}{c|}{$\phi\left(^{\mathbf{}}\right)$} \\
\cline { 2 - 6 } $\mathbf{L} / \mathbf{B}$ & $\mathbf{2 6}$ & $\mathbf{3 0}$ & $\mathbf{3 4}$ & $\mathbf{3 7}$ & $\mathbf{4 0}$ \\
\hline 5 & 0,75 & 0,77 & 0,81 & 0,83 & 0,85 \\
\hline 10 & 0,62 & 0,67 & 0,73 & 0,76 & 0,79 \\
\hline 15 & 0,55 & 0,61 & 0,68 & 0,73 & 0,77 \\
\hline 20 & 0,49 & 0,57 & 0,65 & 0,71 & 0,75 \\
\hline 25 & 0,44 & 0,53 & 0,63 & 0,70 & 0,74 \\
\hline
\end{tabular}




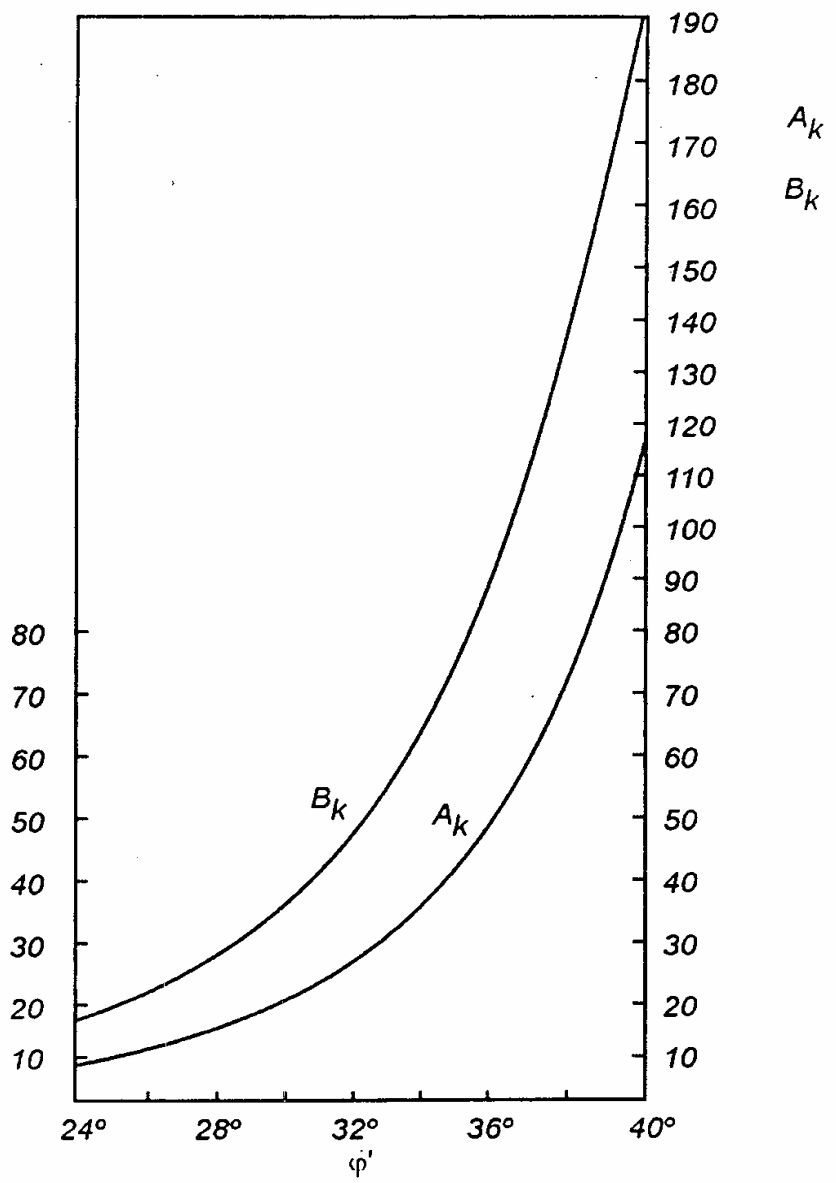

Figura 4.6 - Fatores de capacidade de carga Berezantzev et al (1961)

\subsubsection{Vesic (1975)}

O autor apresenta uma solução em que a resistência de ponta é função da resistência da rigidez do solo. O seu mecanismo de ruptura assemelha-se com soluções desenvolvidas para expansão de cavidades esféricas em meio elasto-plástico, conforme Figura 4.4.d.

Vesic (1975) sugere a seguinte expressão para a resistência de ponta:

$q_{p-u l t}=c \cdot N_{c}+\sigma 0 \cdot N_{\sigma}$

sendo: $\sigma_{0}=\frac{1+2 K_{0}}{3} \sigma^{\prime} v$

$\mathrm{K}_{0}=$ coeficiente de empuxo no repouso

$\sigma_{\mathrm{v}}^{\prime}=$ tensão efetiva no nível da ponta da estaca 
$\mathrm{N}_{\mathrm{c}}$ e $\mathrm{N}_{\sigma}=$ fatores de capacidade de carga, relacionados pela expressão:

$N_{c}=(N \sigma-1) \cot \phi$

Para a obtenção do parâmetro $\mathrm{N}_{\sigma}$, Vesic iguala a tensão normal média à pressão última necessária para expandir uma cavidade esférica em uma massa infinita de solo, tendo esta massa um comportamento elasto-plástico ideal, caracterizado pelos parâmetros de resistência c e $\phi$, pelos parâmetros de deformação $\mathrm{E}$ e v e por um parâmetro de variação volumétrica $\Delta$.

Com base nestas hipóteses, chegou à expressão:

$N \sigma=\frac{3}{3-\operatorname{sen} \phi} e^{\left(\frac{\pi}{2}-\phi\right) \operatorname{tg} \phi} \cdot \operatorname{tg}^{2}\left(\frac{\pi}{4}+\frac{\phi}{2}\right) \operatorname{Irr} \frac{4 \operatorname{sen} \phi}{3(1+\operatorname{sen} \phi)}$

na qual:

$\mathrm{I}_{\mathrm{rr}}=$ índice de rigidez reduzido $=\frac{I r}{1+I_{r} \cdot \Delta}$

Admitindo que a variação de volume seja nula (condições não drenadas) ou muito pequena (solos pouco compressíveis) pode-se igualar o índice $\mathrm{I}_{\mathrm{rr}}$ ao índice de rigidez $\mathrm{I}_{\mathrm{r}}$ :

$$
I r=\frac{E}{2(1+v) \cdot\left(c+\sigma^{\prime} \cdot \operatorname{tg} \phi\right)}=\frac{G}{c+\sigma^{\prime} \cdot \operatorname{tg} \phi}
$$

No caso de solos coesivos em condições não drenadas, Vesic propõe que o valor do fator da capacidade de carga, $\mathrm{N}_{\mathrm{c}}$, seja obtido através da expressão:

$$
N_{c}=\frac{4}{3}\left(\ln I_{r r}+1\right)+\frac{\pi}{2}+1
$$

$\mathrm{Na}$ Tabela 4.5 estão apresentados os valores de $\mathrm{N}_{\mathrm{c}}$ e $\mathrm{N}_{\sigma}$ para os diferentes valores de $\phi$, onde os números superiores referem-se a $\mathrm{N}_{\mathrm{c}}$ e os inferiores, a $\mathrm{N}_{\sigma}$. 
Tabela 4.5 - Fatores de capacidade de carga $\mathrm{N}_{\mathrm{c}}$ e $\mathrm{N}_{\sigma}$, (Vesic, 1975)

\begin{tabular}{|c|c|c|c|c|c|c|c|c|c|c|}
\hline$\phi\left({ }^{\circ}\right)$ & 10 & 20 & 40 & 60 & 80 & 100 & 200 & 300 & 400 & 500 \\
\hline 0 & $\begin{array}{l}6,97 \\
1,00\end{array}$ & $\begin{array}{l}7,90 \\
1,00\end{array}$ & $\begin{array}{l}8,82 \\
1,00\end{array}$ & $\begin{array}{l}9,36 \\
1,00\end{array}$ & $\begin{array}{l}9,75 \\
1,00\end{array}$ & $\begin{array}{l}10,04 \\
1,00\end{array}$ & $\begin{array}{l}10,97 \\
1,00\end{array}$ & $\begin{array}{r}11,51 \\
1,00\end{array}$ & $\begin{array}{l}11,89 \\
1,00\end{array}$ & $\begin{array}{l}12,19 \\
1,00\end{array}$ \\
\hline 5 & $\begin{array}{l}8,99 \\
1,79\end{array}$ & $\begin{array}{r}10,56 \\
1,92\end{array}$ & $\begin{array}{c}12,25 \\
2,07\end{array}$ & $\begin{array}{c}13,30 \\
2,16\end{array}$ & $\begin{array}{l}14,07 \\
2,23\end{array}$ & $\begin{array}{c}14,69 \\
2,28\end{array}$ & $\begin{array}{l}16,69 \\
2,46\end{array}$ & $\begin{array}{c}17,94 \\
2,57\end{array}$ & $\begin{array}{c}18,86 \\
2,65\end{array}$ & $\begin{array}{l}19,59 \\
2,71\end{array}$ \\
\hline 10 & $\begin{array}{r}11,55 \\
3,04\end{array}$ & $\begin{array}{r}14,08 \\
3,48\end{array}$ & $\begin{array}{r}16,97 \\
3,99\end{array}$ & $\begin{array}{r}18,86 \\
4,32\end{array}$ & $\begin{array}{c}20,29 \\
4,58\end{array}$ & $\begin{array}{r}21,46 \\
4,78\end{array}$ & $\begin{array}{r}25,43 \\
5,48\end{array}$ & $\begin{array}{c}28,02 \\
5,94\end{array}$ & $\begin{array}{c}29,99 \\
6,29\end{array}$ & $\begin{array}{c}31,59 \\
6,57\end{array}$ \\
\hline 15 & $\begin{array}{r}14,79 \\
4,96\end{array}$ & $\begin{array}{r}18,66 \\
6,00\end{array}$ & $\begin{array}{r}23,35 \\
7,26\end{array}$ & $\begin{array}{c}26,53 \\
8,11\end{array}$ & $\begin{array}{c}29,02 \\
8,78\end{array}$ & $\begin{array}{c}31,08 \\
9,33\end{array}$ & $\begin{array}{l}38,37 \\
11,28\end{array}$ & $\begin{array}{r}43,32 \\
12,61\end{array}$ & $\begin{array}{l}47,18 \\
13,64\end{array}$ & $\begin{array}{l}50,39 \\
14,50\end{array}$ \\
\hline 20 & $\begin{array}{r}18,83 \\
7,85\end{array}$ & $\begin{array}{r}24,56 \\
9,94\end{array}$ & $\begin{array}{l}31,81 \\
12,58\end{array}$ & $\begin{array}{l}36,92 \\
14,44\end{array}$ & $\begin{array}{l}40,99 \\
15,92\end{array}$ & $\begin{array}{l}44,43 \\
17,17\end{array}$ & $\begin{array}{l}56,97 \\
21,73\end{array}$ & $\begin{array}{l}65,79 \\
24,94\end{array}$ & $\begin{array}{l}72,82 \\
27,51\end{array}$ & $\begin{array}{l}78,78 \\
29,67\end{array}$ \\
\hline 25 & $\begin{array}{r}23,84 \\
12,12\end{array}$ & $\begin{array}{r}32,05 \\
15,95\end{array}$ & $\begin{array}{l}42,85 \\
20,98\end{array}$ & $\begin{array}{l}50,69 \\
24,64\end{array}$ & $\begin{array}{l}57,07 \\
27,61\end{array}$ & $\begin{array}{l}62,54 \\
30,16\end{array}$ & $\begin{array}{l}82,98 \\
39,70\end{array}$ & $\begin{array}{l}97,81 \\
46,61\end{array}$ & $\begin{array}{c}109,88 \\
52,24\end{array}$ & $\begin{array}{c}120,23 \\
57,06\end{array}$ \\
\hline 30 & $\begin{array}{l}30,03 \\
18,24\end{array}$ & $\begin{array}{l}41,49 \\
24,95\end{array}$ & $\begin{array}{l}57,08 \\
33,95\end{array}$ & $\begin{array}{l}68,69 \\
40,66\end{array}$ & $\begin{array}{l}78,30 \\
46,21\end{array}$ & $\begin{array}{l}86,64 \\
51,02\end{array}$ & $\begin{array}{c}118,53 \\
69,43\end{array}$ & $\begin{array}{c}142,27 \\
83,14\end{array}$ & $\begin{array}{l}161,91 \\
94,48\end{array}$ & $\begin{array}{c}178,98 \\
104,33\end{array}$ \\
\hline 35 & $\begin{array}{r}37,65 \\
27,36\end{array}$ & $\begin{array}{r}53,30 \\
38,32\end{array}$ & $\begin{array}{l}75,22 \\
53,67\end{array}$ & $\begin{array}{l}91,91 \\
65,36\end{array}$ & $\begin{array}{l}10,92 \\
75,17\end{array}$ & $\begin{array}{c}118,22 \\
83,78\end{array}$ & $\begin{array}{l}166,14 \\
117,33\end{array}$ & $\begin{array}{r}202,64 \\
142,89\end{array}$ & $\begin{array}{l}233,27 \\
164,33\end{array}$ & $\begin{array}{r}260,15 \\
183,16\end{array}$ \\
\hline 40 & $\begin{array}{l}47,03 \\
40,47\end{array}$ & $\begin{array}{r}68,04 \\
58,10\end{array}$ & $\begin{array}{l}98,21 \\
83,40\end{array}$ & $\begin{array}{l}121,62 \\
103,05\end{array}$ & $\begin{array}{l}141,51 \\
119,74\end{array}$ & $\begin{array}{l}159,13 \\
134,52\end{array}$ & $\begin{array}{l}228,97 \\
193,13\end{array}$ & $\begin{array}{l}283,19 \\
238,62\end{array}$ & $\begin{array}{l}329,24 \\
277,26\end{array}$ & $\begin{array}{l}370,04 \\
311,50\end{array}$ \\
\hline 45 & $\begin{array}{l}58,66 \\
59,66\end{array}$ & $\begin{array}{l}86,48 \\
87,48\end{array}$ & $\begin{array}{l}127,28 \\
128,28\end{array}$ & $\begin{array}{l}159,48 \\
160,48\end{array}$ & $\begin{array}{l}187,12 \\
188,12\end{array}$ & $\begin{array}{l}211,79 \\
212,79\end{array}$ & $\begin{array}{l}311,04 \\
312,04\end{array}$ & $\begin{array}{l}389,35 \\
390,35\end{array}$ & $\begin{array}{l}456,57 \\
457,57\end{array}$ & $\begin{array}{r}516,58 \\
517,58\end{array}$ \\
\hline
\end{tabular}

Os valores para a primeira linha de cada ângulo de atrito correspondem ao $\mathrm{N}_{\mathrm{c}}$ e os da segunda ao $\mathrm{N}_{\sigma}$. 


\subsection{Métodos para a estimativa de recalques}

Para o entendimento do comportamento da estaca é preciso estudar o mecanismo de transferência de carga para o solo, chamado de interação estaca-solo. A Figura 4.7.b ilustra como se dá esta transferência, no caso do atrito ser constante com a profundidade. A Figura 4.7.d mostra outras formas possíveis de transferência de carga em profundidade.
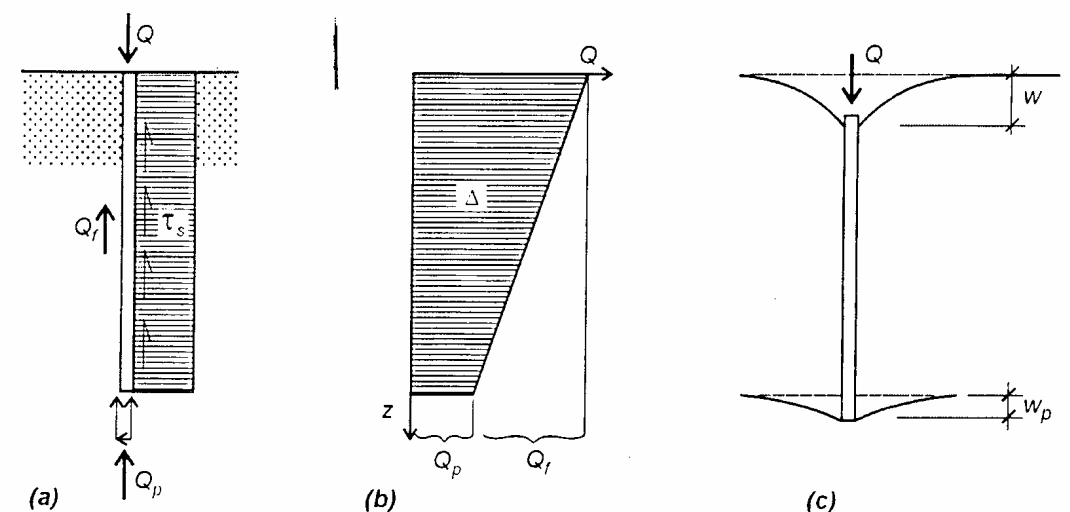

(c)
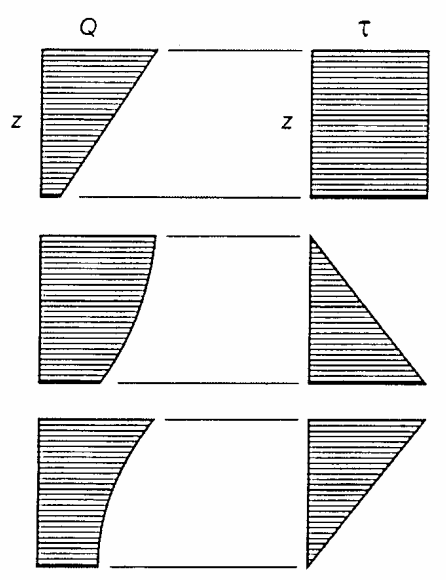

(d)

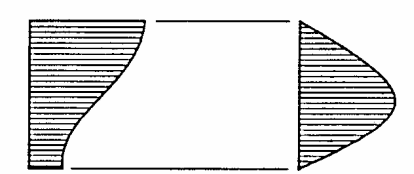

Figura 4.7 - Elementos do mecanismo de transferência de carga da estaca para o solo.

a) cargas e tensões na estaca, b) diagrama carga-profundidade, c) recalques e d) diagramas de atrito lateral e de carga axial - (Vesic, 1977 apud Velloso e Lopes 2002).

Considerando a Figura 4.7.c., as seguintes relações podem ser estabelecidas em termos de recalques:

$$
w=w p+\rho
$$


onde $\rho$ é o encurtamento elástico da estaca que vale:

$$
\rho=\int_{0}^{L} \frac{Q(z)}{A E_{p}} d z
$$

sendo Q é a carga aplicada na estaca, A é a área da seção transversal da estaca, e $E_{p}$ é o seu módulo de elasticidade. Se a rigidez da estaca, dada por $\mathrm{AE}_{\mathrm{p}} / \mathrm{L}$, for constante, tem-se:

$$
\rho=\frac{1}{A \cdot E_{p}} \int_{0}^{L} Q(z) \cdot d z
$$

Admitindo que a área do diagrama da Figura 4.7.b seja igual a $\Delta$, pode-se escrever:

$$
\rho=\frac{\Delta}{A \cdot E_{p}}
$$

Os métodos para a previsão dos recalques podem ser classificados da seguinte forma:

- Métodos baseados na Teoria da Elasticidade

- Métodos teóricos baseados nas funções ou nos diagrama de transferência de carga

- Métodos semi-empíricos

Para os propósitos deste trabalho, ater-se-á ao método de Poulos e Davis, baseado na Teoria da Elasticidade, e ao método de Randolph e Wroth, baseado em funções de transferência de carga. Estes métodos parecem ser os mais indicados, visto que o ensaio dilatométrico pode fornecer os parâmetros de entrada necessários para os cálculos.

\subsubsection{Método de Poulos e Davis}

Poulos e Davis (1980) apresentaram um método baseado na solução de Mindlin (1936) para carga pontual num maciço de terra, suposto linearmente elástico. A metodologia consiste em dividir a estaca em elementos uniformemente carregados e impor a compatibilidade entre os deslocamentos da estaca e do solo adjacente, para cada elemento da estaca. Esses deslocamentos são obtidos considerando a compressibilidade da estaca frente à carga axial. 


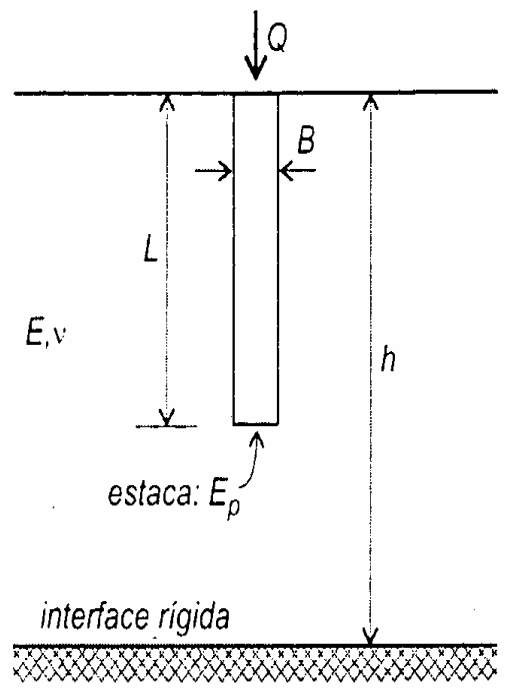

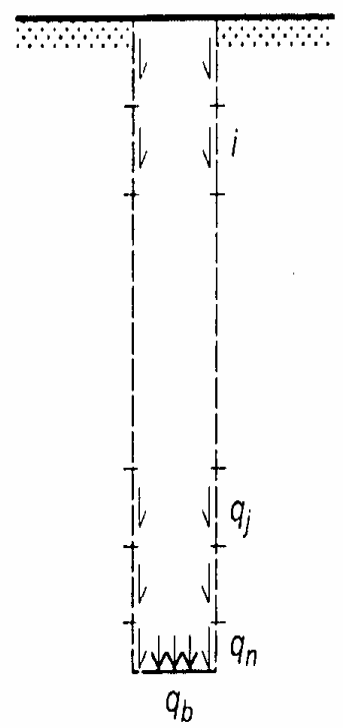

(c)

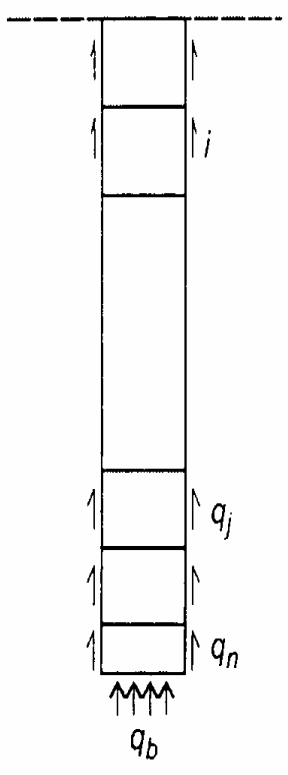

(d)

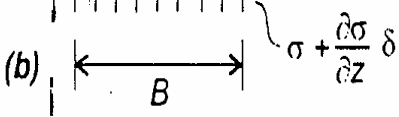

Figura 4.8 - a) problema analisado b) elemento de estaca c) ação da estaca sobre os solo e d) ação do solo sobre a estaca (Poulos e Davis 1974)

Primeiramente os autores admitiram uma estaca incompressível em um meio elástico semi-infinito, com coeficiente de Poisson igual a 0,5. Obtiveram a seguinte expressão para a estimativa do recalque no topo da estaca:

$$
w=\frac{Q \cdot I o}{E \cdot B}
$$

sendo:

$\mathrm{B}=$ diâmetro da estaca

$\mathrm{I}_{\mathrm{o}}=$ é o fator de influencia, que depende da relação entre o diâmetro da base da estaca $\left(\mathrm{B}_{\mathrm{b}}\right)$ e o diâmetro da estaca (B), conforme está indicado na Figura 4.9.a.

Nesta figura K é definido através da expressão:

$$
K=\frac{E p}{E s} \cdot(R A)
$$


em que:

Ep = módulo de elasticidade da estaca

Es = módulo de elasticidade do solo

$\mathrm{RA}=$ relação entre a área da seção da estaca e a área externa, para estacas vazadas $\mathrm{RA} \neq 1$.
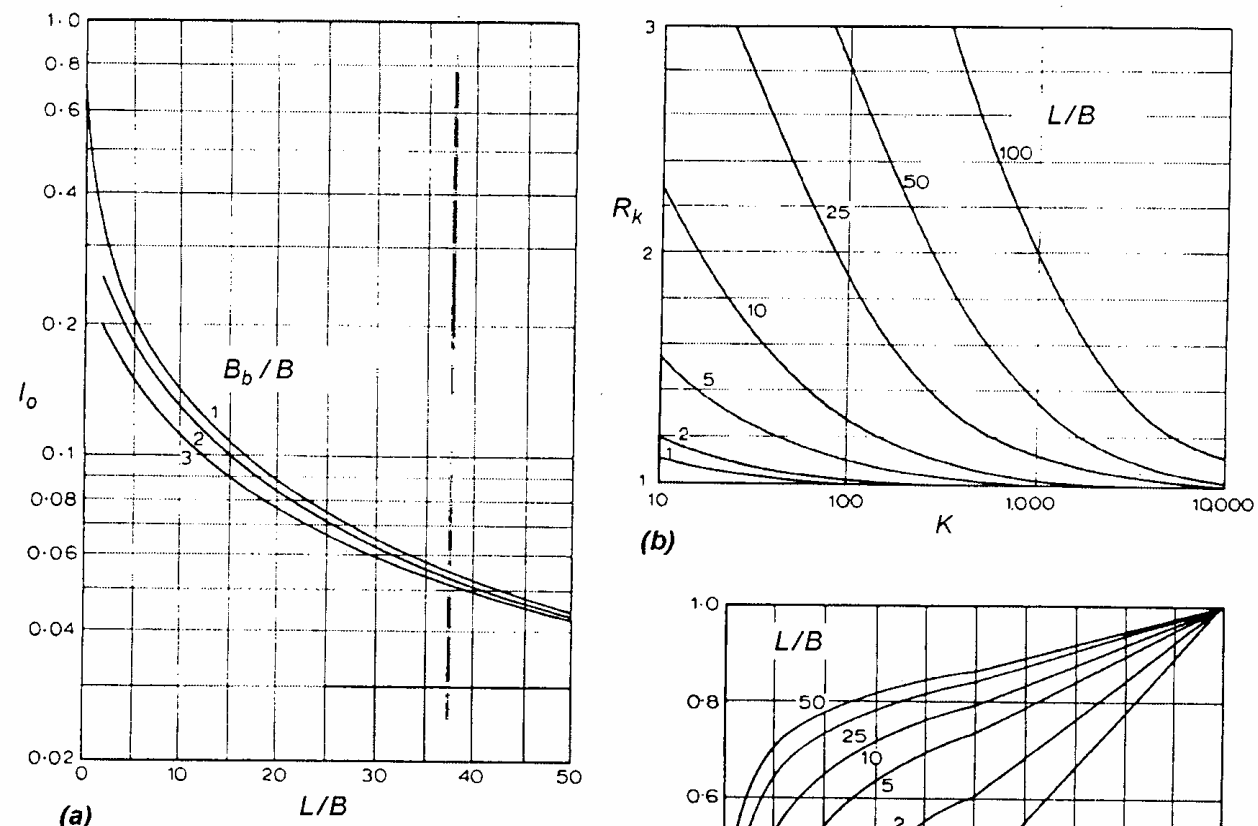

(b)
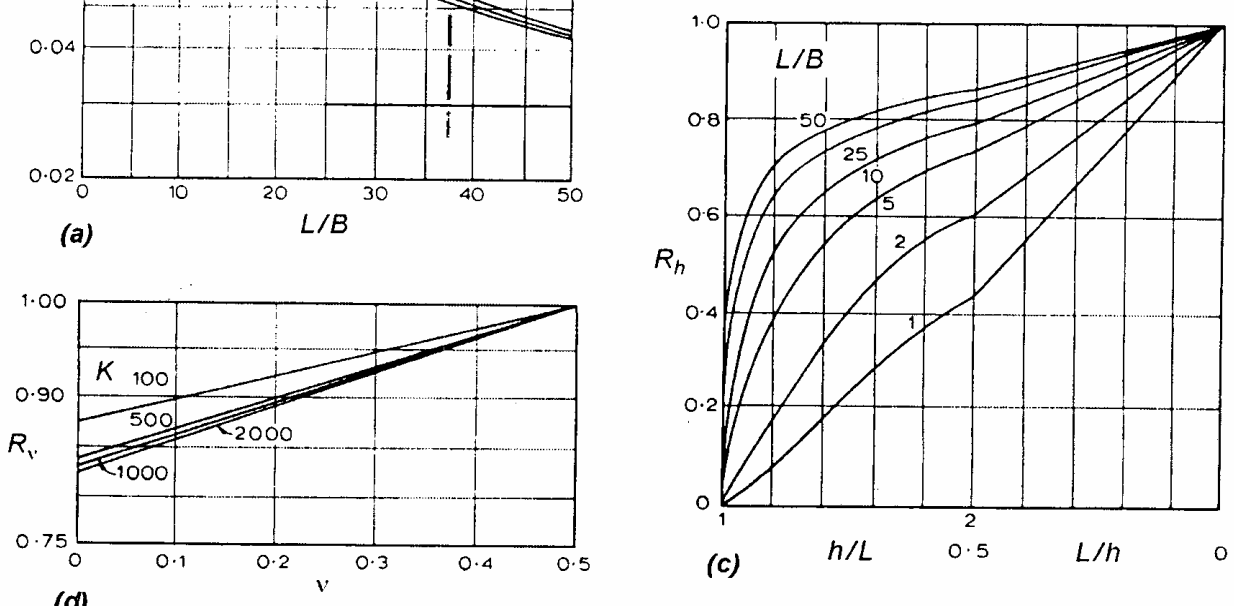

Figura 4.9 - Fatores para o cálculo de recalque de estacas: a) fator $I_{0}$, b) Influência da compressibilidade da estaca, c) da espessura "finita" do solo compressível, d) do coeficiente de Poisson do solo (Poulo e Davis, 1974)

A generalização da solução para uma estaca compressível, em solo de espessura finita e com ponta em material resistente, com diferentes coeficientes de Poisson, foi feita, tendo os autores alterado a expressão 4.31 para:

$w=\frac{Q \cdot I}{E \cdot B}$ 
sendo:

$I=I_{0} \cdot R_{k} \cdot R_{h} \cdot R_{v} \cdot R_{b}$

na qual:

$\mathrm{R}_{\mathrm{k}}=$ fator de correção para compressibilidade da estaca - Figura $4.9 \mathrm{~b}$

$\mathrm{R}_{\mathrm{h}}=$ fator de correção para a espessura $\mathrm{h}$ (finita) de solo compressível - Figura 4.9c

$\mathrm{R}_{\mathrm{v}}=$ fator de correção para o coeficiente de Poisson do solo $(v)-$ Figura $4.9 \mathrm{~d}$

$\mathrm{R}_{\mathrm{b}}=$ fator de correção para a base ou ponta em solo mais rígido, sendo $\mathrm{E}_{\mathrm{b}} \mathrm{o}$ módulo de Young do solo sob a base. - Figura 4.10

(a)

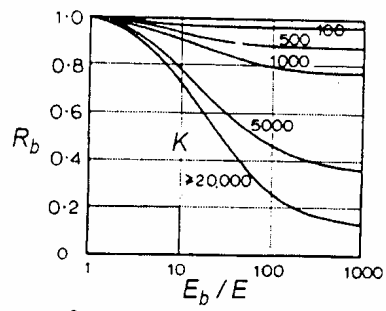

(c)

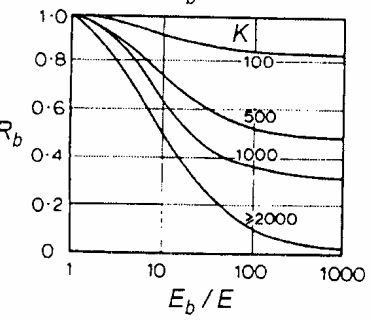

(b)

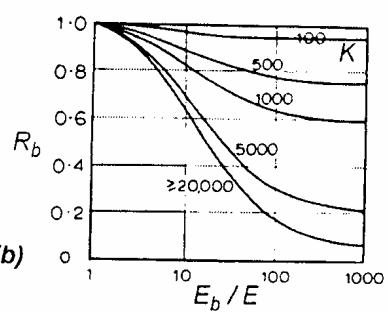

(d)

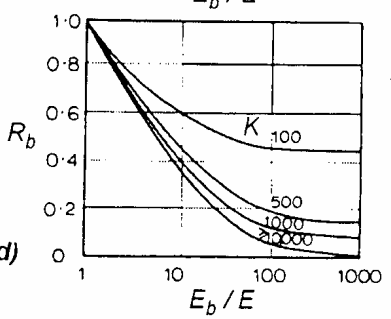

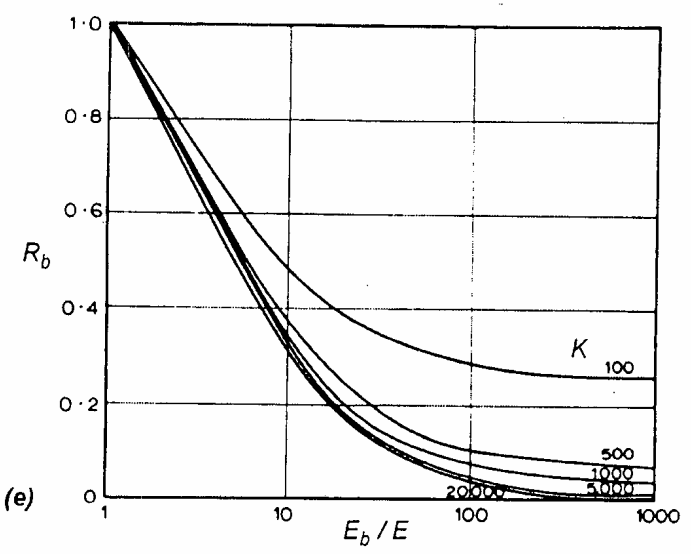

Figura 4.10 - Fator de correção para a base da estaca em solo mais rígido: a) para $\mathrm{L} / \mathrm{B}=75$, b) para $\mathrm{L} / \mathrm{B}=50$, c) para $\mathrm{L} / \mathrm{B}=25$, d) para $\mathrm{L} / \mathrm{B}=10$ e e) para $\mathrm{L} / \mathrm{B}=5$ (Poulos e Davis, 1980)

Poulos e Davis (1980) avaliaram o método através de algumas provas de carga em estaca e sugeriram alguns valores para $\mathrm{E}_{\mathrm{s}}$, apresentados na Tabela 4.6. 
Tabela 4.6 - Valores de E, v (Poulos e Davis, 1980 apud Velloso e Lopes, 2002)

\begin{tabular}{|c|c|c|c|}
\hline \multirow{3}{*}{ Solo } & Consistência/compacidade & $\mathbf{E}_{\mathbf{s}}$ & $\mathbf{v}$ \\
\hline \multirow{4}{*}{ Argila } & mole & \multirow{2}{*}{$200<\mathrm{E}_{\mathrm{s}} / \mathrm{s}_{\mathrm{u}}<400$} & 0,4 \\
\cline { 2 - 2 } & Média & & 0,3 \\
\cline { 2 - 3 } & rija & 0,15 \\
\hline \multirow{4}{*}{ Areia } & fofa & $27-55 \mathrm{MN} / \mathrm{m}^{2}$ & \\
\cline { 2 - 3 } & médian. compacta & $55-70 \mathrm{MN} / \mathrm{m}^{2}$ & 0,3 \\
\cline { 2 - 3 } & compacta & $70-110 \mathrm{MN} / \mathrm{m}^{2}$ & \\
\hline
\end{tabular}

\subsubsection{Método de Randolph e Wroth}

Randolph e Wroth $(1977,1978)$ propuseram um método que admite o solo como elástico e consideram a transferência de carga pelo fuste e pela base separadamente. O solo é dividido em duas camadas conforme ilustram as Figuras 4.11.a e 4.11.b. Admite-se que a camada superior se deforma pelo efeito da carga transferida através do fuste e a camada inferior se deforma devido à carga da base, Figura 4.11.c. No que segue será empregada a notação adotada por Velloso e Lopes (2002).

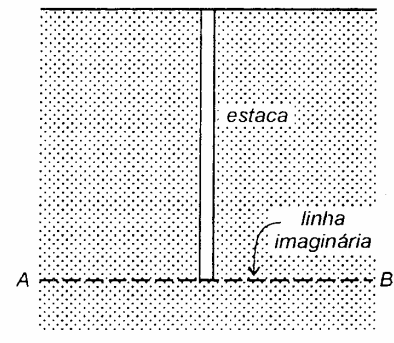

(a)

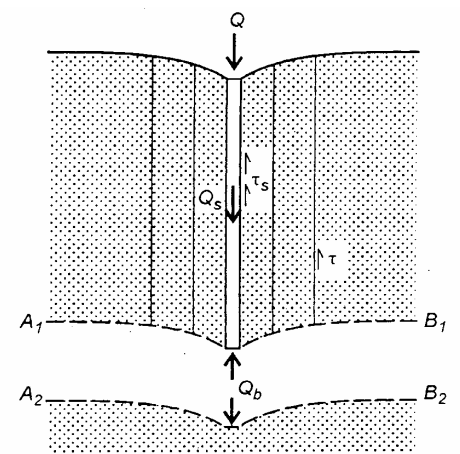

(b)

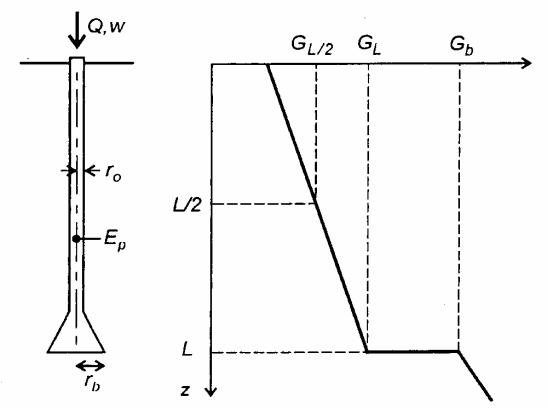

Figura 4.11 - Deformação das camadas (Randolph, 1977 apud Velloso e Lopes 2002) 
a) A interação solo e fuste da estaca pode ser expressa pela equação de equilíbrio em coordenadas cilíndricas:

$\frac{\partial}{\partial r}(r, \tau)+\frac{\partial \sigma_{z}}{\partial z}=0$

Como o estado de deformação ao redor do fuste de uma estaca segundo (Cooke, 1974) pode ser considerado como cisalhamento puro, a parcela $\partial \sigma_{\mathrm{z}} / \partial \mathrm{z}$ é muito pequena, podendo ser desprezada. Tomando-se uma estaca de raio $r_{0}$ e uma tensão cisalhante lateral $\tau_{\mathrm{s}}$, os autores chegaram à seguinte equação:

$\tau(r)=\frac{\tau_{s} \cdot r_{0}}{r}$

Supondo que o módulo de elasticidade transversal ou de cisalhamento $G$ não varia com a profundidade, a distorção do solo na primeira camada é dada pela por:

$\gamma=\frac{\tau}{G}=\frac{\partial u}{\partial z}+\frac{\partial w_{s}}{\partial r}$

sendo:

$\mathrm{u}=$ deslocamento radial, horizontal

ws $=$ deslocamento vertical do fuste

Admitindo novamente que a parcela $\partial \mathrm{u} / \partial \mathrm{z}$ é praticamente nula diante da parcela vertical e combinando as duas últimas expressões:

$w_{s}=\int_{r_{0}}^{r_{m}} \gamma d r=\int_{r_{0}}^{r_{m}} \frac{\tau_{s} \cdot r_{0}}{G r} d r=\frac{\tau_{s} \cdot r_{0}}{G} \zeta$

em que:

$\mathrm{r}_{\mathrm{m}}=$ raio mágico ou raio de influência, dado por:

$\mathrm{r}_{\mathrm{m}} \approx 2,5 \mathrm{~L}(1-v)$

sendo L o comprimento da estaca e:

$\zeta=\ln \left(\mathrm{r}_{\mathrm{m}} / \mathrm{r}_{0}\right)$

Na prática pode-se adotar $\zeta$ aproximadamente igual a 4. 
A carga axial transferida ao solo, relacionada com a tensão cisalhante, é dada pela seguinte expressão:

$$
\frac{d Q(z)}{d z}=-2 \pi \cdot r_{0} \cdot \tau_{s}
$$

Admitindo que a tensão cisalhante não varia com a profundidade, obtém-se a carga total transferida pela estaca ao solo ao longo do fuste:

$$
Q_{s}=2 \pi \cdot r_{0} \cdot \tau_{s} \cdot L
$$

Combinando as expressões 4.38 e 4.42 obtém-se a relação entre carga do fuste e recalque:

$$
\frac{Q_{s}}{w_{s}}=\frac{2 \pi \cdot L \cdot G}{\zeta}
$$

b) O recalque da base da estaca, (Figura 4.11) é dado pela equação:

$$
w b=\frac{(1-v) Q_{b}}{4 r_{0} \cdot G}
$$

sendo

$\mathrm{Q}_{\mathrm{b}}$ é a carga mobilizada pela base e $\mathrm{w}_{\mathrm{b}}$ é o deslocamento vertical da base.

Os autores simplesmente aplicaram a teoria da elasticidade para uma área carregada, correspondente à ponta da estaca, praticamente ignorando o efeito do embutimento.

c) Combinando a parcela do fuste com a parcela da base, para uma estaca rígida, valem as seguintes expressões:

$\mathrm{w}=\mathrm{w}_{\mathrm{s}}=\mathrm{w}_{\mathrm{b}}$

e

$$
\mathrm{Q}=\mathrm{Q}_{\mathrm{s}}+\mathrm{Q}_{\mathrm{b}}
$$

Combinando-se as expressões 4.43 e 4.44 chega-se a:

$$
\frac{Q}{w \cdot r_{0} \cdot G}=\frac{4}{(1-v)}+\frac{2 \pi \cdot L}{\zeta \cdot r_{0}}
$$


d) Para estacas compressíveis as equações 4.35 e 4.36 continuaram válidas, mas o recalque e a tensão cisalhante variam com a profundidade. Da mesma forma que para a estaca rígida, a relação entre a tensão cisalhante na interface solo-estaca e a carga axial atuante no fuste pode ser expressa como:

$\frac{d Q(z)}{d z}=-2 \pi \cdot r_{0} \cdot \tau_{s}(z)$

Considerando a compressibilidade da estaca, a aplicação da Lei de Hooke permite que se escreva:

$\frac{d w s(z)}{d z}=-\frac{Q(z)}{\pi \cdot r_{0}^{2} \cdot E_{p}}$

sendo, $\mathrm{E}_{\mathrm{p}}$ é o Módulo de Young da estaca. O sinal negativo deve-se ao fato de o deslocamento vertical do fuste $\left(\mathrm{w}_{\mathrm{s}}\right)$ diminuir à medida em que a profundidade $(\mathrm{z})$ aumenta.

Derivando a expressão (4.49) e usando a expressão (4.48), chega-se a:

$\frac{d^{2} w s(z)}{d z^{2}}=\frac{2}{r_{0}^{2} \cdot \zeta \cdot \lambda} w_{s}(z)$

em que:

$\lambda=\frac{E_{p}}{G}$ (rigidez relativa)

Resolvendo a equação diferencial dada pela expressão (4.50) com as condições de contorno relativas à base:

$$
\begin{aligned}
& w b(z=L)=\frac{(1-v)}{4} \cdot \frac{Q_{b}}{r_{0} \cdot G} \\
& \frac{d w b}{d z}(z=L)=\frac{Q_{b}}{\pi \cdot r_{0}{ }^{2} \cdot \lambda \cdot G}
\end{aligned}
$$


Randolph e Wroth (1978) chegaram à seguinte expressão estaca:

$$
\frac{Q}{w \cdot r 0 \cdot G}=\left[\frac{\frac{4}{(1-v)}+\frac{2 \pi}{\zeta} \cdot \frac{L}{r 0} \cdot \frac{\operatorname{tgh}(\mu \cdot L)}{\mu \cdot L}}{1+\frac{4}{(1-v)} \cdot \frac{1}{\pi \cdot \lambda} \cdot \frac{L}{r_{0}} \cdot \frac{\operatorname{tgh}(\mu \cdot L)}{\mu \cdot L}}\right]
$$

sendo:

$$
\mu \cdot L=\frac{L}{r_{0}}\left(\frac{2}{\zeta \cdot \lambda}\right)^{1 / 2}
$$

e) Na solução aproximada para solos não homogêneo é possível considerar que a rigidez do solo varia linearmente com a profundidade (solo de Gibson), isto é:

$$
G=m(b+z)
$$

Sendo a expressão geral para a estaca rígida:

$$
\frac{Q}{w \cdot r_{0} \cdot G L}=\frac{4}{(1-v)}+\frac{2 \pi \cdot L}{\zeta \cdot r_{0}}
$$

na qual:

$$
\begin{aligned}
& \rho=\frac{G_{L / 2}}{G_{L}} \\
& \lambda=\frac{E_{p}}{G_{L}} \\
& r m=2,5 L(1-v) \rho
\end{aligned}
$$

Para casos de estaca compressível em solo tipo Gibson a solução é bastante complexa, mas pode-se aproximar para:

$$
\frac{Q}{w \cdot r_{0} \cdot G_{L}}=\left[\frac{\frac{4}{(1-v)}+\frac{2 \pi}{\zeta} \cdot \frac{L}{r_{0}} \cdot \frac{\operatorname{tgh}(\mu \cdot L)}{\mu \cdot L} \rho}{1+\frac{4}{(1-v)} \cdot \frac{1}{\pi \cdot \lambda} \cdot \frac{L}{r_{0}} \cdot \frac{\operatorname{tgh}(\mu \cdot L)}{\mu \cdot L}}\right]
$$


Randolph (1985) apud Velloso e Lopes (2002) sugeriu ainda outras modificações para a equação 4.61, considerando que as estacas apóiem em um substrato mais rígido do que aquele que envolve o fuste e que a base pode ser alargada, com raio $r_{b}$ :

$$
\frac{Q}{w \cdot r_{0} \cdot G}=\left[\frac{\frac{4 n}{(1-v) \Omega}+\frac{2 \pi}{\zeta} \cdot \frac{L}{r_{0}} \cdot \frac{\operatorname{tgh}(\mu \cdot L)}{\mu \cdot L} \rho}{1+\frac{4 n}{(1-v) \Omega} \cdot \frac{1}{\pi \cdot \lambda} \cdot \frac{L}{r_{0}} \cdot \frac{\operatorname{tgh}(\mu \cdot L)}{\mu \cdot L}}\right]
$$

sendo:

$\Omega=\mathrm{G}_{\mathrm{L}} / \mathrm{G}_{\mathrm{b}}$

$\mathrm{n}=\mathrm{r}_{\mathrm{b}} / \mathrm{r}_{0}$

Finalmente é importante destacar que, para cargas não superiores à carga de trabalho, o valor de $\mathrm{G}$ a usar deve ser o máximo, isto é, $\mathrm{G}_{0}$. Randolph (1994) fez esta proposta com base no argumento de que as deformações no solo adjacente ao fuste são pequenas para esta condição de carga.

\subsection{Métodos empíricos para a previsão da capacidade de carga em estacas utilizando o DMT}

Marchetti et al (2001) apresenta algumas considerações, feitas por ele e por outros autores, sobre a previsão da capacidade de carga em estacas carregadas axialmente.

A seguir serão apresentados métodos de cálculo da capacidade de carga em estacas que recorrem diretamente a parâmetros do DMT e não a parâmetros dos solos.

\subsubsection{Método de Marchetti et al para estacas cravadas em argila}

Este método foi desenvolvido por Marchetti et al (1986) apud Marchetti et al (2001) para o caso de estacas cravadas em argila, baseando-se na determinação de $\sigma_{h c}^{\prime}$ (tensão horizontal efetiva contra a lâmina de DMT após o término do readensamento). Os autores propõem a aplicação de um fator $\rho$ ao $\sigma_{h c}^{\prime}$ e este produto é usado como uma estimativa do atrito lateral da estaca $\left(f_{s}=\rho \sigma_{h c}^{\prime}\right)$. 
Segundo Marchetti et al (2001), este método é baseado nos conceitos de teorias desenvolvidas por Baligh (1985), mas apresenta duas desvantagens.

a) A primeira é que em argilas, de baixa permeabilidade, o readensamento ao redor da lâmina, pode levar muitas horas, se não um ou dois dias, fazendo com que a determinação de $\sigma_{h c}^{\prime}$ seja inviável economicamente.

b) A segunda desvantagem é referente ao fator $\rho$, o qual foi introduzido para não ser uma constante, e sim um fator bastante variável (na maioria das vezes variando entre 0,10 a 0,20 ), gerando incertezas na obtenção do $\mathrm{f}_{\mathrm{s}}$.

O autor indica este método como complementação de outros métodos.

\subsubsection{Método de Powell et al. (2001) para estacas cravadas em argila}

Powell et al. (2001) desenvolveram um método para a determinação da capacidade de carga axial de estacas cravadas em argila, usando parâmetros diretos e intermediários do DMT. Estes autores basearam-se em provas de carga executadas em aproximadamente 60 estacas cravadas ou macaqueadas, executadas em argilas do Reino Unido, Noruega, França e Dinamarca.

Neste método o atrito lateral qs é expresso em função do índice do material $\mathrm{I}_{\mathrm{D}}$ e $\left(\mathrm{p}_{1}\right.$ $\mathrm{p}_{0}$ ). As expressões indicadas para o atrito lateral em argilas (tensão e compressão na estaca) são:

$\mathrm{I}_{\mathrm{D}}<0.1 \quad \mathrm{q}_{\mathrm{s}} /\left(\mathrm{p}_{1}-\mathrm{p}_{0}\right)=0.5$

$0.1<\mathrm{I}_{\mathrm{D}}<0.65 \quad \mathrm{q}_{\mathrm{s}} /\left(\mathrm{p}_{1}-\mathrm{p}_{0}\right)=-0.73077 \mathrm{I}_{\mathrm{D}}+0.575$

$\mathrm{I}_{\mathrm{D}}>0.65 \quad \mathrm{q}_{\mathrm{s}} /\left(\mathrm{p}_{1}-\mathrm{p}_{0}\right)=0.1$

As expressões 4.65 a 4.67 foram modificadas por Powell et al. (2001) para estimar o atrito lateral das estacas apenas à compressão:

$$
\begin{array}{ll}
\mathrm{I}_{\mathrm{D}}<0.6 & \mathrm{q}_{\mathrm{s}} /\left(\mathrm{p}_{1}-\mathrm{p}_{0}\right)=-1.1111 \mathrm{I}_{\mathrm{D}}+0.775 \\
\mathrm{I}_{\mathrm{D}}>0.6 & \mathrm{q}_{\mathrm{s}} /\left(\mathrm{p}_{1}-\mathrm{p}_{0}\right)=0.11
\end{array}
$$

Para estacas onde a relação comprimento pelo raio for superior a $50(\mathrm{~h} / \mathrm{R}>50)$, devese acrescentar às expressões 4.68 e 4.69, um multiplicador de 0,85 . 
De acordo com Powell et al. (2001), a resistência de ponta da estaca $\mathrm{q}_{\mathrm{p}}$ é avaliada como:

$\mathrm{q}_{\mathrm{p}}=\mathrm{k}_{\mathrm{di}} \mathrm{p}_{1 \mathrm{e}}$

em que:

$\mathrm{p}_{1 \mathrm{e}}=\mathrm{p} 1$ equivalente, média satisfatória abaixo da base da estaca

$\mathrm{k}_{\mathrm{di}}=$ fator de capacidade de carga do DMT.

Os valores de $\mathrm{k}_{\mathrm{di}}$ indicados para estacas de seção cheia (não vazadas) são:

para $E_{D}>2 \mathrm{MPa} \quad k_{d i}=1.3$

para $E_{D}<2 \mathrm{MPa} \quad k_{d i}=0.7$

Para estacas de seção vazada multiplica-se $\mathrm{k}_{\mathrm{di}}$ por 0,5 .

Os autores sugerem que sejam feitos mais estudos para uma melhor aferição de kdi com tipo de solo, principalmente na transição de $\mathrm{E}_{\mathrm{D}}=2 \mathrm{MPa}$.

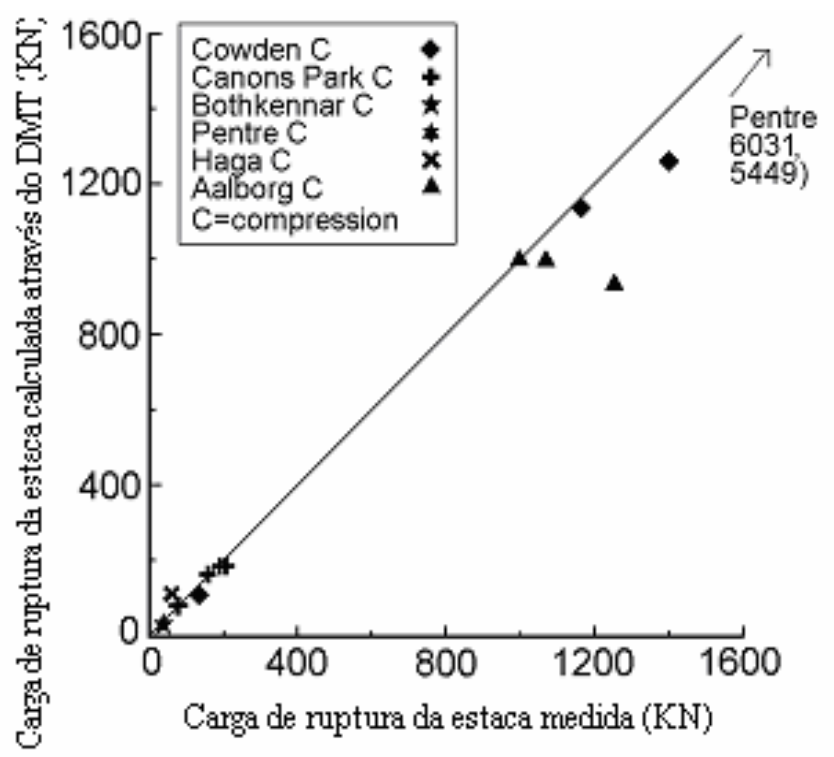

Figura 4.12 - Previsão versus medidas da capacidade de carga de estaca usando o método de compressão via DMT (Powell et al. 2001 apud Marchetti et al 2001). 


\section{CAMPO EXPERIMENTAL DE FUNDAÇÃO DA USP/ABEF - COMPARAÇÕES DE RESULTADOS OBTIDOS NO CAMPO x PREVISÕES UTILIZANDO O DMT.}

\subsection{Introdução}

Para se compreender melhor o comportamento de alguns tipos de fundação em solos tropicais, a escola Politécnica da USP e a ABEF (Associação Brasileira de Engenharia de Fundações e Serviços Geotécnicos), implementaram o Campo Experimental da USP/ABEF no campus da Universidade de São Paulo, Capital, ocupando uma área de aproximadamente $5.000 \mathrm{~m}^{2}$. Os resultados destes estudos foram publicados pela ABEF em 1989. A realização destes estudos foi viabilizada pela contribuição de diversos laboratórios e empresas do Estado de São Paulo.

Neste Campo Experimental foram executados, para fins de reconhecimento e caracterização geotécnica, três poços de inspeção, dos quais extraíram-se amostras indeformadas e deformadas, para os ensaios de laboratório (granulometria, limites de consistência, permeabilidade, compressibilidade e resistência), sete ensaios de cone do tipo CPT e oito sondagens à percussão do tipo SPT. Todos os ensaios publicados pela ABEF foram executados em 9 meses. Posteriormente, foram executadas sondagens à percussão com medida do torque (SPT-T), em outra campanha, por Peixoto (2001). Além das estacas instaladas em 1989 no Campo Experimental da USP (CEUSP), Souza (2001) realizou ensaios com estacas pilotos instrumentadas para sua tese de doutorado. E, por fim, para realização deste trabalho, executaram-se três ensaios dilatométricos (DMT) e mais três sondagens à percussão do tipo SPT-T ao lado de cada DMT. Está apresentada na Figura 5.2 a locação dos ensaios e estacas executados no Campo Experimental.

\subsection{Caracterização Geológica e Geotécnica}

O Campo Experimental da USP está localizado na extremidade oeste da bacia de São Paulo, onde o subsolo é composto por solo saprolítico de migmatito, coberto por uma pequena camada de solo coluvionar, silte argiloso poroso, amarelo e marrom. O solo saprolítico forma uma espessa camada de $20 \mathrm{~m}$ e é basicamente constituído por silte micáceo, arenoso, de cor púrpura, com ocorrências de areia fina siltosa, conforme ABEF (1989). Ensaios de laboratório indicaram coesões da ordem de 22 a $115 \mathrm{KPa}$ e ângulo de atrito do solo de 23 a $36^{\circ}$. O índice 
de atividade do silte do local faz os solos residuais caírem fora dos parâmetros de Skempton. O solo do Campo Experimental é bastante heterogêneo, conforme apresentado na Figura 5.1.

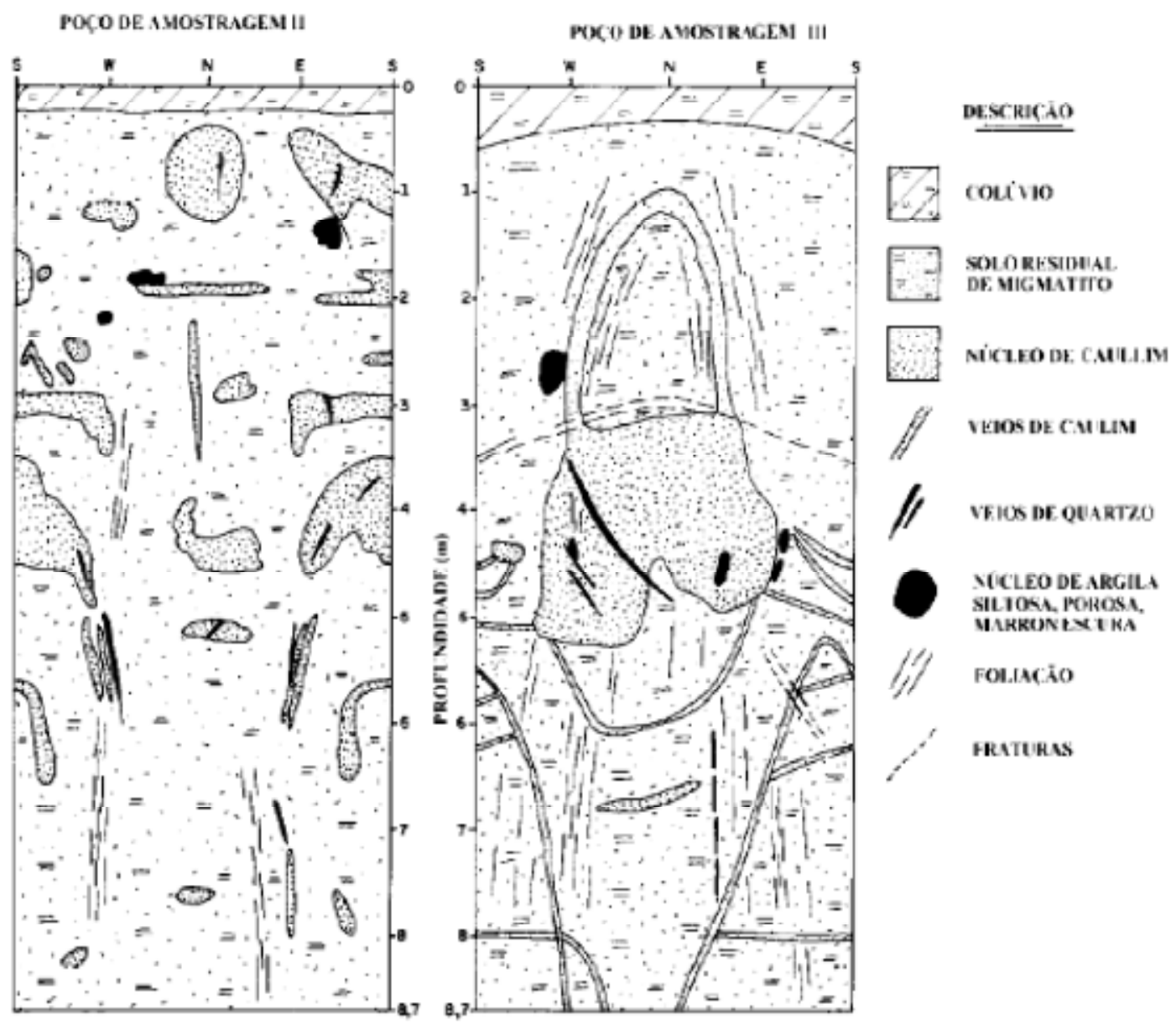

Figura 5.1 - Perfil ilustrativo de amostras indeformadas retirada do CEUSP.

O solo do Campo Experimental onde foram realizados os ensaios dilatométricos, já foi objeto de vários estudos (Azevedo e Niyama,1990; Niyama e Aoki, 1990; Massad, 1991a; Massad, 1991b; Décourt, 1995; Souza, 2001; Siviero, 2003; entre outros).

Uma análise dos perfis das sondagens de simples reconhecimento (Figuras 5.4, 5.5 e 5.6) confirma resultados obtidos anteriormente (ABEF, 1989 e Peixoto, 2001) quanto:

a) aos tipos de solos ocorrentes;

b) à grande heterogeneidade do subsolo;

c) apesar da heterogeneidade, conseguiu-se obter valores do número de golpes $(\mathrm{N})$ e medidas do torque (T) da mesma ordem de grandeza. 
Uma comparação dos resultados obtidos por Siviero (2003) e dos obtidos destes ensaios dilatométricos executados para esta dissertação está apresentada nas Figuras 5.9 a 5.11 e 5.13 .

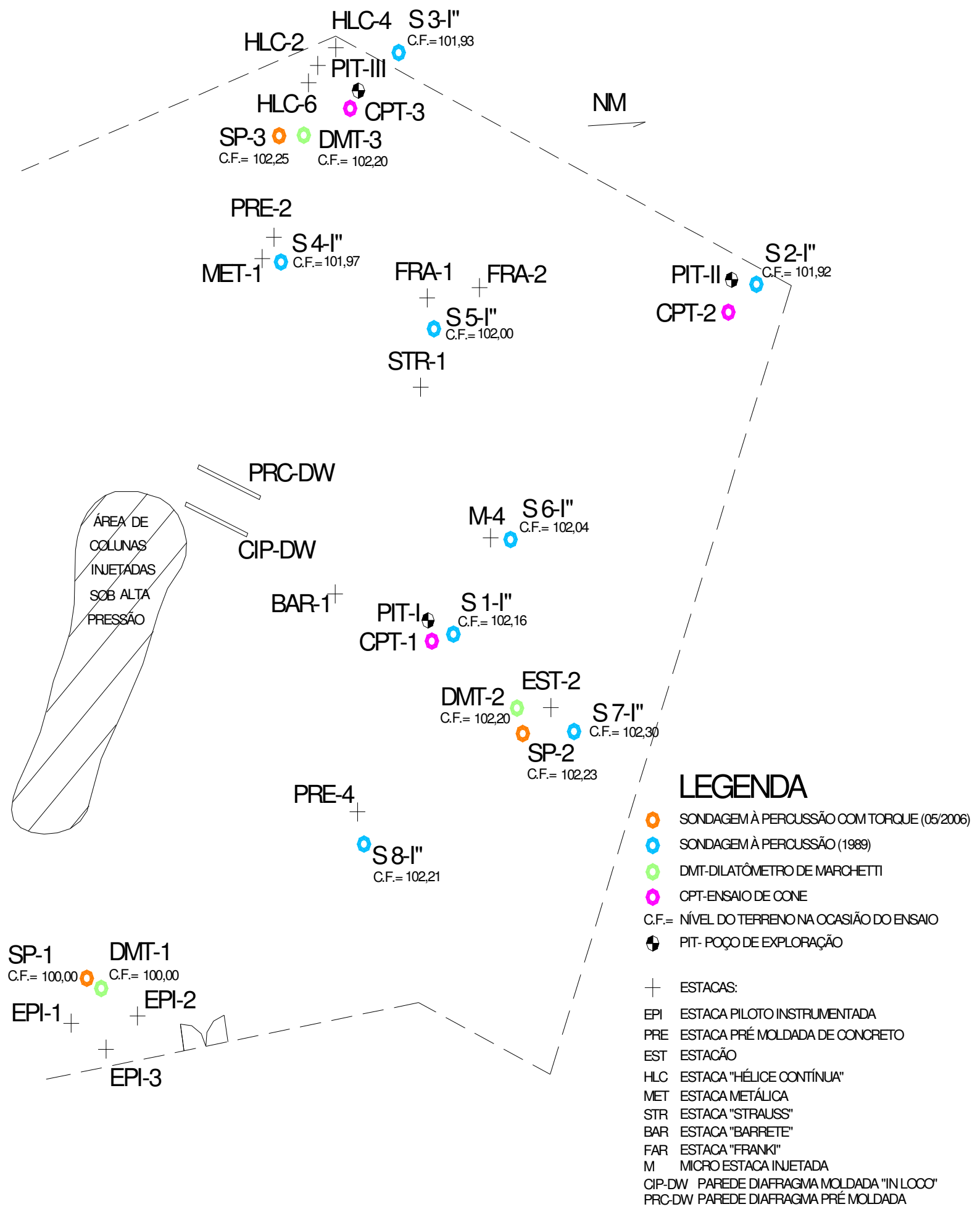

Figura 5.2 - Croquis da locação dos ensaios e das estacas executados no Campo Experimental da USP (ABEF, 1989 e Souza, 2001) modificado. 


\subsection{Execução dos ensaios dilatométricos}

Os ensaios dilatométricos foram executados para se obter parâmetros geotécnicos do solo para previsão da capacidade de carga vertical das estacas. Como havia também resultados de ensaios de laboratório, esses parâmetros podem ser comparados e analisados.

Foram executados três ensaios dilatométricos e três sondagens de simples reconhecimento (SPT-T) para a elaboração desta dissertação, sendo estes locados o mais próximo possível de regiões onde havia o maior número de estacas. A cravação foi feita com o mesmo sistema usado para o cone do CPT, cravação estática, sendo este sistema o mais aconselhável para a realização deste ensaio.

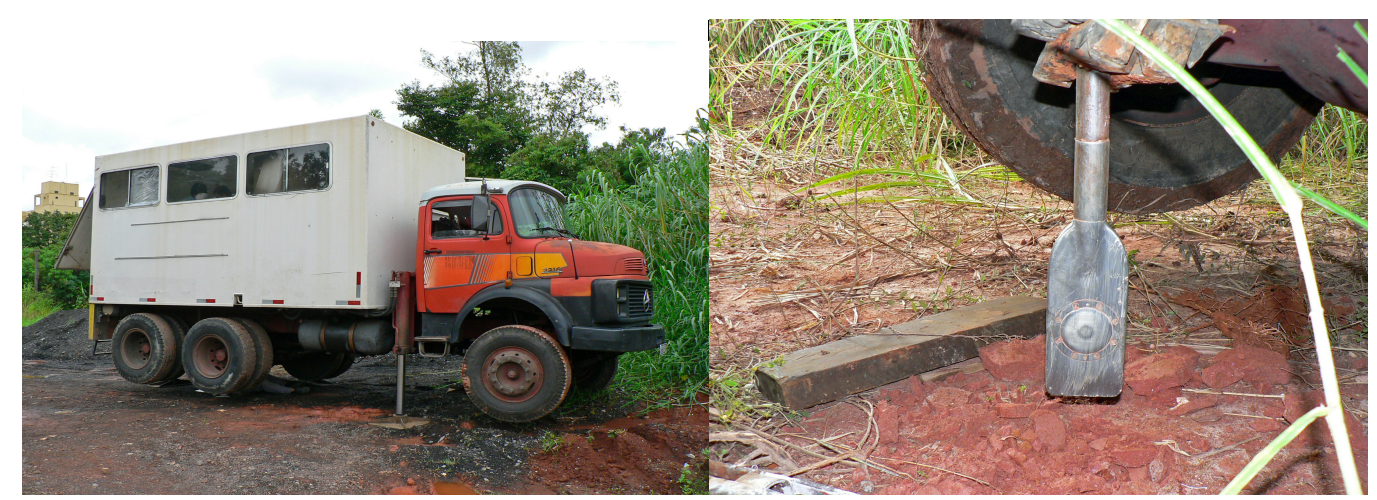

Figura 5.3 - Vista do caminhão na execução da cravação do DMT no CEUSP.

Na Figura 5.3 mostram-se fotos do porte do caminhão e do conjunto haste e lâmina, sendo cravados no solo estaticamente no Campo Experimental da USP.

Os resultados obtidos nos ensaios de DMT e SPT-T estão apresentados nas Figuras 5.4, 5.5 e 5.6. Estes ensaios foram realizados especialmente para este trabalho. Observa-se no resultado do DMT que os ensaios foram realizados a partir do nível 0,60 $\mathrm{m}$, isto porque os primeiros $60 \mathrm{~cm}$ continham aterro com alguns pedregulhos, podendo danificar a membrana logo no início do ensaio.

Executou-se primeiramente a calibração da membrana e posteriormente as leituras das pressões A e B, que depois foram corrigidas da forma indicada no Capítulo 3, para calcular-se as pressões $\mathrm{p}_{0}$ e $\mathrm{p}_{1}$. A leitura da pressão $\mathrm{C}$ não foi feita, pois o nível d’água não foi atingido pelas sondagens anteriores até a profundidade que se desejava estudar. Posteriormente ao ensaio de DMT, realizou-se o SPT-T e foi constatado que no furo de sondagem SP-02 o nível de água foi atingido a aproximadamente 7,8 metros de profundidade. O avanço se deu de 20 em $20 \mathrm{~cm}$. A seguir serão apresentados os resultados obtidos referentes aos ensaios de DMT's, bem como os de sondagens à percussão, executados para esta pesquisa. 
SONDAGEM À PERCUSSÃO (SPT) COM MEDIDA DE TORQUE

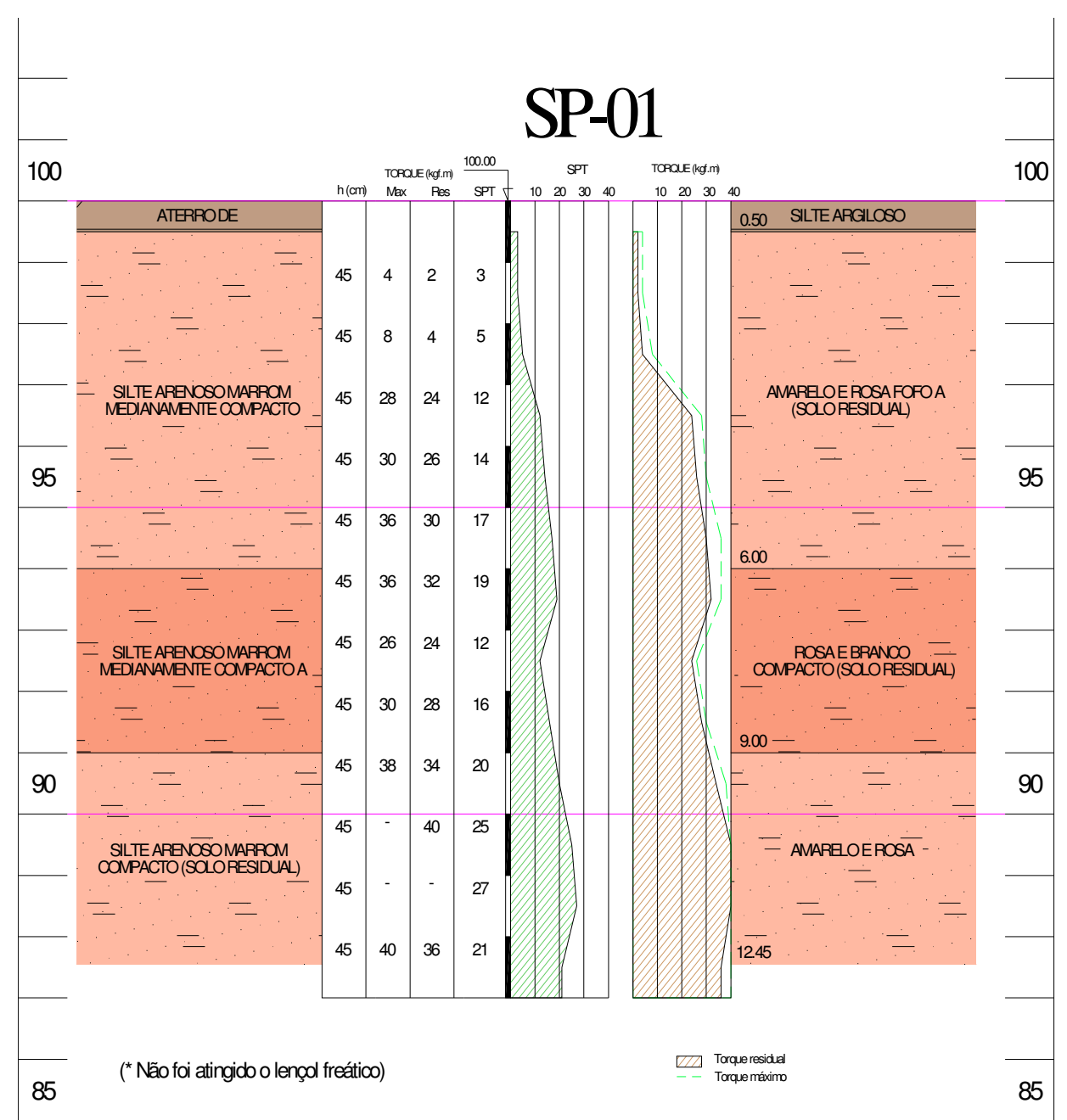

Figura 5.4 - Sondagem SP-01 e DMT-1

\section{ENSAIO COM O DILATÔMETRO DE MARCHETTI (DMT)}

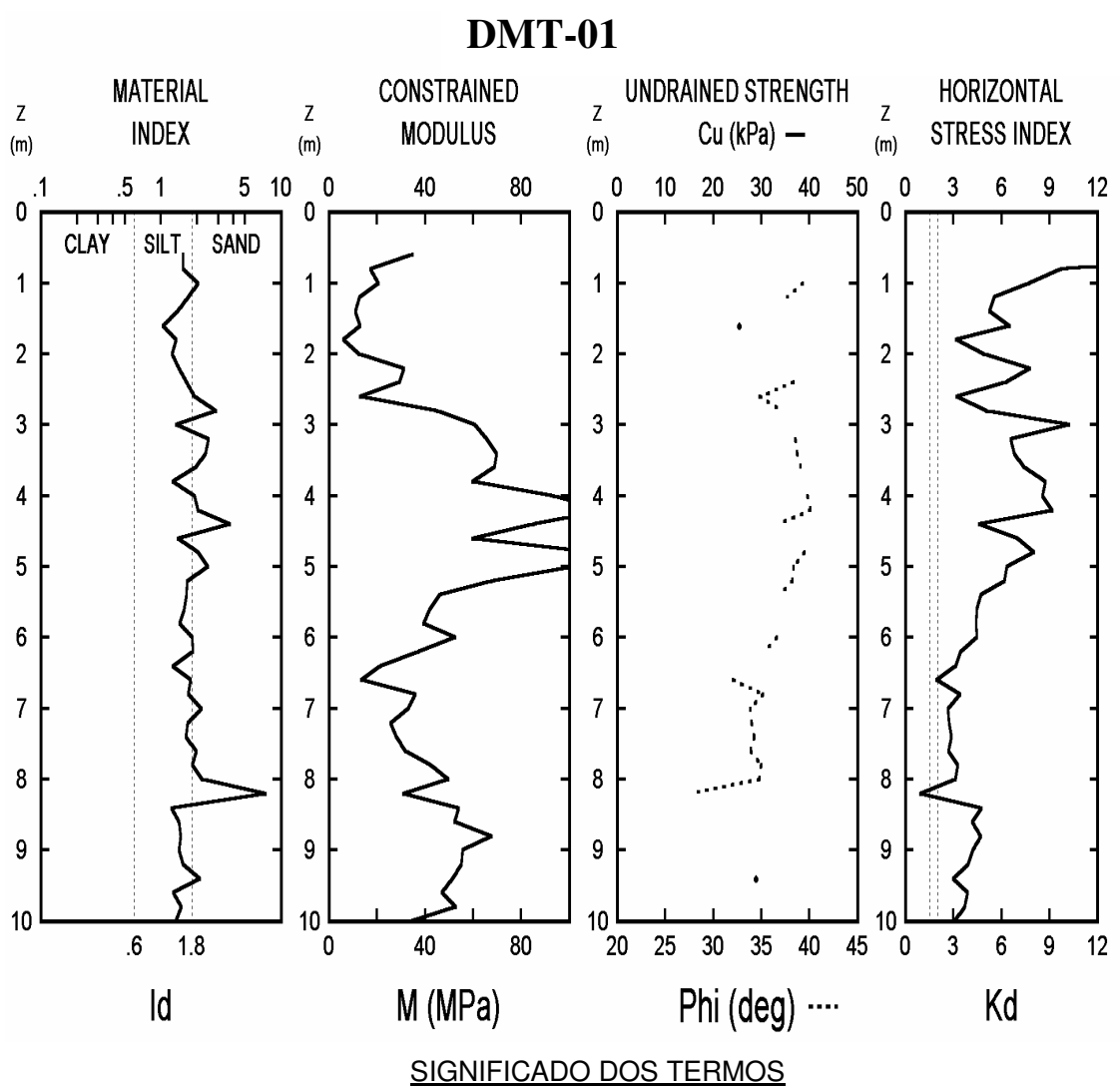

-Nas sondagens "SPT" h=penetracão do amostrador no terren

torque máx.=max. resist. à rotação do amostrador após a penetração torque res=resist. residual após uma volta completa do amostrador SPT=número de golpes necessários para a penetração do amostrador no terreno, em $30 \mathrm{~cm}$, após uma penetração inicial de $15 \mathrm{~cm}$

-No ensaio "DMT" material index=indice do material

clay=argila silt=silte $\quad$ sand $=$ areia

constrained modulus=módulo de deformabilidade edométrica

undrained strength=resist. ao cisalhamento em condições não drenadas

horizontal stress index= índice de tensão horizontal

phi (deg)=ângulo de atrito do solo (graus) 
SONDAGEM À PERCUSSÃO (SPT) COM MEDIDA DE TORQUE

105

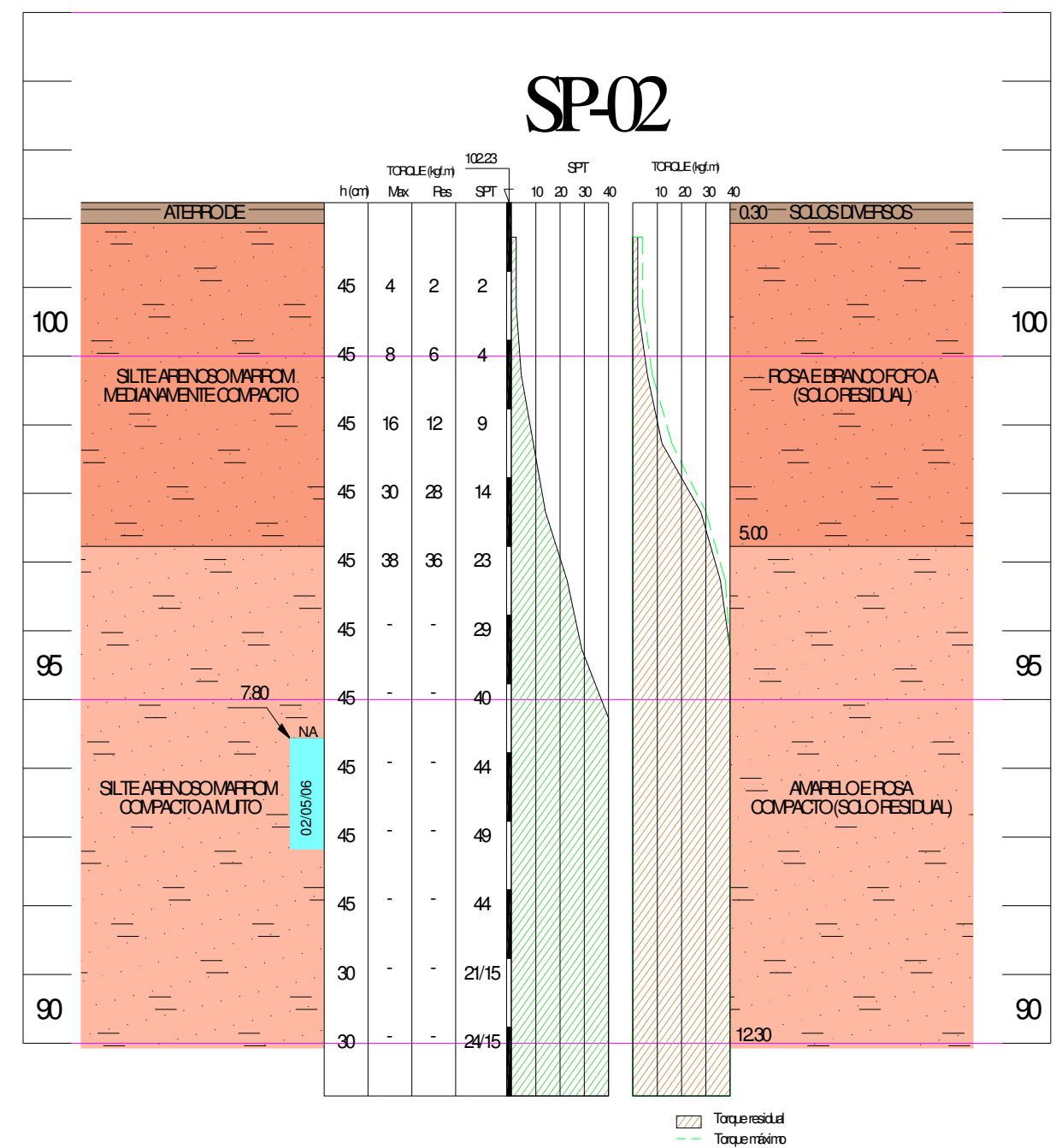

\section{ENSAIO COM O DILATÔMETRO DE MARCHETTI (DMT)}

DMT-02

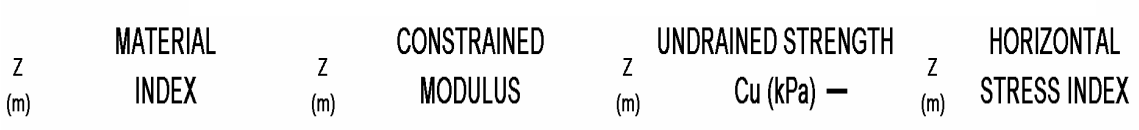

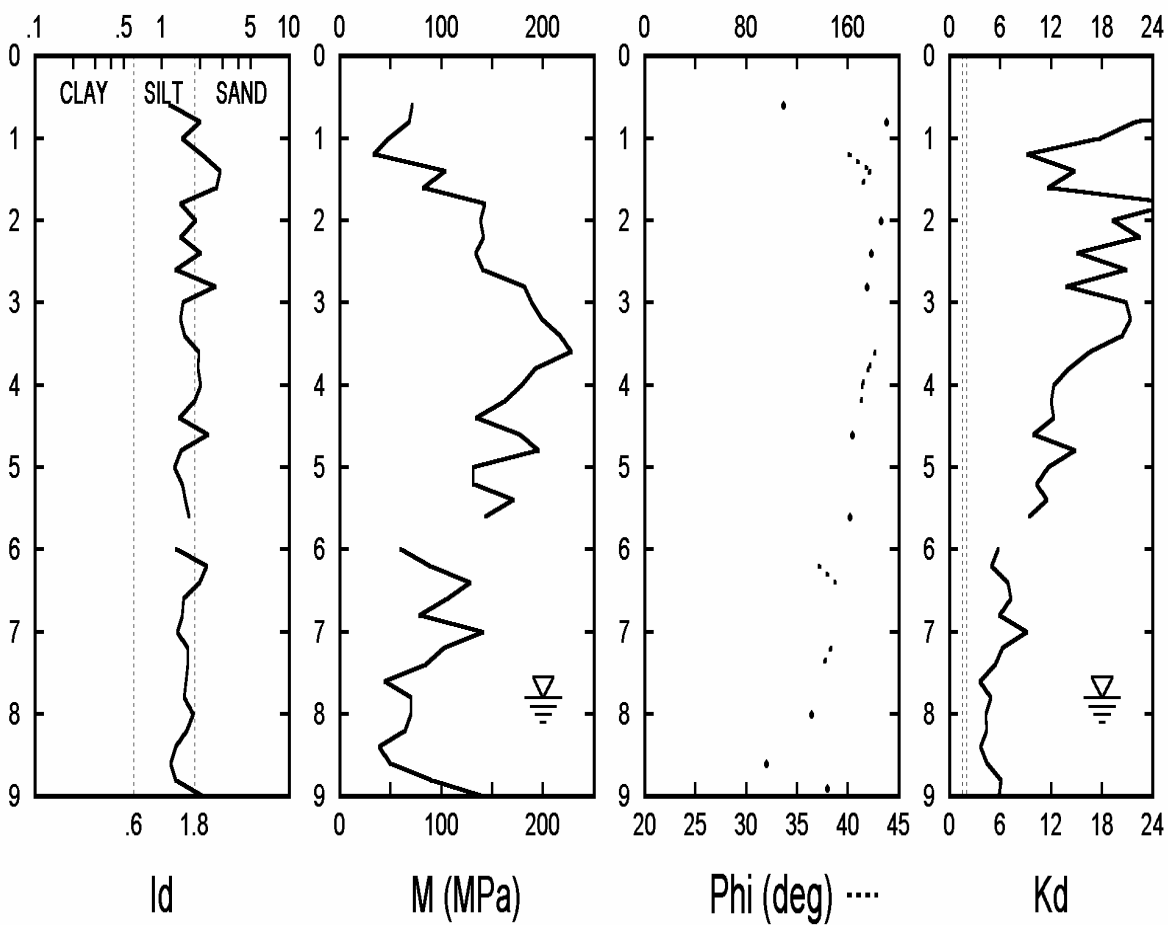

Figura 5.5 - Sondagem SP-02 e DMT-2 


\section{SONDAGEM À PERCUSSÃO (SPT) COM MEDIDA DE TORQUE}

105

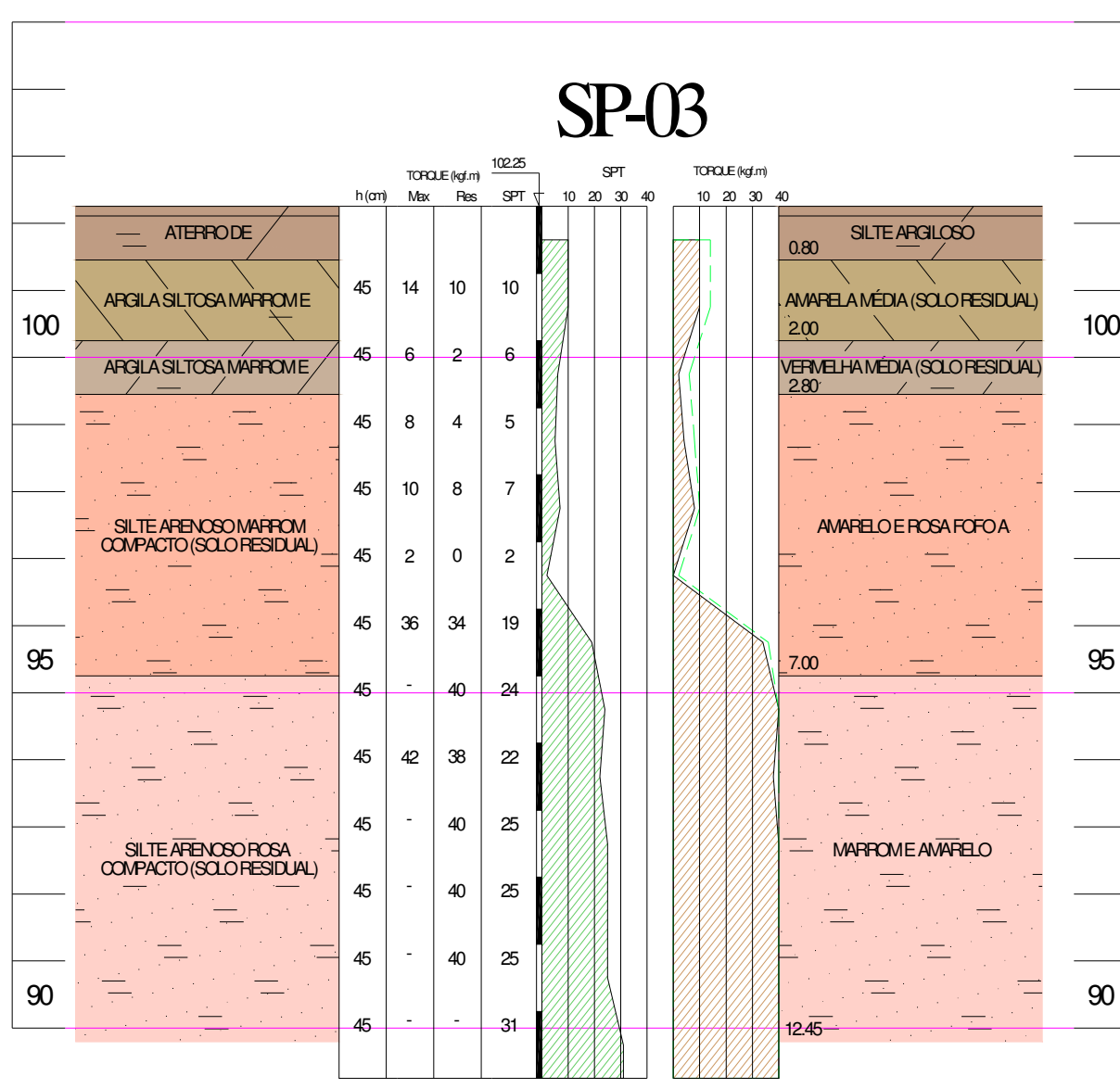

\section{ENSAIO COM O DILATÔMETRO DE MARCHETTI (DMT)}

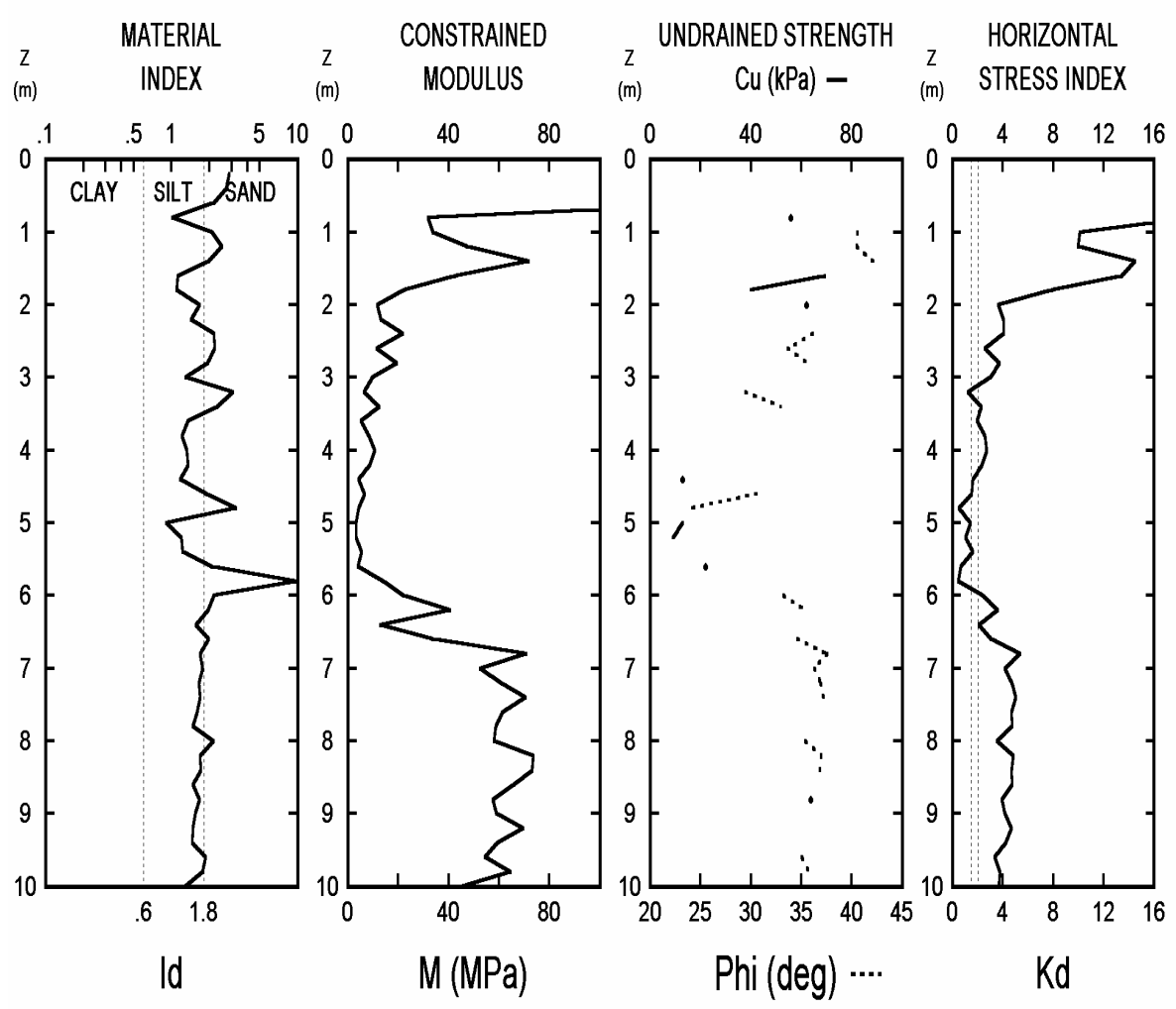

( Não foi atingido o lençol freático)

Figura 5.6 - Sondagem SP-03 e DMT-3 


\subsection{Análise dos ensaios de DMT}

A execução de três ensaios dilatométricos em pontos diferentes, acompanhados de sondagens à percussão, foi estrategicamente pensado, visto que na publicação da ABEF já se tinha uma prévia de que o solo no Campo Experimental da USP era muito heterogêneo, como se pode observar nas Figuras 5.7 e 5.8 .

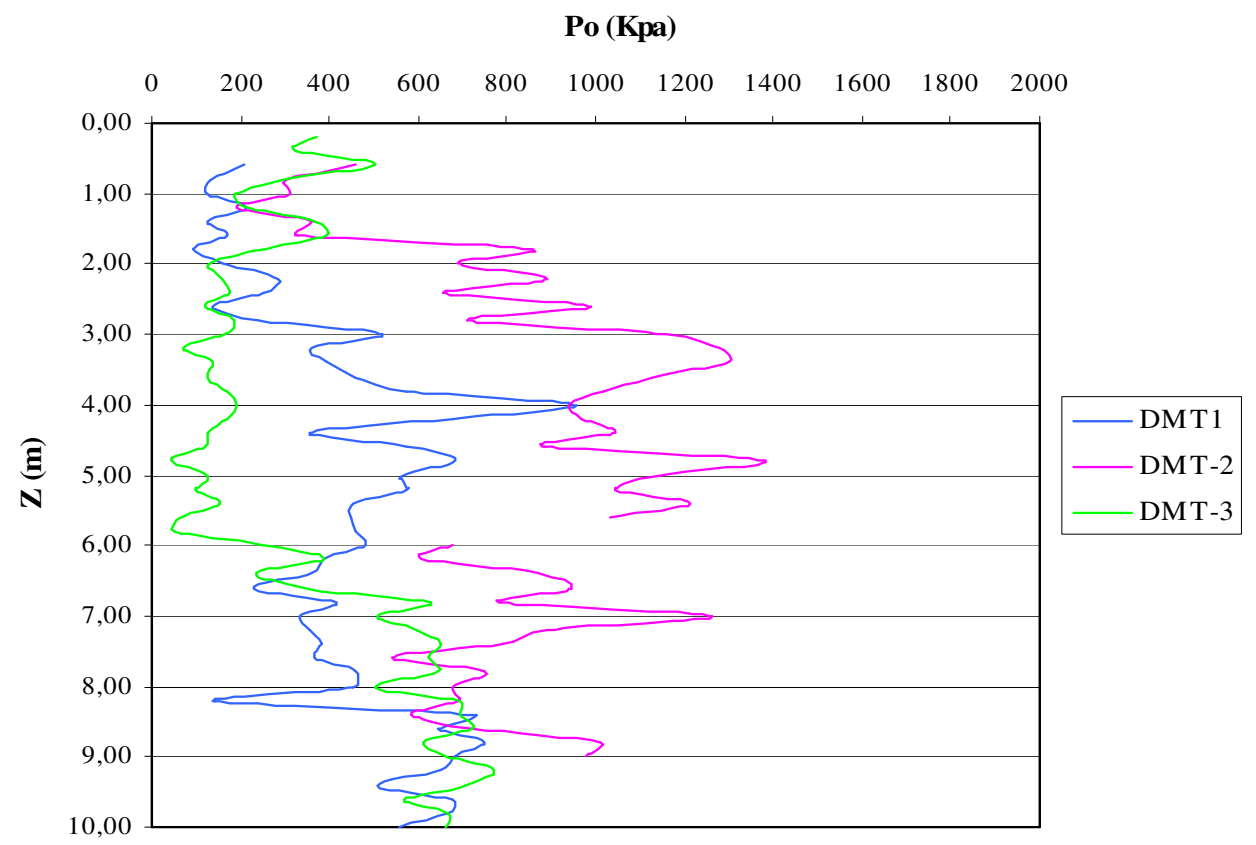

Figura 5.7 - Medida da pressão $\mathrm{p}_{0} \mathrm{x}$ profundidade - Contendo os 3 ensaios de DMT.

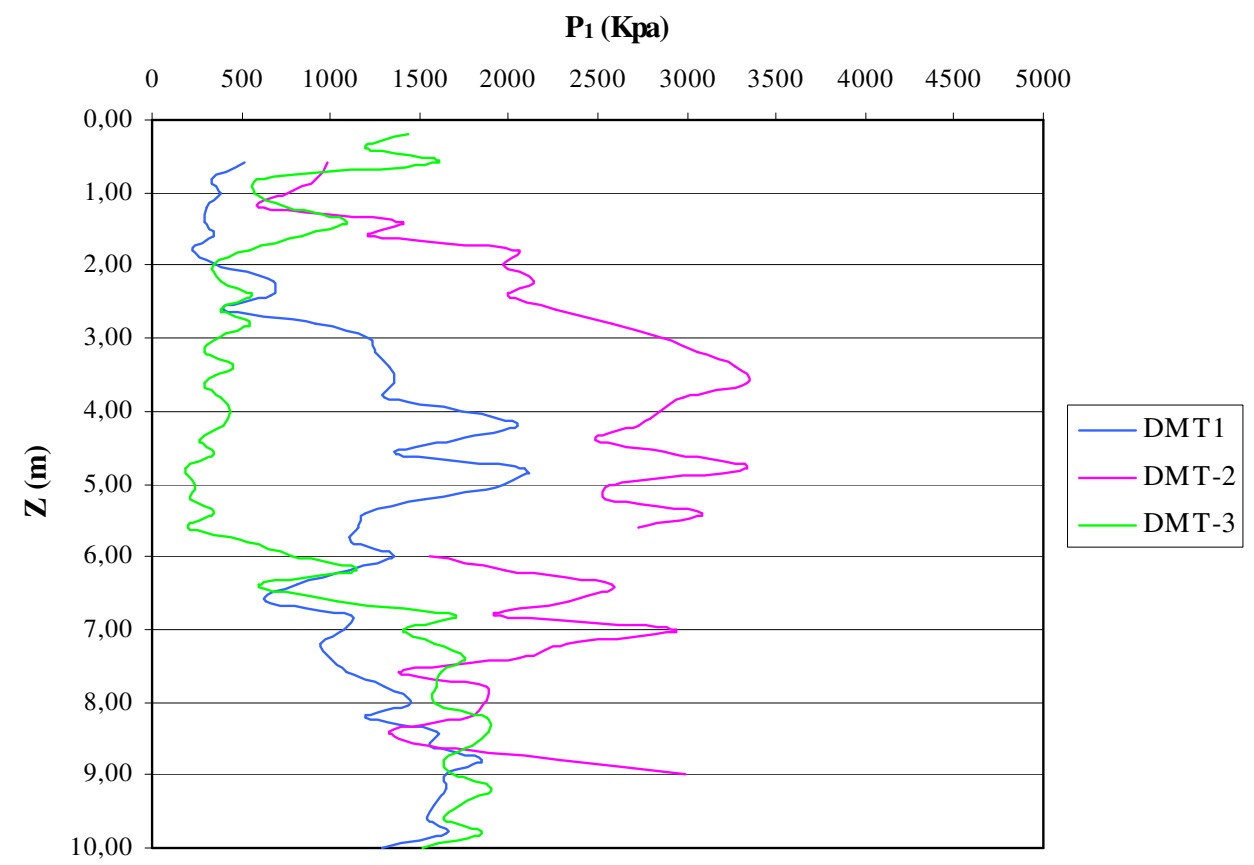

Figura 5.8 - Medida da pressão $\mathrm{p}_{1}$ x profundidade - Contendo os 3 ensaios de DMT. 
As duas pressões $\mathrm{A}$ e $\mathrm{B}$, que são lidas no manômetro e transformadas nas pressões $\mathrm{p}_{1} \mathrm{e}$ $\mathrm{p}_{0}$, conforme citado anteriormente nas expressões 3.1 a 3.3, dão origem aos parâmetros intermediários $I_{D}, K_{D}$ e $E_{D}$. Os resultados obtidos nos três diferentes furos do DMT são apresentados na Figura $5.9\left(\mathrm{I}_{\mathrm{D}}\right)$, Figura $5.10\left(\mathrm{~K}_{\mathrm{D}}\right)$ e Figura $5.11\left(\mathrm{E}_{\mathrm{D}}\right)$.

ID

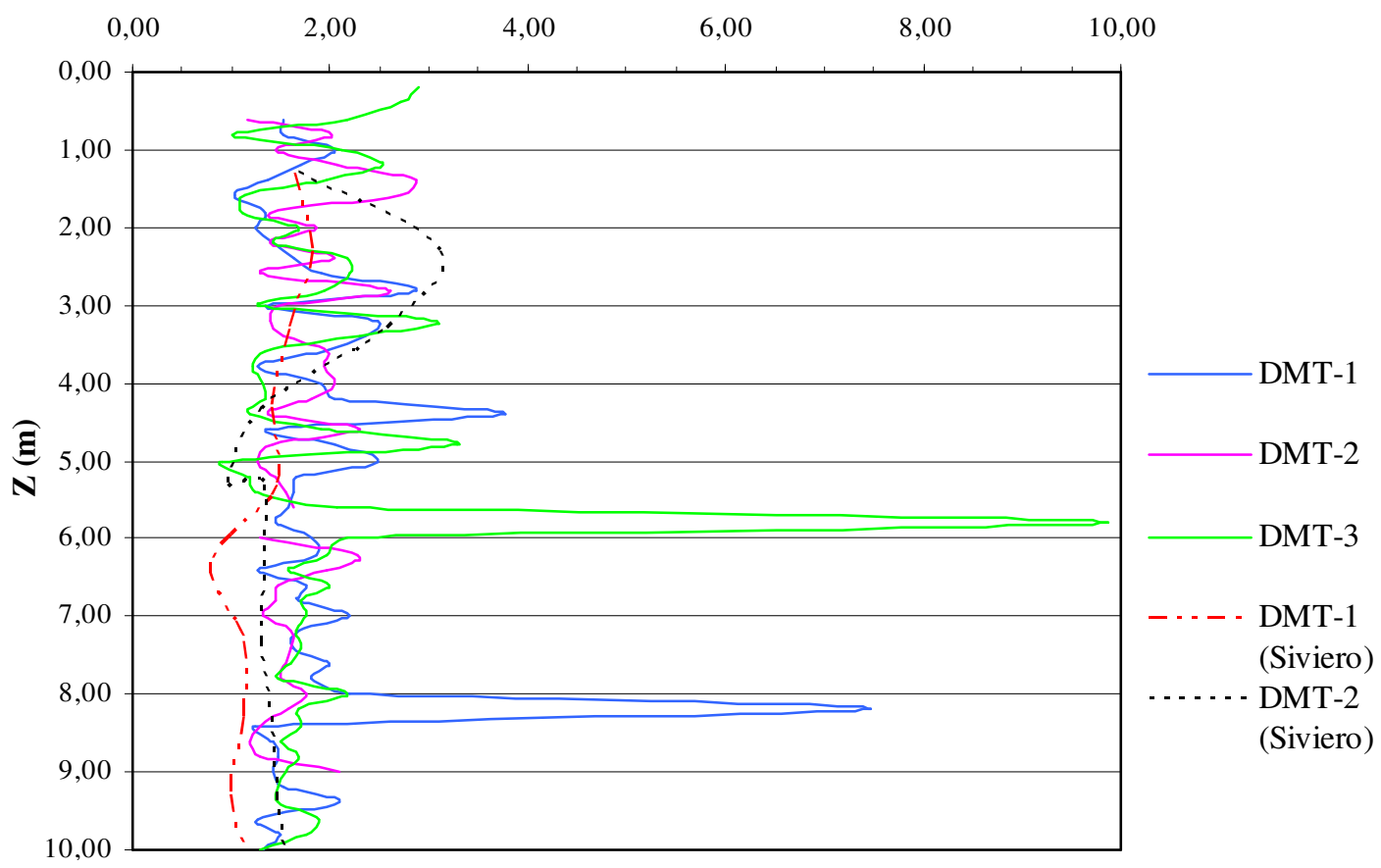

Figura $5.9-I_{D}$ x profundidade - Nos 3 ensaios indicando o material como silte arenoso, conforme sondagem local.

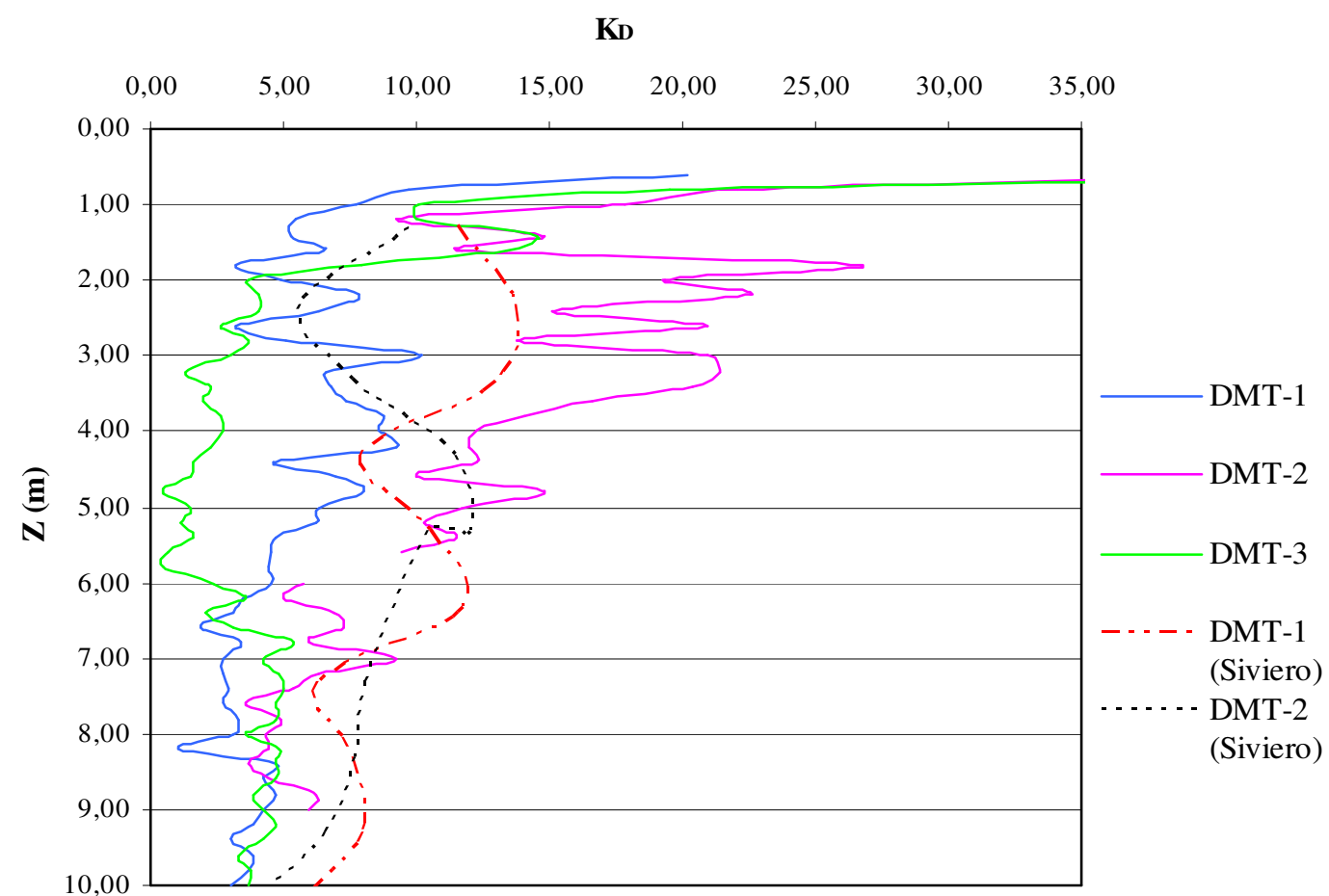

Figura 5.10 - $\mathrm{K}_{\mathrm{D}} \mathrm{x}$ profundidade - Solo identificado como sobre-adensado por possuir valores acima de 2,3 e com valor diminuindo com profundidade. 


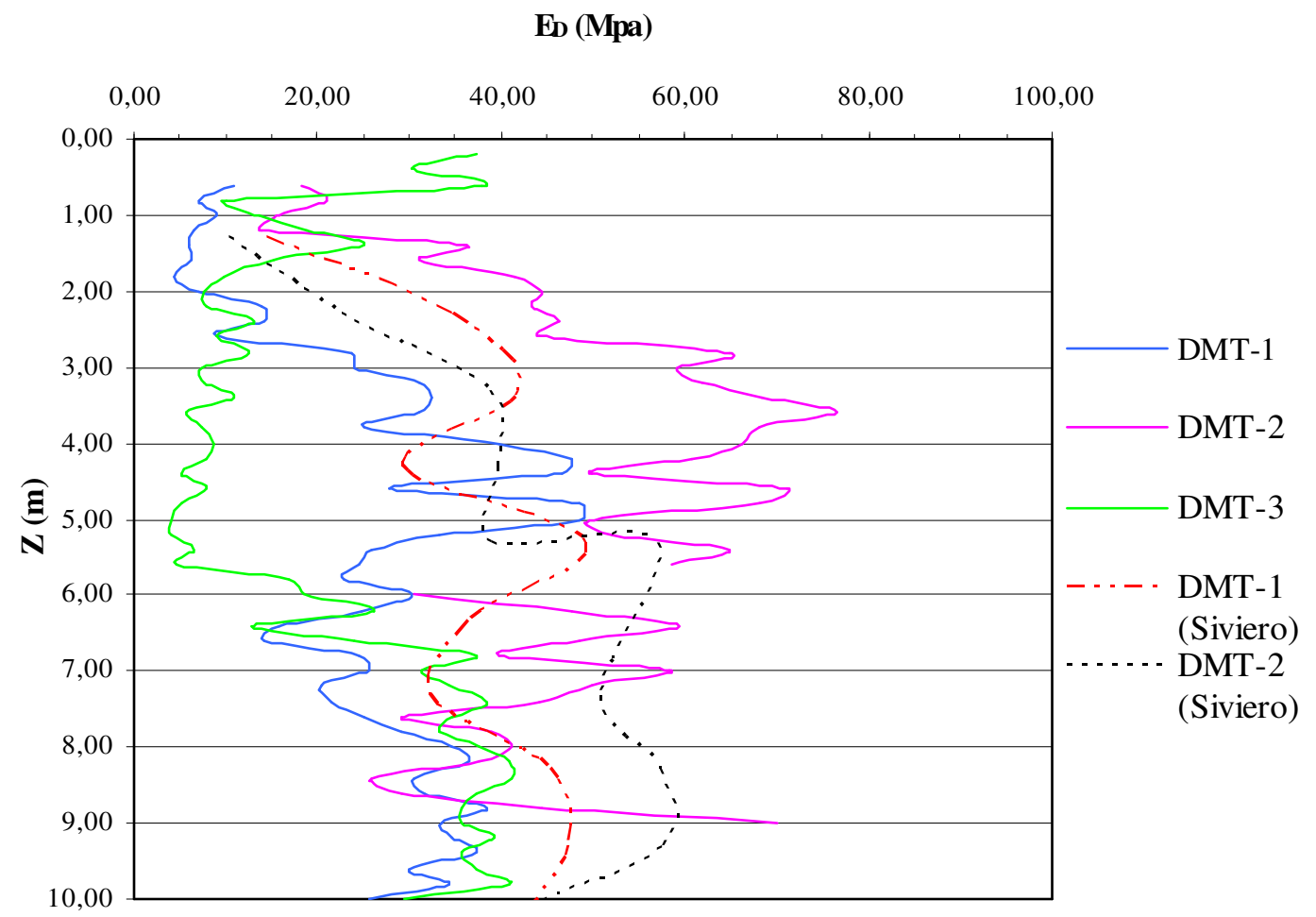

Figura $5.11-\mathrm{E}_{\mathrm{D}} \mathrm{x}$ Profundidade

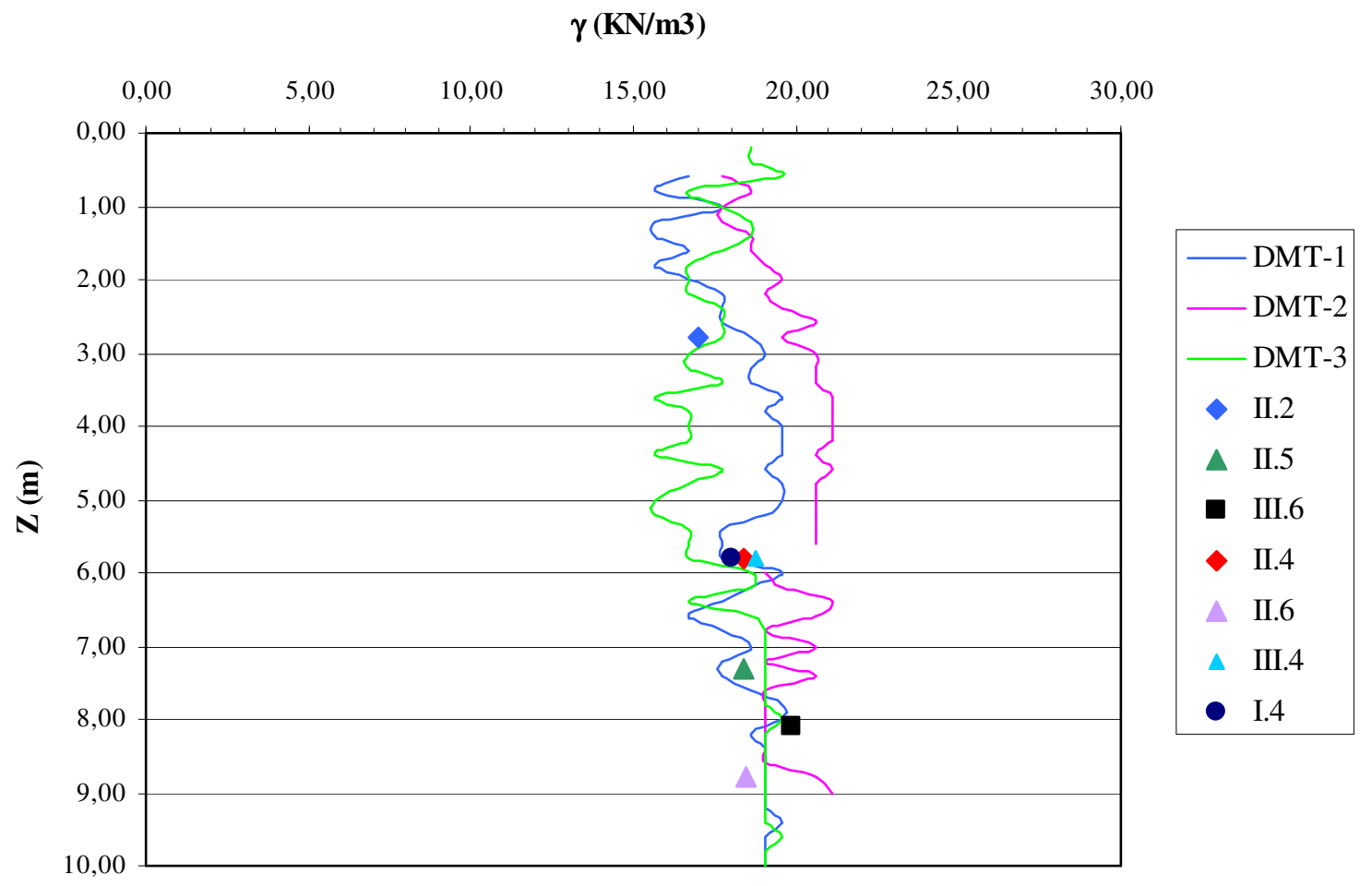

Figura $5.12-\gamma \times$ Profundidade

Na Figura 5.12, observa-se que os valores do peso específico natural obtidos pela ABEF (poços de exploração I, II e III) estão na mesma faixa de valores dos calculados através do ábaco proposto por Marchetti e Craps (1981) (Figura 3.11) para os DMT's. 
Os parâmetros geotécnicos são essenciais como entrada para os diversos cálculos de obtenção da capacidade de carga e recalque em estacas. Os resultados dos parâmetros que serão utilizados são apresentados nas Figuras 5.13 a 5.20.

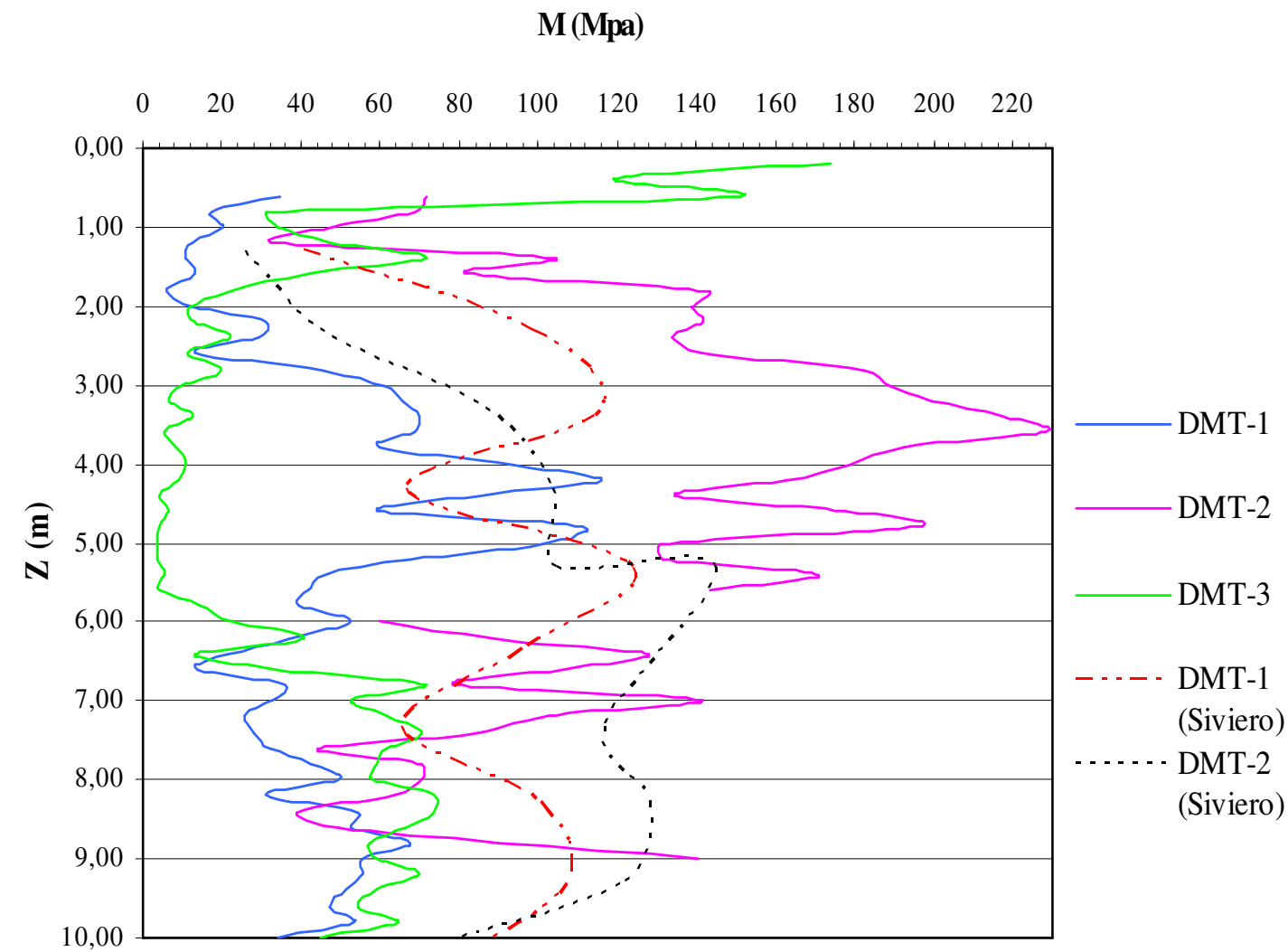

Figura 5.13 - Módulo Edométrico do DMT $\left(\mathrm{M}_{\mathrm{DMT}}\right)$ variando com a profundidade, calculado segundo Marchetti (1980), Eq. 3.39 e Tabela 3.5.

Foi aplicada, para os solos do CEUSP, para a determinação do módulo de deformação cisalhante $\left(\mathrm{G}_{0}\right)$, a proposta de Hryciw (1990), expressão 3.50, pois esta expressão, segundo o autor, pode ser empregada tanto para solos coesivos como para não coesivos. O uso desta expressão está representado graficamente na Figura 5.14. Vê-se que o $\mathrm{G}_{0}$ praticamente cresce linearmente com a profundidade (z), pelo menos abaixo dos 3 metros. 


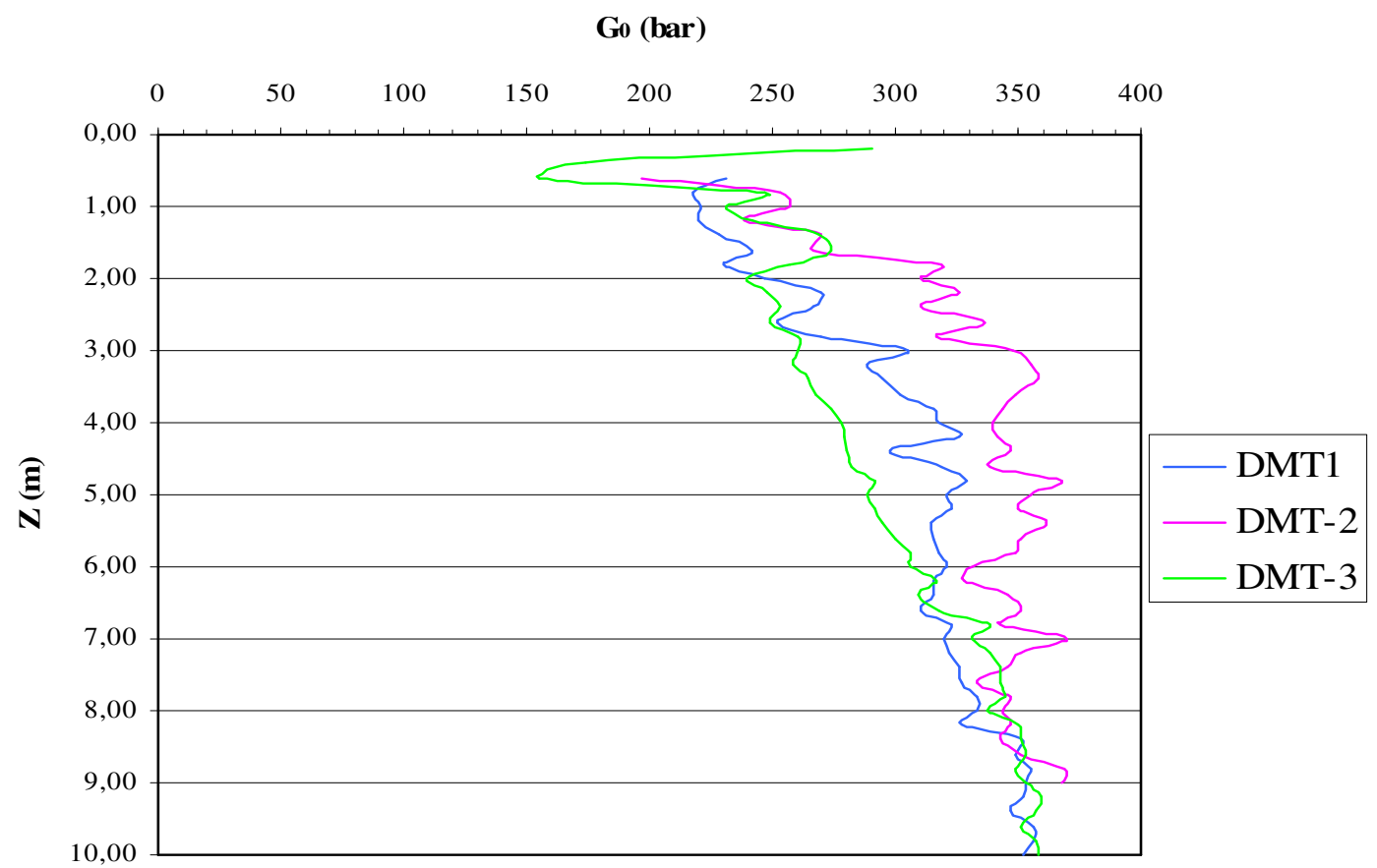

Figura 5.14 - Módulo de deformação cisalhante $\left(\mathrm{G}_{0}\right)$ proposta de Hryciw (1990) - Eq. 3.50.

Robertson et al. (1989) propôs que o módulo de Young (E) seja calculado pela expressão 3.42, isto é, $\mathrm{E}=\mathrm{F}$. $\mathrm{E}_{\mathrm{D}}$, onde $\mathrm{E}_{\mathrm{D}}$ é o módulo dilatométrico (apresentado na Figura 5.11). Na Tabela 3.6 é mostrada uma sugestão de valores para esta constante F, para o solo ensaiado no CEUSP, classificado como silte arenoso, adotou-se um valor intermediário entre areia e argila e tomou-se F=4. O módulo "E” assim calculado está indicado na Figura 5.15.

E do solo (KN/m2)

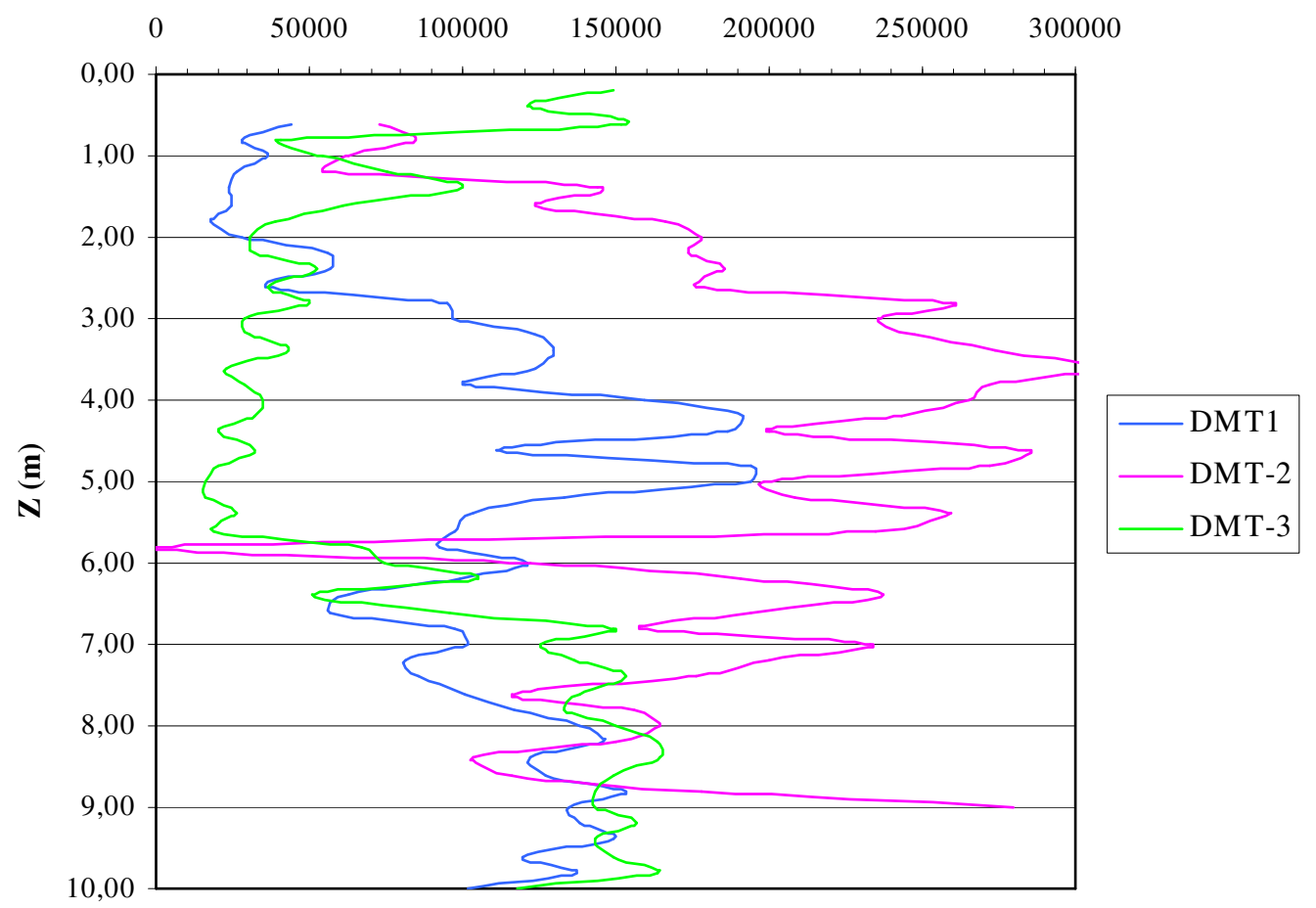

Figura 5.15 - Módulo de Young (E) variando com a profundidade, Robertson et al. (1989). 
Marchetti (1997) sugere que o módulo de elasticidade seja obtido a partir do módulo edométrico, conforme a expressão 3.43 ( $\mathrm{E}=0,8 \mathrm{M}_{\mathrm{DMT}}$ ). A Figura 5.13 mostra que o " $\mathrm{M}_{\mathrm{DMT}}$ " varia erraticamente com a profundidade. O uso desta expressão é apresentado na Figura 5.16.

\section{E do solo $(\mathrm{KN} / \mathrm{m} 2)$}

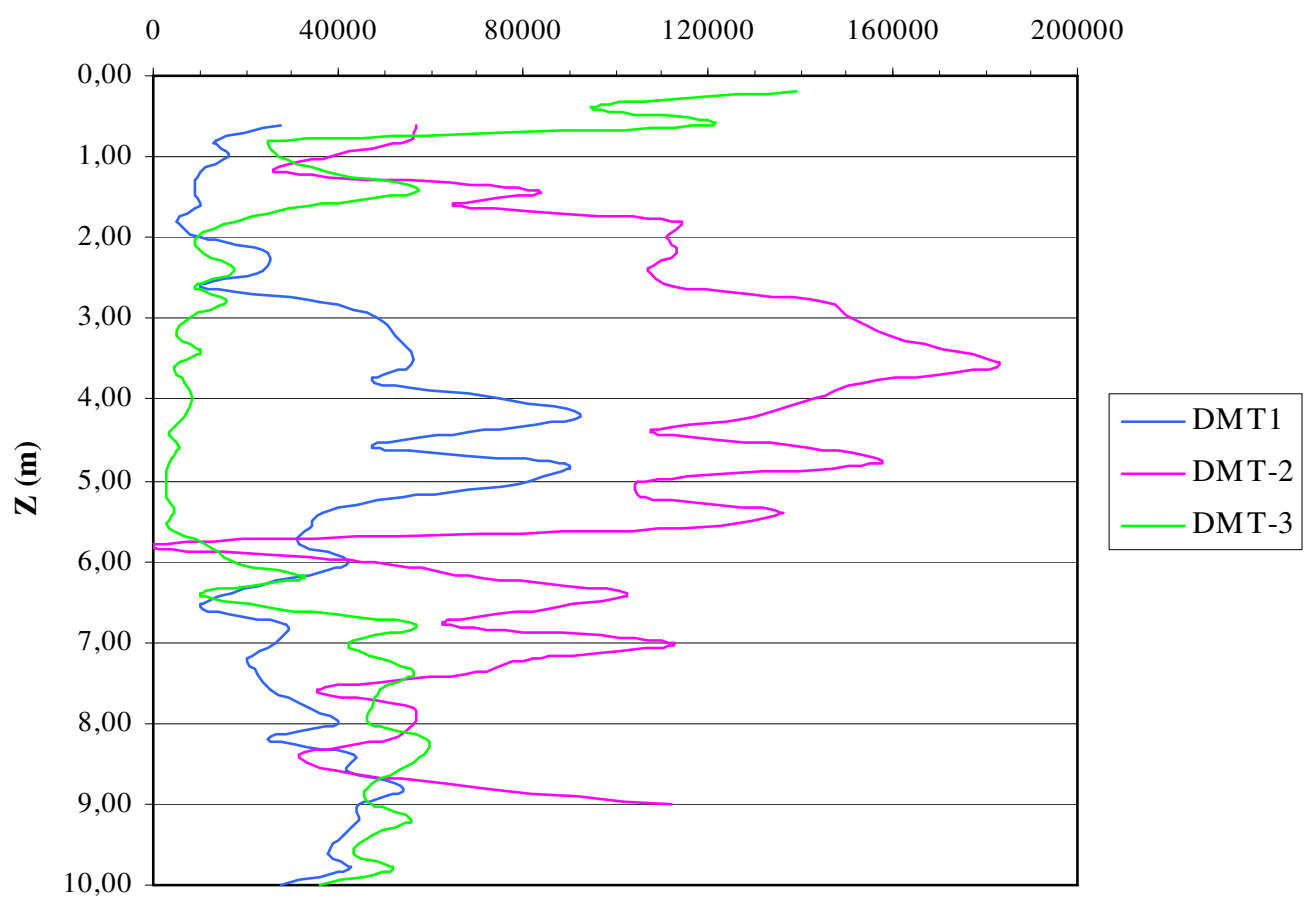

Figura 5.16 - Módulo de Young (E) variando com a profundidade, Marchetti (1997).

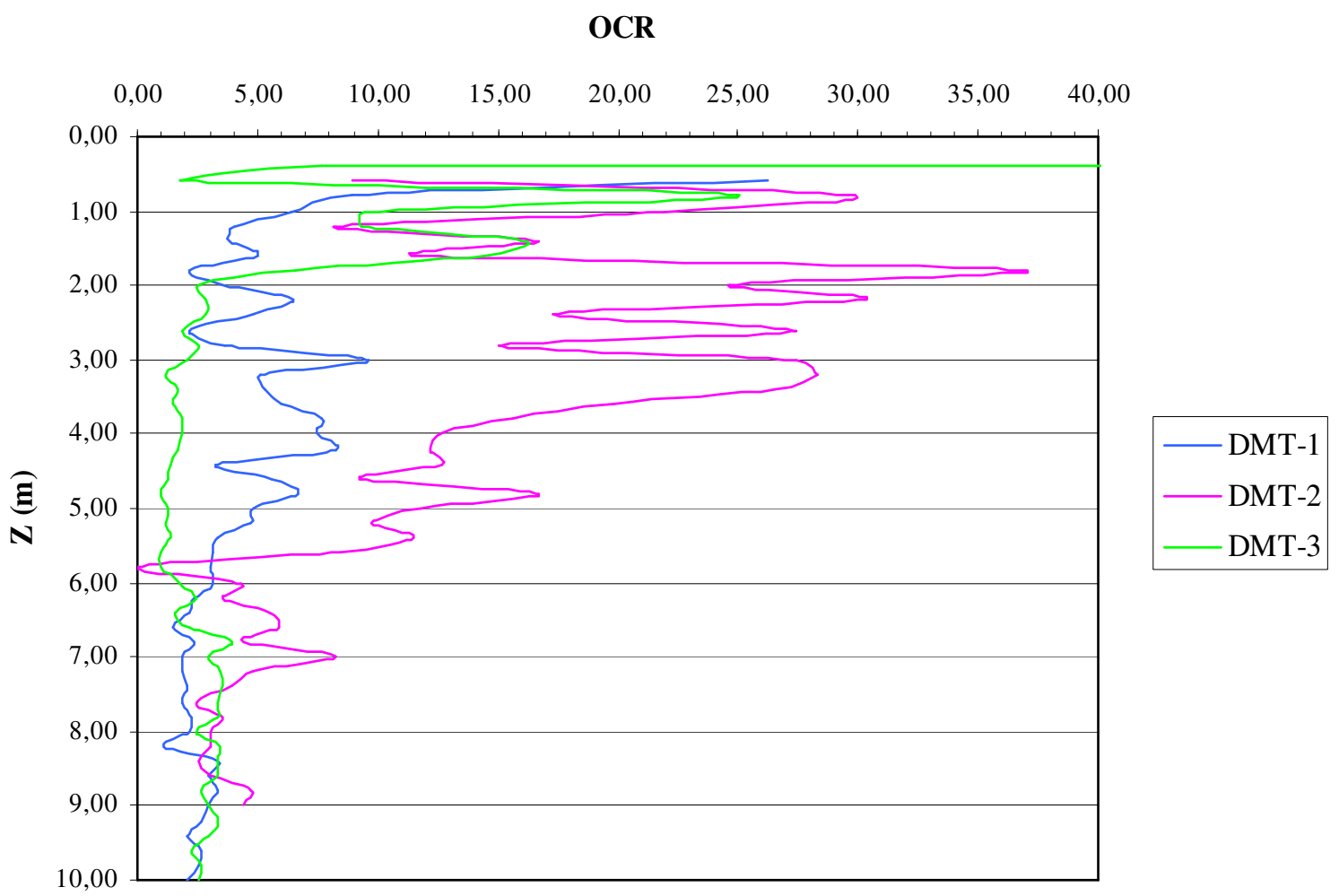

Figura 5.17 - Valores de OCR variando com a profundidade, Schmertmann (1988), Eq. 3.23 
A Figura 5.18 mostra valores de $\mathrm{K}_{0}$ para solos arenosos calculados pela proposta de Schmertmann (1983), equação 3.12, cuja aplicação requer o conhecimento dos valores de $\phi$ '(ângulo de atrito efetivo do solo), determinados com base na expressão 3.37, proposta por Marchetti (1997) e apresentadas na Figura 5.20.

Como na publicação da $\mathrm{ABEF}$ (1989) não foram apresentados valores de $\mathrm{K}_{0}$, foram feitos cálculos empregando a fórmula de Jaky modificada, que leva em conta a razão de sobre-adensamento do solo.

$\mathrm{K}_{0}=\left(1-\operatorname{sen} \phi^{\prime}\right) \cdot(\mathrm{RSA})^{\mathrm{sen} \phi^{\prime}}$

Os valores de $\phi$ ’ foram obtidos traçando as envoltórias de Mohr-Coulomb de ensaios CD (adensado e drenado), para baixos níveis de tensão. Os valores de $\mathrm{K}_{0}$ assim obtidos estão também indicados na Figura 5.18, mostrando boa concordância com os obtidos através dos DMT's.

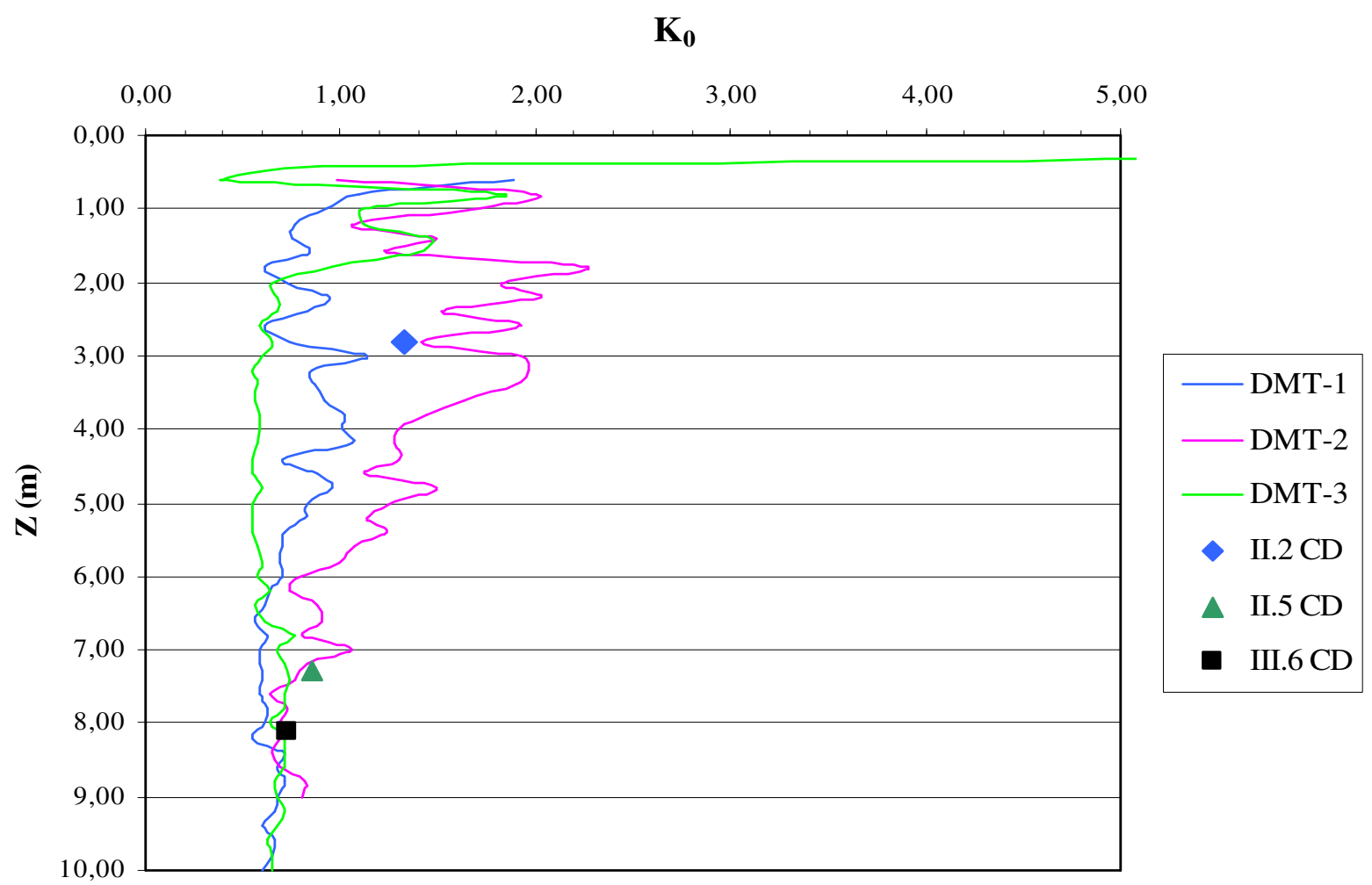

Figura 5.18 - Valores de $\mathrm{K}_{0}$ variando com a profundidade, Schmertmann (1983). 


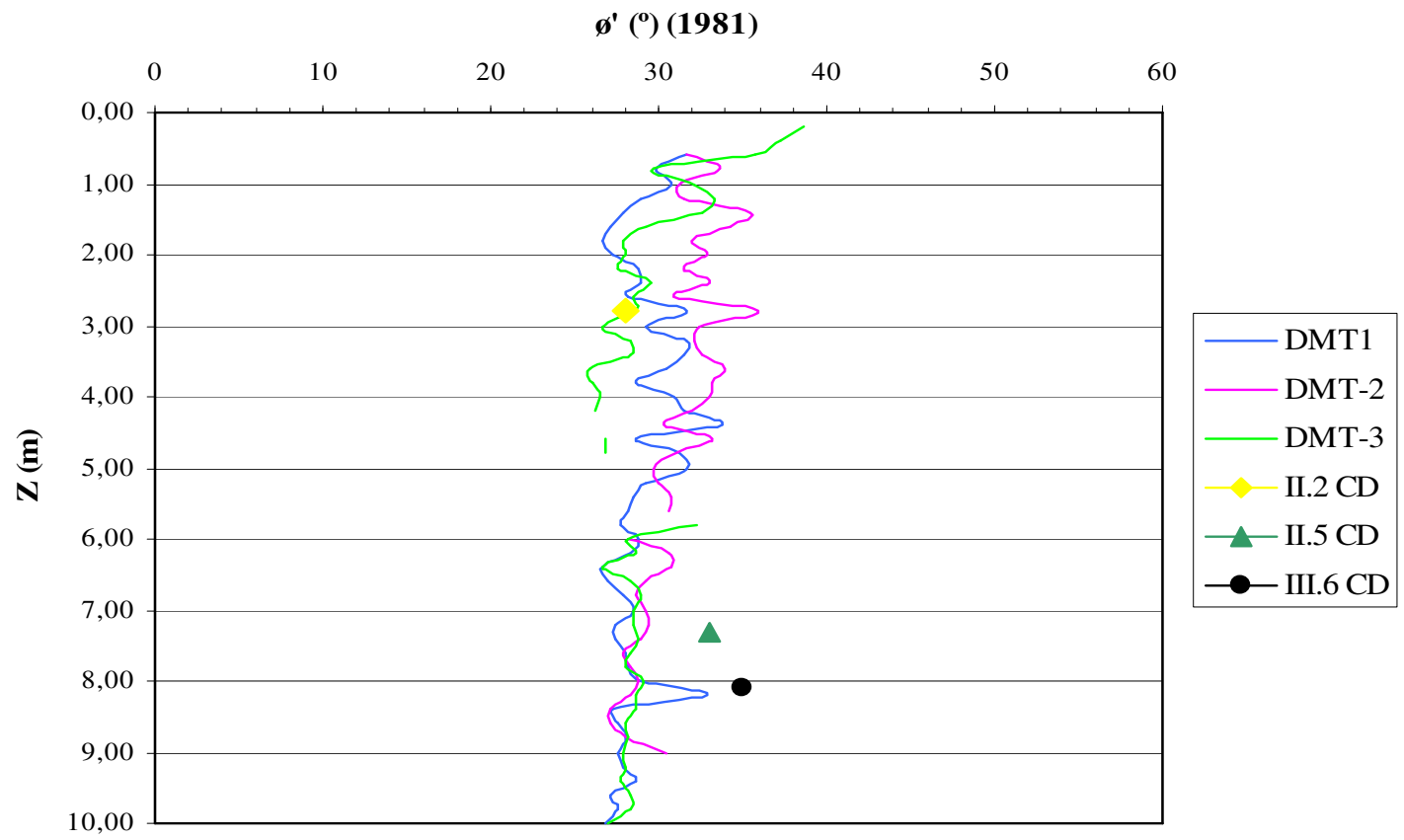

Figura 5.19 - Comparação da estimativa do ângulo de atrito através dos ensaios de DMT por Marchetti e Crapps (1981), eq. 3.33. e os ensaios de laboratório.

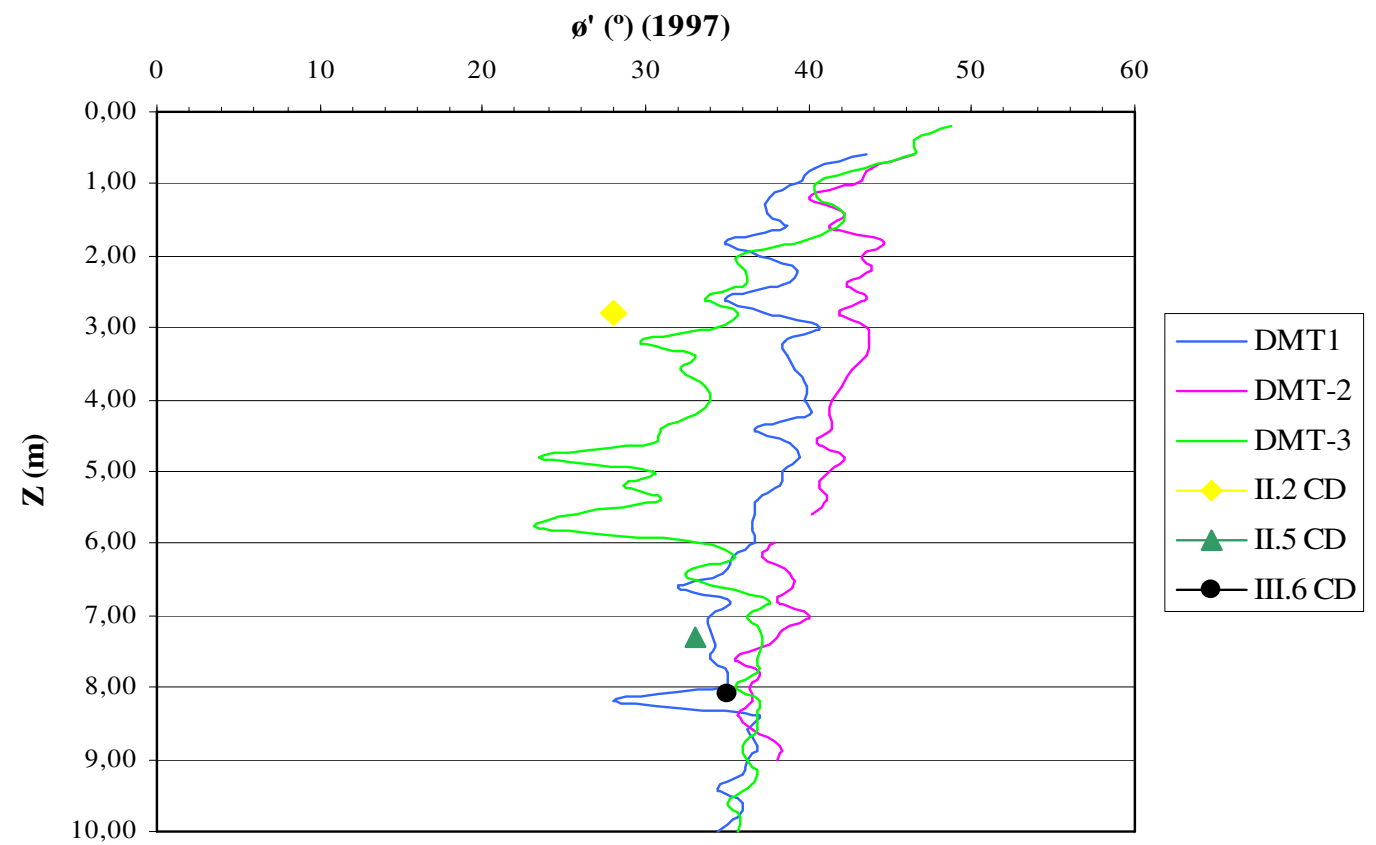

Figura 5.20 - Comparação da estimativa do ângulo de atrito através dos ensaios de DMT por Marchetti (1997), eq. 3.37 e os ensaios de laboratório.

Enquanto os parâmetros elásticos oscilaram muito, face à heterogeneidade dos solos, o ângulo de atrito efetivo ( $\phi$ ') praticamente variou pouco.

Para o propósito deste trabalho, adotou-se, para $\phi$, os valores indicados na Figura 5.20, por ser a proposta mais recente de Marchetti e por ter apresentado resultados mais 
próximos dos valores inferidos de ensaios de laboratório. Convém observar que esta proposta depende do índice de tensão horizontal $\mathrm{K}_{\mathrm{D}}$, cuja dispersão bastante grande, é atenuada pelos logaritmos da expressão 3.37. Em conseqüência, a dispersão em $\phi ’$ é bem menor.

\subsection{Análise das provas de carga publicadas pela ABEF em comparação com os resultados dos DMT's.}

\subsubsection{Tipos de fundação e Provas de Cargas executadas no Campo Experimental da USP}

Executaram-se vários tipos de fundação profunda no Campo Experimental, as mais comumente executadas em solos brasileiros. As estacas executadas foram do tipo: Estacão, Hélice, Franki, Barrete, Pré-moldada de concreto, Micro estaca, Metálica, Strauss e posteriormente EPI (Estaca Piloto Instrumentada).

Foram realizadas provas de carga nestas estacas e algumas foram também instrumentadas ao longo da profundidade, obtendo-se a transferência de carga ao terreno. As provas de carga foram do tipo lenta (SML) e rápida (QML), de acordo com a norma vigente da época.

Na Tabela 5.1 apresenta-se um resumo das características das estacas, bem como alguns dos resultados das provas de carga.

Tabela 5.1 - Resumo das características das estacas e dos resultados de prova de carga de acordo com Alonso, 1991 e Souza, 2001.

\begin{tabular}{|c|c|c|c|c|c|c|c|c|}
\hline \multirow[b]{2}{*}{ EST } & \multirow[b]{2}{*}{ TIPO } & \multirow[b]{2}{*}{$\mathrm{D}(\mathrm{cm})$} & \multirow{2}{*}{$\begin{array}{l}\text { Comp. } \\
\text { Cravado } \\
\text { (m) }\end{array}$} & \multirow{2}{*}{$\begin{array}{c}\text { Carga de } \\
\text { trabalho } \\
(\mathrm{KN})\end{array}$} & \multicolumn{2}{|c|}{ Ensaio Lento } & \multicolumn{2}{|c|}{ Ensaio Rápido } \\
\hline & & & & & $\begin{array}{l}\text { Carga máx. } \\
(\mathrm{KN})\end{array}$ & $\begin{array}{c}\text { Recalque } \\
(\mathrm{mm})\end{array}$ & $\begin{array}{c}\text { Carga máx. } \\
(\mathrm{KN})\end{array}$ & $\begin{array}{l}\text { Recalque } \\
\text { (mm) }\end{array}$ \\
\hline HLC-4 & hélice & 35 & 7,50 & 400 & 480 & 14,39 & 640 & 62,19 \\
\hline HLC-6 & hélice & 42,5 & 7,50 & 450 & 720 & 26,76 & 820 & 41,66 \\
\hline FRA-1 & franki & 40 & 5,00 & - & 1990 & 10,75 & - & - \\
\hline FRA-2 & franki & 40 & 5,00 & - & 1200 & 3,82 & 1240 & 44,77 \\
\hline EST-2 & estacão & 70 & 7,50 & 1600 & 980 & 88,21 & 2240 & 266,29 \\
\hline BAR-1 & barrete & $165 \times 40$ & 7,50 & 2400 & 3000 & 64,54 & 5000 & 173,23 \\
\hline PRÉ-2 & $\begin{array}{c}\text { pré- } \\
\text { moldada }\end{array}$ & $50(e) 32(i)$ & 9,03 & 1300 & 1500 & 1,99 & 3200 & 65,88 \\
\hline PRÉ-4 & $\begin{array}{c}\text { pré- } \\
\text { moldada }\end{array}$ & $50(e) 32(i)$ & 7,50 & 1300 & 2100 & - & 3300 & 14,89 \\
\hline M-4 & $\begin{array}{l}\text { micro- } \\
\text { estaca }\end{array}$ & 12,7 & 7,00 & 500 & 750 & 7,09 & 700 & 9,88 \\
\hline MET-1 & metálica & I 10" & 6,00 & 400 & 270 & 34,16 & 270 & 78,65 \\
\hline STR-1 & strauss & 32 & 7,50 & 400 & 640 & 24,62 & 900 & 62,36 \\
\hline EPI-1 & piloto & 8,89 & 4,20 & - & - & - & 68,1 & 40 \\
\hline EPI-2 & piloto & 8,89 & 4,20 & - & - & - & 66,4 & 41 \\
\hline EPI-3 & piloto & 32 & 6,98 & - & - & - & 129,1 & 42 \\
\hline
\end{tabular}


De posse dos resultados da Tabela 5.1 e de cálculos baseados nos resultados de DMT, serão apresentados gráficos comparativos de "previsto x medido", para cada método de cálculo que foi objeto da revisão bibliográfica.

\subsubsection{Análise comparativa da capacidade de carga em estacas}

Foram feitos cálculos de capacidade de carga das estacas apresentadas na Tabela 5.1 pelos seguintes métodos que de alguma forma requerem parâmetros passíveis de determinação pelo DMT:

- Powell et al (2001);

- Método $\beta$ (parcela do atrito lateral) combinado com Método de Terzaghi (parcela de ponta);

- Método $\beta$ (parcela do atrito lateral) combinado com Método de Berezantzev (parcela de ponta); e - Método $\beta$ (parcela do atrito lateral) combinado com Método de Vesic (parcela de ponta);

Não se empregou o método de Meyerhof para estimar a parcela de ponta por ter se mostrado inadequado, ficando com valores muito altos da parcela da ponta, tornando-se impossível apresentar os valores em forma de gráfico. Por este motivo não serão apresentados os resultados de aplicação deste método. À mesma conclusão chegou Jardim (1998) ao analisar estacas instaladas no Campo Experimental de Brasília.

Das propostas apresentadas na revisão bibliográfica para o cálculo da parcela de atrito lateral, foi testado o método das tensões efetivas " $\beta$ ". A escolha se deu porque o solo do CEUSP foi classificado por silte arenoso, que possibilitou a estimativa do ângulo de atrito efetivo do solo $(\phi$ '), o que tornou o método " $\beta$ ” ideal para a análise. Os métodos “ $\alpha$ ” " “ $\lambda$ “ são adequados para solos argilosos e utilizam, na sua formulação, a resistência não drenada (su), razão pela qual não foram empregados nesta pesquisa.

As estacas analisadas foram agrupadas em função do DMT mais próximo, como mostra a Tabela 5.2.

Tabela 5.2 - Agrupamento de estacas segundo proximidade aos ensaios de DMT

\begin{tabular}{|c|c|c|}
\hline \multirow{2}{*}{ ENSAIO } & $\begin{array}{c}\text { ESTACAS } \\
\text { PRÓXIMAS }\end{array}$ & TIPO DA ESTACA \\
\hline DMT-1 & EPI-1, EPI-2 e EPI-3 & PILOTO INSTUMENTADA \\
\hline \multirow{4}{*}{ DMT-2 } & EST-2 & ESCAVADA COM LAMA \\
\cline { 2 - 3 } & PRE-4 & PRÉ-MOLDADA \\
\cline { 2 - 3 } & M-4 & MICRO-ESTACA \\
\cline { 2 - 3 } & BAR-1 & BARRETE \\
\hline \multirow{3}{*}{ DMT-3 } & PRE-4 e HLC-6 & HÉLICE CONTÍNUA \\
\cline { 2 - 3 } & MET-1 & PRÉ-MOLDADA \\
\hline \multirow{2}{*}{ MÉDIA } & STR-1 & METÁLICA \\
\cline { 2 - 3 } & FRA-1 e FRA-2 & FRANKI \\
\hline
\end{tabular}




\subsubsection{Método de Powell et al}

O primeiro método utilizado foi o proposto por Powell et al (2001), apresentado em detalhes na revisão bibliográfica. Apesar de ter sido concebido para estacas pré-moldadas, cravadas em solo argiloso, resolveu-se testá-lo para o solo siltoso do CEUSP, inclusive para estacas escavadas, por ser um método empírico. É mostrada, na Figura 5.21, a carga de ruptura medida comparada com a carga de ruptura calculada pelos DMT's.

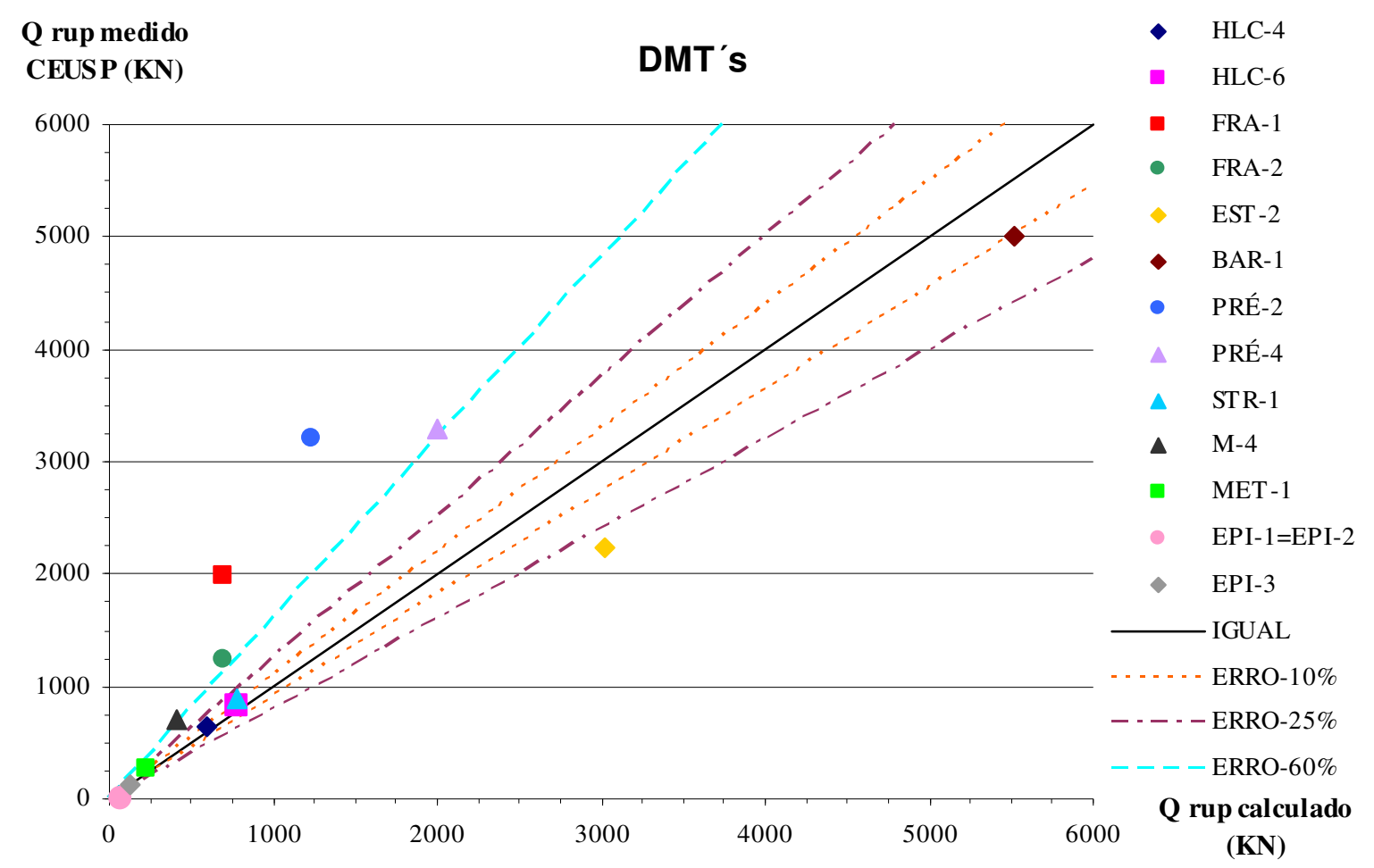

Figura 5.21 - Carga de ruptura medida versus calculada utilizando oS DMT's (Powell et al).

Analisando a Figura 5.21 conclui-se que:

a) as estacas HLC-4, HLC-6, MET-1, STR-1, EPI-1, EPI-2 e EPI-3 apresentaram uma concordância muito boa entre valores calculados pelo método de Powell et al e os medidos nas provas de carga;

b) a estaca BAR-1 mostrou concordância satisfatória; e

c) as estacas FRA-1, FRA-2, EST-2, M-4, PRE-2 e PRE-4 apresentaram desvios acima de $40 \%$.

É interessante constatar que as estacas PRE-2 e PRE-4, embora sejam estacas pré- 
moldadas, e portanto cravadas, situaram-se entre as que apresentaram maiores desvios.

A Figura 5.22 mostra como a resistência de ponta, calculada pelo Método de Powell et al (2001), varia com a profundidade. Na mesma figura estão indicados os valores medidos nas estacas instrumentadas. Vê-se que o Método de Powell subestimou a resistência de ponta das estacas instrumentadas do CEUSP, inclusive das estacas piloto instrumentada (Souza, 2001), com exceção das estacas "tipo hélice contínua” (HLC-4 e HLC-6).

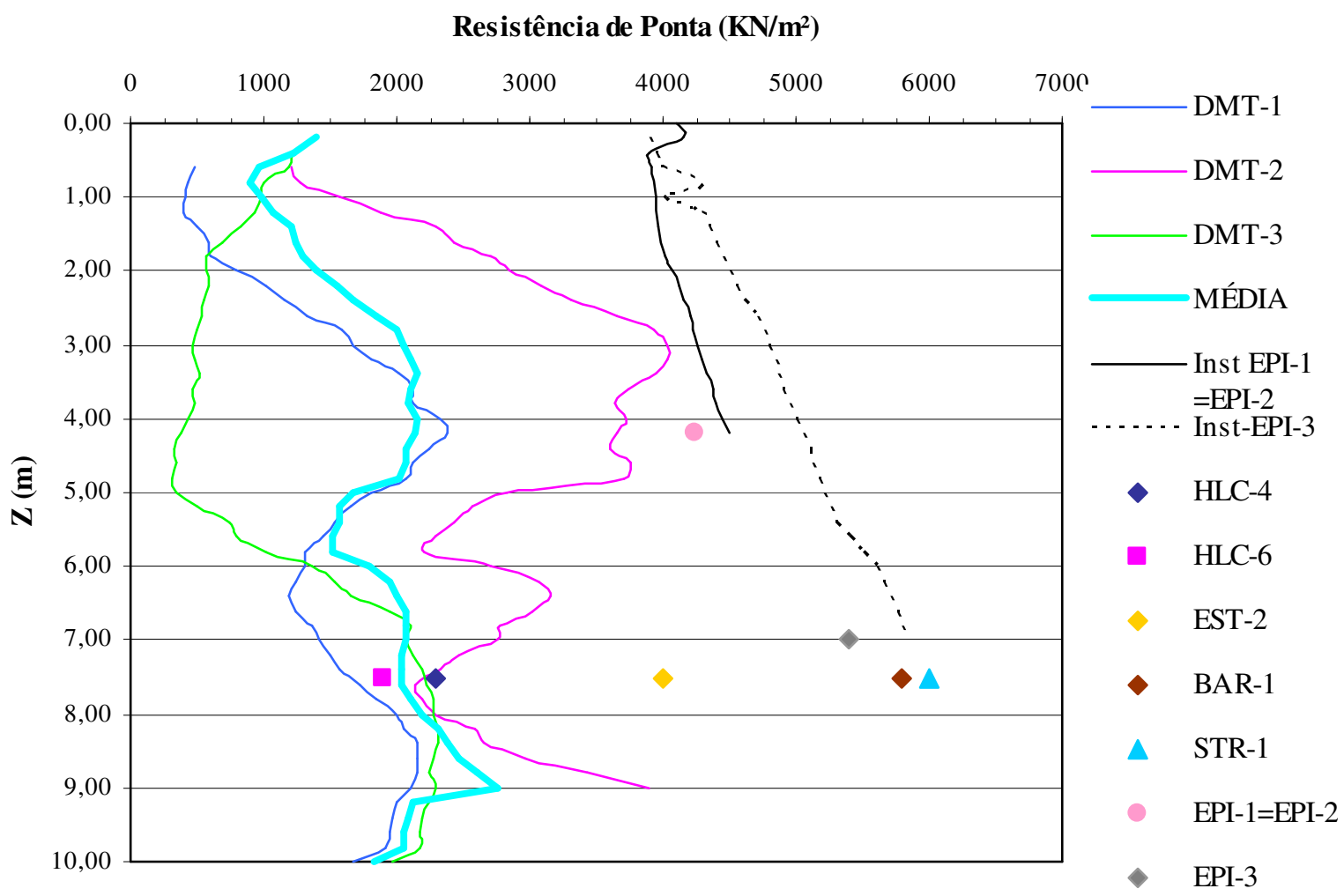

Figura 5.22 - Comparação entre a resistência de ponta calculada ao longo da profundidade e resistência de ponta medida (Powell et al, 2001).

Com relação ao atrito unitário médio das estacas, pode-se observar na Figura 5.23 que os resultados obtidos através do método de Powell et al (2001) se mostraram muito semelhantes aos resultados encontrados nas provas de carga das estacas HLC-4, HLC-6 (DMT-3) e STR-1 (Média). A exceção ficou por conta do DMT-2, em que houve uma discrepância considerável com relação às estacas BAR-1 e EST-2, possivelmente porque o solo é muito heterogêneo. Nesta mesma figura pode-se comparar as instalações e as provas de carga das estacas piloto instrumentadas (EPI-1, EPI-2 e EPI-3) com o DMT-1, que é o furo mais próximo, e seus resultados tiveram uma boa concordância. Mais uma vez fica evidente a heterogeneidade do solo do CEUSP e a importância de se executar mais de um ensaio. 


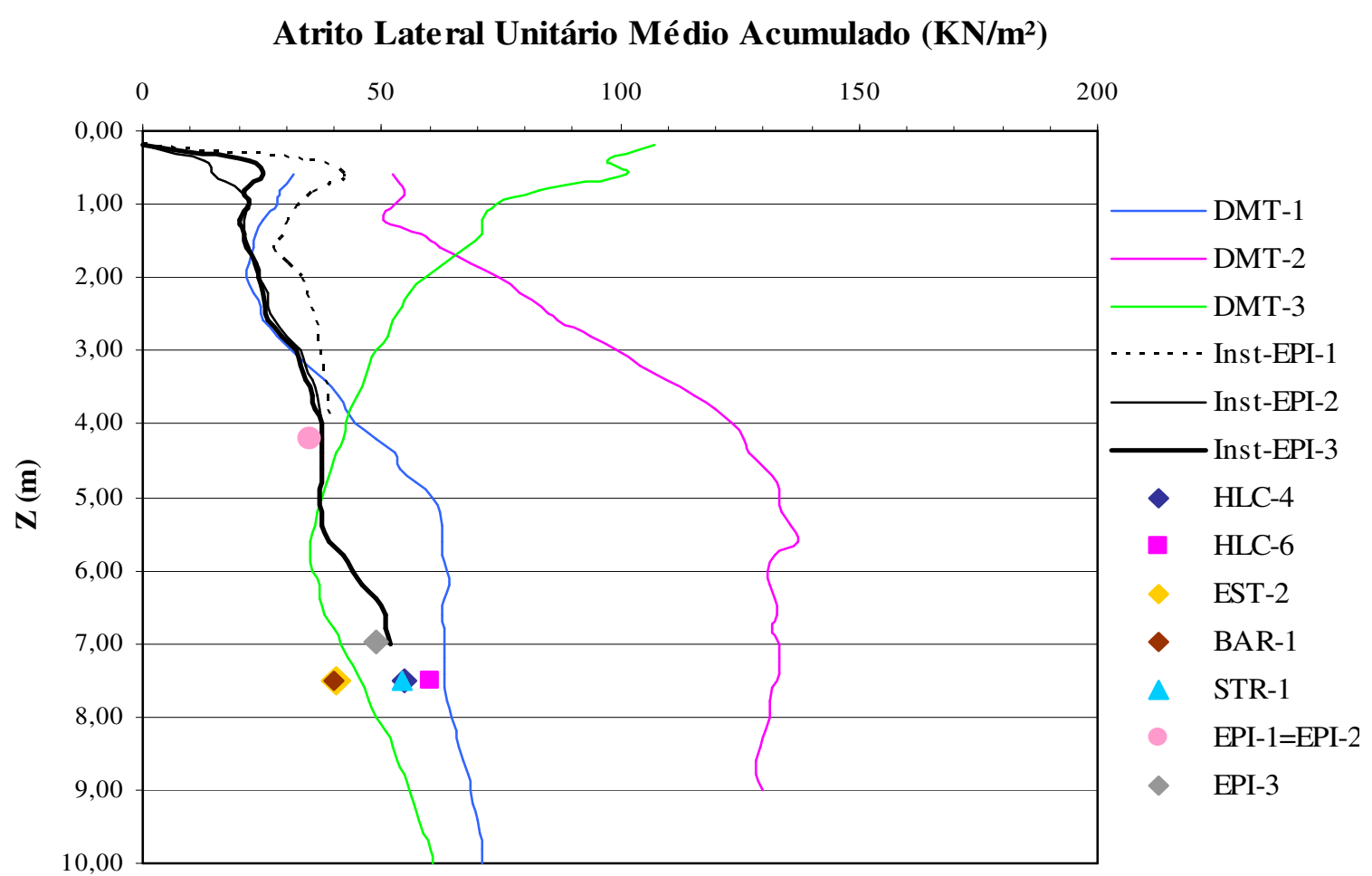

Figura 5.23-Comparação entre atrito lateral unitário médio calculado e medido (Powell et al)

\subsubsection{Combinação da resistência de atrito lateral (método $\beta$ ) e de ponta (Terzaghi)}

As combinações de parcela de atrito lateral (método “ $\beta$ ”) somadas com a resistência de ponta de Terzaghi são apresentadas na Figura 5.24.

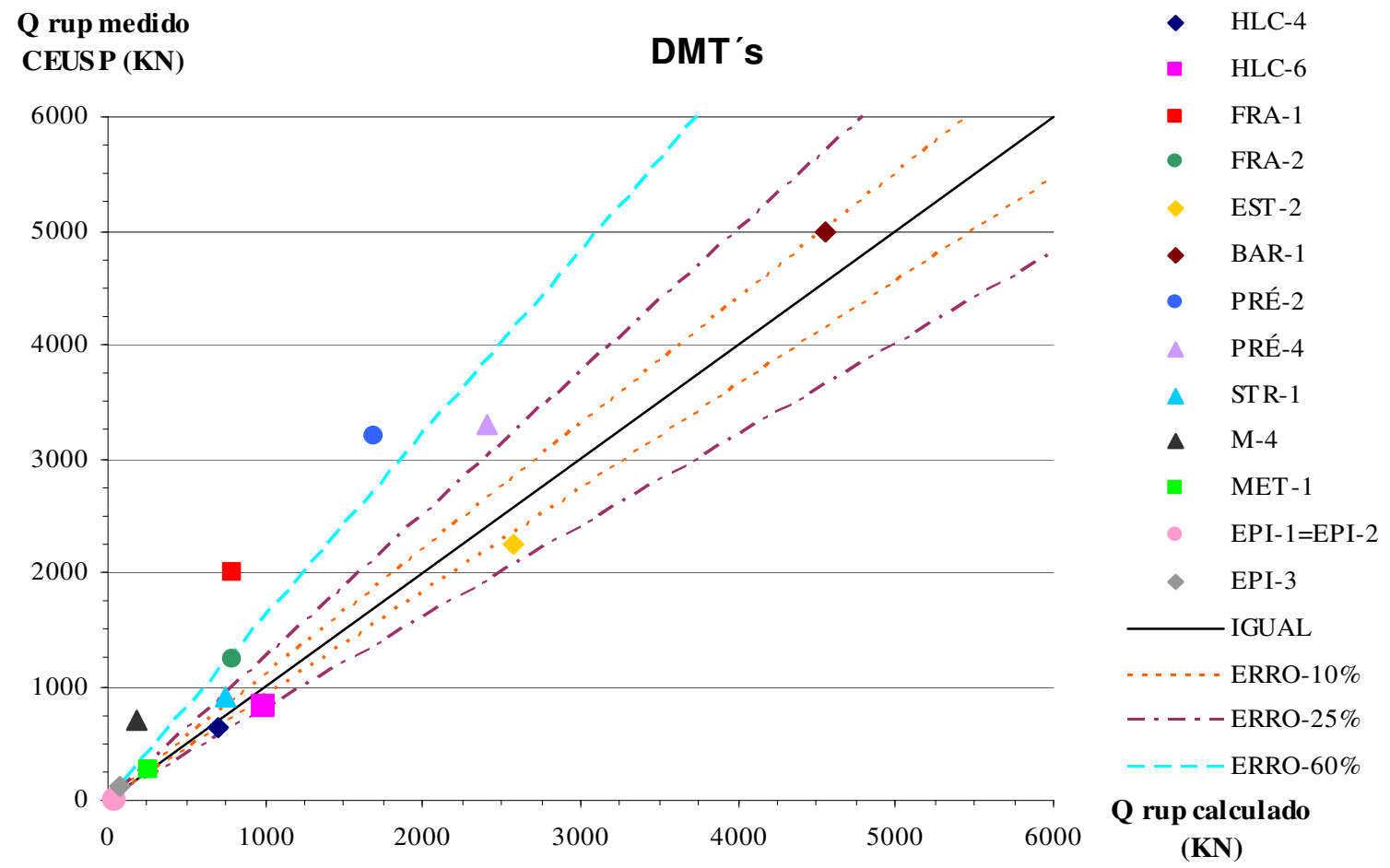

Figura 5.24 - Carga de ruptura medida versus calculada ( " $\beta$ " + Terzaghi, 1943). 
Da análise da Figura 5.24 pode se concluir que:

a) as estacas HLC-4, HLC-6, BAR-1 e MET-1 apresentaram uma concordância muito boa entre valores calculados pelo método $\beta$ (parcela do atrito lateral), combinado com método de Terzaghi (parcela de ponta), e os medidos nas provas de carga;

b) as estacas STR-1, EPI-1, EPI-2, PRE-4 e EST-2 mostraram concordâncias satisfatórias; e

c) as estacas EPI-3, FRA-1, FRA-2, M-4 e PRE-2 apresentaram desvios acima de $35 \%$.

\subsubsection{Combinação da resistência de atrito lateral (método ß) e ponta (Berezantzev 1961)}

As combinações da parcela de atrito lateral (método" $\beta ")$ somada com a resistência de ponta de Berezantzev (1961) são apresentadas na Figura 5.25.
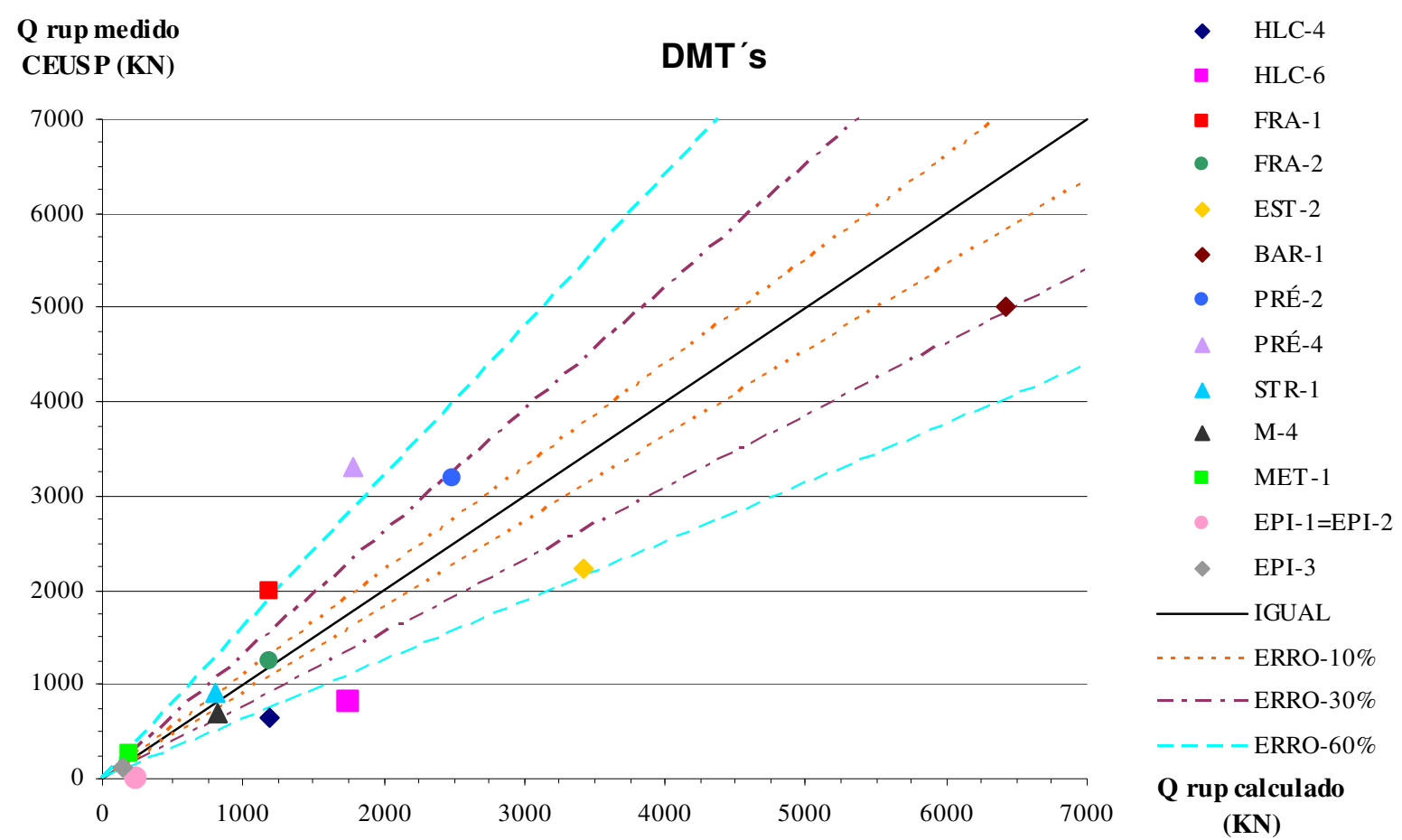

Figura 5.25 - Carga de ruptura medida versus calculada utilizando a média dos DMT's (Método das Tensões Efetivas “ $\beta$ ” + Critério de Ponta por Berezantzev, 1961).

Pode-se concluir da Figura 5.25 que:

a) as estacas EPI-3, FRA-2 e STR-1 apresentaram uma concordância muito boa entre valores calculados pelo método $\beta$ (parcela do atrito lateral), combinado com método de Berezantzev (parcela de ponta), e os medidos nas provas de carga; 
b) as estacas BAR-1, PRE-2, M-4 e MET-1 mostraram concordâncias satisfatórias; e

c) as estacas FRA-1, HLC-4, HLC-6, EPI-1, EPI-2, PRE-4 e EST-2, apresentaram desvios acima de $40 \%$.

\subsubsection{Combinação da resistência de atrito lateral (método ß) e de ponta (Vesic, 1975)}

Os resultados da aplicação do método " $\beta$ " somados com a resistência de ponta de Vesic (1975) estão apresentados na Figura 5.26.
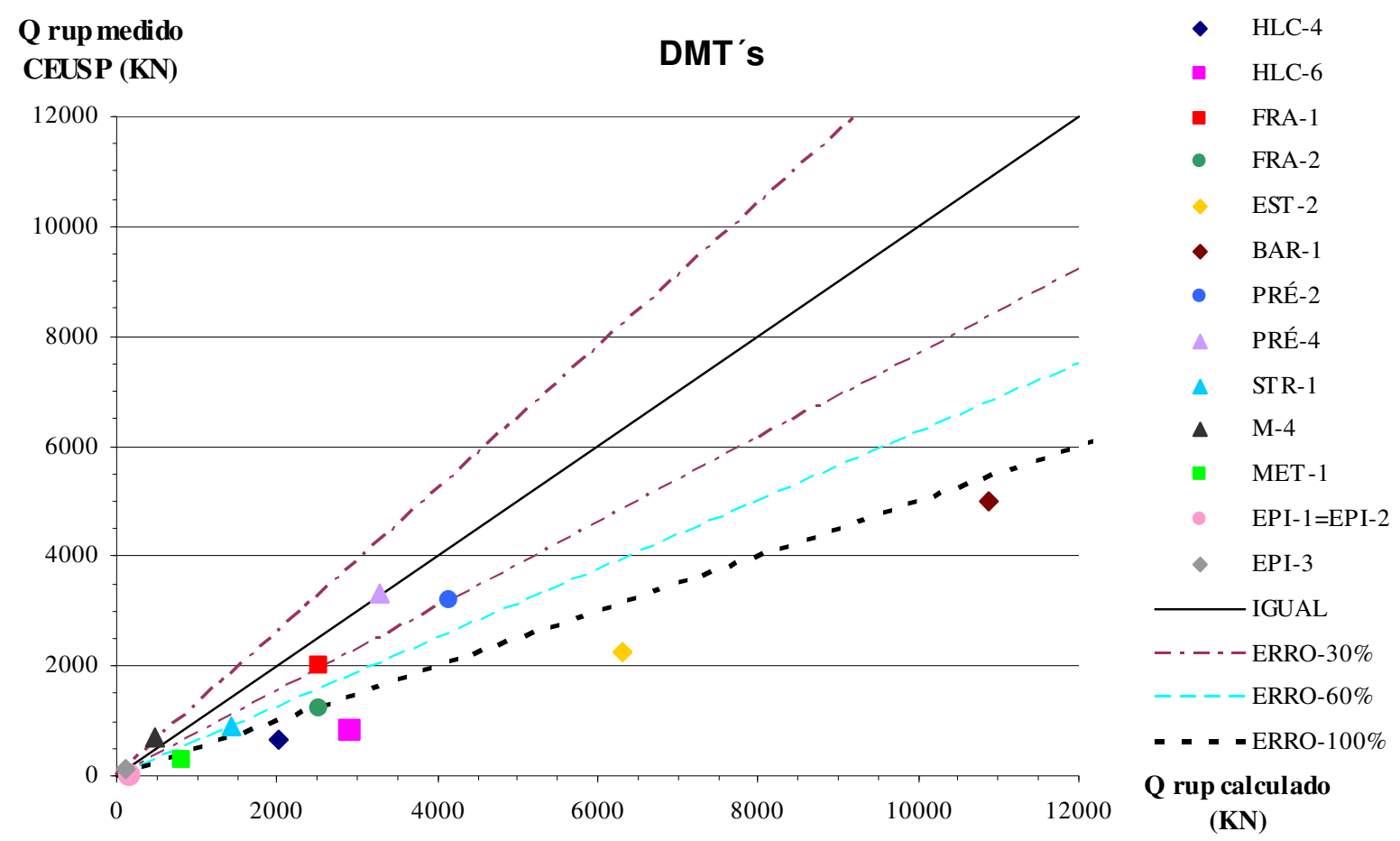

Figura 5.26 - Carga de ruptura medida versus calculada utilizando o DMT-1 (Método das Tensões Efetivas “ $\beta$ ” + Critério de Ponta por Vesic, 1975).

Com a Figura 5.26 pode-se concluir que:

a) as estacas EPI-3 e PRE-4 apresentaram uma concordância muito boa entre valores calculados pelo método $\beta$ (parcela do atrito lateral), combinado com método de Vesic (parcela de ponta), e os medidos nas provas de carga;

b) as estacas FRA-1, PRE-2, M-4 mostraram concordâncias satisfatórias; e

c) as estacas FRA-2, BAR-1, MET-1, HLC-4, HLC-6, STR-1, EPI-1, EPI-2 e EST-2, apresentaram desvios acima de $60 \%$.

Esta última combinação não apresentou resultados tão bons quanto as combinações de " $\beta$ " com Terzaghi e " $\beta$ " com Berezantzev, pois superestimou em excesso as capacidades de carga na maior parte das estacas. 


\subsubsection{Análise das parcelas de atrito e ponta}

Nas análises anteriores para a estimativa da parcela de atrito lateral pelo Método proposto por Burland (1973) “ $\beta$ “ foi feita supondo solos normalmente adensados, apesar dos ensaios de DMT classificarem o solo do CEUSP como sobre-adensado. Isto porque, de acordo com Burland, o solo junto ao fuste sofre um amolgamento devido à instalação das estacas, perdendo o seu efeito de sobre-adensamento.

Se se quiser levar em conta este efeito, pode-se recorrer à seguinte expressão de Meyerhof (1976), para o cálculo do coeficiente de empuxo horizontal $\mathrm{K}_{\mathrm{s}}$ das expressões $4.6 \mathrm{e}$ 4.7:

$\mathrm{K}_{\mathrm{s}}=1,5 \cdot\left(1-\operatorname{sen} \phi^{\prime}\right) \cdot(\mathrm{RSA})^{\mathrm{sen} \phi^{\prime}}$

Na Figura 5.27 é apresentada a estimativa dos valores do atrito lateral unitário médio acumulados ao longo da profundidade (z), calculados pelo DMT, através das propostas de Burland (solo normalmente adensado) e Meyerhof (solo sobre-adensado), comparando-os com os medidos nas provas de carga instrumentadas em profundidade no CEUSP.

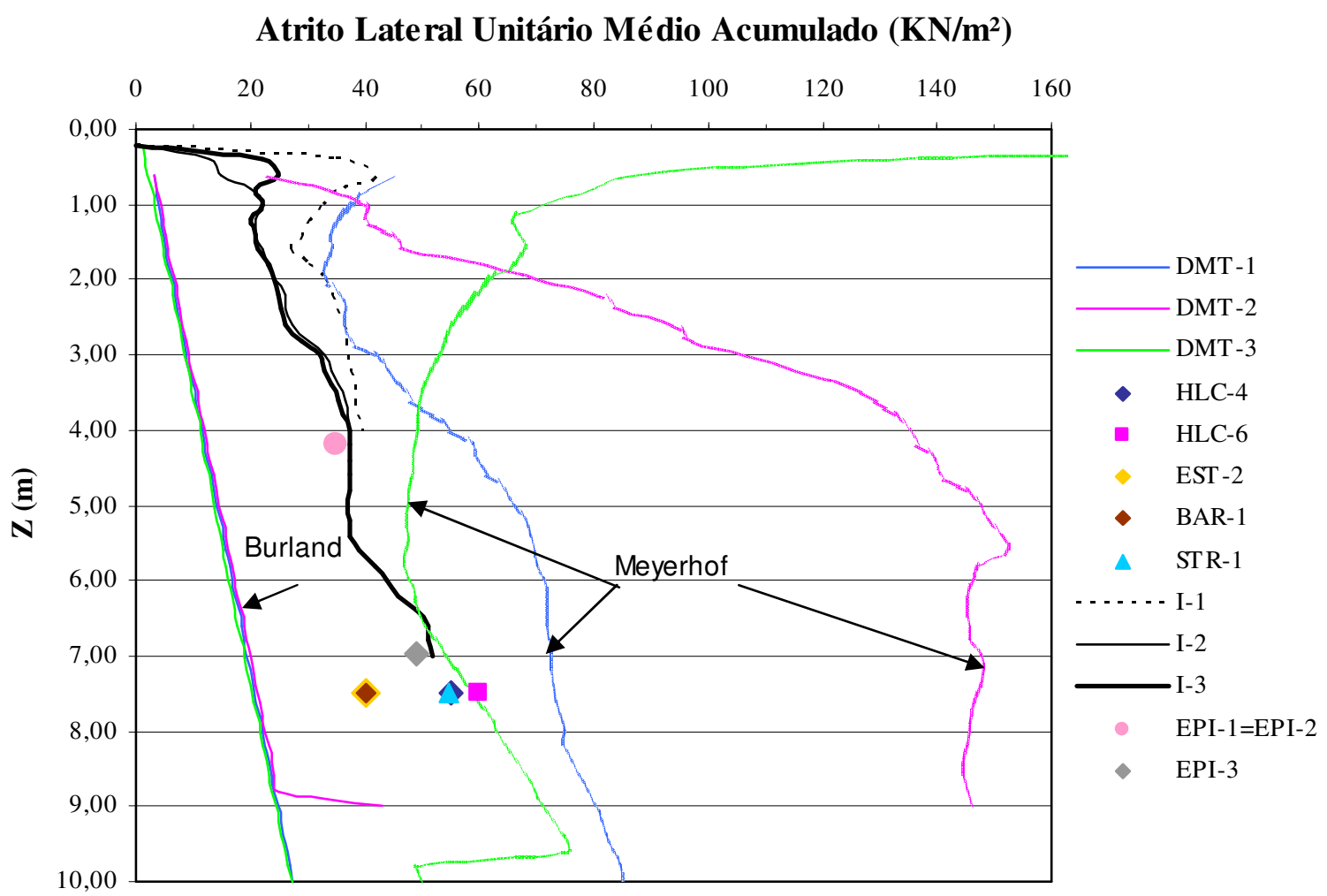

Figura 5.27 - Comparação entre atrito lateral unitário médio calculado e medido (Método $\beta$ ).

Observa-se que o método de tensões efetivas (" $\beta$ “), calculado pela proposta de Burland, que considera o solo normalmente adensado, subestimou o de atrito lateral unitário 
médio das estacas; já a proposta de Meyerhof, que considera o sobre-adensamento do solo, superestimou este atrito, com exceção das estacas HLC-4 e HLC-6 do grupo do DMT-3 (ver Tabela 5.2)

Da Figura 5.27 pode-se ainda concluir que os atritos laterais unitários médios, acumulados a longo da profundidade, calculados de acordo com a proposta de Burland (solo normalmente adensado), foram insensíveis à variabilidade do solo apresentadas pelos DMT's. Isto porque $\beta$ é pouco sensível as variações do ângulo de atrito efetivo do solo ( $\left.\phi^{\prime}\right)$. Tal fato pode ser exemplificado: tomando $\phi^{\prime}=25^{\circ}$ tem-se $\beta=0,27$ e, para $\phi^{\prime}=45^{\circ}, \beta=0,29$, de outra maneira, $\beta$ é praticamente constante, o que implica em atritos laterais linearmente crescentes com a profundidade. Mas a conclusão mais importante refere-se à grande distância entre os valores de atrito calculados pelo método de Burland (solo normalmente adensado) e os medidos em diversas provas de carga do CEUSP.

Na Figura 5.28 é apresentada a comparação entre a resistência de ponta calculada pelo método de Terzaghi (1943), utilizando os parâmetros do DMT, e a resistência de ponta medida nas referidas provas de carga.

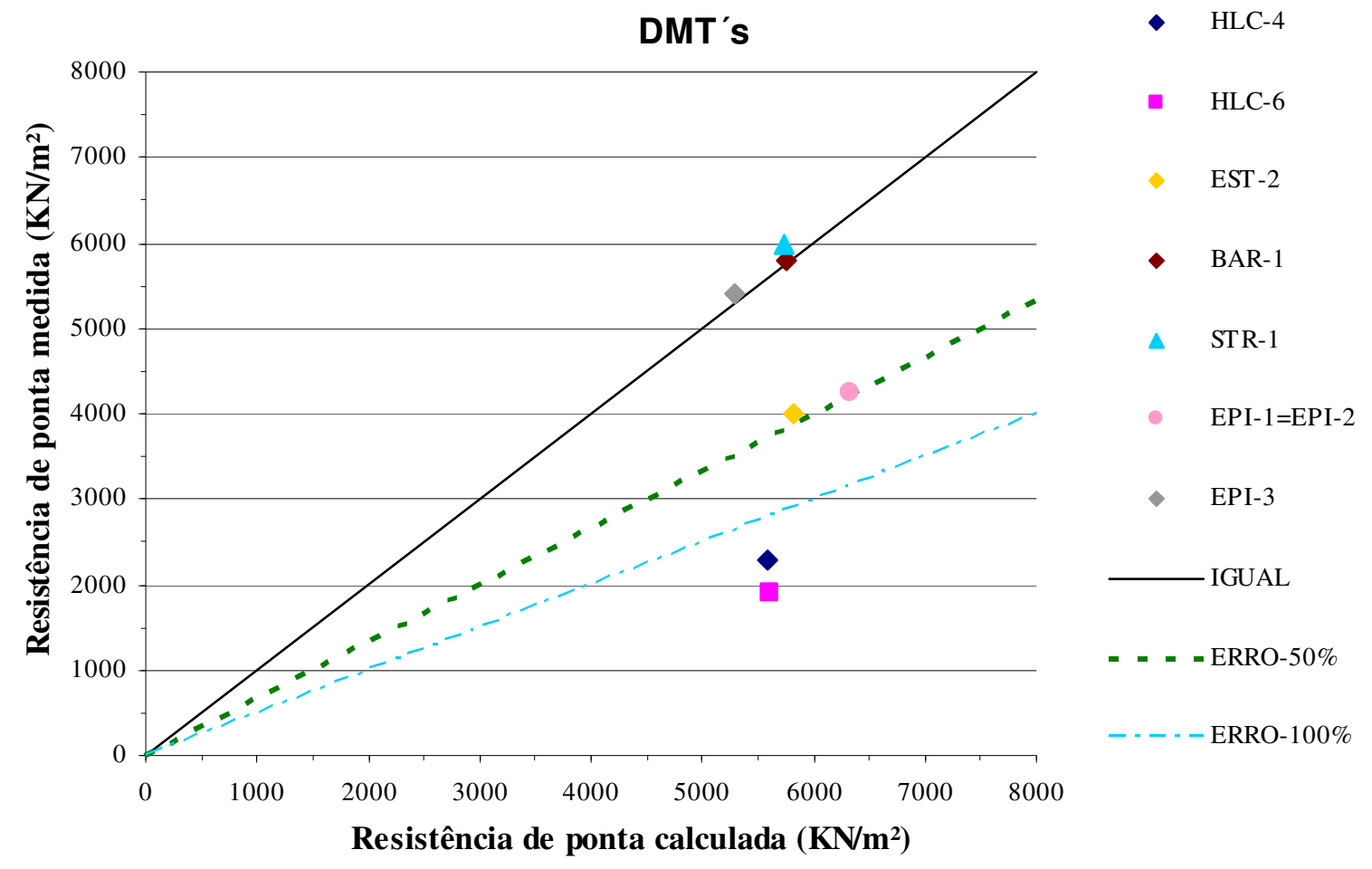

Figura 5.28 - Comparação entre a resistência de ponta calculada e resistência de ponta medida (Método Terzaghi 1943). 
A Figura 5.28 mostra que os valores calculados pelo método de Terzaghi ficaram bem acima dos medidos, com exceção STR-1, BAR-1 e EPI-3, para as quais obteve-se resultados muito bons se comparados com os valores medidos.

Como o método " $\beta$ ", supondo solo normalmente adensado, subestimou sistematicamente a parcela de atrito lateral na ruptura, e como o método de Terzaghi superestimou em geral a parcela de ponta, compreende-se porque, em alguns casos, obteve-se bons resultados para a capacidade de carga das estacas quando comparados com valores medidos. O mesmo raciocínio poderia ser aplicado aos cálculos pelo método " $\beta$ ",supondo solo normalmente adensado, combinados com os cálculos de resistência de ponta com Berezantzev e Vesic.

Nas Figuras 5.29 e 5.30 são apresentadas as comparações das resistências de ponta calculadas pelos métodos de Berezantzev (1961) e Vesic (1975), respectivamente, com as resistências medidas nas provas de carga das estacas do CEUSP.

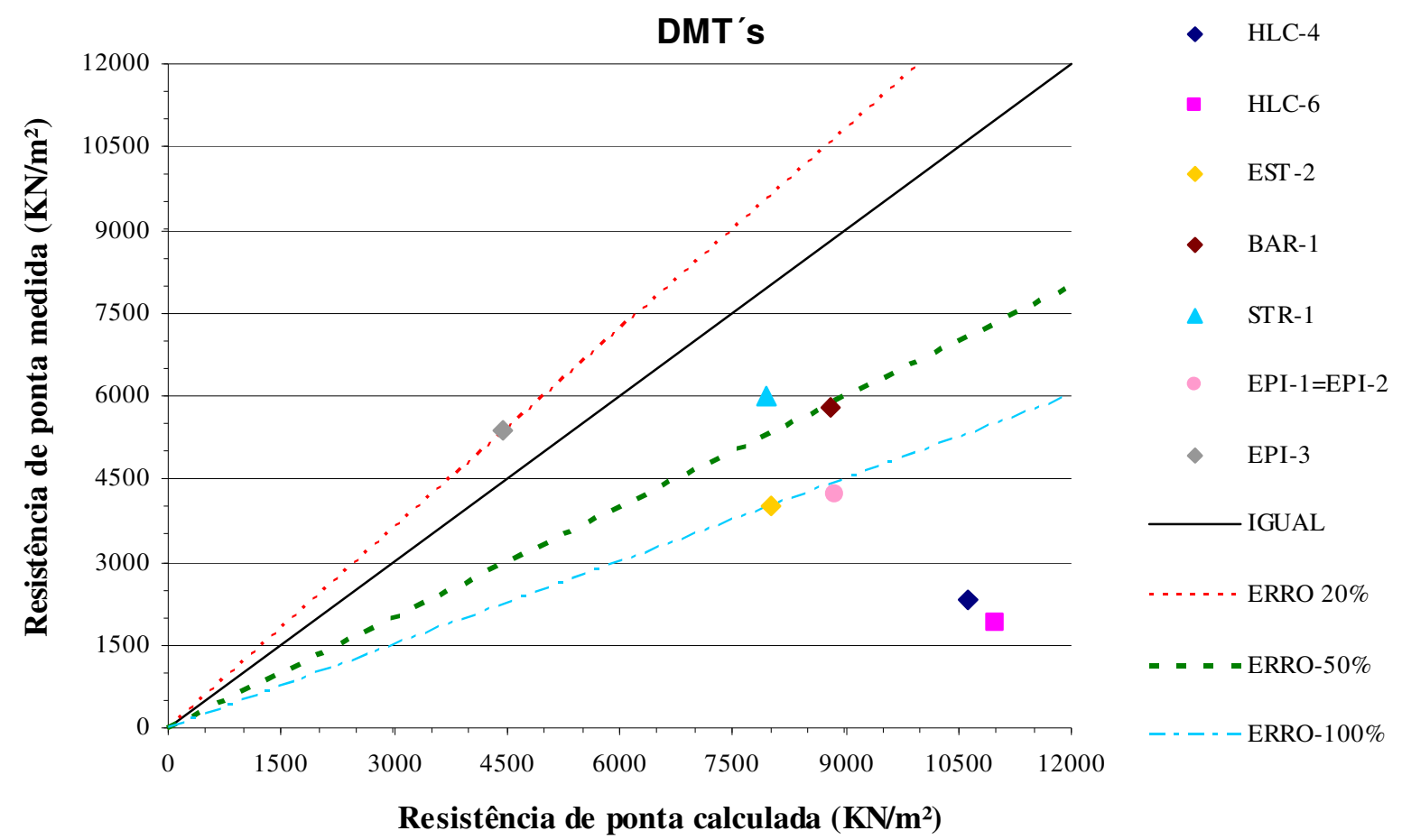

Figura 5.29 - Comparação entre a resistência de ponta calculada e resistência de ponta medida (Método Berezantzev, 1961) 
DMT's

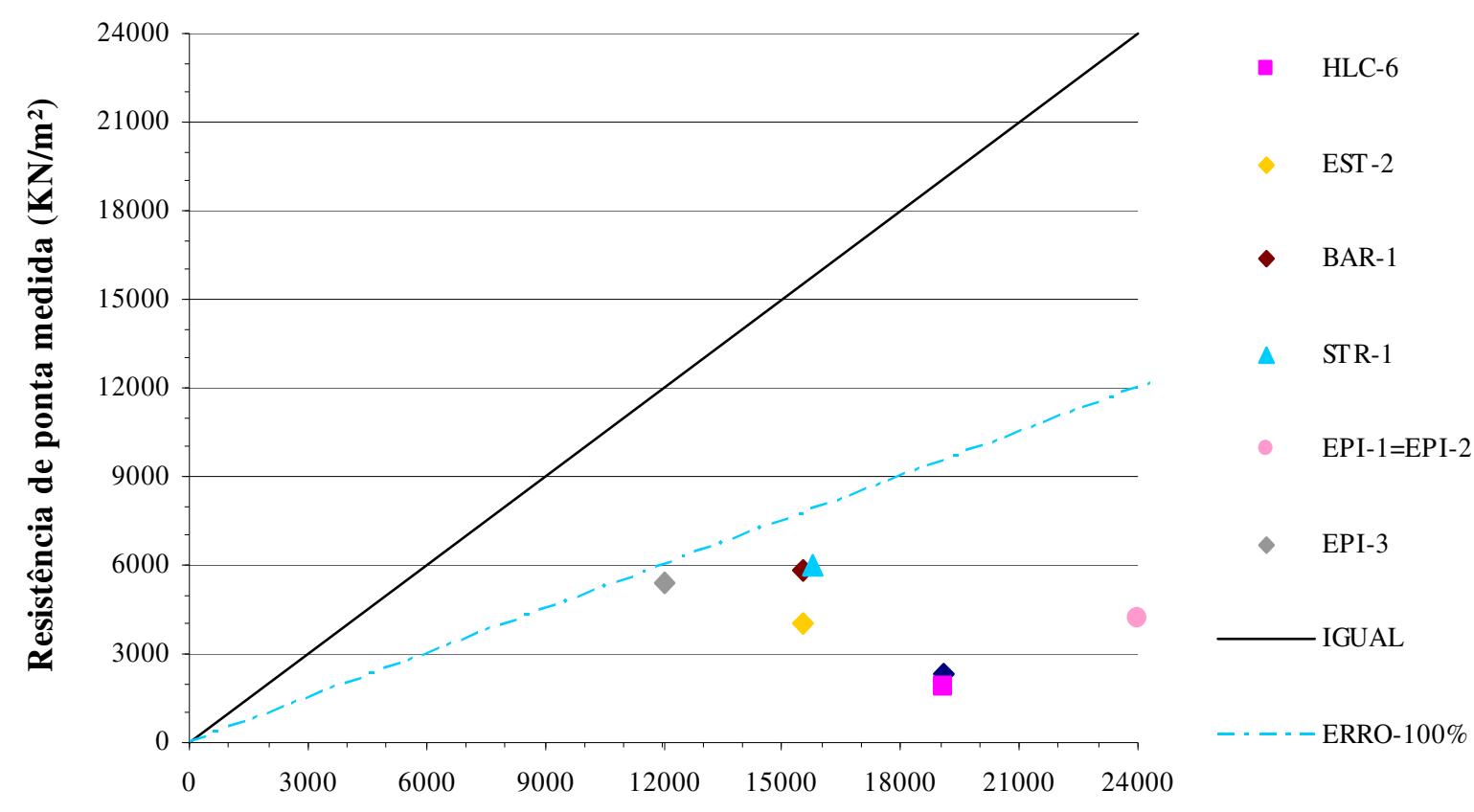

Resistência de ponta calculada $\left(\mathrm{KN} / \mathrm{m}^{2}\right)$

Figura 5.30 - Comparação entre a resistência de ponta calculada ao longo da profundidade e resistência de ponta medida (Método Vesic 1975).

O método proposto por Vesic, 1975 para o cálculo da resistência de ponta foi o que mais superestimou a capacidade de carga das estacas, como mostra a Figura 5.30. Por esta razão que na sua combinação com o método de tensões efetivas " $\beta$ " tenha-se obtido resultados para capacidade das estacas também maiores que os obtidos nos outros métodos (Powel, Terzaghi e Berezantzev).

\subsubsection{Análise comparativa dos recalques nas estacas}

As cargas utilizadas para os cálculos de recalque foram as cargas de trabalho das estacas. Para as estacas em que não haviam sido publicadas as suas cargas de trabalho, o critério para estabelecer esta carga foi a carga de ruptura dividida por dois. Utilizou-se a carga de trabalho, pois, para os primeiros incrementos de carga, a hipótese de solo elástico é mais aceitável. Para cada estaca são comparados os recalques calculados e os medidos nas provas de carga lenta e rápida. Para esta última, tomaram-se os recalques não acumulados. 


\subsubsection{Método de Poulos e Davis (1980)}

O primeiro método de estimativa de recalque a ser testado é o de Poulos e Davis (1980). Este método utiliza como parâmetro geotécnico o Módulo de Young (E) que, neste trabalho foi estimado pelas propostas de Robertson et al (1989) e a de Marchetti (1997), conforme as Figuras 5.15 e 5.16, respectivamente.

\section{a) Módulo Young (E) segundo Robertson et al (1989)}

Nas Figuras 5.31 a 5.41 pode-se observar um melhor resultado para cargas baixas, menores que as cargas de trabalho das estacas. Isso pode ser explicado pelo fato do fator de proporcionalidade $\mathrm{F}=4$ de Robertson et al. (1989) conduzir, a rigor, a estimativas do módulo $\mathrm{E}_{\mathrm{i}}$ (módulo tangente inicial).

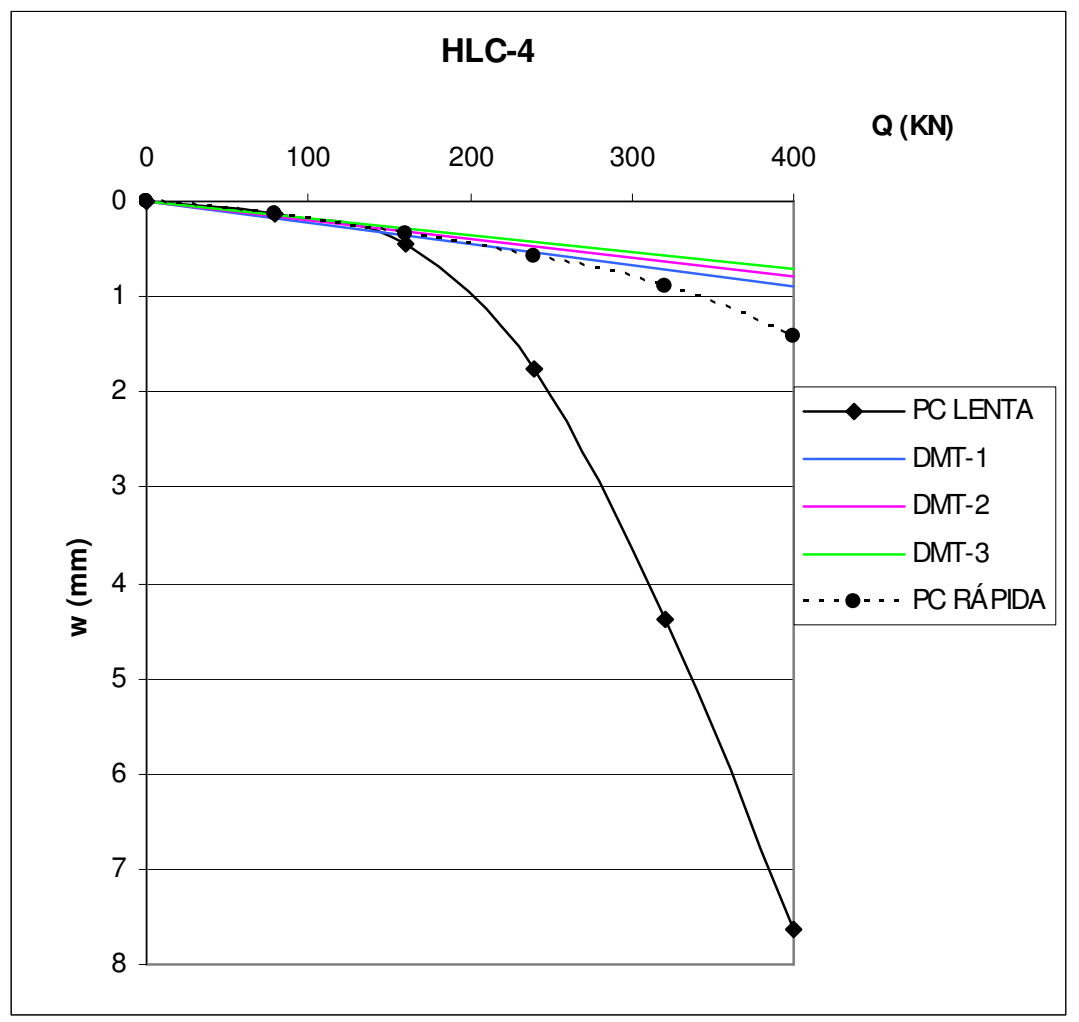

Figura 5.31 - Gráfico de carga versus recalque para estaca hélice contínua (HLC-4), método de Poulos e Davis, utilizando expressão 3.42 e F=4. 


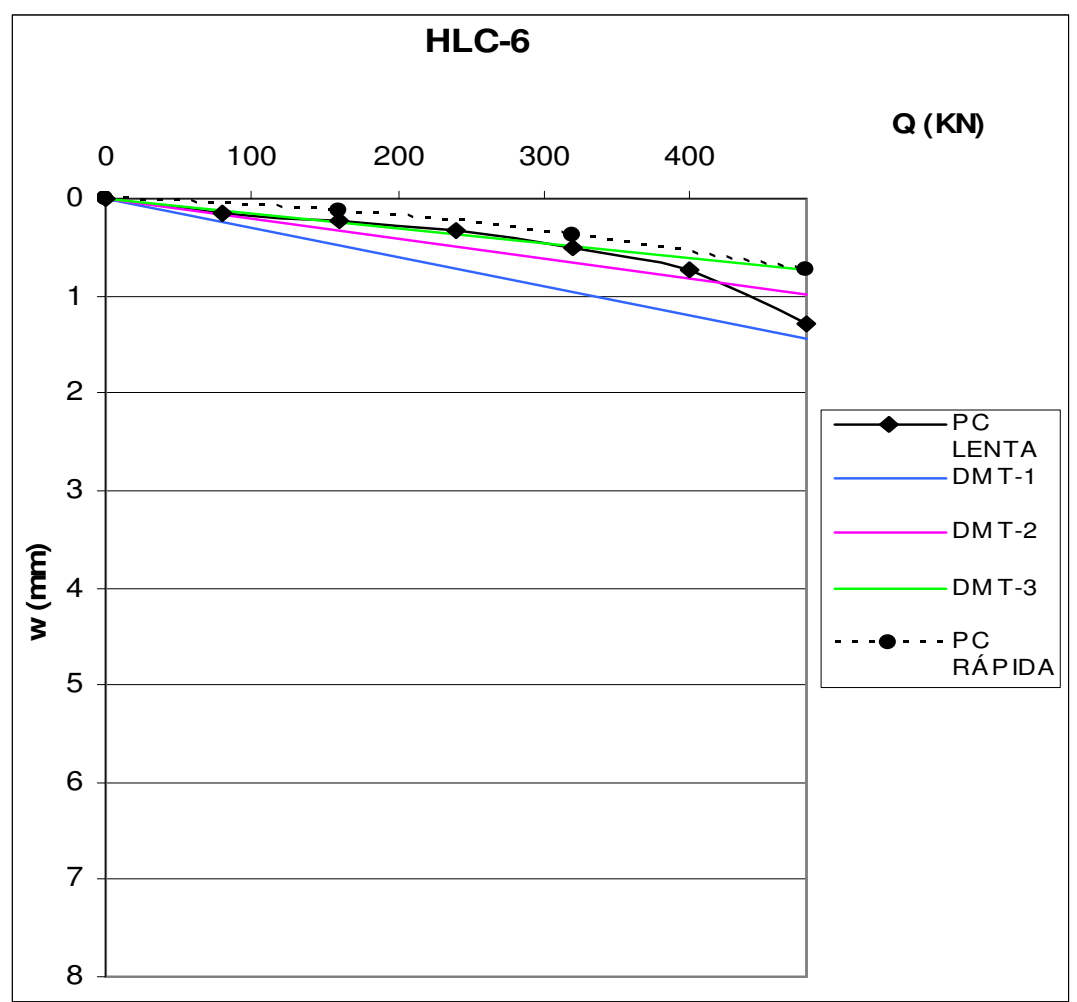

Figura 5.32 - Gráfico de carga versus recalque para estaca hélice contínua (HLC-6), método de Poulos e Davis, utilizando expressão 3.42 e F=4.

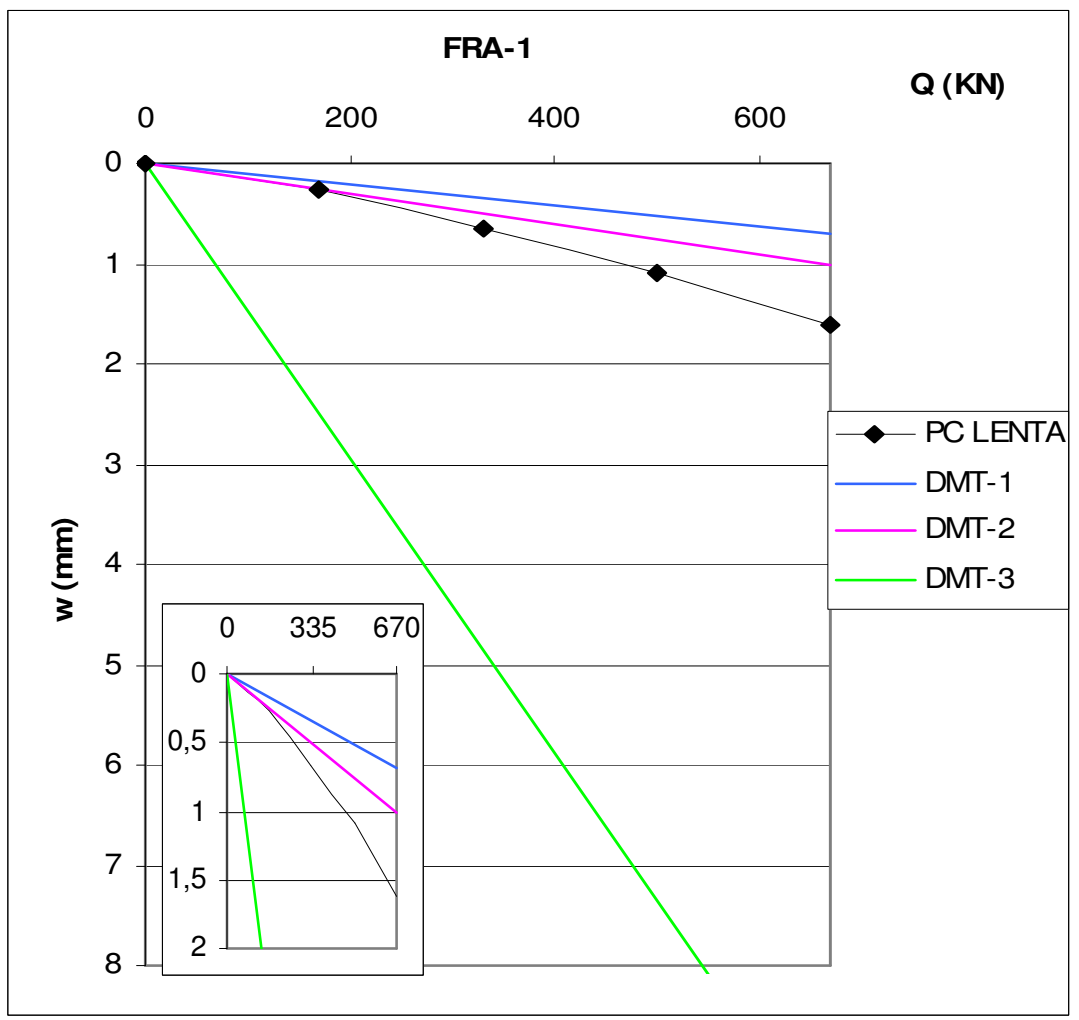

Figura 5.33 - Gráfico de carga versus recalque para estaca franki (FRA-1), método de Poulos e Davis, utilizando expressão 3.42 e F=4. 


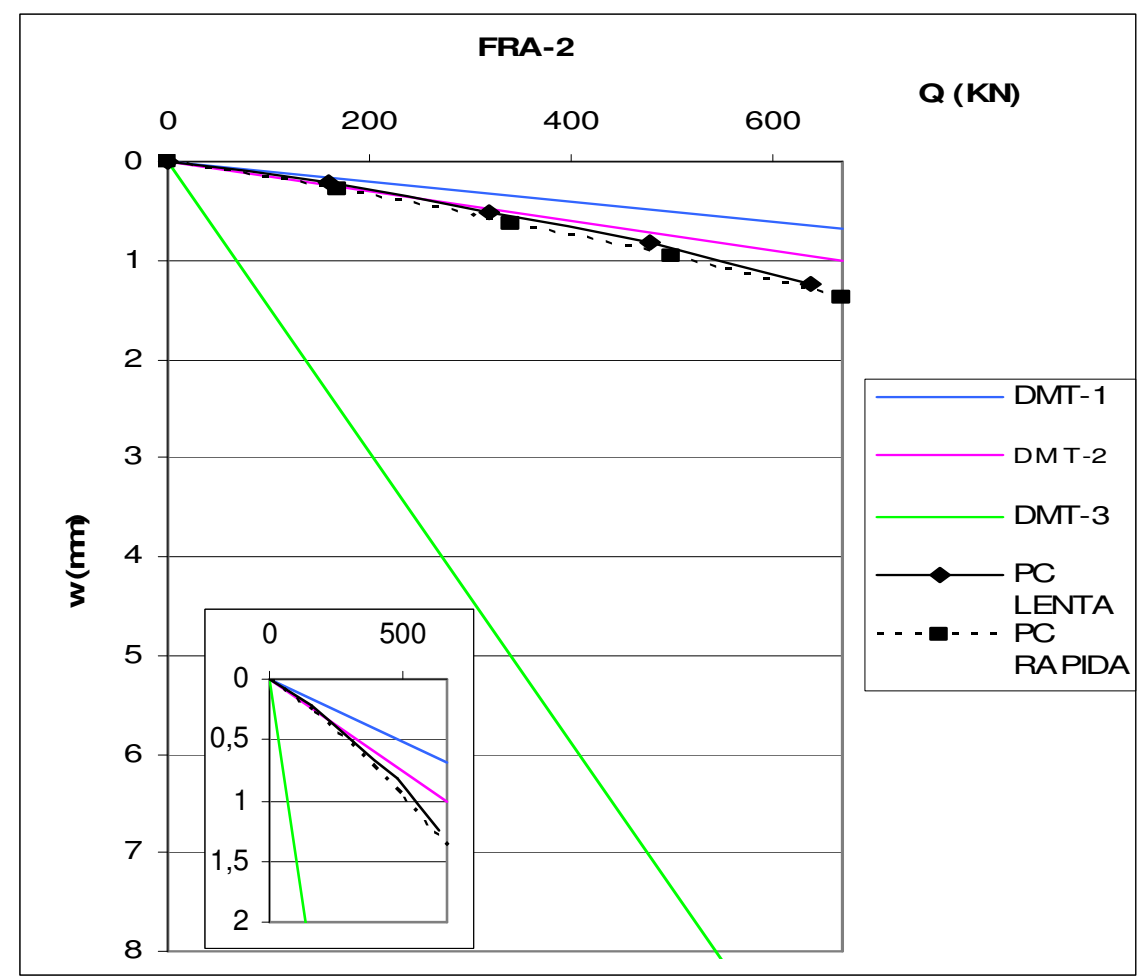

Figura 5.34 - Gráfico de carga versus recalque para estaca franki (FRA-2), método de Poulos e Davis, utilizando expressão 3.42 e F=4.

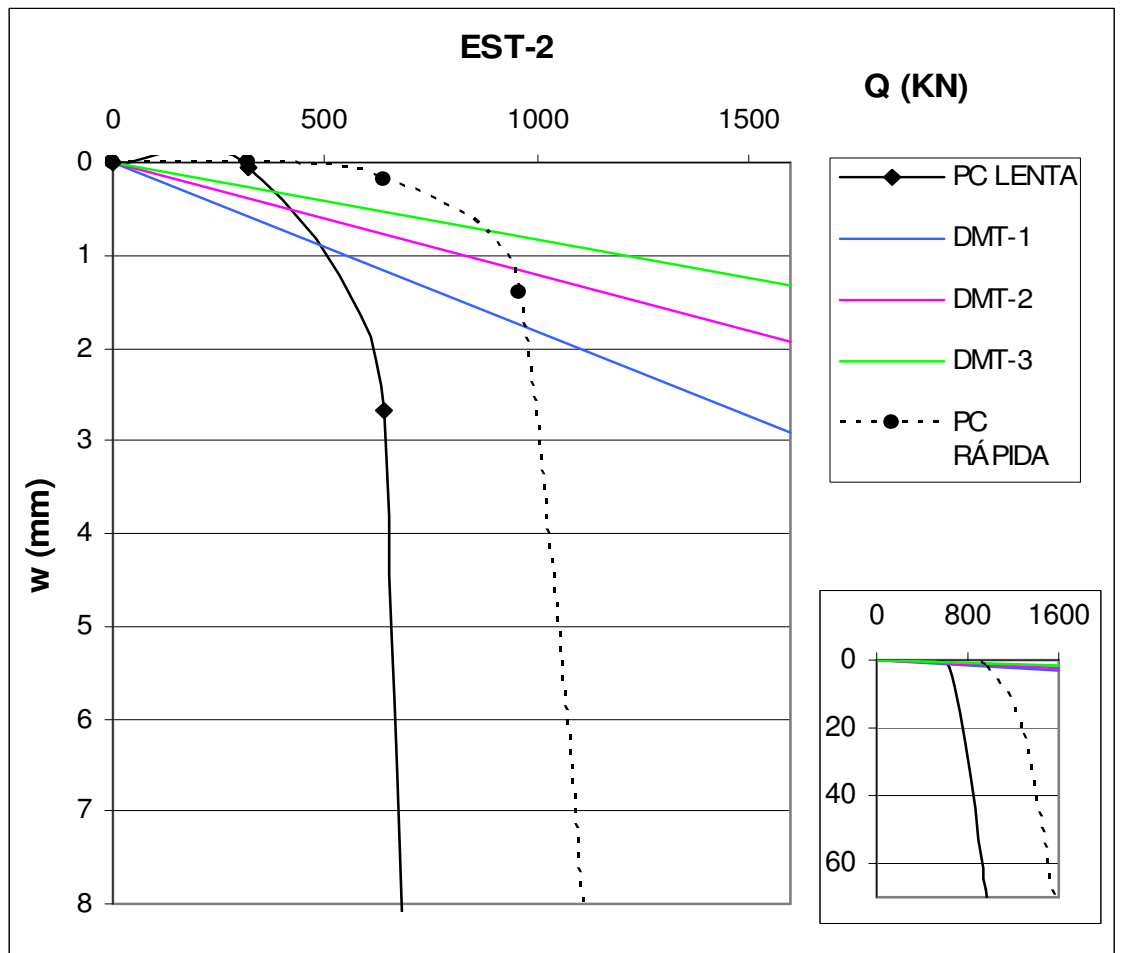

Figura 5.35 - Gráfico de carga versus recalque para estaca escavada com lama bentonítica (EST-2), método de Poulos e Davis, utilizando expressão 3.42 e F=4. 


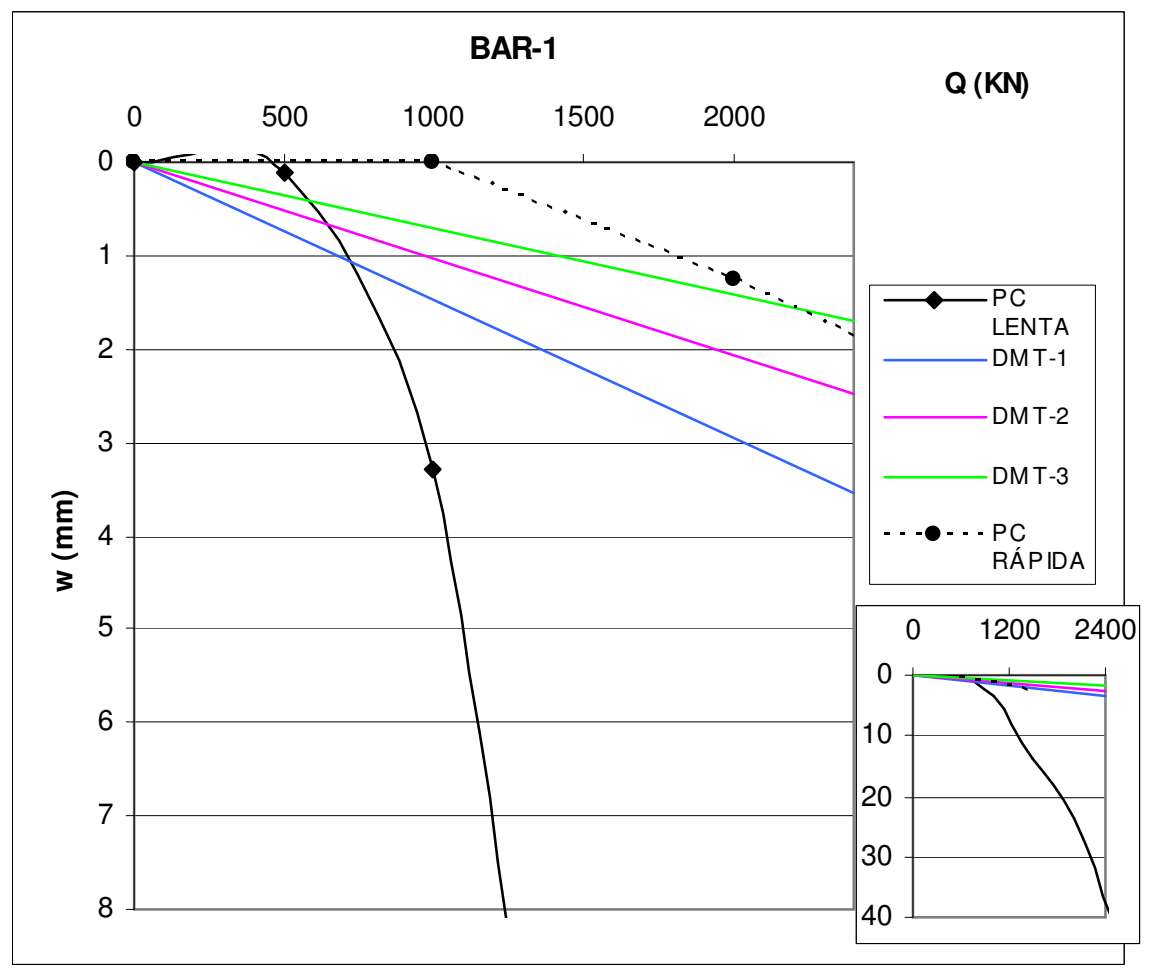

Figura 5.36 - Gráfico de carga versus recalque para estaca barrete (BAR-1), método de Poulos e Davis, utilizando expressão 3.42 e F=4.

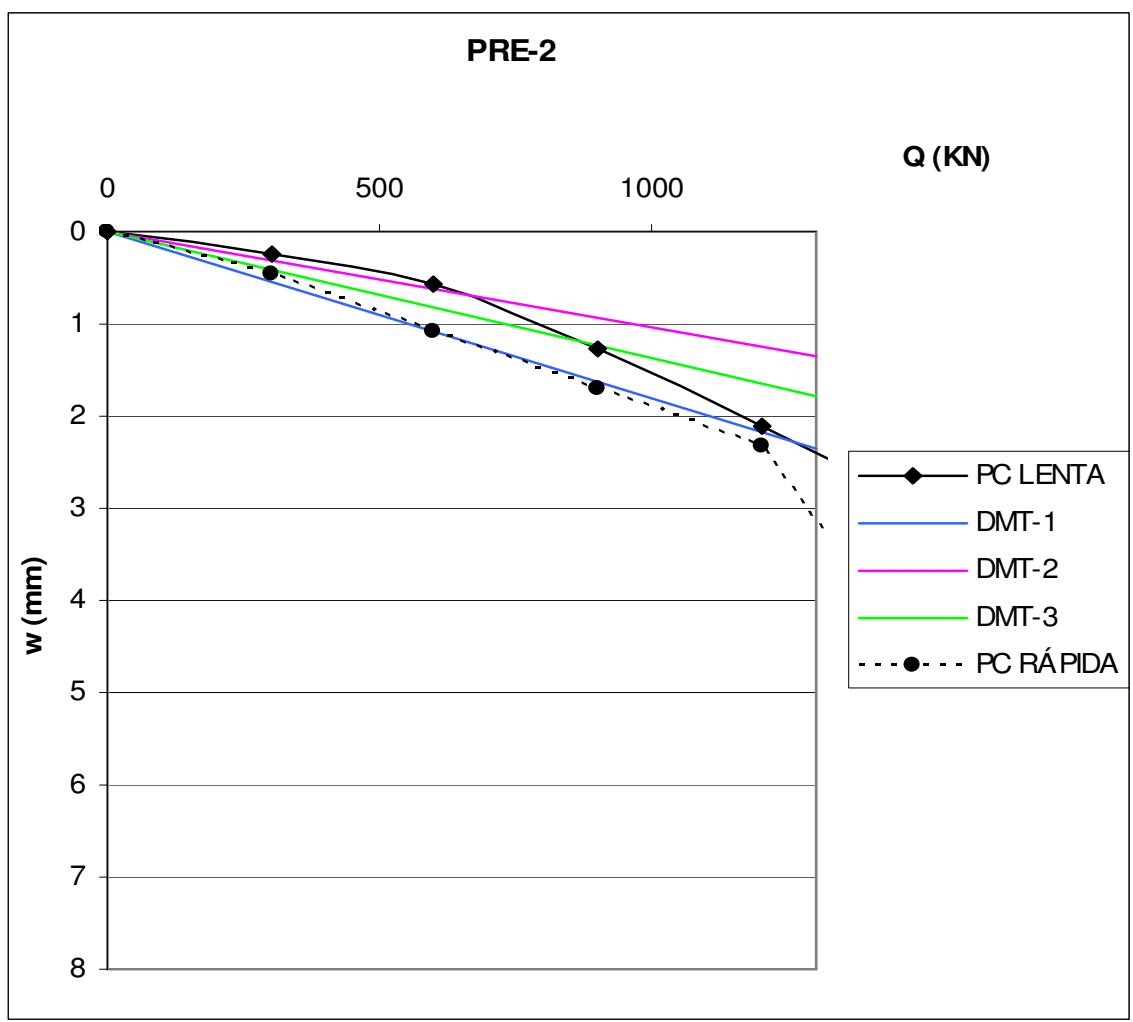

Figura 5.37 - Gráfico de carga versus recalque para estaca pré-moldada (PRE-2), método de Poulos e Davis, utilizando expressão 3.42 e F=4. 


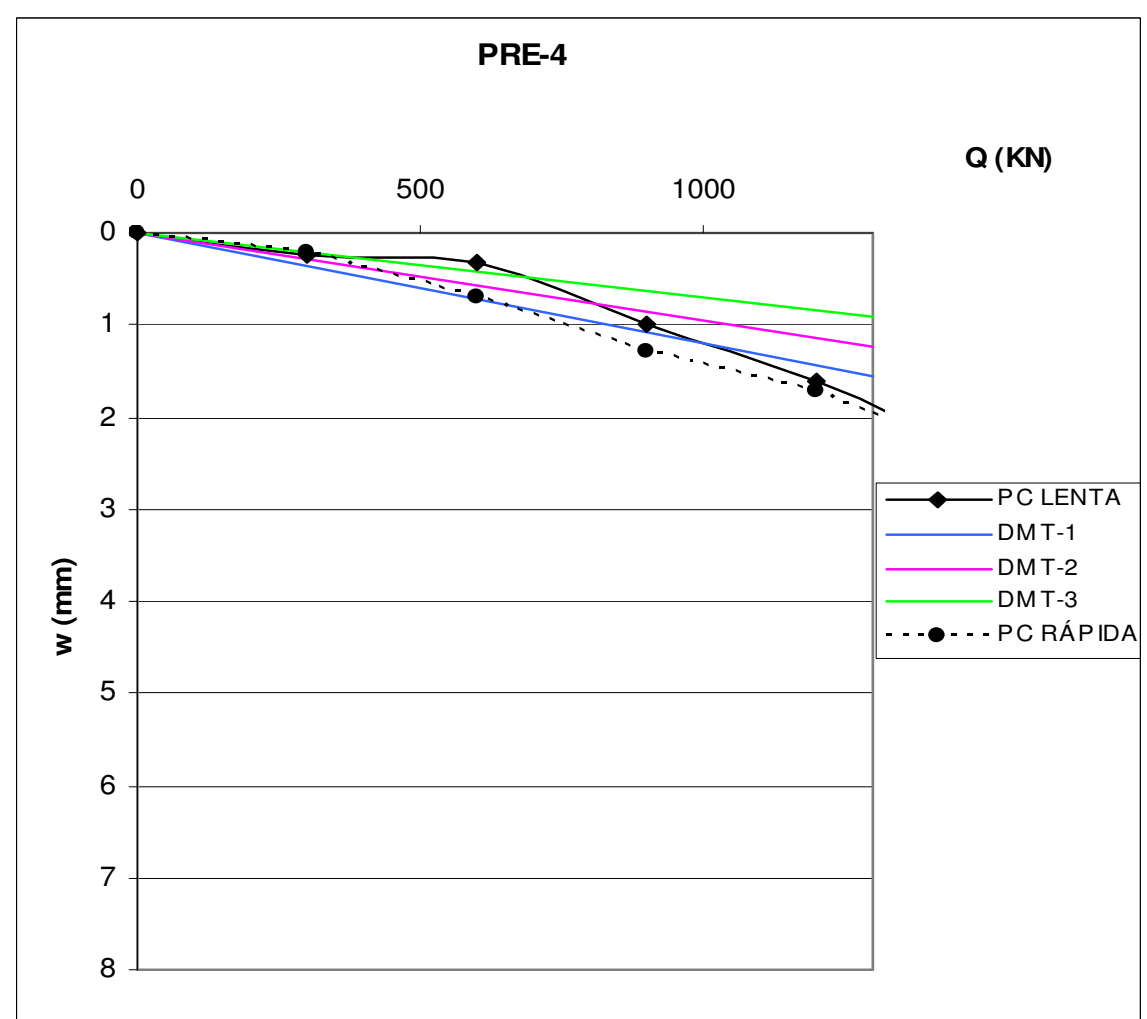

Figura 5.38 - Gráfico de carga versus recalque para estaca pré-moldada (PRE-4), método de Poulos e Davis, utilizando expressão 3.42 e F=4.

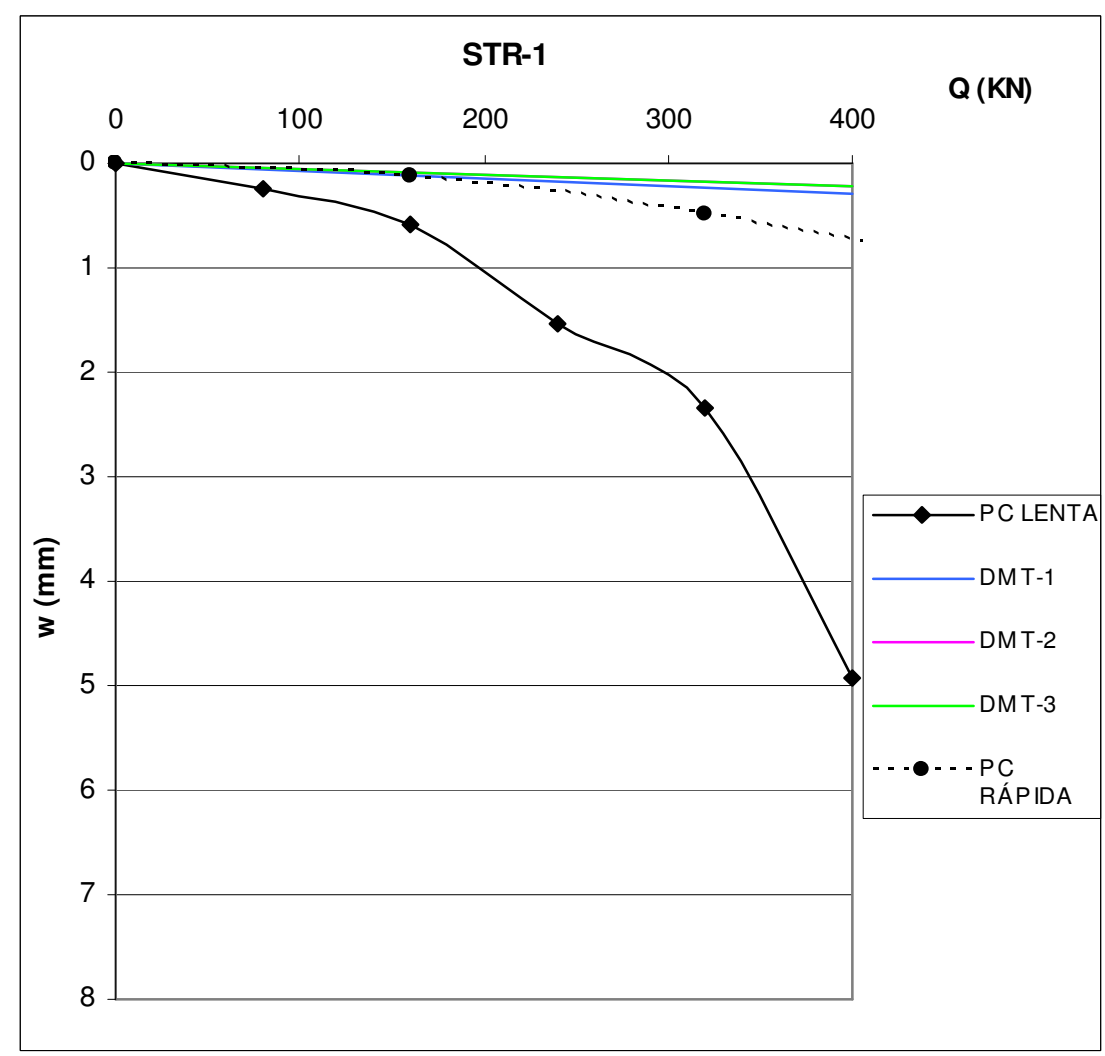

Figura 5.39 - Gráfico de carga versus recalque para estaca strauss (STR-1), método de Poulos e Davis, utilizando expressão 3.42 e $\mathrm{F}=4$. 


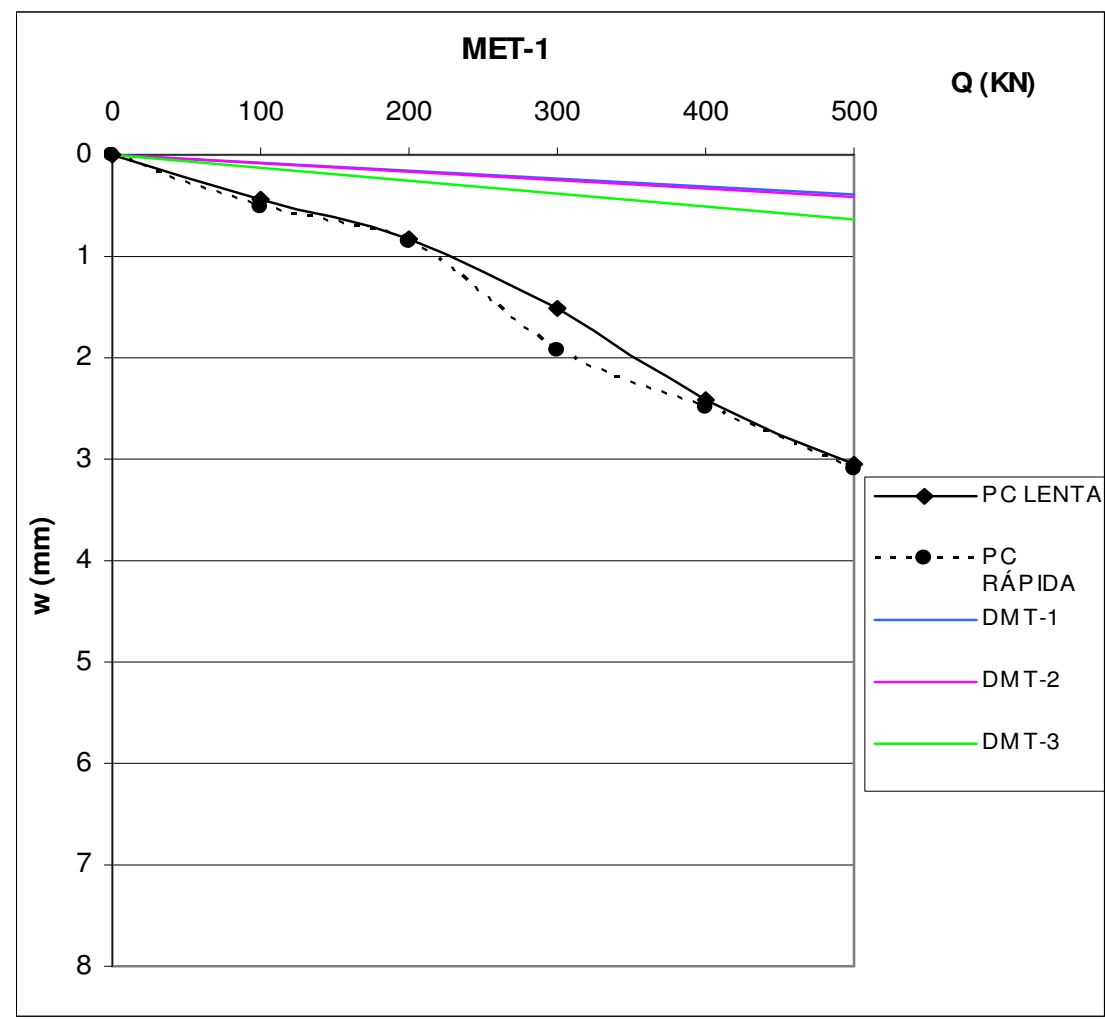

Figura 5.40 - Gráfico de carga versus recalque para estaca metálica (MET-1), método de Poulos e Davis, utilizando expressão 3.42 e F=4.

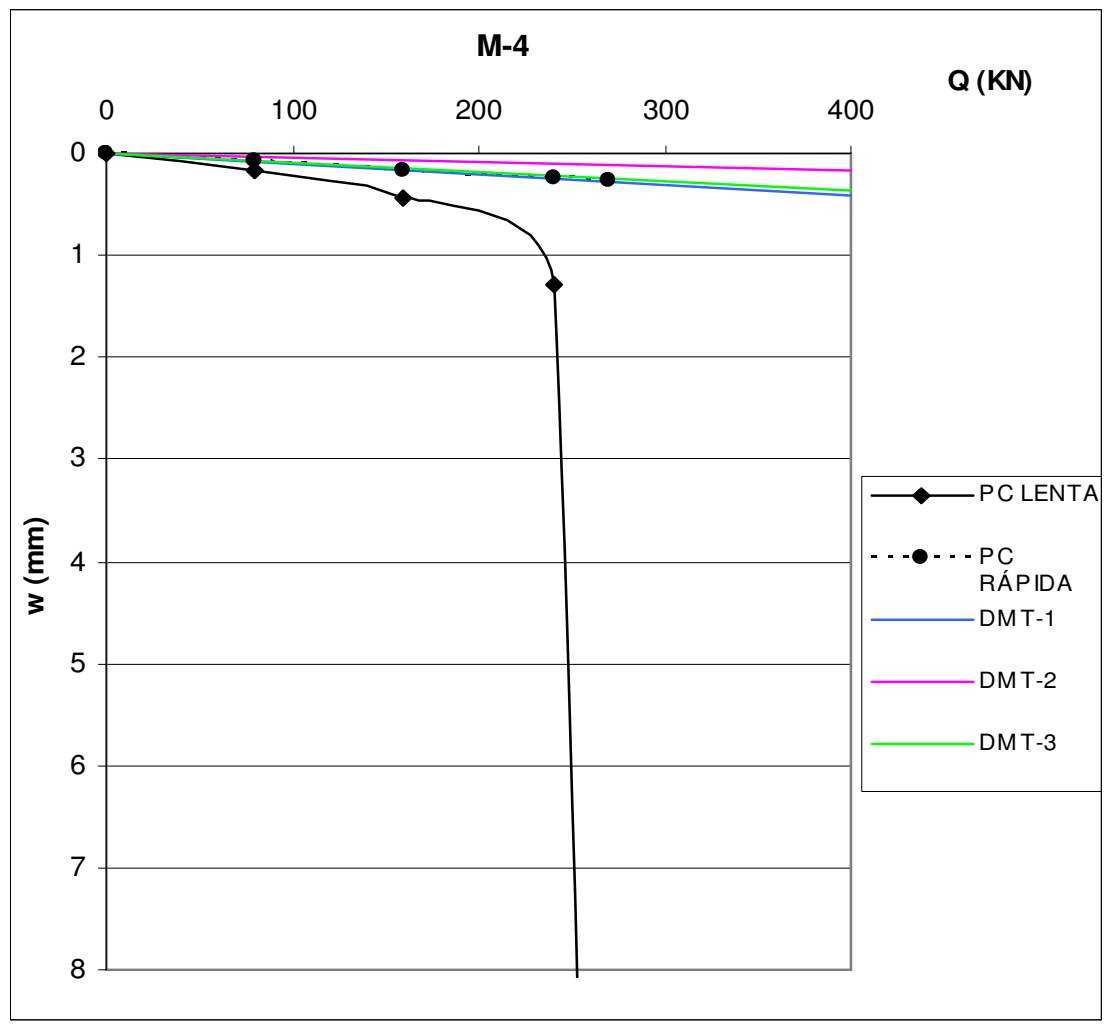

Figura 5.41 - Gráfico de carga versus recalque para micro-estaca (M-4), método de Poulos e Davis, utilizando expressão 3.42 e $\mathrm{F}=4$. 
A Tabela 5.3 apresenta um resumo dos recalques obtidos através do cálculo pelo método de Poulos e Davis utilizando o E da proposta de Robertson et al. (1989). Os valores da última coluna se referem aos cálculos com os DMT's mais próximos das estacas, conforme a Tabela 5.2.

Tabela 5.3 - Tabela resumo de recalques calculados pelo método de Poulos e Davis utilizando a proposta de Robertson et al., $1989\left(\mathrm{E}=\mathrm{F} . \mathrm{E}_{\mathrm{D}}\right)$.

\begin{tabular}{|c|c|c|c|c|}
\hline ESTACAS & $\begin{array}{c}\text { Carga de } \\
\text { trabalho } \\
(\mathrm{KN})\end{array}$ & $\begin{array}{c}\text { Recalque } \\
\text { ensaio lento } \\
(\mathrm{mm})\end{array}$ & $\begin{array}{c}\text { Recalque } \\
\text { ensaio rápido } \\
(\mathrm{mm})\end{array}$ & $\begin{array}{c}\text { Recalque } \\
\text { Poulos e Davis } \\
(\mathrm{mm})\end{array}$ \\
\hline HLC-4 & 400 & 7,62 & 1,42 & 0,96 \\
\hline HLC-6 & 480 & 1,28 & 0,76 & 0,74 \\
\hline FRA-1 & 670 & 1,62 & - & 3,86 \\
\hline FRA-2 & 670 & 1,38 & 1,24 & 3,86 \\
\hline EST-2 & 1600 & 88,21 & 77,81 & 1,95 \\
\hline BAR-1 & 2400 & 41,00 & 2,76 & 2,47 \\
\hline PRÉ-2 & 1300 & 2,57 & 4,13 & 1,78 \\
\hline PRÉ-4 & 1300 & 2,13 & 2,15 & 1,23 \\
\hline STR-1 & 400 & 4,92 & 0,84 & 0,25 \\
\hline MET-1 & 500 & 3,05 & 3,1 & 0,64 \\
\hline M-4 & 400 & 34,16 & 0,27 & 0,18 \\
\hline
\end{tabular}

Os recalques calculados para o estacão (EST-2), barrete (BAR-1) e para a micro-estaca (M-4) foram muito diferentes dos medidos, devido a estas estacas terem rompido antes de se chegar à carga de trabalho nominal.

Em geral, os recalques calculados via DMT apresentaram melhor concordância com os recalques da prova de carga rápida.

\section{b) Módulo Young (E) segundo Marchetti (1997)}

Ainda para o método de Poulos e Davis (1980) utilizou-se da proposta de Marchetti (1997), expressão 3.43, para estimar o módulo de elasticidade (E) e comparar os recalques obtidos via DMT com os medidos nas provas de carga lentas e rápidas. As Figuras 5.42 a 5.52 permitem melhores análises.

Segundo Marchetti (1997) o módulo de elasticidade obtido é o correspondente a uma deformação de $0,1 \%$. 


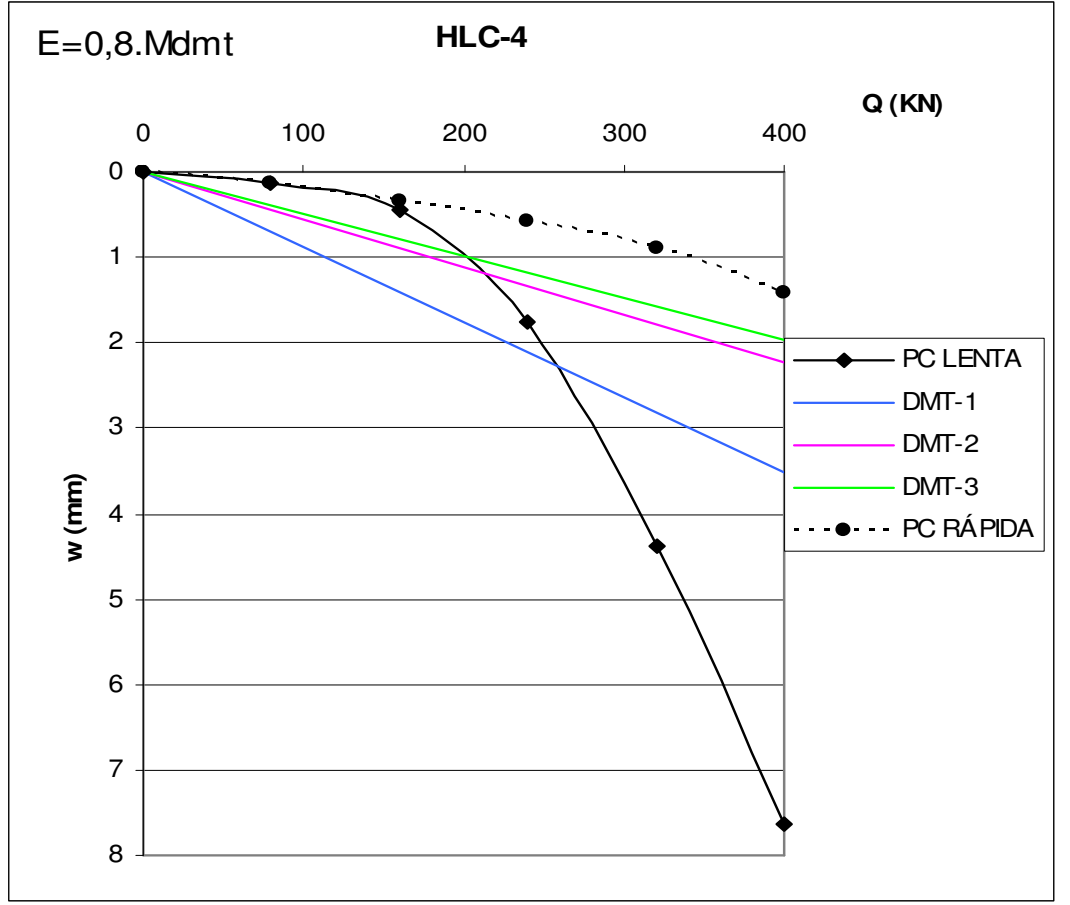

Figura 5.42 - Gráfico de carga versus recalque para estaca hélice contínua (HLC-4), método de Poulos e Davis, utilizando expressão 3.43.

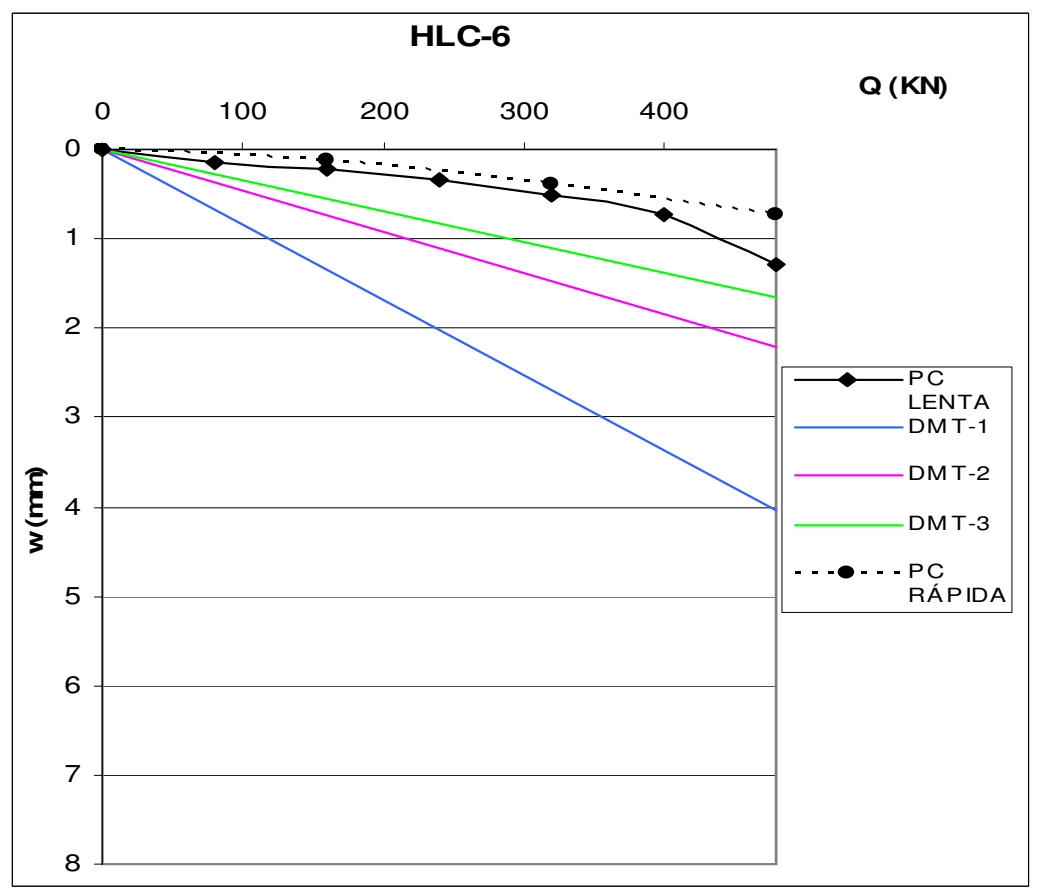

Figura 5.43 - Gráfico de carga versus recalque para estaca hélice contínua (HLC-6), método de Poulos e Davis, utilizando expressão 3.43.

Nas Figuras 5.42 e 5.43, observa-se que o recalque calculado através do DMT-3 (o mais próximo das estacas hélice contínua) se aproxima do recalque medido para a carga de trabalho nas provas de carga lenta ou rápida. 


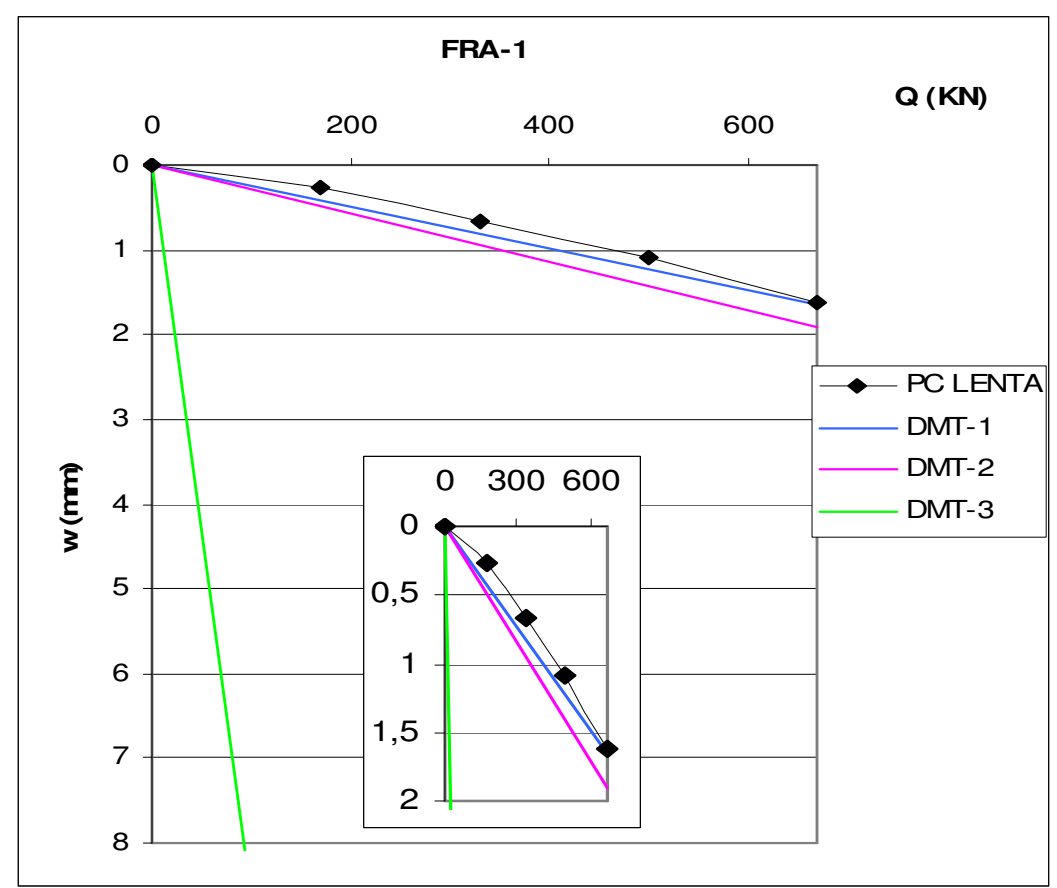

Figura 5.44 - Gráfico de carga versus recalque para estaca franki (FRA-1), método de Poulos e Davis, utilizando expressão 3.43 .

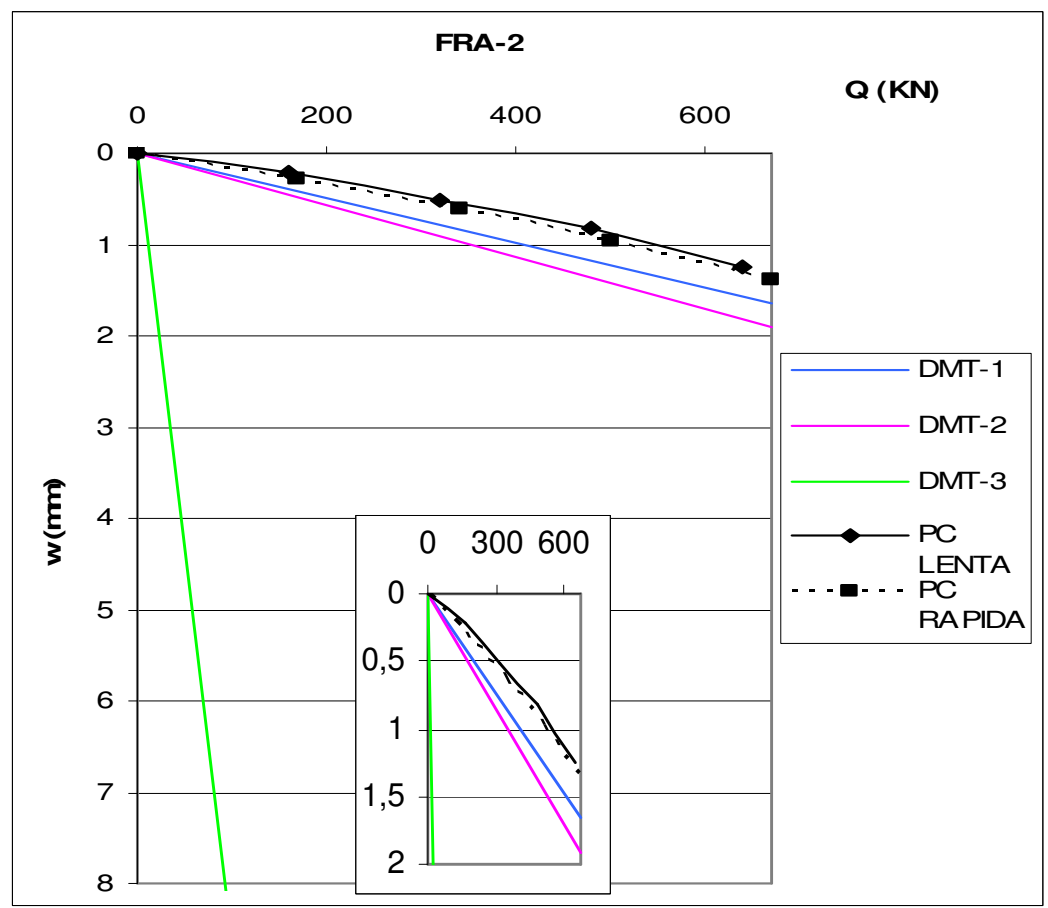

Figura 5.45 - Gráfico de carga versus recalque para estaca franki (FRA-2), método de Poulos e Davis, utilizando expressão 3.43.

Nas Figuras 5.44 e 5.45, observa-se que os recalques calculados nos ensaios DMT-1 e DMT-2 se aproximam do recalque medido para a carga de trabalho das estacas Franki (FRA-1 e FRA-2) nas provas de carga lenta e rápida. 


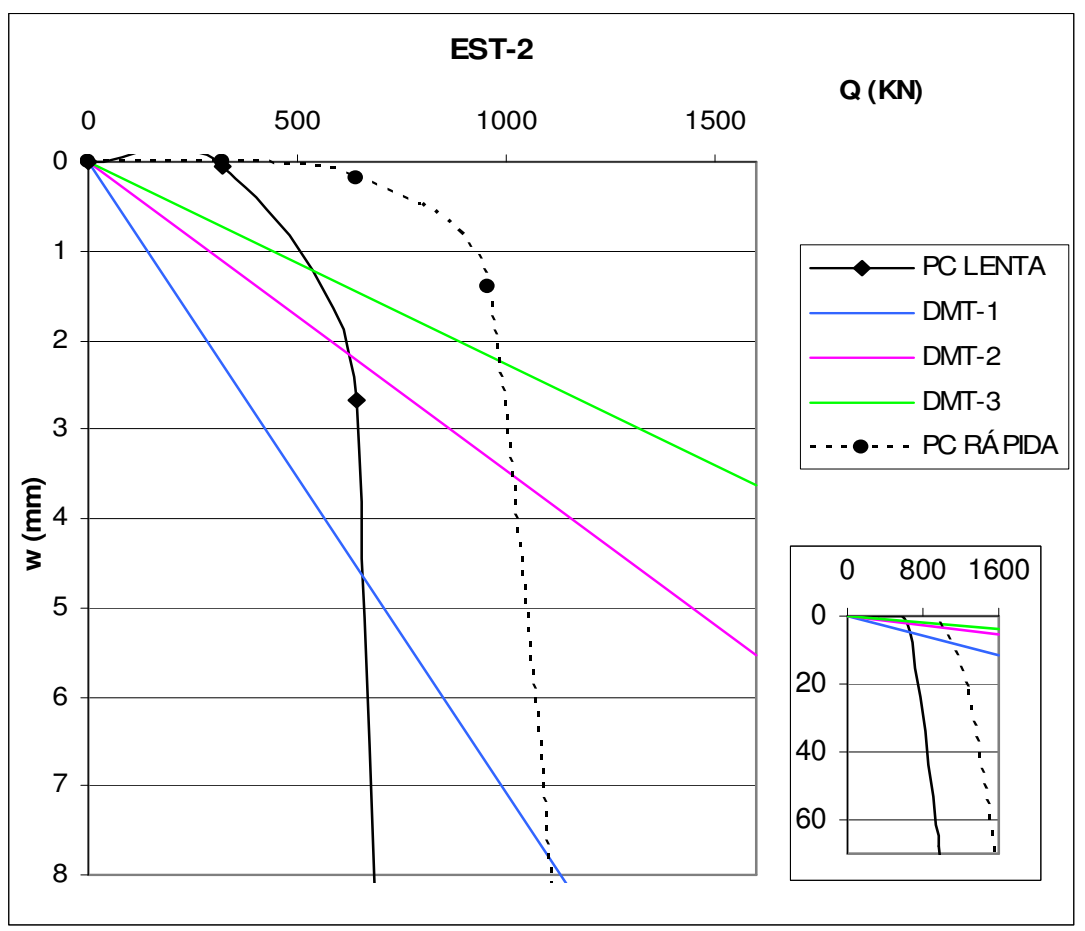

Figura 5.46 - Gráfico de carga versus recalque para estaca estacão (EST-2 método de Poulos e Davis, utilizando expressão 3.43 .

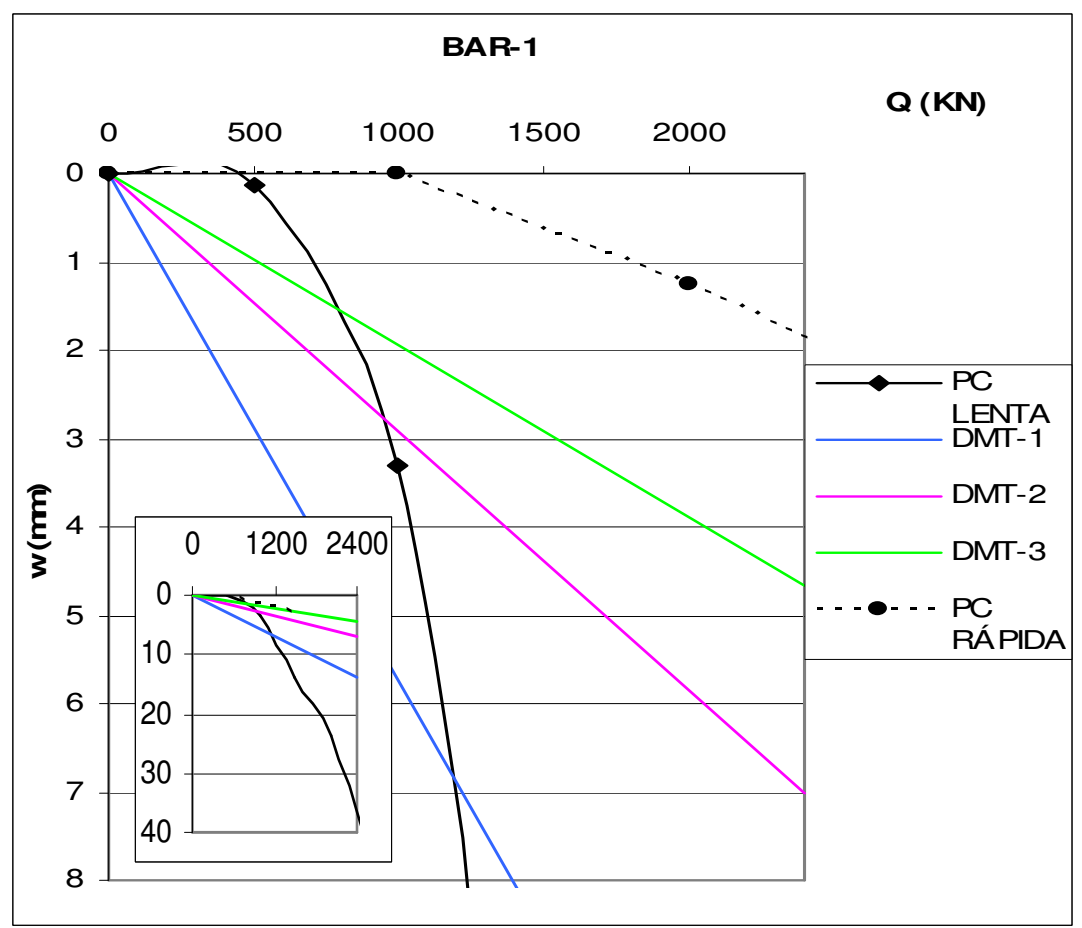

Figura 5.47 - Gráfico de carga versus recalque para estaca barrete (BAR-1), método de Poulos e Davis, utilizando expressão 3.43.

Como as estacas EST-2 e BAR-1 haviam rompido antes de se atingir a carga de trabalho, imaginava-se que os recalques calculados não seriam próximos aos recalques medidos, o que de fato acabou ocorrendo (Figura 5.46 e 5.47). 


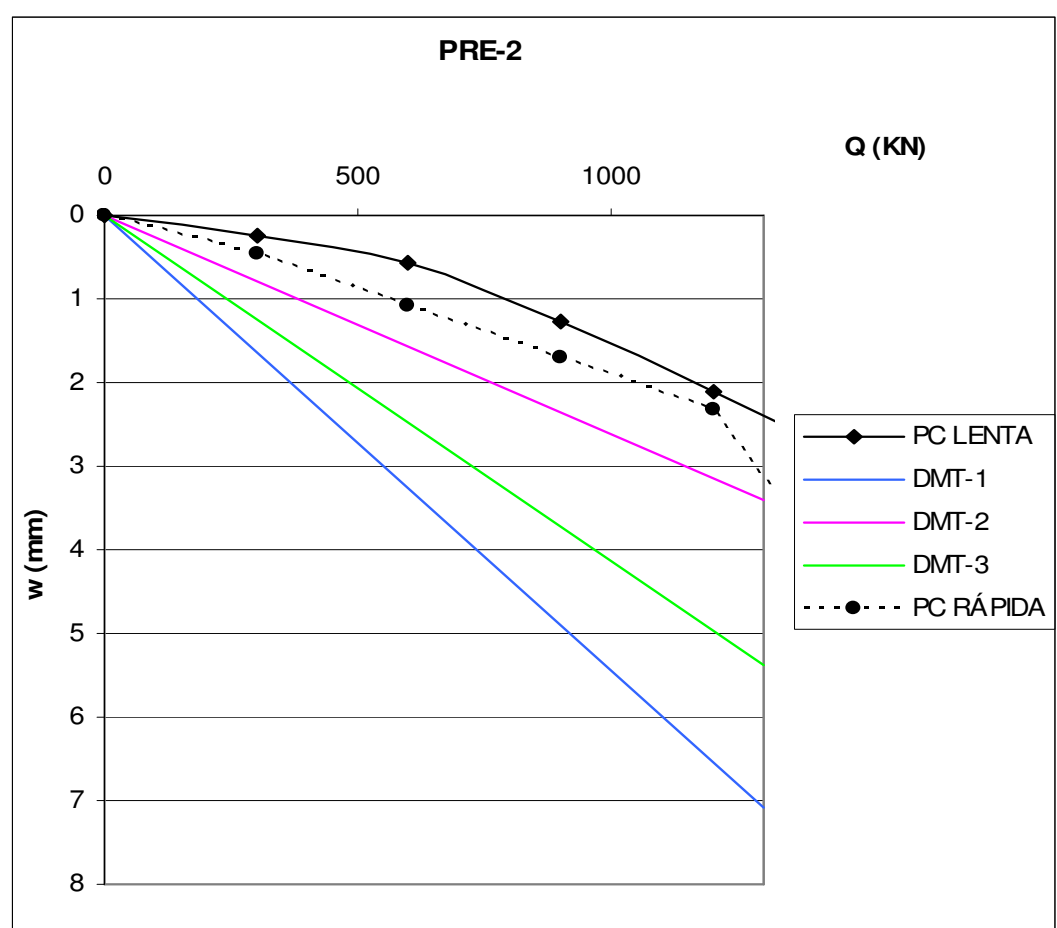

Figura 5.48 - Gráfico de carga versus recalque para estaca pré-moldada (PRE-2), método de Poulos e Davis, utilizando expressão 3.43.

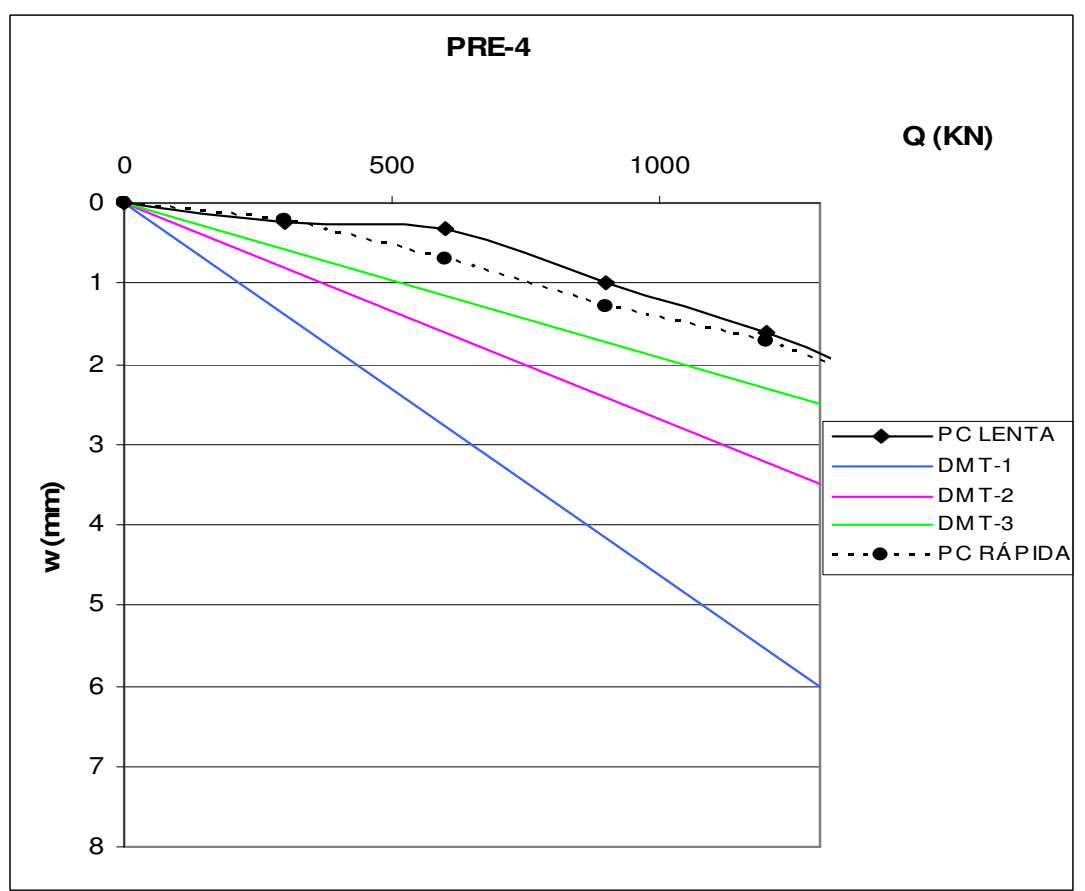

Figura 5.49 - Gráfico de carga versus recalque para estaca pré-moldada (PRE-4), método de Poulos e Davis, utilizando expressão 3.43.

Observa-se na Figura 5.48 e 5.49, que os recalques calculados para as estacas PRE-2 e PRE-4, não apresentaram boa concordância com os recalques medidos se comparados com os ensaios mais próximos, apresentados na Tabela 3.2. 


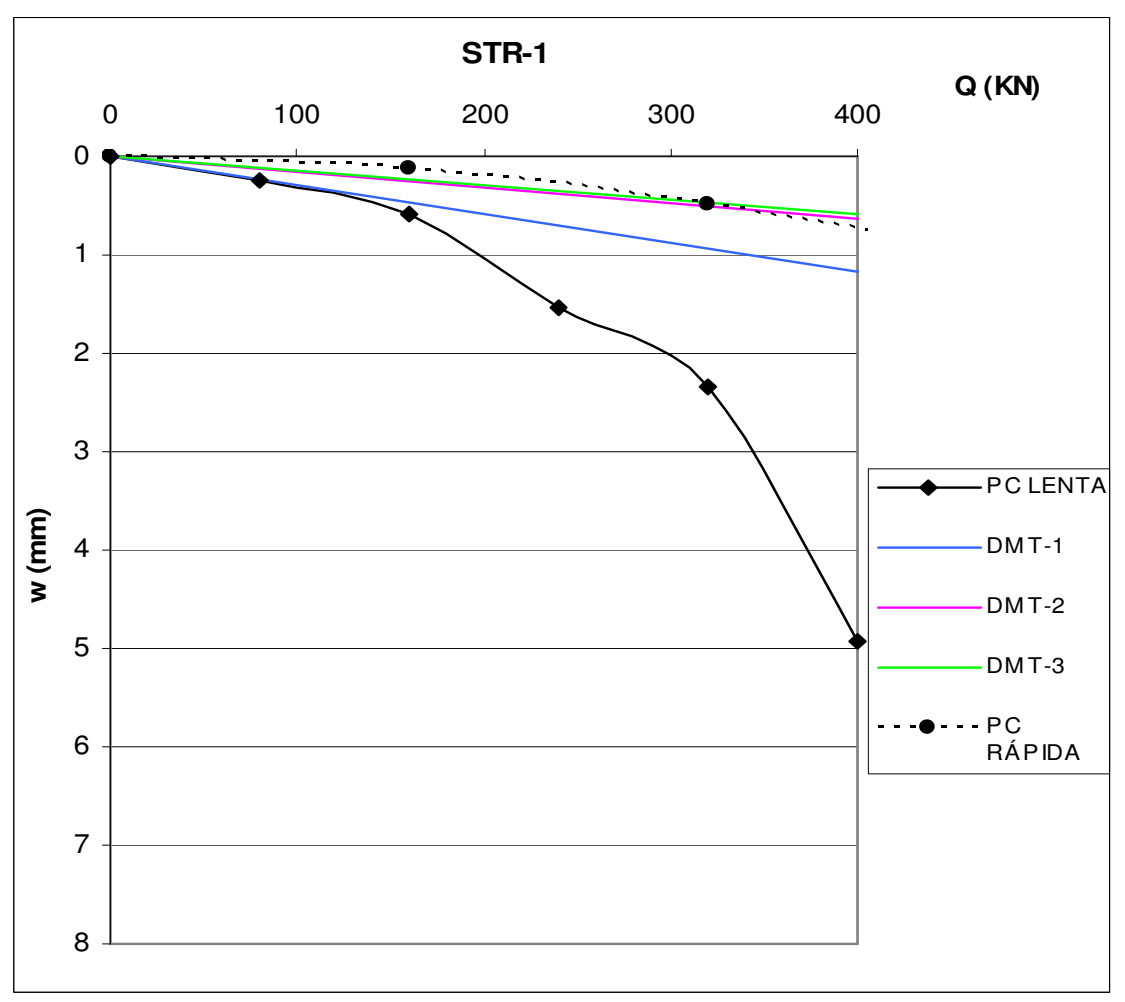

Figura 5.50 - Gráfico de carga versus recalque para estaca strauss (STR-1), método de Poulos e Davis, utilizando expressão 3.43.

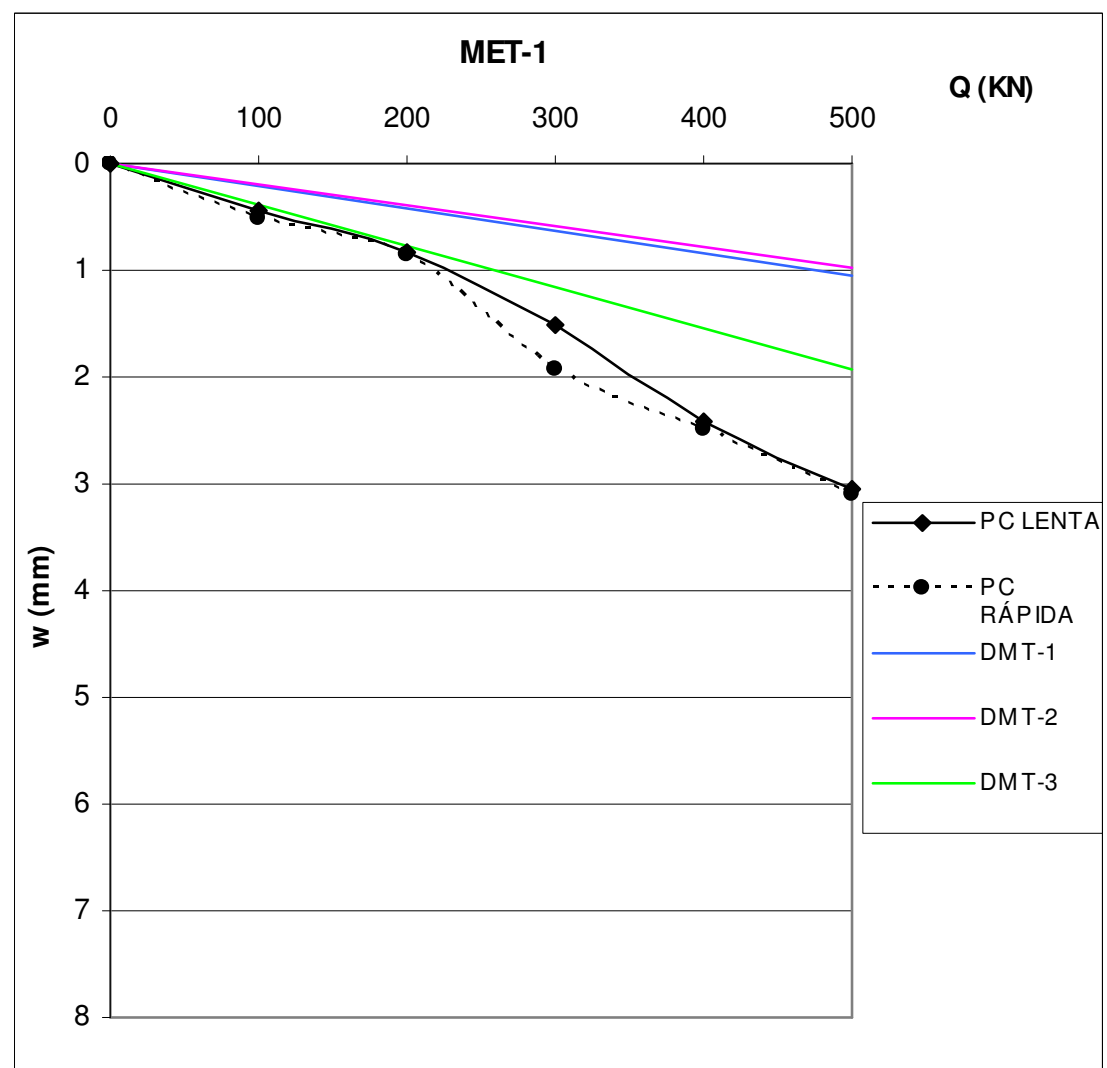

Figura 5.51 - Gráfico de carga versus recalque para estaca metálica (MET-1), método de Poulos e Davis, utilizando expressão 3.43. 


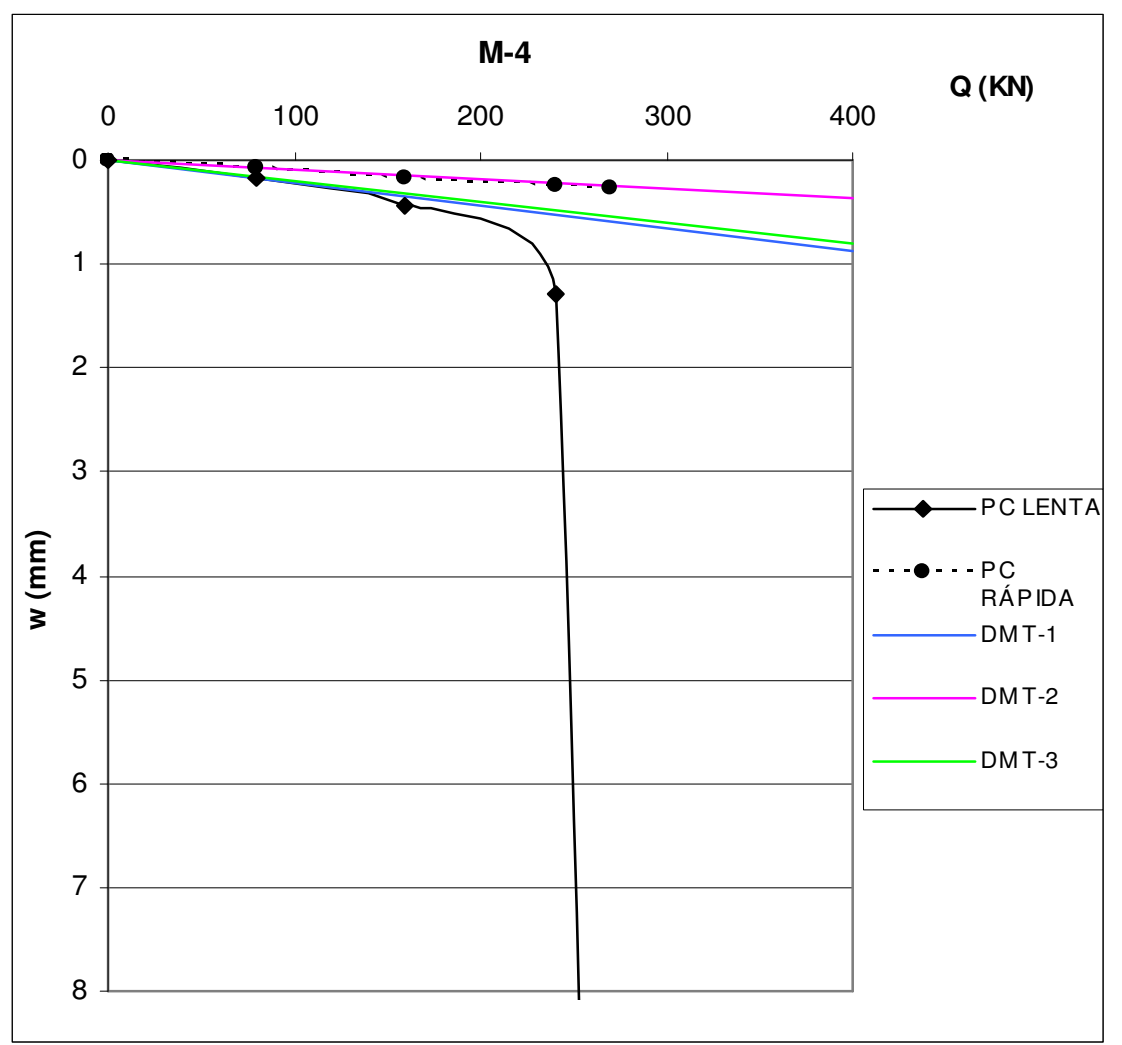

Figura 5.52 - Gráfico de carga versus recalque para micro-estaca (M-4), método de Poulos e Davis, utilizando expressão 3.43 .

Na Figura 5.50, observa-se que o recalque calculado através dos ensaios DMT-2 e DMT-3 (a estaca strauss localiza-se entre esses dois furos) se aproxima do recalque medido para a carga de trabalho, na prova de carga rápida.

O ensaio DMT-3 foi o que mais se aproximou dos recalques calculados para a estaca MET-1 se comparados aos medidos na prova de carga rápida e lenta, por este ser o furo mais próximo (Figura 5.51).

Na Figura 5.52, pode-se observar que apesar da estaca M-4 ter rompido na prova de carga lenta, antes de atingir a carga de trabalho, quando comparado com a prova de carga rápida os recalques calculados com o ensaio DMT-2 ficaram muito próximos.

A Tabela 5.4 apresenta um resumo dos recalques obtidos através do cálculo pelo método de Poulos e Davis utilizando o E da proposta de Marchetti (1997). Os valores da última coluna se referem aos DMT's mais próximos das estacas, conforme Tabela 5.2. 
Tabela 5.4 - Tabela resumo de recalques calculados pelo método de Poulos e Davis utilizando a proposta de Marchetti., 1997 ( $\left.\mathrm{E}=0,8 \mathrm{M}_{\mathrm{DMT}}\right)$.

\begin{tabular}{|c|c|c|c|c|}
\hline LEGENDA & $\begin{array}{c}\text { Carga de } \\
\text { trabalho } \\
(\mathrm{KN})\end{array}$ & $\begin{array}{c}\text { Recalque } \\
\text { ensaio lento } \\
(\mathrm{mm})\end{array}$ & $\begin{array}{c}\text { Recalque } \\
\text { ensaio rápido } \\
(\mathrm{mm})\end{array}$ & $\begin{array}{c}\text { Recalque } \\
\text { Poulos e Davis } \\
(\mathrm{mm})\end{array}$ \\
\hline HLC-4 & 400 & 7,62 & 1,42 & 1,98 \\
\hline HLC-6 & 480 & 1,28 & 0,76 & 1,64 \\
\hline FRA-1 & 670 & 1,62 & - & 1,78 \\
\hline FRA-2 & 670 & 1,38 & 1,24 & 1,78 \\
\hline EST-2 & 1600 & 88,21 & 77,81 & 5,53 \\
\hline BAR-1 & 2400 & 41,00 & 2,76 & 7,02 \\
\hline PRÉ-2 & 1300 & 2,57 & 4,13 & 5,38 \\
\hline PRÉ-4 & 1300 & 2,13 & 2,15 & 3,40 \\
\hline STR-1 & 400 & 4,92 & 0,84 & 0,80 \\
MET-1 & 500 & 3,05 & 3,1 & 1,94 \\
\hline M-4 & 400 & 34,16 & 0,27 & 0,36 \\
\hline
\end{tabular}

De sua análise pode-se concluir que os recalques obtidos nas provas de carga rápidas comparam-se bem com os recalques calculados pelo DMT para as estacas, M-4, MET-1, STR-1, HLC-4, PRE-4 e PRE-2. Para as estacas HLC-6 e FRA-1 e FRA-2 a comparação foi melhor com as provas de carga lenta. Para as estacas BAR-1 e EST-2 não se obteve bons resultados, pelos motivos expostos anteriormente.

\subsubsection{Método de Randolph e Wroth $(1977,1978)$}

As Figuras 5.53 a 5.63 mostram os resultados obtidos pelo método de Randolph e Wroth $(1977,1978)$, utilizando o $\mathrm{G}_{0}$ da proposta de Hryciw (1990), expressão 3.50.

O coeficiente de Poisson do solo utilizado para os cálculos foi 0,35 , por se tratar de um silte arenoso. A adoção deste módulo de cisalhamento inicial $\left(\mathrm{G}_{0}\right)$ foi justificada no item 4.3.2 da Revisão Bibliográfica.

De um modo geral, como os $\mathrm{G}_{0}$ variam relativamente pouco em relação ao ensaio de DMT-1, 2 e 3 (ver Figura 5.14), os valores calculados dos recalques foram praticamente coincidentes. 


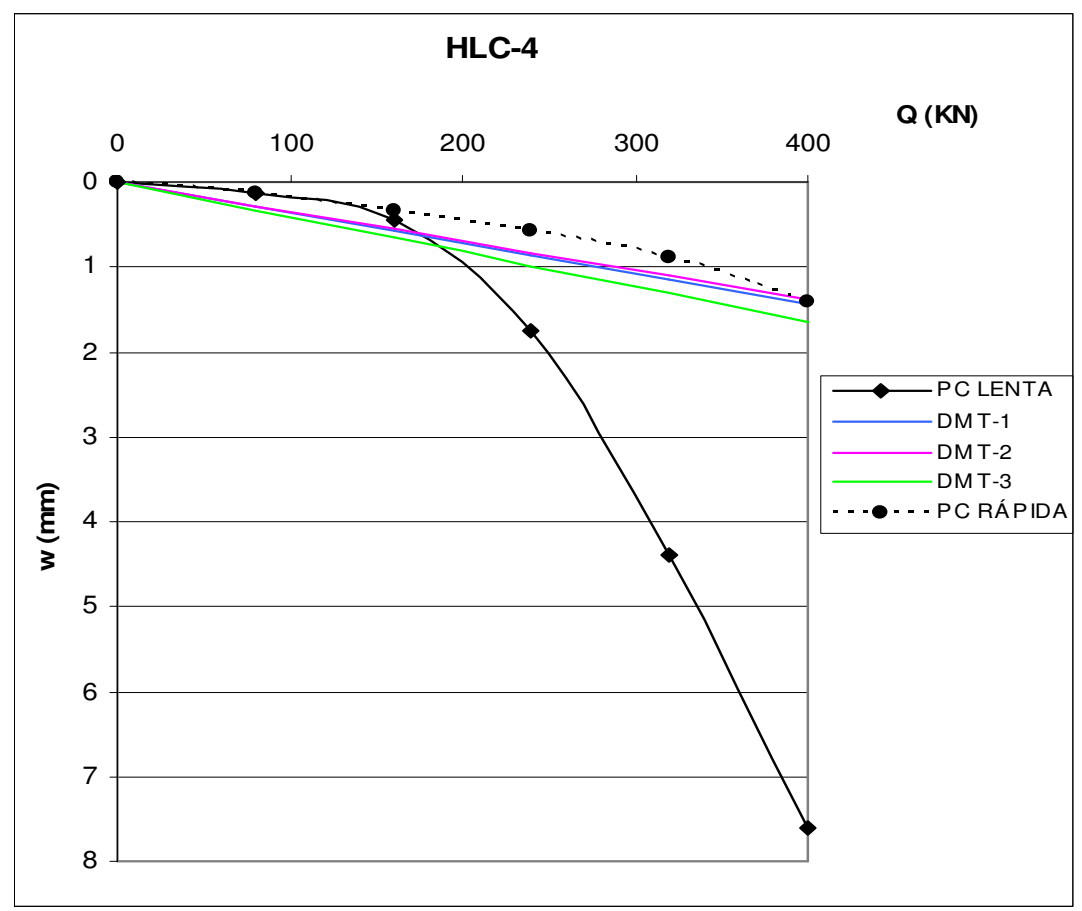

Figura 5.53 - Gráfico de carga versus recalque para estaca hélice (HLC-4), método de Randolph e Wroth $(1977,1978)$ utilizando a expressão 3.50.

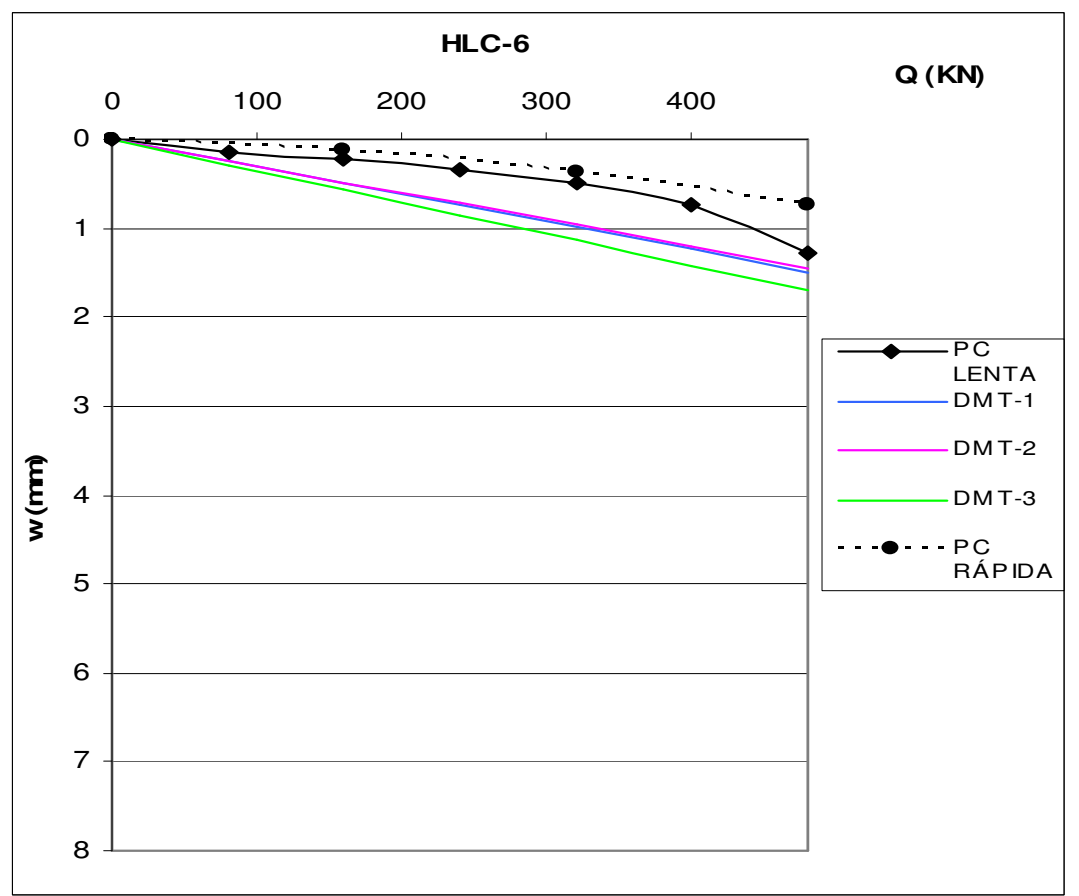

Figura 5.54 - Gráfico de carga versus recalque para estaca hélice (HLC-6), método de Randolph e Wroth $(1977,1978)$ utilizando a expressão 3.50.

Nas Figuras 5.53 e 5.54, os recalques calculados para as estacas hélice aproximaramse bem dos medidos nas provas de carga. 


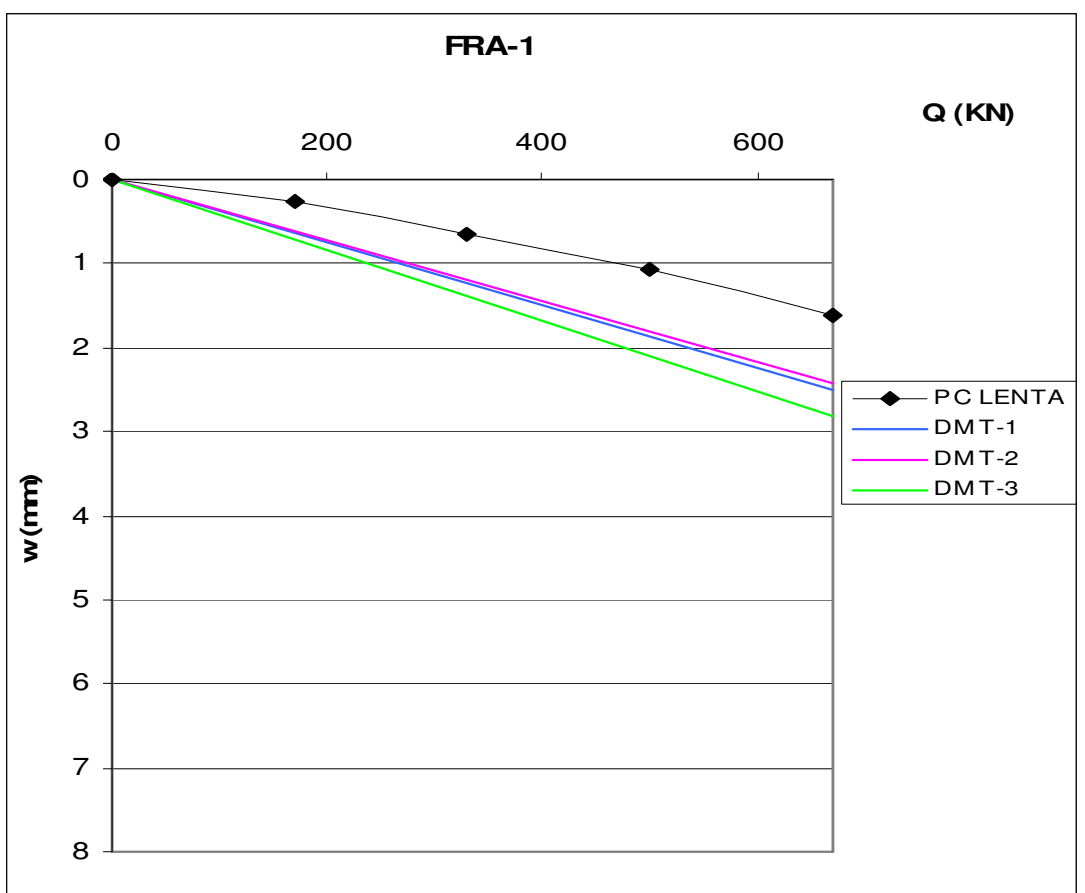

Figura 5.55 - Gráfico de carga versus recalque para estaca franki (FRA-1), método de Randolph e Wroth $(1977,1978)$ utilizando a expressão 3.50.

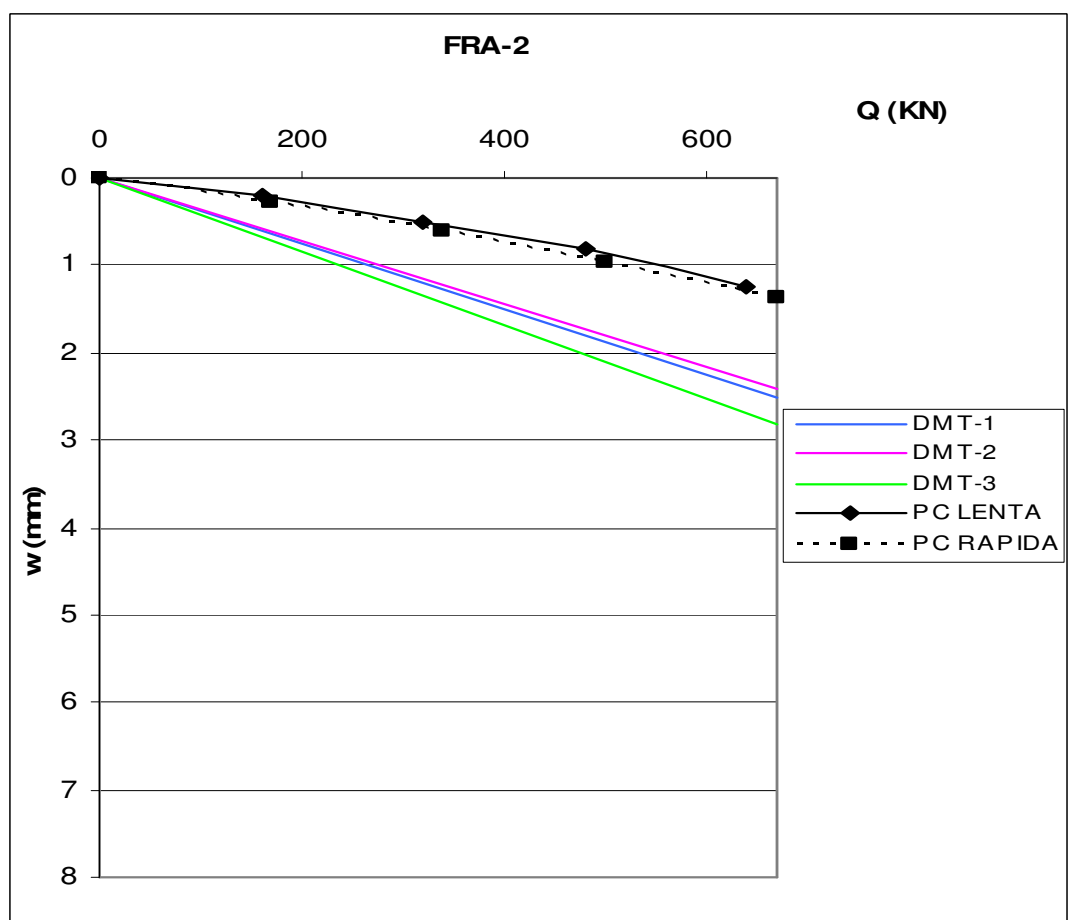

Figura 5.56 - Gráfico de carga versus recalque para estaca franki (FRA-2), método de Randolph e Wroth $(1977,1978)$ utilizando a expressão 3.50.

A comparação dos recalques medidos com os calculados, para as estacas FRA-1 e FRA-2, podem ser considerada como satisfatória, levando-se em conta que os valores apresentados nos gráficos são em milímetros. 


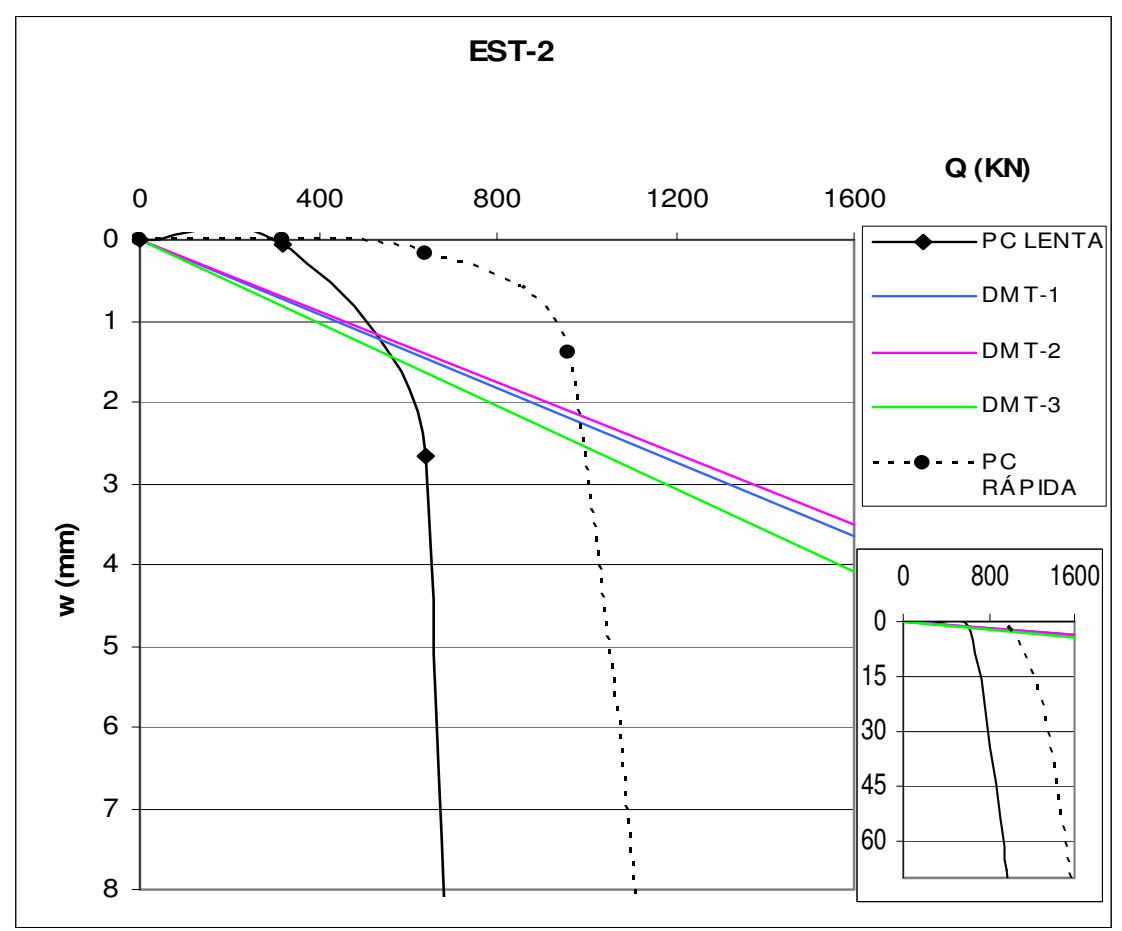

Figura 5.57 - Gráfico de carga versus recalque para o estacão (EST-2), método de Randolph e Wroth $(1977,1978)$ utilizando a expressão 3.50.

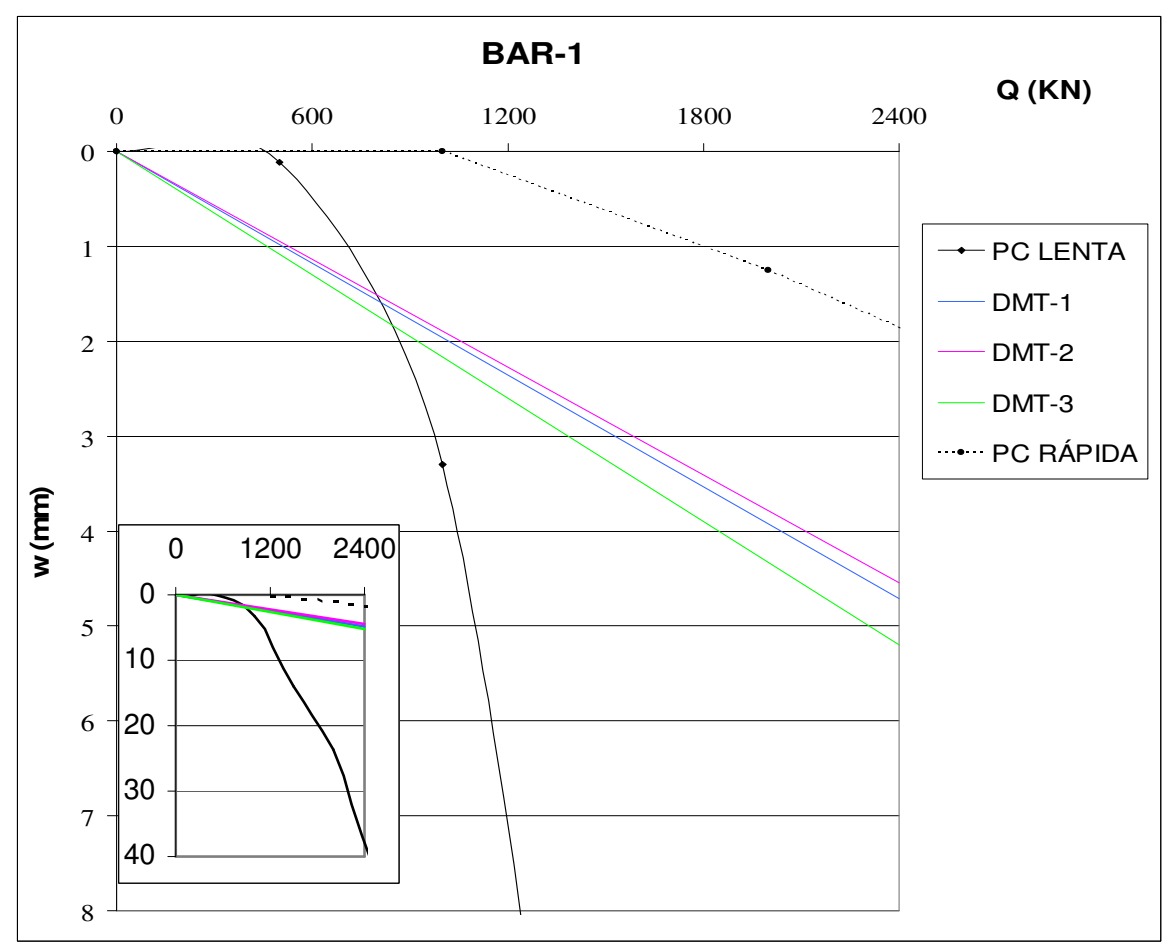

Figura 5.58 - Gráfico de carga versus recalque para estaca barrete (BAR-1), método de Randolph e Wroth $(1977,1978)$ utilizando a expressão 3.50.

Igualmente nas propostas apresentadas de Poulos e Davis, a previsão dos recalques calculados para o estacão e a barrete foi muito diferente dos medidos, talvez por estas estacas terem rompido antes de se atingir a carga de trabalho (Figura 5.56 e 5.57). 


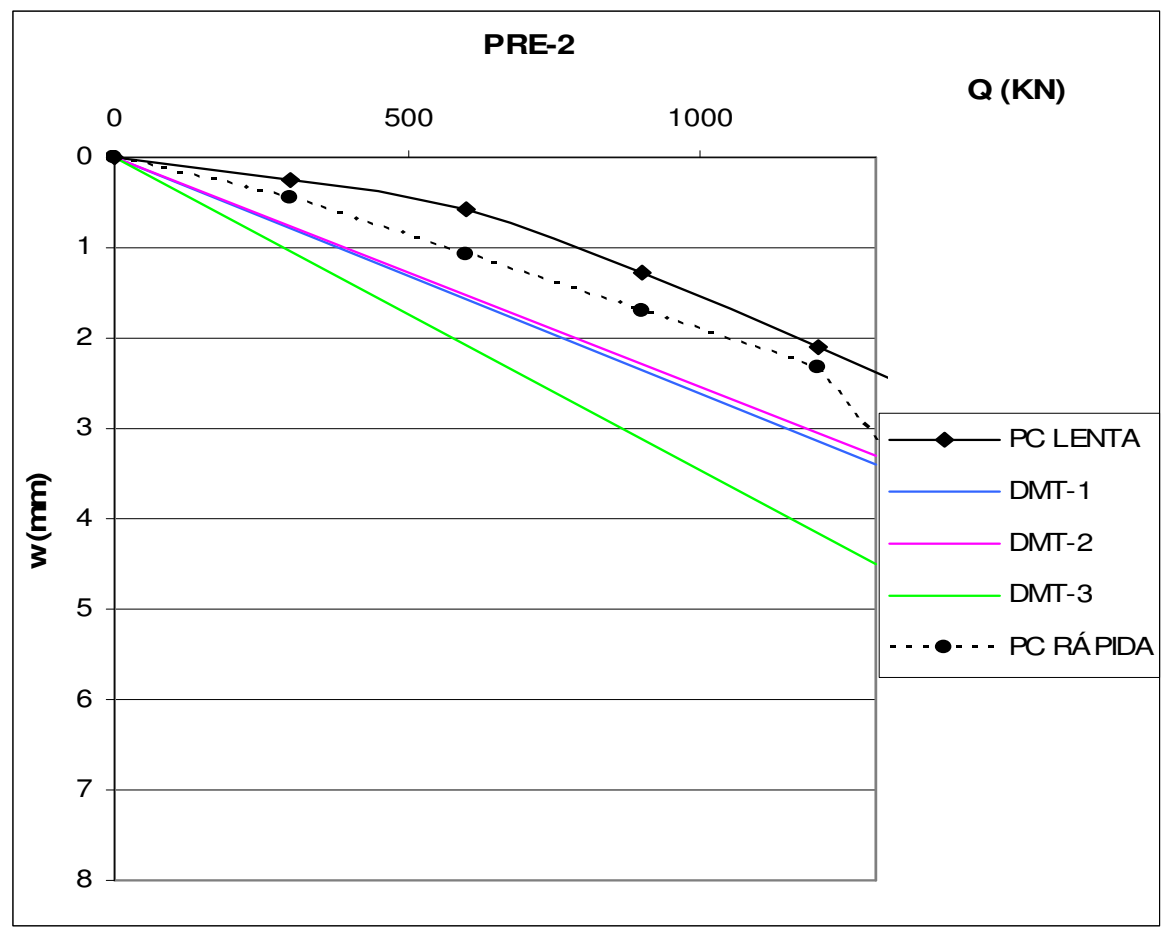

Figura 5.59 - Gráfico de carga versus recalque para estaca pré-moldada (PRE-2), método de Randolph e Wroth $(1977,1978)$ utilizando a expressão 3.50.

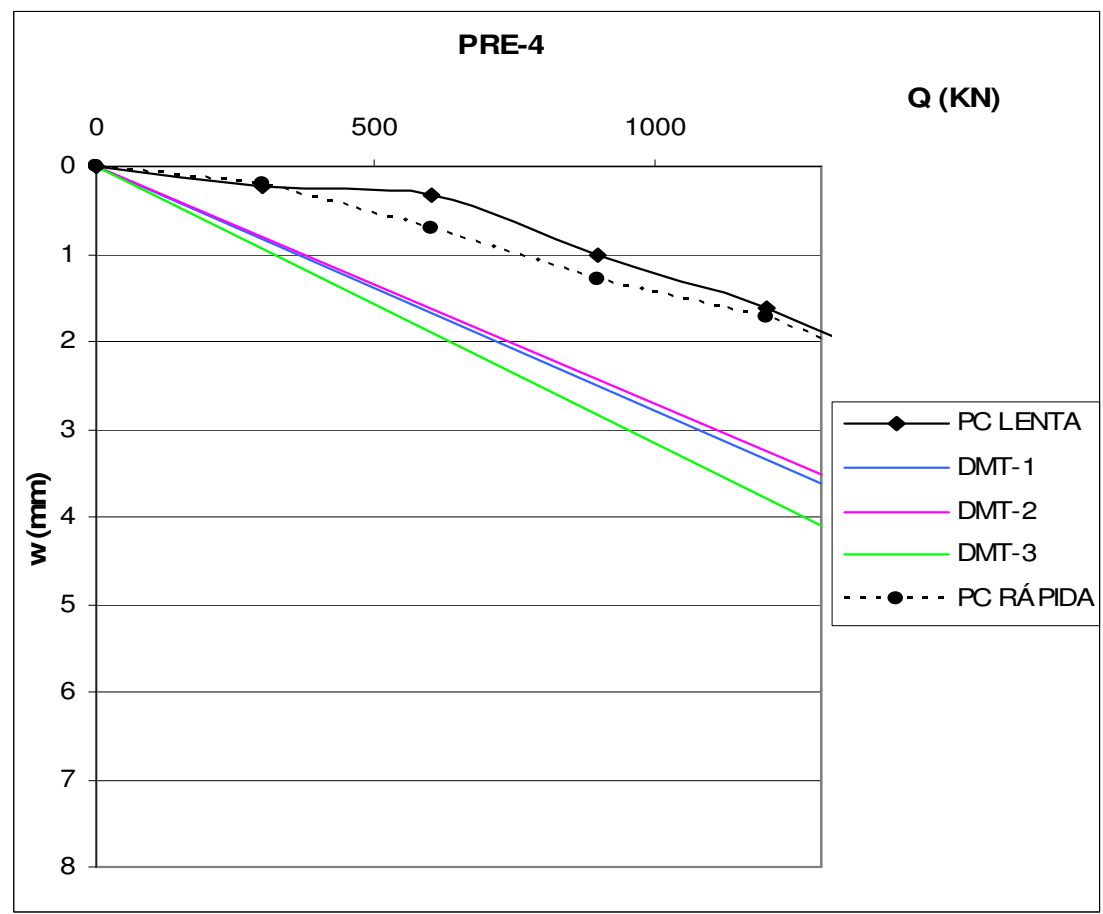

Figura 5.60 - Gráfico de carga versus recalque para estaca pré-moldada (PRE-4), método de Randolph e Wroth $(1977,1978)$ utilizando a expressão 3.50.

Verifica-se na Figura 5.59 e 5.60, que os recalques calculados para as estacas PRE-2 e PRE-4, não apresentaram boa concordância com os recalques medidos se comparados com os ensaios mais próximos, apresentados na Tabela 3.2. 


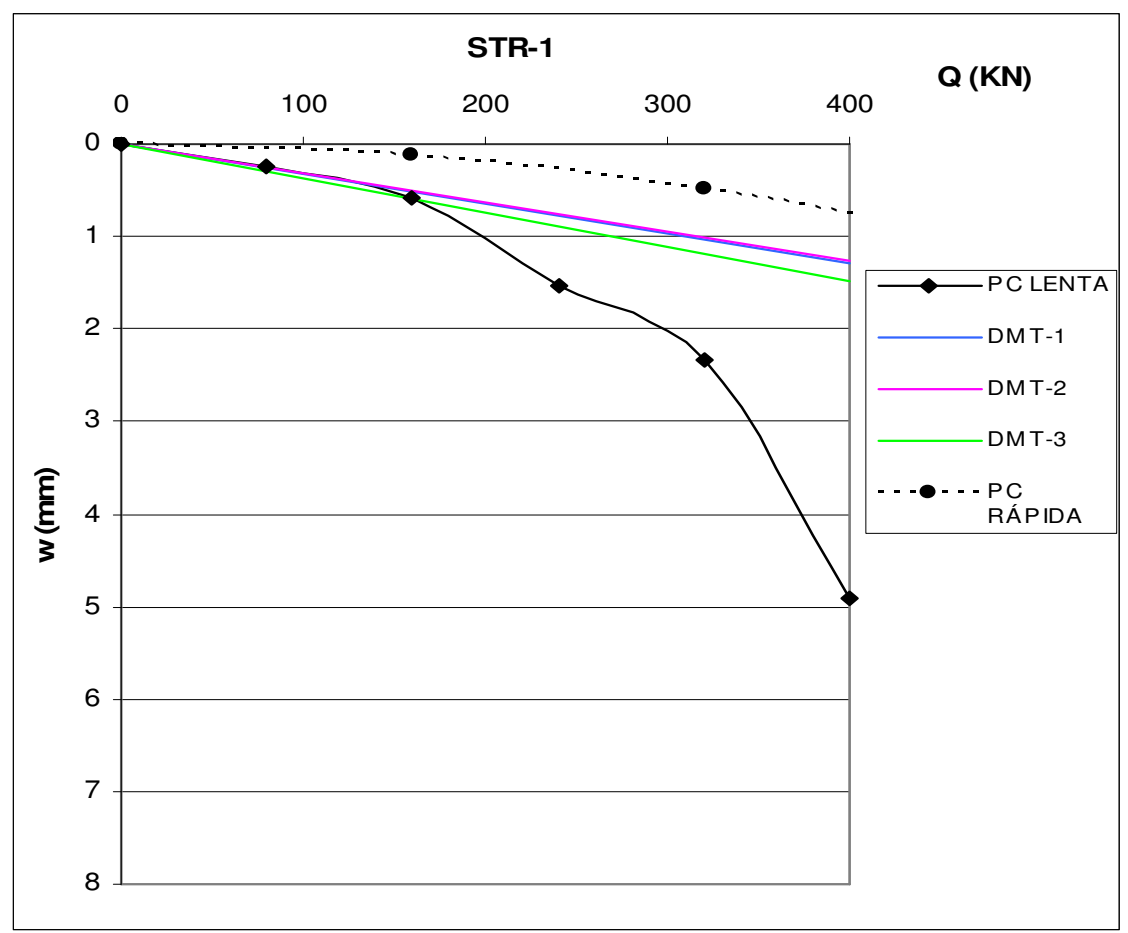

Figura 5.61 - Gráfico de carga versus recalque para estaca strauss (STR-1), método de Randolph e Wroth $(1977,1978)$ utilizando a expressão 3.50.

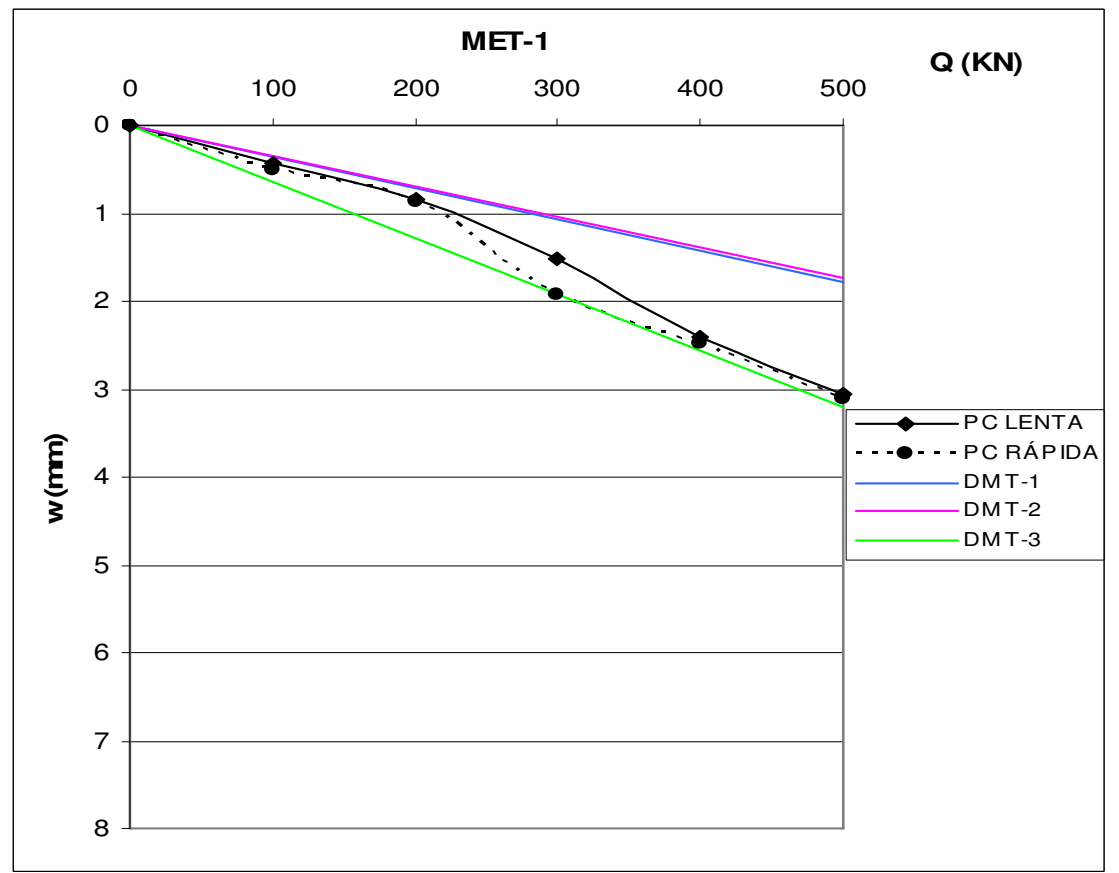

Figura 5.62 - Gráfico de carga versus recalque para estaca metálica (MET-1), método de Randolph e Wroth $(1977,1978)$ utilizando a expressão 3.50.

Na Figura 5.61, observa-se que o recalque calculado através dos ensaios se aproxima do recalque medido para a carga de trabalho, na prova de carga rápida.

O ensaio DMT-3 conseguiu prever os recalques medidos na prova de carga rápida e lenta, para a estaca MET-1, por este ser o furo mais próximo (Figura 5.62). 


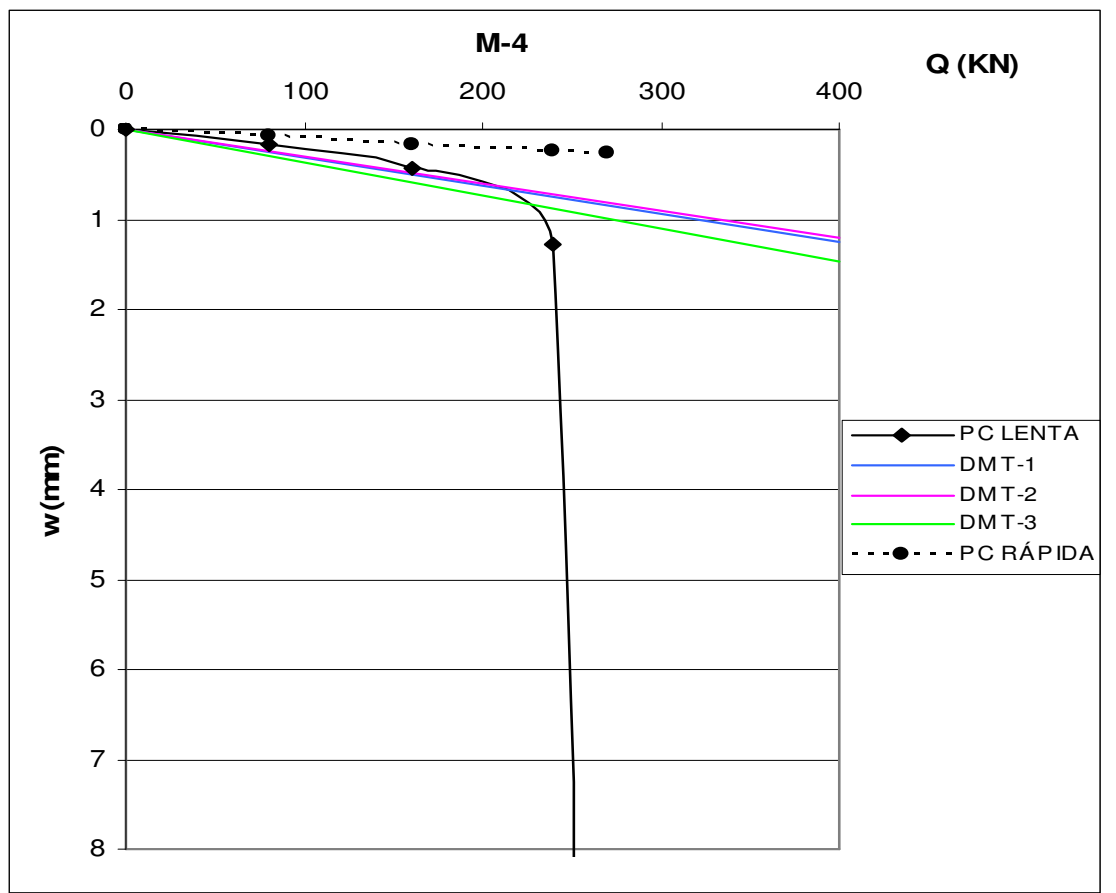

Figura 5.63 - Gráfico de carga versus recalque para micro-estaca (M-4), método de Randolph e Wroth $(1977,1978)$ utilizando a expressão 3.50.

Na Figura 5.63, pode-se observar que apesar da estaca M-4 ter rompido na prova de carga lenta, antes de atingir a carga de trabalho, quando comparado com a prova de carga lenta, até a carga de $230 \mathrm{KN}$, os recalques calculados com o ensaio DMT-2 ficaram muito próximos.

A Tabela 5.5 apresenta um resumo dos recalques obtidos através do cálculo pelo método de Randolph e Wroth $(1977,1978)$ e $\mathrm{G}_{0}$ da proposta de Hryciw, 1990 (eq. 3.49). Os valores da última coluna se referem aos ensaios de DMT's mais próximos das estacas.

Tabela 5.5 - Tabela resumo de recalques calculados pelo método de Randolph e Wroth (1977, 1978) utilizando o $\mathrm{G}_{0}$ proposto por Hryciw, 1990 (expressão 3.50).

\begin{tabular}{|c|c|c|c|c|}
\hline LEGENDA & $\begin{array}{c}\text { Carga de } \\
\text { trabalho } \\
(\mathrm{KN})\end{array}$ & $\begin{array}{c}\text { Recalque } \\
\text { ensaio lento } \\
(\mathrm{mm})\end{array}$ & $\begin{array}{c}\text { Recalque } \\
\text { ensaio rápido } \\
(\mathrm{mm})\end{array}$ & $\begin{array}{c}\text { Recalque } \\
\text { Randolph e Wroth } \\
(\mathrm{mm})\end{array}$ \\
\hline HLC-4 & 400 & 7,62 & 1,42 & 1,64 \\
\hline HLC-6 & 480 & 1,28 & 0,76 & 1,70 \\
\hline FRA-1 & 670 & 1,62 & - & 2,58 \\
\hline FRA-2 & 670 & 1,38 & 1,24 & 2,58 \\
\hline EST-2 & 1600 & 88,21 & 77,81 & 3,52 \\
\hline BAR-1 & 2400 & 41,00 & 2,76 & 4,54 \\
\hline PRÉ-2 & 1300 & 2,57 & 4,13 & 4,49 \\
\hline PRÉ-4 & 1300 & 2,13 & 2,15 & 3,51 \\
\hline STR-1 & 400 & 4,92 & 0,84 & 1,34 \\
\hline MET-1 & 500 & 3,05 & 3,1 & 3,20 \\
\hline M-4 & 400 & 34,16 & 0,27 & 1,22 \\
\hline
\end{tabular}




\subsubsection{Comparação entre os Métodos de cálculo}

Para uma comparação mais efetiva entre os métodos de Poulos e Davis, de um lado, e o método Randolph e Wroth, de outro, procedeu-se a cálculos em que foram mantidas fixas as formas de estimar os parâmetros elásticos, com está indicado na Tabela 5.6.

Tabela 5.6 - Indicação de parâmetros utilizados.

\begin{tabular}{|c|c|c|c|}
\hline $\begin{array}{c}\text { Estimativa de } \\
\text { parâmetros elásticos }\end{array}$ & $\begin{array}{c}\text { Método de } \\
\text { Poulos e Davis }\end{array}$ & $\begin{array}{c}\text { Método de Randolph } \\
\text { e Wroth }\end{array}$ & Resultados \\
\hline Robertson et al (1989) & $\mathrm{E}=4 . \mathrm{E}_{\mathrm{D}}$ & $\mathrm{G}_{0}=4 . \mathrm{E}_{\mathrm{D}} / 2(1+\mathrm{v})$ & Figuras 5.64 e 5.65 \\
\hline Marchetti $(1997)$ & $\mathrm{E}=0,8 . \mathrm{M}_{\mathrm{DMT}}$ & $\mathrm{G}_{0}=0,8 . \mathrm{M}_{\mathrm{DMT}} / 2(1+\mathrm{v})$ & Figuras 5.66 e 5.67 \\
\hline Hryciw $(1977,01978)$ & $\mathrm{E}=2(1+\mathrm{v}) \cdot \mathrm{G}_{0}$ & $\left(\mathrm{G}_{0}\right.$ da expressão 3.50) & Figuras 5.68 e 5.69 \\
\hline
\end{tabular}

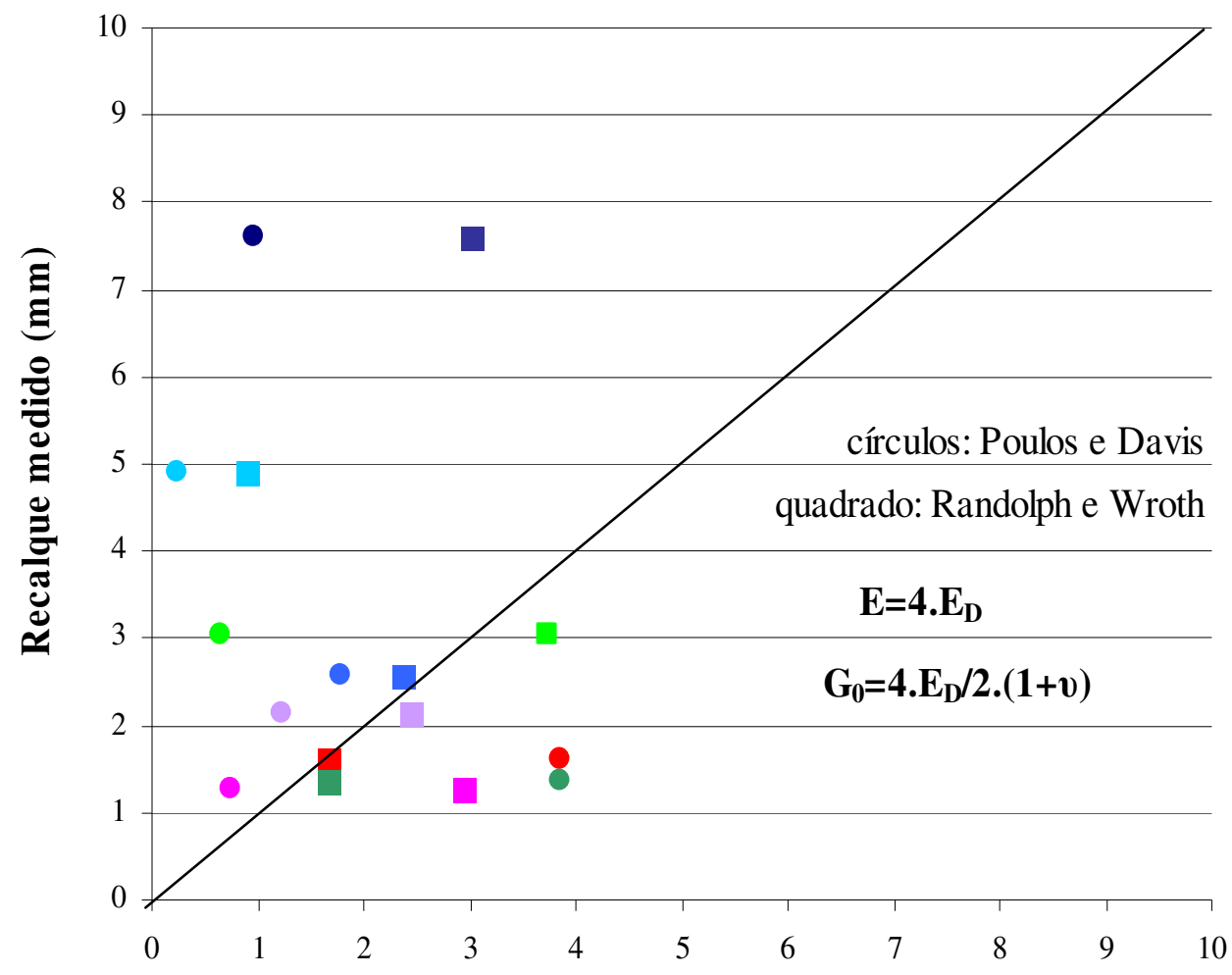

- HLC-4 - P

- HLC-6 - P

- FRA-1 - P

- FRA-2 - P

- PRE-2 - P

- PRE-4 - P

- STR-1 - P

- MET-1- P

HLC-4 - R

HLC-6 - R

FRA-1 - R

FRA-2 - R

PRE-2 - R

PRE-4 - R

STR-1 - R

MET-1- R

Recalque

calculado

(mm)

Figura 5.64 - Comparação entre recalques medidos no ensaio lento e recalques calculados. 


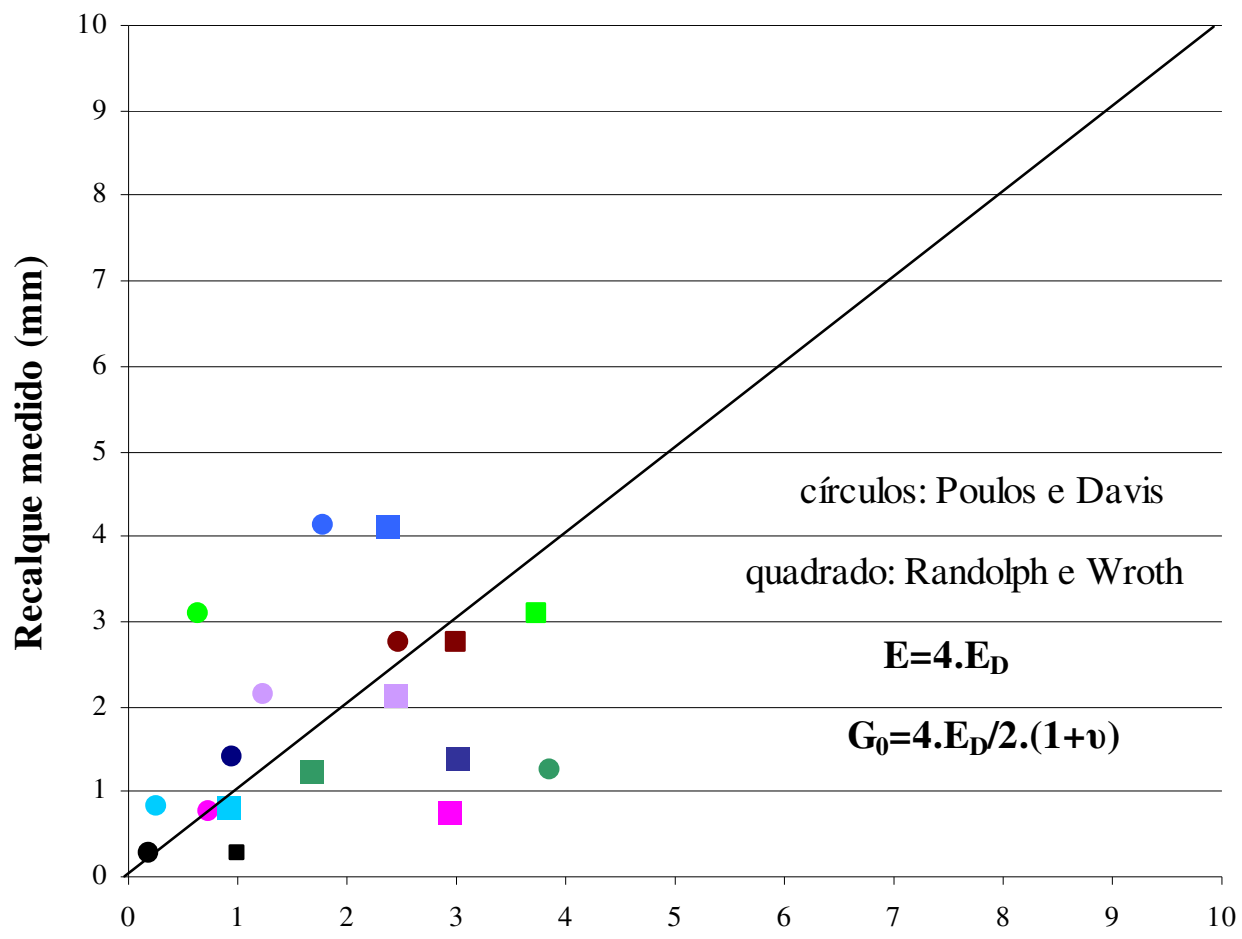

- HLC-4 - P

- HLC-6 - P

- FRA-2 - P

- BAR-1 - P

- PRE-2 - P

PRE-4 - P

- STR-1 - P

- MET-1 - P

- M-4 - P

HLC-4 - R

HLC-6 - R

FRA-2 - R

- BAR-1 - R

PRE-2 - R

PRE-4 - R

STR-1 - R

MET-1 - R

- M-4 - R

\section{Recalque} calculado (mm)

Figura 5.65 - Comparação entre recalques medidos no ensaio rápido e recalques calculados.

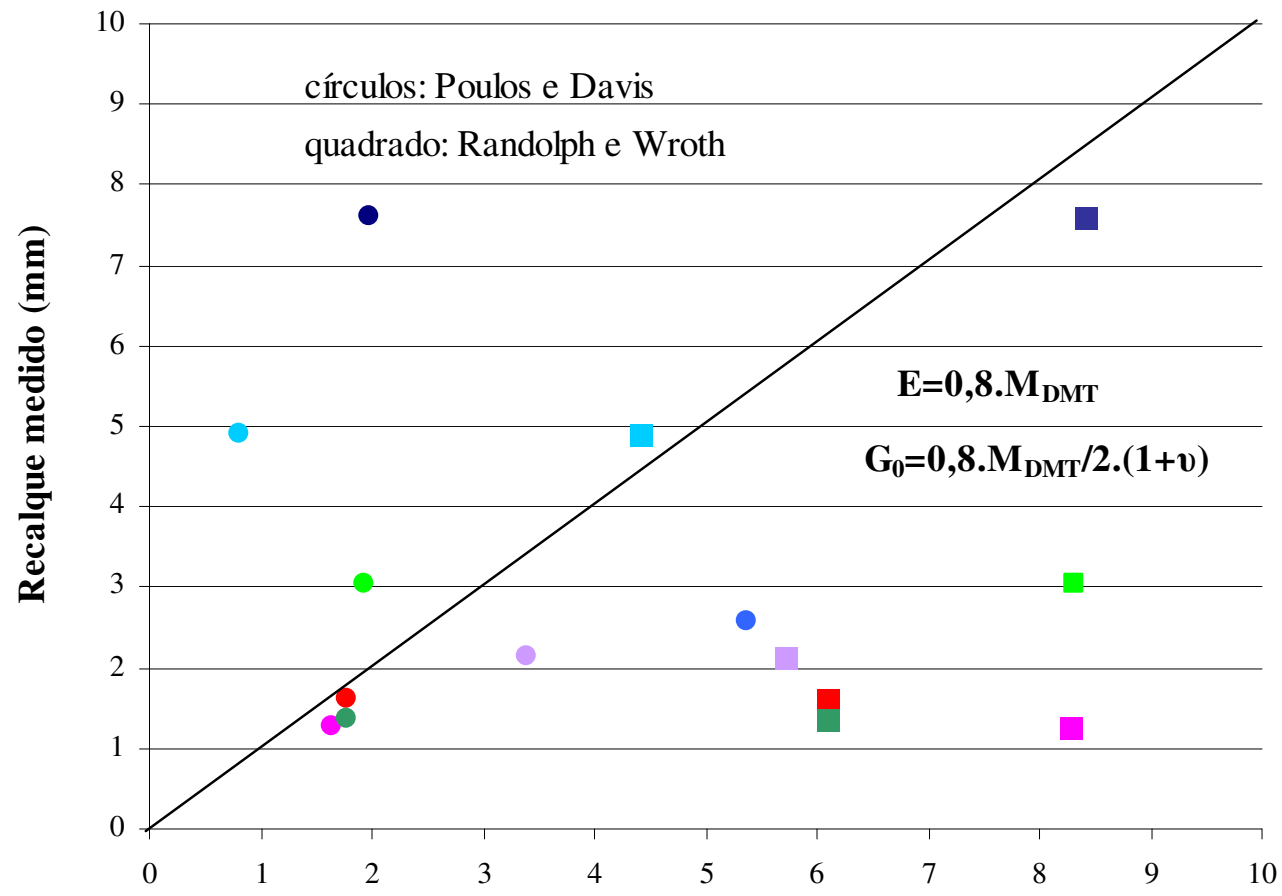

- HLC-4 - P

- HLC-6 - P

- FRA-1 - P

- FRA-2 - P

- PRE-2 - P

- PRE-4 - P

- STR-1 - P

- MET-1 - P

HLC-4 - R

HLC-6 - R

FRA-1 - R

FRA-2 - R

PRE-2 - R

PRE-4 - R

STR-1 - R

MET-1 - R

Recalque calculado (mm)

Figura 5.66 - Comparação entre recalques medidos no ensaio lento e recalques calculados. 


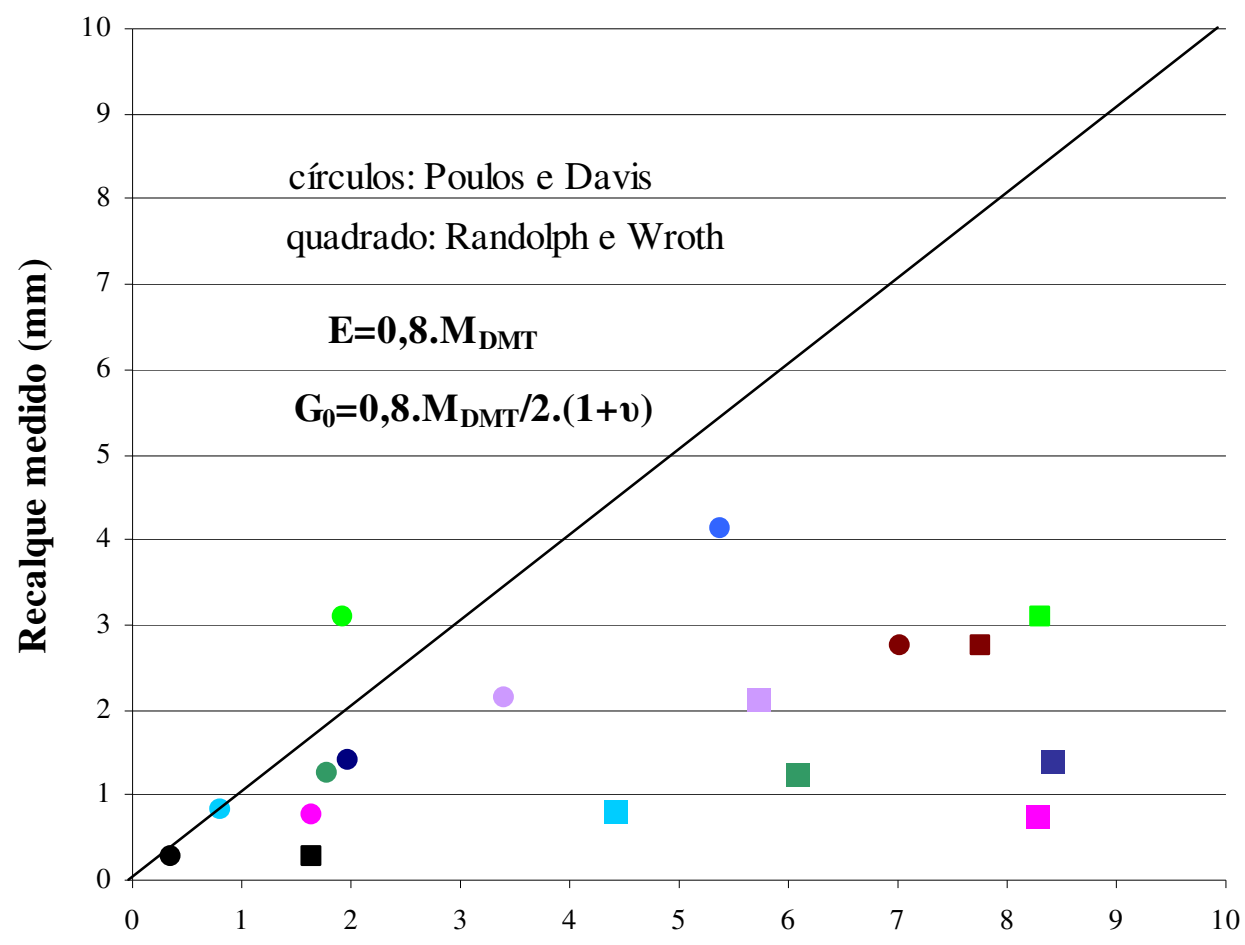

- HLC-4 - P

HLC-6 - P

- FRA-2 - P

- BAR-1 - P

PRE-2 - P

- PRE-4 - P

- STR-1 - P

MET-1 - P

- M-4 - P

HLC-4 - R

HLC-6 - R

FRA-2 - R

- BAR-1 - R

PRE-2 - R

PRE-4 - R

STR-1 - R

MET-1 - R

- M-4 - R

\section{Recalque} calculado (mm)

Figura 5.67 - Comparação entre recalques medidos no ensaio rápido e recalques calculados.

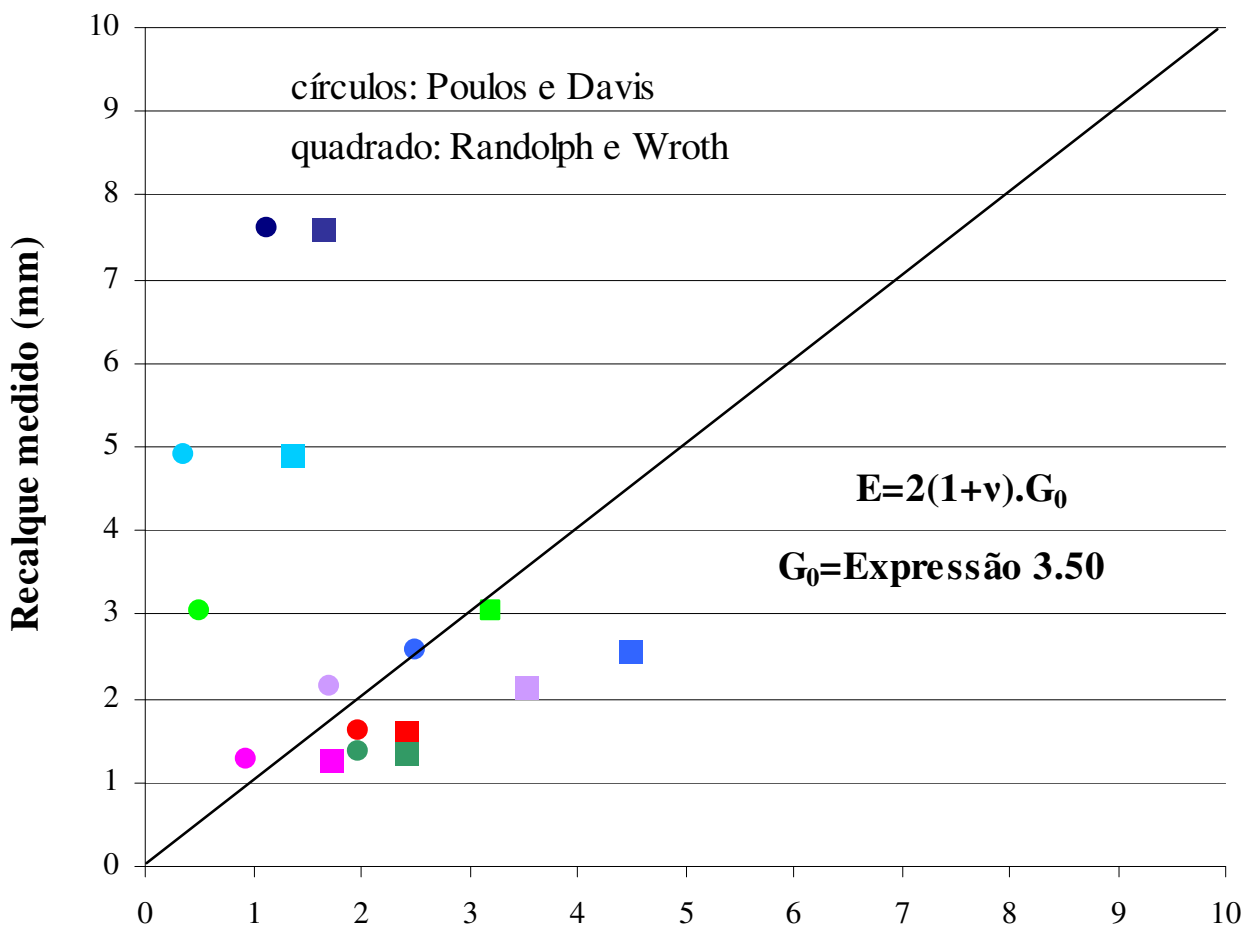

- HLC-4 - P

- HLC-6 - P

- FRA-1 - P

- FRA-2 - P

- PRE-2 - P

PRE-4 - P

- STR-1 - P

- MET-1 - P

HLC-4 - R

HLC-6 - R

FRA-1 - R

FRA-2 - R

PRE-2 - R

PRE-4 - R

STR-1 - R

MET-1 - R

Recalque calculado (mm)

Figura 5.68 - Comparação entre recalques medidos no ensaio lento e recalques calculados. 


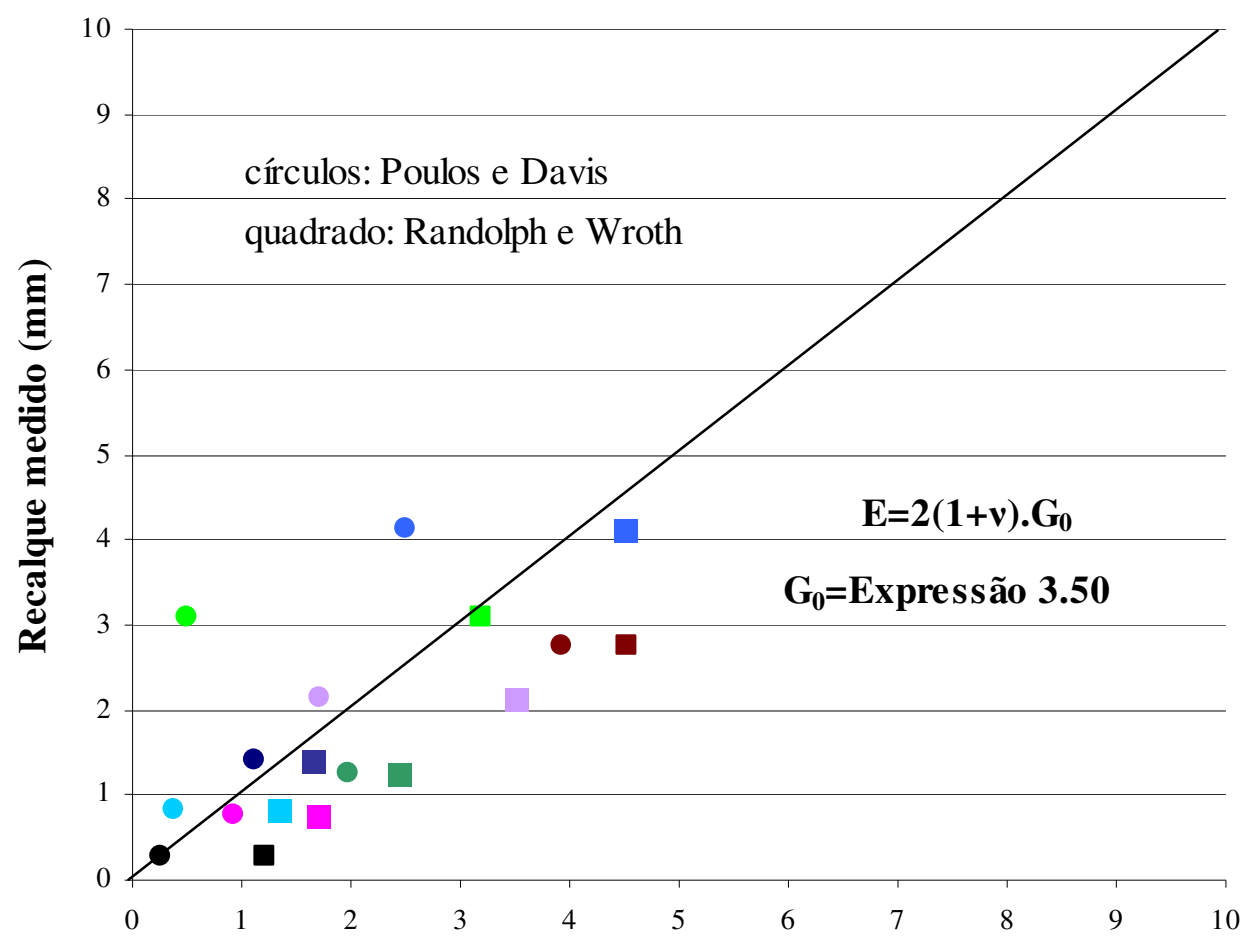

- HLC-4 - P

- HLC-6 - P

- FRA-2 - P

- BAR-1 - P

- PRE-2 - P

- PRE-4 - P

- STR-1 - P

- MET-1 - P

- M-4 - P

- HLC-4 - R

- HLC-6 - R

FRA-2 - R

- BAR-1 -R

DRE-2 - R

PRE-4 - R

- STR-1 - R

MET-1 - R

- M-4 - R

Recalque calculado (mm)

Figura 5.69 - Comparação entre recalques medidos no ensaio rápido e recalques calculados.

As estacas EST-2, BAR-1 e M-4 não foram incluídas nas Figuras 5.64, 5.66 e 5.68, por terem seus recalques medidos na prova de carga lenta valores muito altos se comparados com os calculados pelo DMT e com os recalques das demais estacas, o que prejudicaria a visualização dos gráficos e não acrescentaria nenhuma informação.

De uma forma geral os recalques calculados pelo método de Randolph e Wroth se aproximaram mais dos recalques medidos, tanto para as provas de carga lentas quanto para as rápidas, utilizando a proposta de Robertson et al (1989) como entrada do parâmetro elástico, no caso $\mathrm{G}_{0}=4 . \mathrm{E}_{\mathrm{D}} / 2(1+v)$, observados nas Figuras 5.64 e 5.65 .

Os recalques estimados pelo método de Poulos e Davis se aproximaram mais do recalques medidos, tanto para as provas de carga lentas quanto para as rápidas, utilizando a proposta de Hryciw $(1977,1978)$ como entrada do parâmetro elástico, no caso $E=2(1+v) \cdot G_{0}$, sendo $\mathrm{G}_{0}$ calculado através da expressão 3.50. Tal comentário pode ser observado nas Figuras 5.68 e 5.69 .

As Figuras 5.66 e 5.67 foram as que apresentaram maior dispersão dos recalques calculados e medidos, tanto para a proposta de Poulos e Davis quanto para Randolph e Wroth. 


\section{CONCLUSÕES}

A seguir, serão apresentadas as principais conclusões desta pesquisa, no que se refere:

a) à revisão bibliográfica;

b) à classificação e parâmetros dos solos;

c) à previsão da capacidade de carga; e

d) à estimativa dos recalques.

\subsection{Revisão Bibliográfica}

A revisão bibliográfica permitiu constatar os seguintes pontos:

- o uso do DMT é pouco difundido no Brasil;

- a existência de várias propostas para a estimativa de parâmetros dos solos, revela que não se atingiu, até o momento, consenso entre os autores; e

- a existência de alguma deficiência na classificação dos solos dos Campos Experimentais da UNICAMP, USP de São Carlos e UNESP, pelo DMT, que levou a uma inversão de camadas como argila arenosa ou areia argilosa, classificando-as em faixas de silte, conforme Giacheti et al (2006).

\subsection{Classificação e parâmetros dos solos}

A classificação do solo do Campo Experimental da USP(CEUSP), feita através do DMT, foi coerente tanto com as análises tátil-visuais dos testemunhos das sondagens à percussão quanto com os ensaios granulométricos, apresentados na publicação da ABEF (1989).

As novas sondagens à percussão, executadas próximas aos ensaios dilatométricos, apresentaram uma boa concordância com as sondagens realizadas anteriormente, apresentadas pela ABEF, (1989) e por Peixoto (2001), relativamente aos tipos de solos ocorrentes, à sua grande heterogeneidade, aos valores do número de golpes (N do SPT) e aos torques $(\mathrm{T})$.

Obteve-se outra boa concordância com os parâmetros intermediários do DMT, calculados neste trabalho, quando comparados aos resultados obtidos por Siviero (2003), em dois furos de DMT no CEUSP. 
O peso específico natural, estimado através da proposta de Marchetti e Craps (1981), aproximou muito bem dos resultados apresentados pela ABEF (poço de exploração I, II e III). Os valores do módulo edométrico (M) também se situaram bem próximos dos obtidos por Siviero (2003).

A razão de sobre-adensamento (OCR), determinada através do DMT, permitiu identificar o solo do CEUSP como sobre-adensado. Tal fato pode ser confirmado pela boa concordância que se encontrou entre o coeficiente de empuxo em repouso $\left(\mathrm{K}_{0}\right)$ para solos arenosos (Schmertmann, 1983), quando comparado com valores inferidos dos ensaios laboratoriais, divulgados pela ABEF (1989).

Ainda para os parâmetros dos solos, os valores dos ângulos de atrito efetivo ( $\left.\phi^{\prime}\right)$, calculados com base no DMT, a partir da proposta de Marchetti (1997), expressão 3.37, se mostraram satisfatórios quando comparados aos calculados através das envoltórias de tensão dos ensaios drenados, fornecidos pela ABEF (1989).

\subsection{Previsão da Capacidade de Carga em estacas}

Analisando as parcelas de atrito e ponta, separadamente, conclui-se que:

- o Método de Powell subestimou a resistência de ponta das estacas instrumentadas do CEUSP, inclusive das estacas piloto instrumentadas (Souza, 2001), com exceção das estacas "tipo hélice contínua” (HLC-4 e HLC-6);

- já o Método de Terzaghi superestimou a resistência de ponta, com exceção das estacas STR-1, BAR-1 e EPI-3, para as quais obteve-se resultados muito aproximados se comparados com os valores medidos;

- os Métodos de Berezantzev (1961) e Vesic (1972) também superestimaram a resistência de ponta das estacas, na sua grande maioria, tendo este último autor diferenças entre as resistências medidas e calculadas em mais de $100 \%$;

- os atritos unitários médios das estacas, estimados pelo Método de Powell et al (2001), se mostraram muito semelhantes aos resultados encontrados nas provas de carga das estacas HLC-4, HLC-6 (DMT-3) e STR-1 (Média) e nas instalações e nas provas de carga das EPI-1, EPI-2 e EPI-3 (DMT-1). A exceção ficou por conta do DMT-2, em que houve uma discrepância considerável com relação às estacas BAR-1 e EST-2; e

- o Método de tensões efetivas (" $\beta$ “), calculado pela proposta de Burland, (solo n.a.), subestimou o atrito lateral unitário médio das estacas. 
Com base nas análises feitas no Capítulo 5, foi preparada a Figura 6.1, para um melhor entendimento dos resultados obtidos para as cargas totais. As linhas horizontais tracejadas, na cor vermelha, indicam as cargas de ruptura ou as cargas máximas, medidas nas provas de carga.
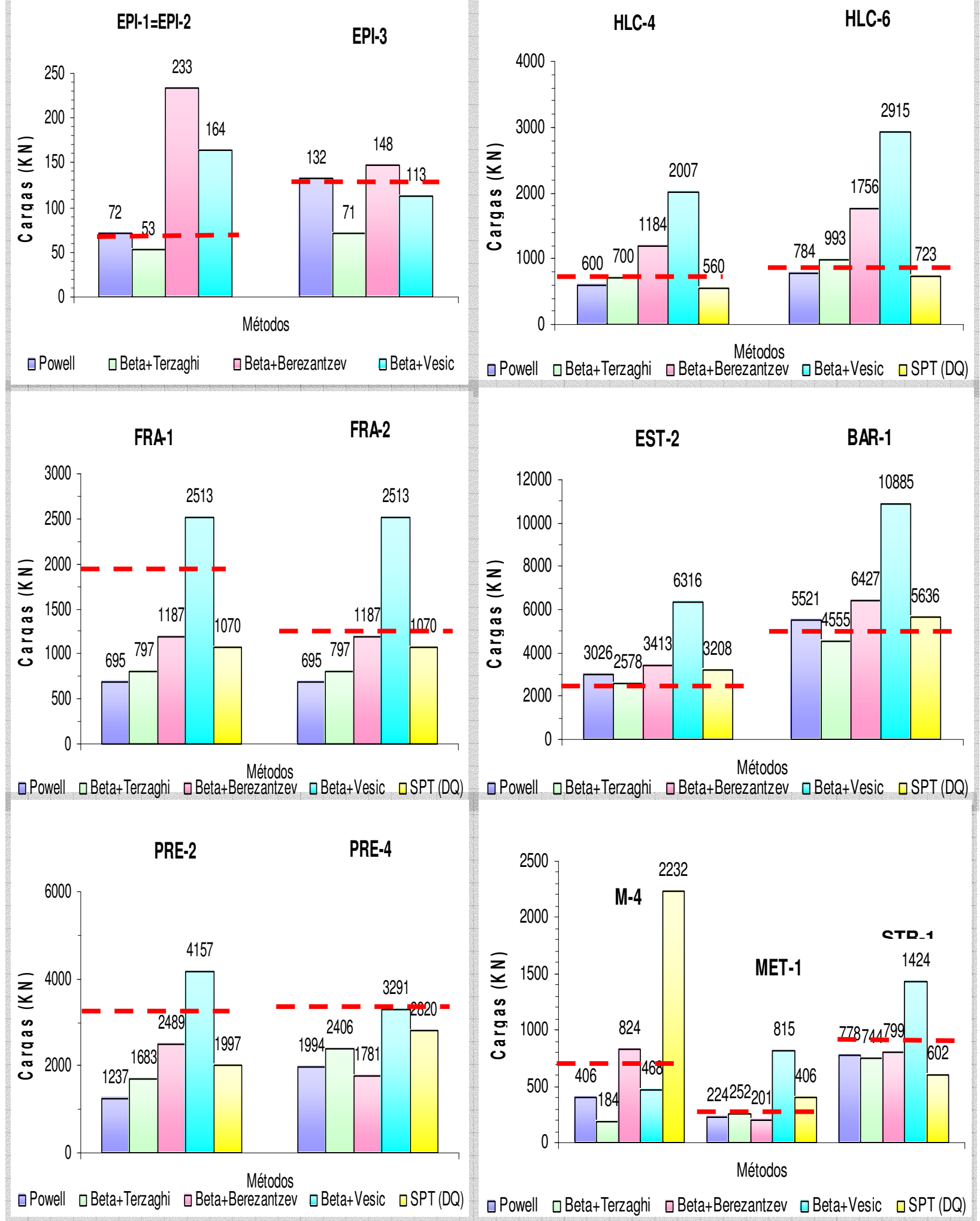

Figura 6.1 - Comparação da capacidade de carga medida nas provas de carga das estacas executadas no CEUSP e as capacidades de carga previstas por diferentes métodos. 
Esta figura contêm as previsões das capacidades de carga de todas as estacas, analisadas pelo métodos baseados no DMT, a saber: o método semi-empírico (Powell) e os métodos teóricos $(\beta+$ Terzaghi, $\beta+$ Berezantzev, $\beta+$ Vesic). Entendeu-se que para uma melhor comparação entre os métodos que utilizam o DMT, apresentados nesta pesquisa, era interessante também incluir um método de previsão de capacidade de carga baseado no SPT. Escolheu-se, então o método de Decourt-Quaresma apud Decourt (1996).

Observa-se na Figura 6.1 que para as estacas EPI-1, EPI-2, EPI-3, HLC-4, HLC-6, EST-2, BAR-1, MET-1 e STR-1 os métodos de Powell e $\beta+$ Terzaghi forneceram as melhores estimativas da capacidade de carga, sempre mais próximas do que a previsão pelo método de Decourt-Quaresma, que utiliza o SPT.

Ainda analisando a Figura 6.1, pode-se observar que as estacas FRA-2, PRE-2 e M-4 tiveram suas capacidades de carga muito próximas às medidas nas provas de carga quando estimadas pela proposta de $\beta+$ Berezantzev. Mais uma vez o método de Decourt-Quaresma, que utiliza o SPT, se aproximou menos da carga medida das estacas, quando comparado com o método de $\beta+$ Berezantzev. Em particular, para a estaca M-4, o método de DecourtQuaresma superestimou a capacidade de carga da estaca em mais de 3 vezes.

E por fim o método que melhor se adequou para a previsão de capacidade de carga das estacas FRA-1 e PRE-4 foi o $\beta+$ Vesic, com resultados mais próximos dos medidos do que o método de Decourt-Quaresma.

Das análises acima pode-se concluir que para a previsão da capacidade de carga de estacas o uso do ensaio dilatométrico se mostrou muito eficiente, até mais eficiente do que metodologia que vem se empregando sistematicamente no Brasil, que se baseia nos resultados da sondagem à percussão.

\subsection{Estimativa dos recalques elásticos em estacas}

No que se refere à previsão dos recalques elásticos das estacas, isto é, recalques para cargas inferiores à carga de trabalho, foi possível concluir o que segue.

O emprego do ensaio dilatométrico para a previsão dos recalques elásticos se mostrou 
ora muito bom, ora satisfatório, para a maioria das estacas, com exceção das estacas do tipo barrete (BAR-1) e estacão (EST-2).

Já para a micro-estaca (M-4), até a carga de aproximadamente $220 \mathrm{KN}$, as propostas apresentadas Poulos e Davis e Randolph e Wroth mostraram-se bastante adequadas, conforme as Figuras 5.41, 5.52 e 5.63.

De uma forma geral os recalques calculados pelo método de Randolph e Wroth se aproximaram mais dos recalques medidos, tanto para as provas de carga lentas quanto para as rápidas, utilizando a proposta de Robertson et al (1989) como entrada do parâmetro elástico, no caso $\mathrm{G}_{0}=4 . \mathrm{E}_{\mathrm{D}} / 2(1+v)$, como se pode observar nas Figuras 5.64 e 5.65.

Para o método de Poulos e Davis os recalques estimados se aproximaram mais do recalques medidos, tanto para as provas de carga lentas quanto para as rápidas, utilizando a proposta de Hryciw $(1977,1978)$ como entrada do parâmetro elástico, no caso $E=2(1+v) \cdot G_{0}$, sendo $\mathrm{G}_{0}$ calculado através da expressão 3.50, conforme as Figuras 5.68 e 5.69.

\subsection{Conclusão geral quanto ao uso do DMT para fundações em estacas}

Conclui-se, portanto, que a utilização do ensaio de DMT, para a previsão da capacidade de carga e dos recalques elásticos em estacas, pode ser uma ferramenta muito importante para a tomada de decisão dos projetos de fundação profunda. Longe de se pretender excluir a sondagem à percussão, mesmo porque, esta é extremamente importante para o reconhecimento e classificação do solo, visto que o DMT não retira amostra do solo.

O ideal é que se façam mais investigações geotécnicas para a realização de projetos de fundação, pois a prática de se executar apenas ensaios de SPT prejudica um entendimento mais profundo do comportamento do solo, muitas vezes gerando dúvidas no que diz respeito à elaboração do projeto de fundações e também desperdícios do ponto de vista econômico. 


\section{SUGESTÃO PARA FUTURAS PESQUISAS}

Para futuras pesquisas sugerem-se as seguintes propostas:

a) Analisar a capacidade de carga das estacas por outros métodos teóricos não utilizados nesta pesquisa;

b) Ajustar as correlações aqui apresentadas, ou estabelecer novas correlações, para a estimativa dos parâmetros do solo, via ensaios dilatométricos;

c) Aprimorar o Método de Powell (2001) ou desenvolver novas metodologias de previsão direta de capacidade de carga e estimativa de recalque com o DMT, desenvolvidas especificamente para solos siltosos.

d) Construir banco de dados de ensaios de DMT, feitos em solos brasileiros, para prever o comportamento de fundações diretas e profundas. Sempre com resultados de provas de carga e monitoração de recalques da obra, para que se possa chegar a estimativas mais realistas dos parâmetros dos solos brasileiros. 


\section{REFERÊNCIAS BIBLIOGRÁFICAS.}

Astm Subcommittee D18.02. (1986) - Suggested Method for Performing the Flat Dilatometer Test. Geotechnical Testing Journal, Vol.9, N.2, June 1986, p.93-101.

AstM-D-3441 (1995) - Standard Test Method for Deep, Quasi-Static, Cone and Friction-Cone Penetration Tests of Soil.

AsTM D-5778 (1995) - Standard Test Method for Performing Electronic Friction Cone and Piezocone Penetration Testing of Soils.

ABEF (1989). ABEF Research on Foundation Engineering, Published on the occasion of the XII ICSMF.

Alonso, U. R. (1991). Carga Admissível de Estacas Utilizando-se o Ensaio C.P.T. In: Seminário de Engenharia de Fundações Especiais 2, São Paulo, ABMS/ABMF, Anais, São paulo, Vol. 2: 313-333.

Alonso, U. R. (1996). Estacas Injetadas - Execução de Fundações Profundas. Fundações Teoria e Prática, Pini, São Paulo, SP, p. 361-364.

API RECOMMENDED PRACTICE 2A (RP2A) $18^{\text {th }}$ EDITION (1989). Recommended Pratice for Planning, Designing and Constructing Fixed Offshore Platforms. American Petroleum Institute, Washington, DC.

Azevedo e Niyama (1990). Congresso Brasileiro de Mecânica dos Solos e Engenharia de Fundaçãoes - Anais do $6^{\circ}$ CBGE. IX COBRAMSEF. Salvador, Novembro de 1990.

Baldi, G., Bellotti, R., Ghionna, V., Jamiolkowski, M., Marchetti, S. And Pasqualini, E. (1986). Flat Dilatometer Tests in Calibration Chambers. Proc. In Situ' 86 ASCE Spec. Conf. On "Use of In Situ Tests in Geotechnical Engineering", Virginia Tech, Blacksburg.

COOKE, R.U. Geomorphology in environmental management and introduction, Oxford.

DeCOURT L., (1995). On the load-settlement behavior of piles. Revista Solos e Rochas. Vol. 18 - n.2, Agosto de 1995.

Decourt L., (1996). Fundações: Teoria e Prática - PINI, Capítulo 9, Novembro de 1996.

Durgunoglu, H. T. And Mitchell, J. K. (1975). Static Penetration Resistance of Soils: I Analysis, II Evaluation of Theory and Implication for Practice. Symposium of In Situ Measurements of Soils Properties, ASCE, Raleigh, Vol. 1: 151-171.

FAILMEZGER R. AND TILL P. (2006). DMT testing for redesign using shallow foundations. Proceedings from the Second International Flat Dilatometer Conference, Washington, Abril de 2006, 92-96

FEllenius, B. H. (1996). Basics of Foundation Design. A geotechnical textbook and a background to the UniSoft programs. Static Analysis of Pile Load-Transfer. Cap. 5: 55-72

Giacheti H. L., PeiXoto A. S. P., Mio G. And Carvalho D. (2006). Flat Dilatometer Testing in Brazilian Tropical Soils. Proceedings from the Second International Flat Dilatometer Conference, Washington, Abril de 2006, 103-110.

HRYCIW R. D. (1990). Small-Strain Shear Modulus of Soil by Dilatometer. Journal of Geotechnical Engineering, ASCE, Vol. 116: 1700-1716. 
JamiolkowsKi, M. AND Garassino, A. (1977). Soil Modulus for Laterally Loaded Piles. Specialty Session 10, $9^{\text {th }}$ International Conference on Soil Mechanics and Foundation Engineering, ICSMFE, Vol. 1: 43-58.

JAMIOLKOWSKI, M. LADD, C.C (1985). New Developments in Field and Laboratory Testing soil "XI ISCMFE, Vol. 1, San Francisco, CA: 57-153.

Jamiolkowski, M., Ghionna, V.N., Lancellotta, R. And Pasqualini, E. (1988). New Correlations of Penetration Test for design practice. Proc. $1^{\text {st }}$ Int. Symp. On Penetration Testing, ISOPT-1, Orlando, 263-296.

JARDIM, N. A. (1998). Metodologia de Previsão de Capacidade de Carga Vertical e Horizontal com o Dilatômetro de Marchetti. Dissertação de Mestrado, Publicação G.DM - 054A/98, Departamento de Engenharia Civil, Universidade de Brasília.

LACASSE, S. AND LunE, T. (1988). Calibration of dilatometer correlations. Proc. $1^{\text {st }}$ Int. Symp. on Penetration Testing, ISOPT-1, Orlando, 539-548.

Lambe, T. W. And Whitman, R. V. (1969). Soil Mechanics. John Wiley and Sons Inc.

LunNe, T., LACASSE, S. AND RAD, N. S. (1989). State of the Art Report on In Situ Testing of Soils, $12^{\text {th }}$ International Conference on Soil Mechanic and Foundation Engineering, ICSMFE, Rio de Janeiro, RJ, Vol. 4: 2339-2403.

Lunne, T., Powell, J. J. M., Hauge, E. A., Uglow, I. M. And Mokkelbost, K. H. (1990). Correlation of Dilatometer Readings to Lateral Stress. $69^{\text {th }}$ Anual Meeting of the Transportation Research Board, Washington, DC, USA.

MARShall John P AND O'BerRy ROBERT A. (2006) - Uso do Dilatômetro em investigações Geotécnicas - Anais da Segunda Conferência Internacional de DMT - Washington, São Paulo.

Marchetti, S. (1980). In Situ Tests by Flat Dilatometer. Journal Geotechnical Engineering, ASCE, Vol. 106: 299-321.

MARCHETTI, S. AND CRAPPS, D. K. (1981). Flat Dilatometer Manual. Internal report of GPE Inc., Gainesville, FL

MarchetTi, S. (1985). On the Field Determination of $\mathrm{K}_{0}$ in Sand. Panel presentation Session, In Situ Tests Techniques, $11^{\text {th }}$ Inernational Conference on Soil Mechanics and Foundations Engineering, ICSMFE, San Francisco, Vol. 5: 2667-2672.

Marchetti, S., Totani, G., Calabrese, M. and Monaco, P. (1991). P-y Curves from DMT Data for Piles Driven in Clay. $4^{\text {th }}$ International Conference Deep Foundation, Inst. on Piling and Deep Foundations, Stresa, Vol. 1: 263-272.

Marchetti, S. (1997). The Flat Dilatometer: Design Applications. Third Geotechnical Engineering Conference, Cairo University, Keynote lecture, 26 p.

Marchetti, S., Totani, G., Calabrese, M. and Monaco, P. (2001). The flat dilatometer (DMT). Applications to Geotechnical Design. Report TC16 ISSMGE updated comprehensive ref. University of L'Aquila, Italy. Torino 20 Nov 2001, 57 p.

MASSAD, F. (1991a). Análise da transferência de carga em duas estacas insrumentada, quando submetidas a compressão axial. In: Seminário de Engenharia de Fundações Especiais 2, São Paulo, ABMS/ABMF, Anais, São paulo, Vol. 1: 235-244.

MASSAD, F. (1991b). Estacas escavadas em compressão axial: Comportamento e parâmetros visando a estimativa dos recalques. In: Seminário de Engenharia de Fundações Especiais 
2, São Paulo, ABMS/ABMF, Anais, São paulo, Vol. 1: 255-264.

NiYAma E AOKI (1990). Congresso Brasileiro de Mecânica dos Solos e Engenharia de Fundaçãoes - Anais do $6^{\circ}$ CBGE. IX COBRAMSEF. Salvador, Novembro de 1990.

NBR 12069 (1991). Solo - Ensaio de Penetração do Cone "in situ" (CPT). Associação Brasileira de Normas Técnicas, ABNT, 37 p.

NBR 6122 (1996). Projeto e Execução de Fundações. Associação Brasileira de Normas Técnicas, ABNT, 53 p.

NichidA, YoshichiKA (1954). Considerações teóricas sobre o atrito lateral das estacas de fundação. Instituto de Pesquisa Tecnológica, São Paulo, 36p.

ORtigão, J. A. R. (1994). Dilatometer Tests in Brasília Porous Clay. Proc. $7^{\text {th }}$ International Congress Int. Association. of Engineering Geology, IAEG, Lisboa, Portugal, p. 359-365.

PeiXoto, A.S.P. (2001). Estudo do ensaio SPT e sua aplicação na prática de engenharia de fundações. Tese de Doutorado, Feagri Unicamp, 2001, 468p.

PenNA, A. S. D. (2005). Apostila da palestra apresentada no Instituto de Engenharia, ABMS, São Paulo, Maio de 2005

PEnNA, A. S. D. (2006a). Shallow foundations of tall buildings, designed on the basis of DMT results. Proceedings from the Second International Flat Dilatometer Conference, Washington, Abril de 2006, 162-169

PEnNA, A. S. D. (2006b). Some recent experience obtained with DMT in Brazilian soils. Proceedings from the Second International Flat Dilatometer Conference, Washington, Abril de 2006, 170-177

Pinto, C. S. (2000). Curso Básico de Mecânica dos Solos, Oficina de Textos.

Poulos, H. G. (1979). Settlement of Singl Piles In Non-Homogeneous Soil. Journal of Geotechnical Engeneering, Vol. 105 (5): 627-641.

Poulos, H. G. AND DAVIS, E.H. (1980). Pile Foundation Analysis and Design. Ultimate Load capacity of Piles. Cap.3: 18-30.

Powell, J.J AND UgLOw, M (1988). Marchetti Dilatometer Testing in the UK Soils. Proc. $1^{\text {st }}$ Int. Symp. on Penetration Testing, ISOPT-1, Orlando, 555-562.

Powell, J.J.M., LunNe, T. \& Frank, R. (2001). "Semi-Empirical Design Procedures for axial pile capacity in clays. Proc. XV ICSMGE, Istanbul, Aug., Balkema.

RANDOLPH M.F AND WROTH C. P. (1978). Journal of the Geotechnical Engineering division. Analysis of Deformation of Vertically Loaded Piles, December, 1978.

RANDOLPH M.F. (1994). Design Methods for Pile Groups an Piles Rafts. Methodes de Conception pour Groupes de Pieux et Radiers de Pieux. New Delhi, India, 1994. 61-66.

Robertson, P. K., Davies, M. P., Campanalla, R.G and Sy, A. (1989). An Evaluation of Pile Design in Fraser River Delta Using In Situ Tests. Foundations Engineering Current Principles and Practices, ASCE, Evanston, IL, p. 92-105.

RotTMAnN, E. (1985). Previsões teóricas e resultados de instrumentação como elementos de projeto de estacas. Dissertação de mestrado. Escola Politécnica da USP. São Paulo, vol1, 209 pág.

Schmertmann, J. H. (1982). A Method for Determining the Friction Angle in Sands from the 
Marchetti Dilatometer tests. Proc. $2^{\text {nd }}$ European Symposium on Penetration Testing, ESOPT-II, Amsterdam, Vol. 2: 853-861.

SChMERTMANN, J. H. (1983). Revised Procedure for Calculating $\mathrm{K}_{0}$ and OCR from DMT's with $\mathrm{I}_{\mathrm{D}}>1.2$ and which Incorporates the Penetration Measurement to Permit Calculating the Plane Strain Friction Angle, DMT Digest $n^{0} 1$, GPE Inc, Gainesville, FL.

Schmertmann, J. H. (1986a). Suggested Method for Performing the Flat Dilatometer Test, Geotechnical Testing Journal, GTJODJ, Vol. 9 n ${ }^{\circ}$ 2: 93-101.

Schmertmann, J. H. (1986). Dilatometer to Computer Foundation Settlement. Proc. of In Situ' 86, ASCE Specialty Conference on Use of In Situ Tests and Geotechnical Engeneering, Virginia Tech, Blacksburg, Virginia, p. 303-321.

SCHMERTMANN, J. H. (1988). Guidelines for Using the CPT, CPTU and Marchetti DMT for Geotechnical Desing, Report $n^{0}$ FHWA-PA-87-023, Vol. 3-4.

SCHNAID, F. (2000). Ensaios de campo e suas aplicações à engenharia de fundações, Ed. Oficina de Textos, São Paulo.

Siviero, C. (2003). Obtenção de Parâmetros Geotécnicos Utilizando o Ensaio Dilatométrico (DMT), Dissertação de Mestrado da Escola Politécnica da Universidade de São Paulo.

SouZA, A. (2001). Estaca Piloto instrumentada: uma ferramenta para o estudo da capacidade de carga das estacas quando submetidas a esforços axiais de compressão, Dissertação de Doutorado da Escola Politécnica da Universidade de São Paulo.

TeiXeira, A. H. (1988). Capacidade de Carga de Estacas Pré-moldadas de Concreto nos Sedimentos Quaternários da Baixada Santista. SIDEQUA-Simpósio de Depósitos Quaternários das Baixadas Litorâneas Brasileiras. Rio de Janeiro, RJ. Agosto de 1988. Cap. 5:5.12-5.20.

TerZaghi, K. (1943). Theoretical Soil Mechanics. Joh Wiley and Sons Inc., New York.

TerZAGHI, K. and Peck (1948). Soil Mechanics in engineering practice. New York.

Tomlinsom, L.J. (1994). Pile Design and Construction practice. London, New York $4^{\mathrm{a}}$ ed.

Totani, G., Calabrese, M. And Monaco, P. (1998). In situ determination of $\mathrm{C}_{\mathrm{h}}$ by flat dilatometer (DMT). First International Conference On Site Caracterization ISC98. Atlanta Georgia, USA. Abril de 1998, Vol.2: 883-888.

U. S. Dot (1992). The Flat Dilatometer Test. Civil Eng. Dept. Texas A\&M Univ. For Fed. Highway Administrat., Washington D.C., Publ. FHWA-SA-91-044, by Briaud J.L. and Miran J., 102 p.

VAN DER VeEn, C. (1953). The Bearing Capacity of a Pile. International Conference on Soil Mechanics and Foundation Engineering, Suiça, Vol. 2.

Velloso, D. A E Lopes, F. R. (2002). Fundações. Fundações Profundas. Capacidade de Carga Axial - Métodos Estáticos. Vol.2. Cap.12: 75-102.

Velloso, D. A E Lopes, F. R. (2002). Fundações. Fundações Profundas. Estimativa de Recalques sob Carga Vertical. Vol.2. Cap.14: 179-201.

VESIC, A. S. (1975). Bearing capacity of shallow foundations. Foundation Engineering Handbook. Ed. Winterkorn e Fang, Van Nostrand Reinhold Comp. New York.

VESIC, A. S. (1977). Pile-soil intraction. Design of pile foundation. Syntesis of Highway Pratice n. 42, National Cooperative High Research Program of Transportation Research Board. 
9. ANEXOS 


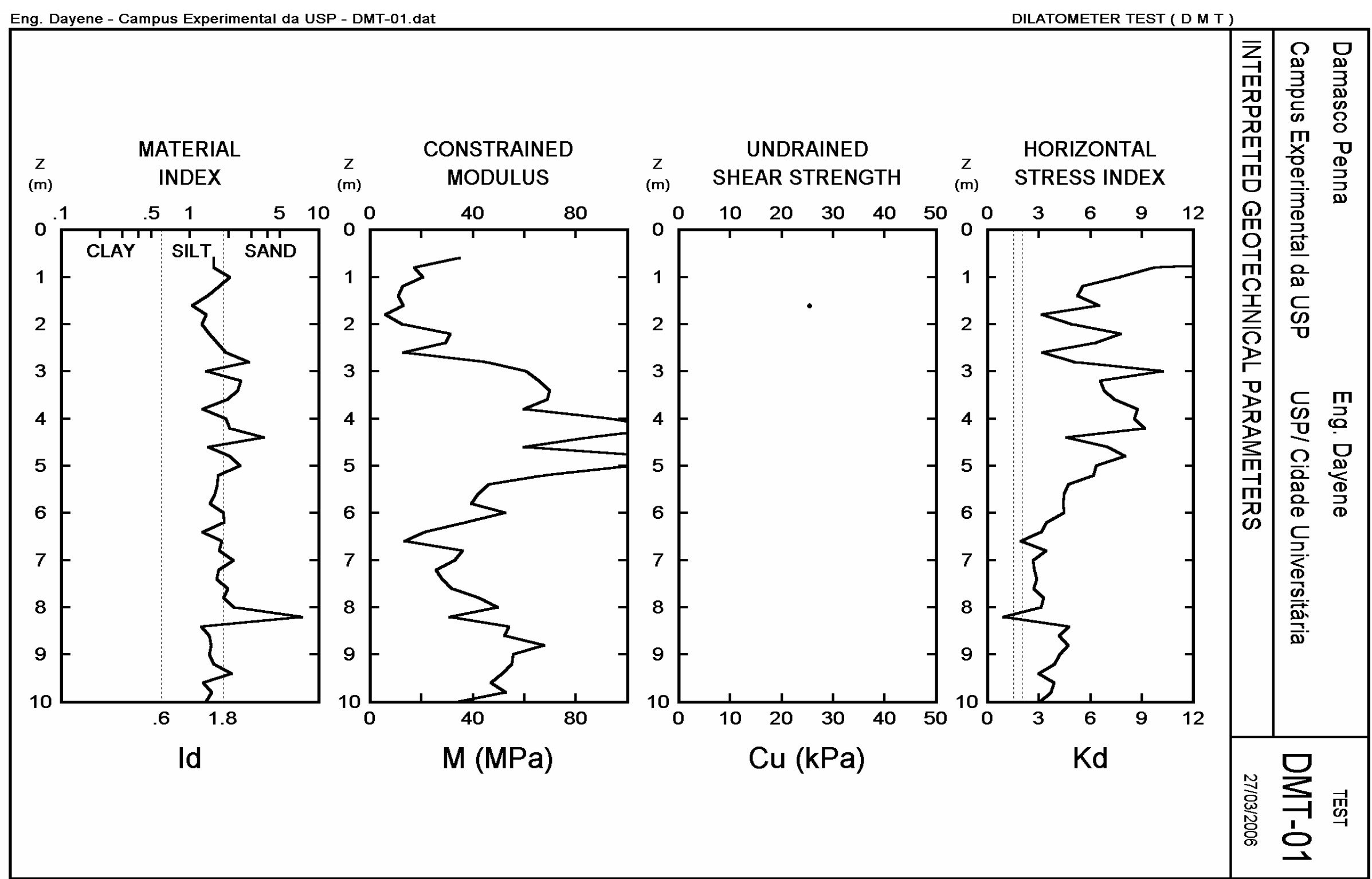




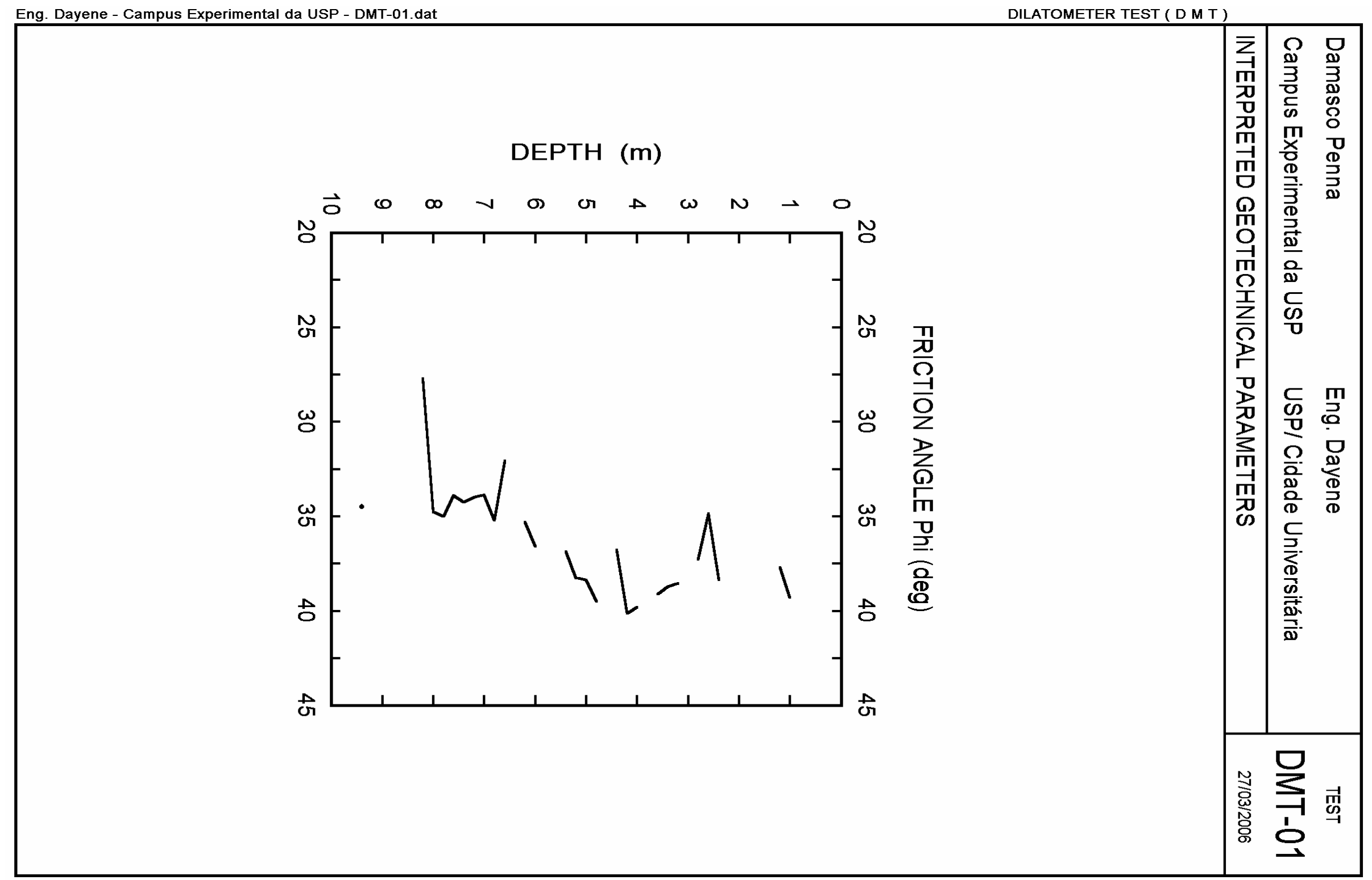




\begin{tabular}{|c|c|c|c|}
\hline DMT-01 & \multirow{3}{*}{$\begin{array}{l}\text { LEGEND } \\
\text { Z = Depth Below Ground Level } \\
\text { PO, P1, P2 = Corrected A, B, C readings } \\
\text { Id = Material Index } \\
\text { Ed = Dilatometer modulus } \\
\text { Ud = Pore Press. Index }=(\mathrm{P} 2-\mathrm{U} 0) /(\mathrm{PO}-\mathrm{U} 0) \\
\text { Garma = Bulk unit weight } \\
\text { Sigma' = Effective overb. stress } \\
\text { UO = Pore pressure }\end{array}$} & \multirow{3}{*}{$\begin{array}{l}\text { INTERPRETED PARAMETERS } \\
\text { Phi = Safe floor value of Friction Angle } \\
\text { Ko = In situ earth press. coeff. } \\
\text { M = Constrained modulus (at Sigma') } \\
\text { Cu = Undrained shear strength } \\
\text { Ocr = Overconsolidation ratio } \\
\text { (OCR = "relative OCR"- generally } \\
\text { realistic. If accurate independent OCR } \\
\text { available, apply suitable OCR Factor) }\end{array}$} & \multirow{3}{*}{$\begin{array}{l}\text { SOUNDING PARAMETERS } \\
\text { DeltaA }=11 \mathrm{kPa} \\
\text { DeltaB }=48 \mathrm{kPa} \\
\text { GammaTop }=17.0 \mathrm{kN} / \mathrm{m}^{\wedge} 3 \\
\text { FactorEd }=34.7 \\
\mathrm{Zm}=0.0 \mathrm{kPa} \\
\mathrm{Zabs}=100.0 \mathrm{~m} \\
\mathrm{Zw}>\text { zfinal }\end{array}$} \\
\hline $\begin{array}{l}\text { 27/03/2006Eng. Dayene - Campus } \\
\text { Experimental da USP - DMT-01.dat }\end{array}$ & & & \\
\hline $\begin{array}{l}\text { Damasco Penna } \\
\text { Eng. Dayene } \\
\text { Campus Experimental da USP } \\
\text { USP/ Cidade Universitária }\end{array}$ & & & \\
\hline
\end{tabular}

Water Level below end of sounding

Reduction formulae according to Marchetti, ASCE Geot.Jnl.Mar. 1980, Vol.109, 299-321; Phi according to TC16 ISSMGE, 2001

\begin{tabular}{|c|c|c|c|c|c|c|c|c|c|c|c|c|c|c|c|c|c|c|c|}
\hline$\underset{(m)}{z}$ & $\underset{(\mathrm{kPa})}{\mathrm{A}}$ & $\underset{(\mathrm{kPa})}{\mathrm{B}}$ & $\underset{(\mathrm{kPa})}{\mathrm{C}}$ & $\begin{array}{l}\mathrm{PO} \\
(\mathrm{kPa})\end{array}$ & $\begin{array}{l}\mathrm{P} 1 \\
\text { (kPa) }\end{array}$ & $\begin{array}{l}\mathrm{P2} \\
\text { (kPa) }\end{array}$ & $\begin{array}{c}\text { Gamma } \\
\left(\mathrm{kN} / \mathrm{m}^{\wedge} 3\right)\end{array}$ & $\begin{array}{l}\text { Sigma' } \\
\text { (kPa) }\end{array}$ & $\begin{array}{c}\mathrm{UO} \\
\text { (kPa) }\end{array}$ & Id & $\mathrm{Kd}$ & $\begin{array}{c}\mathrm{Ed} \\
(\mathrm{MPa})\end{array}$ & Ud & Ko & Ocr & $\begin{array}{l}\text { Phi } \\
\text { (Deg) }\end{array}$ & $\underset{(\mathrm{MPa})}{\mathrm{M}}$ & $\underset{(\mathrm{kPa})}{\mathrm{Cu}}$ & $\begin{array}{l}\text { DMT-01 } \\
\text { DESCRIPTION }\end{array}$ \\
\hline 0.6 & 210 & 570 & & 206 & 522 & & 16.7 & 10 & 0 & 1.53 & 20.2 & 11.0 & & & & & 34.7 & & SANDY SILT \\
\hline 0.8 & 130 & 380 & & 131 & 332 & & 15.7 & 14 & 0 & 1.53 & 9.7 & 7.0 & & & & & 17.2 & & SANDY SILT \\
\hline 1.0 & 130 & 440 & & 128 & 392 & & 17.7 & 17 & 0 & 2.05 & 7.7 & 9.1 & & & & 39 & 20.6 & & SILTY SAND \\
\hline 1.2 & 110 & 350 & & 112 & 302 & & 15.7 & 20 & 0 & 1.70 & 5.5 & 6.6 & & & & 38 & 12.8 & & SANDY SILT \\
\hline 1.4 & 120 & 340 & & 123 & 292 & & 15.7 & 23 & 0 & 1.37 & 5.3 & 5.9 & & & & & 11.0 & & SANDY SILT \\
\hline 1.6 & 170 & 400 & & 172 & 352 & & 16.7 & 26 & 0 & 1.04 & 6.5 & 6.2 & & 1.4 & 6.3 & & 12.9 & 25 & SILT \\
\hline 1.8 & 90 & 270 & & 95 & 222 & & 15.7 & 30 & 0 & 1.34 & 3.2 & 4.4 & & & & & 6.1 & & SANDY SILT \\
\hline 2.0 & 160 & 410 & & 161 & 362 & & 16.7 & 33 & 0 & 1.24 & 4.9 & 7.0 & & & & & 12.5 & & SANDY SILT \\
\hline 2.2 & 290 & 730 & & 282 & 682 & & 17.7 & 36 & 0 & 1.42 & 7.8 & 13.9 & & & & & 31.3 & & SANDY SILT \\
\hline 2.4 & 260 & 710 & & 251 & 662 & & 17.7 & 40 & 0 & 1.63 & 6.3 & 14.2 & & & & 38 & 29.3 & & SANDY SILT \\
\hline 2.6 & 140 & 450 & & 138 & 402 & & 17.7 & 43 & 0 & 1.90 & 3.2 & 9.1 & & & & 35 & 13.0 & & SILTY SAND \\
\hline 2.8 & 260 & 970 & & 238 & 922 & & 18.6 & 47 & 0 & 2.87 & 5.1 & 23.7 & & & & 37 & 45.2 & & SILTY SAND \\
\hline 3.0 & 540 & 1260 & & 518 & 1212 & & 19.1 & 51 & 0 & 1.34 & 10.2 & 24.1 & & & & & 60.7 & & SANDY SILT \\
\hline 3.2 & 390 & 1300 & & 358 & 1252 & & 18.6 & 54 & 0 & 2.49 & 6.6 & 31.0 & & & & 39 & 65.8 & & SILTY SAND \\
\hline 3.4 & 430 & 1380 & & 396 & 1332 & & 18.6 & 58 & 0 & 2.36 & 6.8 & 32.5 & & & & 39 & 69.8 & & SILTY SAND \\
\hline 3.6 & 490 & 1400 & & 458 & 1352 & & 19.6 & 62 & 0 & 1.95 & 7.4 & 31.0 & & & & 39 & 68.8 & & SILTY SAND \\
\hline 3.8 & 600 & 1350 & & 576 & 1302 & & 19.1 & 66 & 0 & 1.26 & 8.8 & 25.2 & & & & & 59.7 & & SANDY SILT \\
\hline 4.0 & 640 & 1790 & & 596 & 1742 & & 19.6 & 70 & 0 & 1.92 & 8.6 & 39.8 & & & & 40 & 93.6 & & SILTY SAND \\
\hline 4.2 & 730 & 2100 & & 675 & 2052 & & 19.6 & 74 & 0 & 2.04 & 9.2 & 47.8 & & & & 40 & 115.6 & & SILTY SAND \\
\hline 4.4 & 410 & 1750 & & 357 & 1702 & & 19.6 & 77 & 0 & 3.77 & 4.6 & 46.7 & & & & 37 & 85.3 & & SAND \\
\hline 4.6 & 600 & 1420 & & 573 & 1372 & & 19.1 & 81 & 0 & 1.39 & 7.0 & 27.7 & & & & & 59.8 & & SANDY SILT \\
\hline 4.8 & 740 & 2130 & & 684 & 2082 & & 19.6 & 85 & 0 & 2.04 & 8.0 & 48.5 & & & & 39 & 111.3 & & SILTY SAND \\
\hline 5.0 & 620 & 2010 & & 564 & 1962 & & 19.6 & 89 & 0 & 2.48 & 6.3 & 48.5 & & & & 38 & 101.2 & & SILTY SAND \\
\hline 5.2 & 610 & 1580 & & 575 & 1532 & & 19.1 & 93 & 0 & 1.66 & 6.2 & 33.2 & & & & 38 & 67.7 & & SANDY SILT \\
\hline 5.4 & 480 & 1250 & & 455 & 1202 & & 17.7 & 97 & 0 & $\begin{array}{l}1.64 \\
1.64\end{array}$ & 4.7 & 25.9 & & & & 37 & 46.0 & & SANDY SIIT \\
\hline 5.6 & 470 & 1200 & & 447 & 1152 & & 17.7 & 100 & 0 & 1.57 & 4.5 & 24.4 & & & & & 42.1 & & SANDY SILT \\
\hline 5.8 & 480 & 1170 & & 459 & 1122 & & 17.7 & 104 & 0 & 1.44 & 4.4 & 23.0 & & & & & 39.3 & & SANDY SILT \\
\hline 6.0 & 510 & 1400 & & 479 & 1352 & & 19.6 & 108 & 0 & 1.82 & 4.5 & 30.3 & & & & 37 & 52.6 & & SILTY SAND \\
\hline 6.2 & 410 & 1150 & & 387 & 1102 & & 18.6 & 111 & 0 & 1.85 & 3.5 & 24.8 & & & & 35 & 37.3 & & SILTY SAND \\
\hline 6.4 & 370 & 860 & & 359 & 812 & & 17.7 & 115 & 0 & 1.26 & 3.1 & 15.7 & & & & & 21.3 & & SANDY SILT \\
\hline 6.6 & 240 & 690 & & 231 & 642 & & 16.7 & 119 & 0 & 1.77 & 1.9 & 14.2 & & & & 32 & 13.5 & & SANDY SILT \\
\hline 6.8 & 440 & 1170 & & 417 & 1122 & & 17.7 & 122 & 0 & 1.69 & 3.4 & 24.4 & & & & 35 & 36.1 & & SANDY SILT \\
\hline 7.0 & 360 & 1120 & & 336 & 1072 & & 18.6 & 126 & 0 & 2.19 & 2.7 & 25.5 & & & & 34 & 32.8 & & SILTY SAND \\
\hline 7.2 & 370 & 990 & & 353 & 942 & & 17.7 & 129 & 0 & 1.67 & 2.7 & 20.4 & & & & 34 & 25.7 & & SANDY SILT \\
\hline 7.4 & 400 & 1050 & & 381 & 1002 & & 17.7 & 133 & 0 & 1.63 & 2.9 & 21.5 & & & & 34 & 28.1 & & SANDY SILT \\
\hline
\end{tabular}




\begin{tabular}{|c|c|c|c|c|c|c|c|c|c|c|c|c|c|c|c|c|c|c|c|c|}
\hline 7.6 & 390 & 1140 & & 366 & 1092 & & 18.6 & 136 & 0 & 1.98 & 2.7 & 25.2 & & & & 34 & 32.0 & & SIITY & SAND \\
\hline 7.8 & 490 & 1350 & & 461 & 1302 & & 19.6 & 140 & 0 & 1.82 & 3.3 & 29.2 & & & & 35 & 42.3 & & SILTY & SAND \\
\hline 8.0 & 490 & 1500 & & 453 & 1452 & & 19.6 & 144 & 0 & 2.20 & 3.1 & 34.6 & & & & 35 & 49.8 & & SILTY & SAND \\
\hline 8.2 & 180 & 1240 & & 141 & 1192 & & 18.6 & 148 & 0 & 7.46 & 1.0 & 36.5 & & & & 28 & 31.0 & & SAND & \\
\hline 8.4 & 750 & 1650 & & 719 & 1602 & & $\begin{array}{l}19.1 \\
19.1\end{array}$ & 152 & 0 & 1.23 & 4.7 & 30.6 & & & & & 54.1 & & SANDY & SILT \\
\hline 8.6 & 680 & 1610 & & 647 & 1562 & & 19.1 & 155 & 0 & 1.41 & 4.2 & 31.7 & & & & & 52.3 & & SANDY & SILT \\
\hline 8.8 & 790 & 1900 & & 748 & 1852 & & 19.1 & 159 & 0 & 1.47 & 4.7 & 38.3 & & & & & 67.7 & & SANDY & SILT \\
\hline $\begin{array}{l}9.0 \\
9.0\end{array}$ & 720 & 1700 & & 685 & 1652 & & 19.1 & 163 & 0 & 1.41 & 4.2 & 33.6 & & & & & 55.6 & & SANDY & SILT \\
\hline$\underset{(\mathrm{m})}{\mathrm{z}}$ & $\underset{(\mathrm{kPa})}{\mathrm{A}}$ & $\underset{(\mathrm{kPa})}{\mathrm{B}}$ & $\underset{(\mathrm{kPa})}{\mathrm{C}}$ & $\begin{array}{l}\mathrm{PO} \\
(\mathrm{kPa})\end{array}$ & $\begin{array}{l}\mathrm{P} 1 \\
(\mathrm{kPa})\end{array}$ & $\begin{array}{l}\text { P2 } \\
\text { (kPa) }\end{array}$ & $\begin{array}{c}\text { Gamma } \\
\left(\mathrm{kN} / \mathrm{m}^{\wedge} 3\right)\end{array}$ & $\begin{array}{l}\text { Sigma' } \\
(\mathrm{kPa})\end{array}$ & $\begin{array}{c}\mathrm{UO} \\
(\mathrm{kPa})\end{array}$ & Id & $\mathrm{Kd}$ & $\begin{array}{c}\mathrm{Ed} \\
(\mathrm{MPa})\end{array}$ & Ud & Ko & Ocr & $\begin{array}{l}\text { Phi } \\
\text { (Deg) }\end{array}$ & $\underset{(\mathrm{MPa})}{\mathrm{M}}$ & $\underset{(\mathrm{kPa})}{\mathrm{Cu}}$ & $\begin{array}{l}\text { DMI-01 } \\
\text { DESCRI }\end{array}$ & $\begin{array}{l}1 \\
\text { IPTION }\end{array}$ \\
\hline 9.2 & 690 & 1700 & & 653 & 1652 & & 19.1 & 167 & 0 & 1.53 & 3.9 & 34.6 & & & & & 55.3 & & SANDY & SILT \\
\hline 9.4 & 550 & 1630 & & 510 & 1582 & & 19.6 & 171 & 0 & 2.10 & 3.0 & 37.2 & & & & 34 & 51.3 & & SILTY & SAND \\
\hline 9.6 & 710 & 1590 & & 680 & 1542 & & 19.1 & 175 & 0 & 1.27 & 3.9 & 29.9 & & & & & 47.1 & & SANDY & SILT \\
\hline 9.8 & 700 & 1700 & & 664 & 1652 & & 19.1 & 179 & 0 & 1.49 & 3.7 & 34.3 & & & & & 52.9 & & SANDY & SILT \\
\hline 10.0 & 580 & 1340 & & 556 & 1292 & & 19.1 & 182 & 0 & 1.32 & 3.0 & 25.5 & & & & & 34.2 & & SANDY & SILT \\
\hline
\end{tabular}




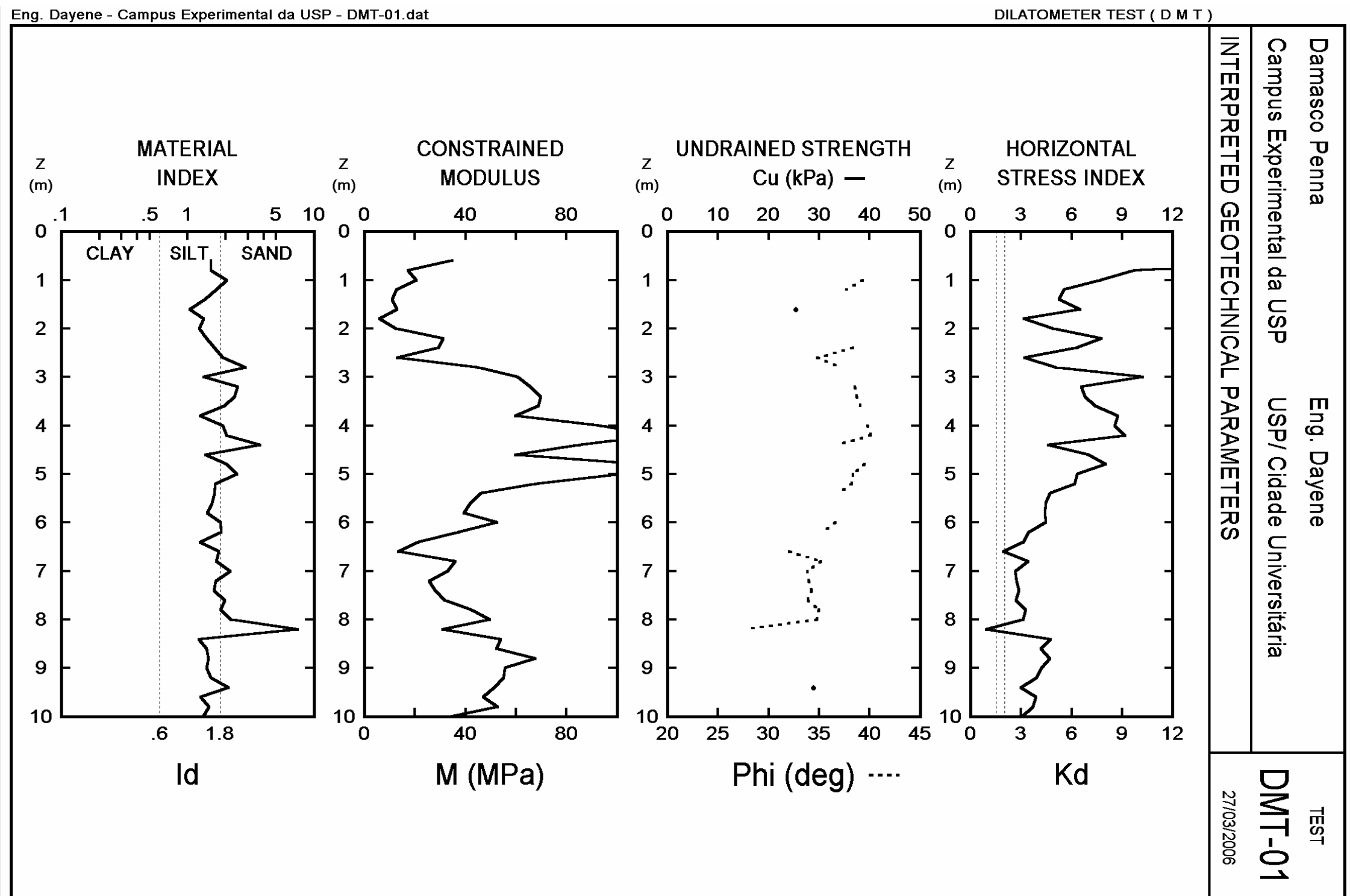




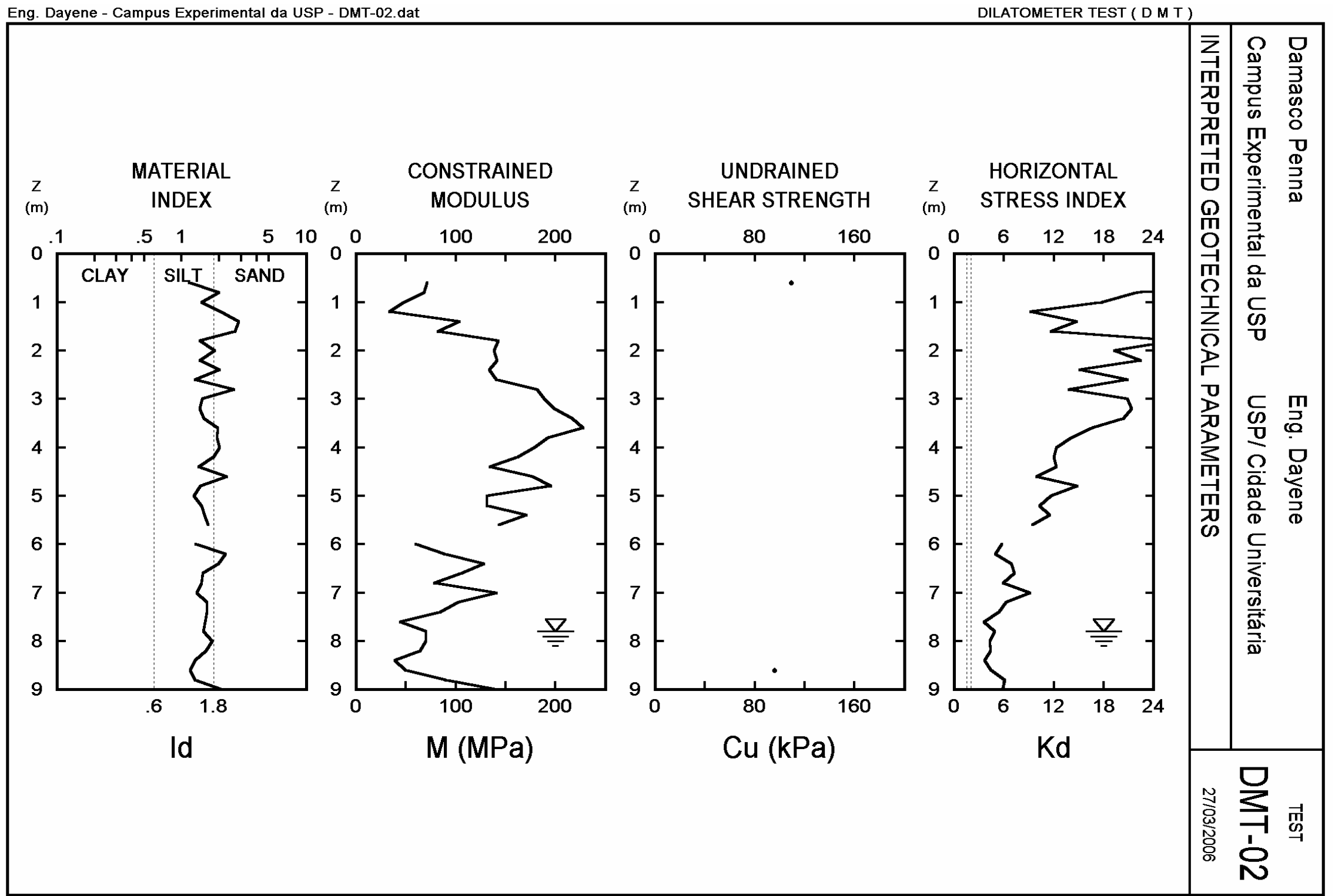




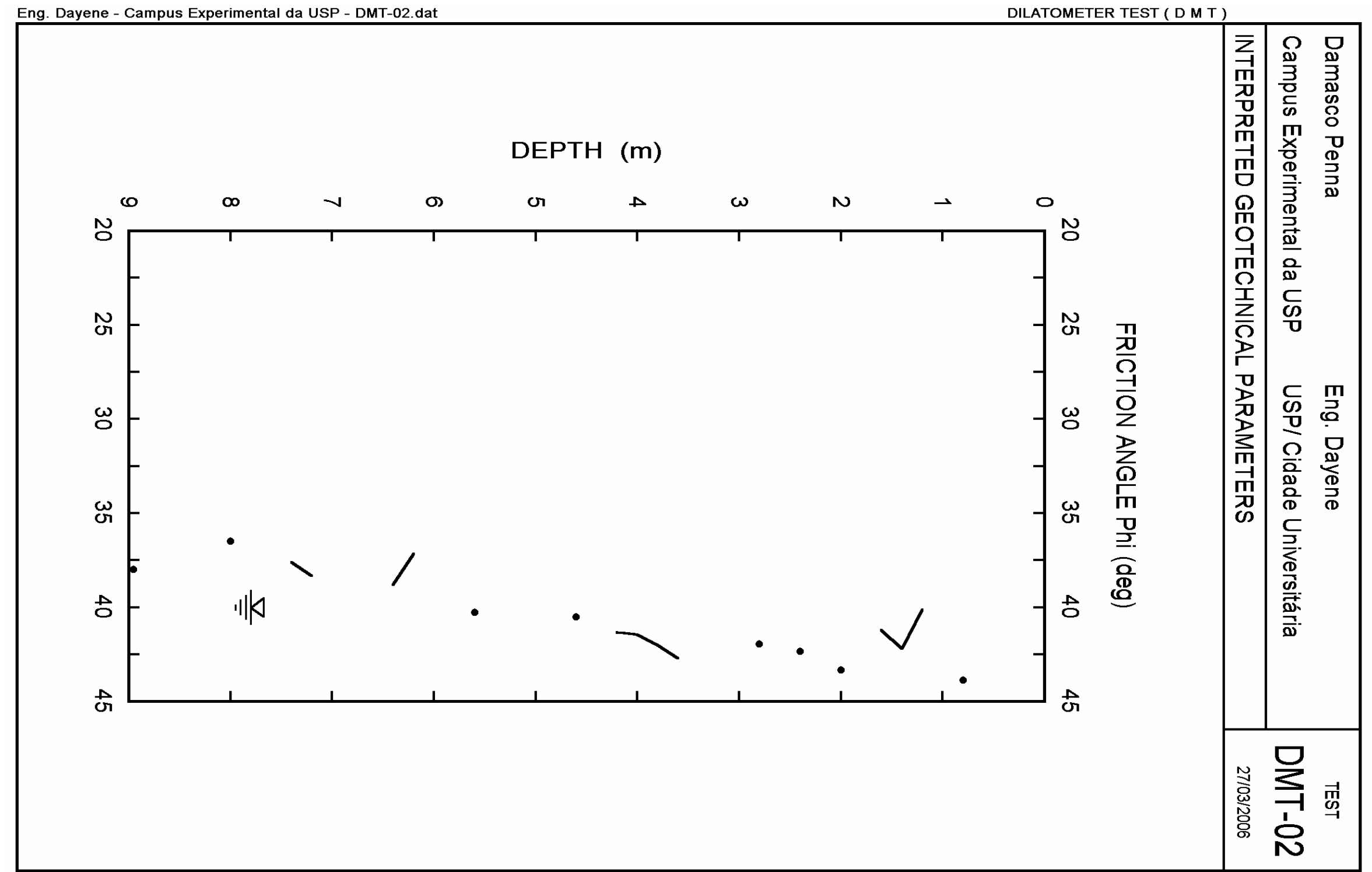




\begin{tabular}{|c|c|c|c|}
\hline DMT-02 & \multirow{3}{*}{$\begin{array}{l}\text { LEGEND } \\
\mathrm{z}=\text { Depth Below Ground Level } \\
\text { P0, P1, P2 = Corrected A, B,C readings } \\
\text { Id = Material Index } \\
\text { Ed = Dilatometer modulus } \\
\text { Ud = Pore Press. Index = (P2-UO) / (P0-U0) } \\
\text { Gamma = Bulk unit weight } \\
\text { Sigma' = Effective overb. stress } \\
\text { UO = Pore pressure }\end{array}$} & \multirow{3}{*}{$\begin{array}{l}\text { TNTERPRETED PARAMETERS } \\
\text { Phi = Safe floor value of Friction Angle } \\
\text { Ko = In situ earth press. coeff. } \\
\text { M = Constrained modulus (at Sigma') } \\
\text { Cu = Undrained shear strength } \\
\text { Ocr = Overconsolidation ratio } \\
\text { (OCR = "relative OCR"- generally } \\
\text { realistic. If accurate independent OCR } \\
\text { available, apply suitable OCR Factor) }\end{array}$} & \multirow{3}{*}{$\begin{array}{l}\text { SOUNDING PARAMETERS } \\
\text { DeltaA }=12 \mathrm{kPa} \\
\text { DeltaB }=58 \mathrm{kPa} \\
\text { GammaTop }=17.0 \mathrm{kN} / \mathrm{m}^{\wedge} 3 \\
\text { FactorEd }=34.7 \\
\mathrm{Zm}=0.0 \mathrm{kPa} \\
\mathrm{Zabs}=102.3 \mathrm{~m} \\
\mathrm{Zw}=7.8 \mathrm{~m}\end{array}$} \\
\hline $\begin{array}{l}\text { 27/03/2006Eng. Dayene - Campus } \\
\text { Experimental da USP - DMT-02.dat }\end{array}$ & & & \\
\hline $\begin{array}{l}\text { Damasco Penna } \\
\text { Eng. Dayene } \\
\text { Campus Experimental da USP } \\
\text { USP/ Cidade Universitária }\end{array}$ & & & \\
\hline
\end{tabular}

WaterTable at $7.8 \mathrm{~m}$

Reduction formulae according to Marchetti, ASCE Geot.Jnl.Mar. 1980, Vol.109, 299-321; Phi according to TC16 ISSMGE, 2001

\begin{tabular}{|c|c|c|c|c|c|c|c|c|c|c|c|c|c|c|c|c|c|c|c|}
\hline$\underset{(m)}{z}$ & $\underset{(\mathrm{kPa})}{\mathrm{A}}$ & $\underset{(\mathrm{kPa})}{\mathrm{B}}$ & $\underset{(\mathrm{kPa})}{\mathrm{C}}$ & $\begin{array}{l}\mathrm{PO} \\
(\mathrm{kPa})\end{array}$ & $\begin{array}{l}\mathrm{P} 1 \\
\text { (kPa) }\end{array}$ & $\begin{array}{l}\mathrm{P2} \\
\text { (kPa) }\end{array}$ & $\begin{array}{c}\text { Gamma } \\
\left(\mathrm{kN} / \mathrm{m}^{\wedge} 3\right)\end{array}$ & $\begin{array}{l}\text { Sigma' } \\
\text { (kPa) }\end{array}$ & $\begin{array}{c}\text { UO } \\
\text { (kPa) }\end{array}$ & Id & $\mathrm{Kd}$ & $\begin{array}{c}\mathrm{Ed} \\
(\mathrm{MPa})\end{array}$ & Ud & Ko & Ocr & $\begin{array}{l}\text { Phi } \\
\text { (Deg) }\end{array}$ & $\underset{(\mathrm{MPa})}{\mathrm{M}}$ & $\underset{(\mathrm{kPa})}{\mathrm{Cu}}$ & $\begin{array}{l}\text { DMT-02 } \\
\text { DESCRIPTION }\end{array}$ \\
\hline 0.6 & 470 & 1040 & & 457 & 982 & & 17.7 & 10 & 0 & 1.15 & 44.8 & 18.2 & & 4.3 & $>99.9$ & & 71.4 & 109 & SILT \\
\hline 0.8 & 320 & 970 & & 303 & 912 & & 18.6 & 14 & 0 & 2.01 & 22.1 & 21.1 & & & & 44 & 68.7 & & SILTY SAND \\
\hline 1.0 & 320 & 820 & & 311 & 762 & & 17.7 & 17 & 0 & 1.45 & 17.8 & 15.7 & & & & & 47.7 & & SANDY SILT \\
\hline 1.2 & 200 & 650 & & 193 & 592 & & 17.7 & 21 & 0 & 2.07 & 9.2 & 13.8 & & & & 40 & 33.5 & & SILTY SAND \\
\hline 1.4 & 400 & 1460 & & 363 & 1402 & & 18.6 & 25 & 0 & 2.87 & 14.8 & 36.1 & & & & 42 & 103.5 & & SILTY SAND \\
\hline 1.6 & 360 & 1280 & & 330 & 1222 & & 18.6 & 28 & 0 & 2.71 & 11.7 & 31.0 & & & & 41 & 81.9 & & SILTY SAND \\
\hline 1.8 & 900 & 2110 & & 855 & 2052 & & 19.1 & 32 & 0 & 1.40 & 26.7 & 41.5 & & & & & 142.5 & & SANDY SILT \\
\hline 2.0 & 740 & 2030 & & 691 & 1972 & & 19.6 & 36 & 0 & 1.85 & 19.3 & 44.5 & & & & 43 & 138.8 & & SILTY SAND \\
\hline 2.2 & 940 & 2200 & & 892 & 2142 & & 19.1 & 40 & 0 & 1.40 & 22.5 & 43.4 & & & & & 141.6 & & SANDY SILT \\
\hline 2.4 & 710 & 2050 & & 658 & 1992 & & 19.6 & 44 & 0 & 2.03 & 15.1 & 46.3 & & & & 42 & 133.8 & & SILTY SAND \\
\hline 2.6 & 1040 & 2320 & & 991 & 2262 & & 20.6 & 47 & 0 & 1.28 & 20.9 & 44.1 & & & & & 141.0 & & SANDY SILT \\
\hline 2.8 & 790 & 2640 & & 713 & 2582 & & 19.6 & 52 & 0 & 2.62 & 13.8 & 64.9 & & & & 42 & 182.0 & & SILTY SAND \\
\hline 3.0 & 1230 & 2920 & & 1161 & 2862 & & 20.6 & 56 & 0 & 1.47 & 20.9 & 59.0 & & & & & 188.8 & & SANDY SILT \\
\hline 3.2 & 1350 & 3120 & & 1277 & 3062 & & 20.6 & 60 & 0 & 1.40 & 21.4 & 61.9 & & & & & 199.5 & & SANDY SILT \\
\hline 3.4 & 1380 & 3330 & & 1298 & 3272 & & 20.6 & 64 & 0 & 1.52 & 20.4 & 68.5 & & & & & 217.3 & & SANDY SILT \\
\hline 3.6 & 1220 & 3390 & & 1127 & 3332 & & 21.1 & 68 & 0 & 1.96 & 16.6 & 76.5 & & & & 43 & 228.0 & & SILTY SAND \\
\hline 3.8 & 1100 & 3040 & & 1019 & 2982 & & 21.1 & 72 & 0 & 1.93 & 14.1 & 68.1 & & & & 42 & 192.6 & & SILTY SAND \\
\hline 4.0 & 1020 & 2910 & & 941 & 2852 & & 21.1 & 76 & 0 & 2.03 & 12.3 & 66.3 & & & & 41 & 178.9 & & SILTY SAND \\
\hline 4.2 & 1040 & 2780 & & 968 & 2722 & & 21.1 & 81 & 0 & 1.81 & 12.0 & 60.8 & & & & 41 & 162.7 & & SILTY SAND \\
\hline 4.4 & 1100 & 2540 & & 1044 & 2482 & & 20.6 & 85 & 0 & 1.38 & 12.3 & 49.9 & & & & & 134.6 & & SANDY SILT \\
\hline 4.6 & 970 & 2990 & & 884 & 2932 & & 21.1 & 89 & 0 & 2.31 & 10.0 & 71.0 & & & & 40 & 177.3 & & SILTY SAND \\
\hline 4.8 & 1460 & 3400 & & 1379 & 3342 & & 20.6 & 93 & 0 & 1.42 & 14.8 & 68.1 & & & & & 195.7 & & SANDY SILT \\
\hline 5.0 & 1190 & 2620 & & 1134 & 2562 & & 20.6 & 97 & 0 & 1.26 & 11.7 & 49.6 & & & & & 131.1 & & SANDY SILT \\
\hline 5.2 & 1100 & 2600 & & 1041 & 2542 & & 20.6 & 101 & 0 & 1.44 & 10.3 & 52.1 & & & & & 131.6 & & SANDY SILT \\
\hline 5.4 & 1290 & 3140 & & 1213 & 3082 & & 20.6 & 105 & 0 & $\begin{array}{l}1.44 \\
1.54\end{array}$ & 11.5 & 64.9 & & & & & 170.7 & & SANDY SIIT \\
\hline 5.6 & 1100 & 2780 & & 1032 & 2722 & & 20.6 & 110 & 0 & 1.64 & 9.4 & 58.7 & & & & 40 & 143.3 & & SANDY SILT \\
\hline 6.0 & 710 & 1620 & & 680 & 1562 & & 19.1 & 118 & 0 & 1.30 & 5.8 & 30.6 & & & & & 60.0 & & SANDY SILT \\
\hline 6.2 & 660 & 2040 & & 606 & 1982 & & 19.6 & 122 & 0 & 2.27 & 5.0 & 47.7 & & & & 37 & 88.9 & & SILTY SAND \\
\hline 6.4 & 940 & 2640 & & 870 & 2582 & & 21.1 & 126 & 0 & 1.97 & 6.9 & 59.4 & & & & 39 & 128.1 & & SILTY SAND \\
\hline 6.6 & 1000 & 2400 & & 945 & 2342 & & 20.6 & 130 & 0 & 1.48 & 7.3 & 48.5 & & & & & 106.3 & & SANDY SILT \\
\hline 6.8 & 830 & 1990 & & 787 & 1932 & & 19.1 & 134 & 0 & 1.45 & 5.9 & 39.7 & & & & & 78.9 & & SANDY SILT \\
\hline 7.0 & 1330 & 3000 & & 1262 & 2942 & & 20.6 & 138 & 0 & 1.33 & 9.2 & 58.3 & & & & & 140.8 & & SANDY SIIT \\
\hline 7.2 & 950 & 2390 & & 893 & 2332 & & 19.1 & 142 & 0 & 1.61 & 6.3 & 49.9 & & & & 38 & 102.7 & & SANDY SILT \\
\hline 7.4 & 840 & 2120 & & 791 & 2062 & & 19.1 & 146 & 0 & 1.61 & 5.4 & 44.1 & & & & 38 & 84.4 & & SANDY SILT \\
\hline
\end{tabular}




$\begin{array}{rrrrrrrrrrr}7.6 & 570 & 1440 & 542 & 1382 & 19.1 & 150 & 0 & 1.55 & 3.6 & 29.1 \\ 7.8 & 790 & 1930 & 748 & 1872 & 19.1 & 153 & 0 & 1.50 & 4.9 & 39.0 \\ 8.0 & 720 & 1920 & 675 & 1862 & 19.1 & 155 & 2 & 1.76 & 4.3 & 41.2 \\ 8.2 & 730 & 1830 & 690 & 1772 & 19.1 & 157 & 4 & 1.58 & 4.4 & 37.5 \\ 8.4 & 610 & 1390 & 586 & 1332 & 19.1 & 159 & 6 & 1.28 & 3.7 & 25.9 \\ 8.6 & 750 & 1620 & 722 & 1562 & 19.1 & 161 & 8 & 1.18 & 4.4 & 29.1 \\ 8.8 & 1060 & 2350 & 1011 & 2292 & 20.6 & 163 & 10 & 1.28 & 6.2 & 44.5 \\ 9.0 & 1060 & 3050 & 976 & 2992 & 21.1 & 165 & 12 & 2.09 & 5.9 & 70.0\end{array}$

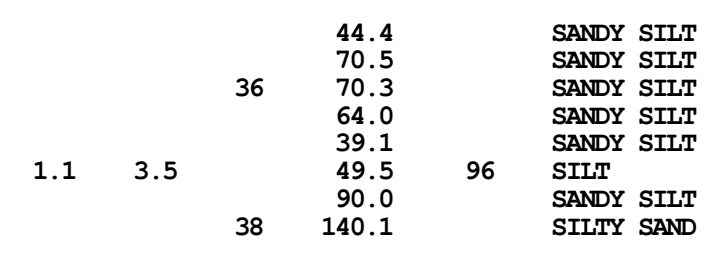




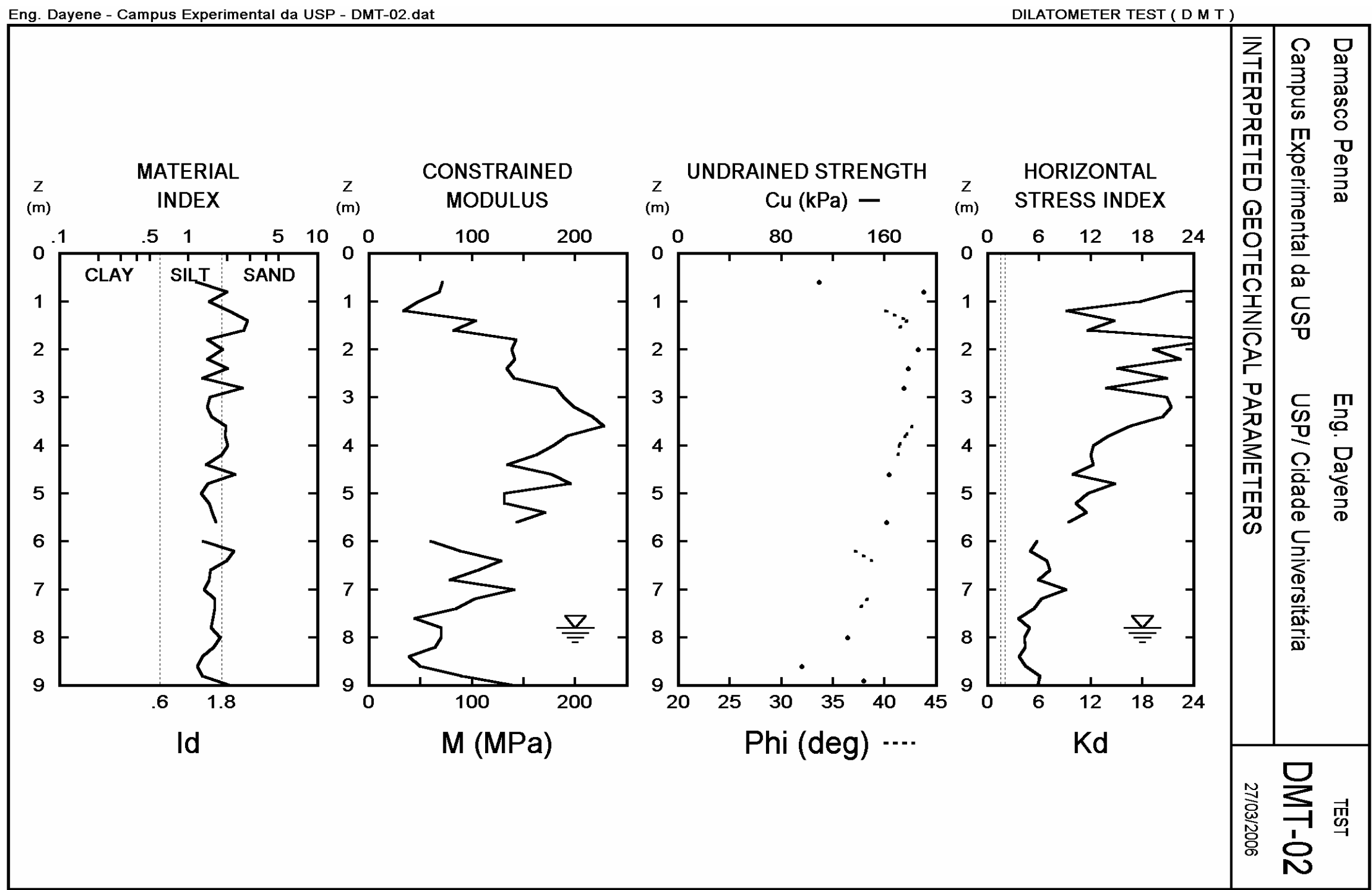




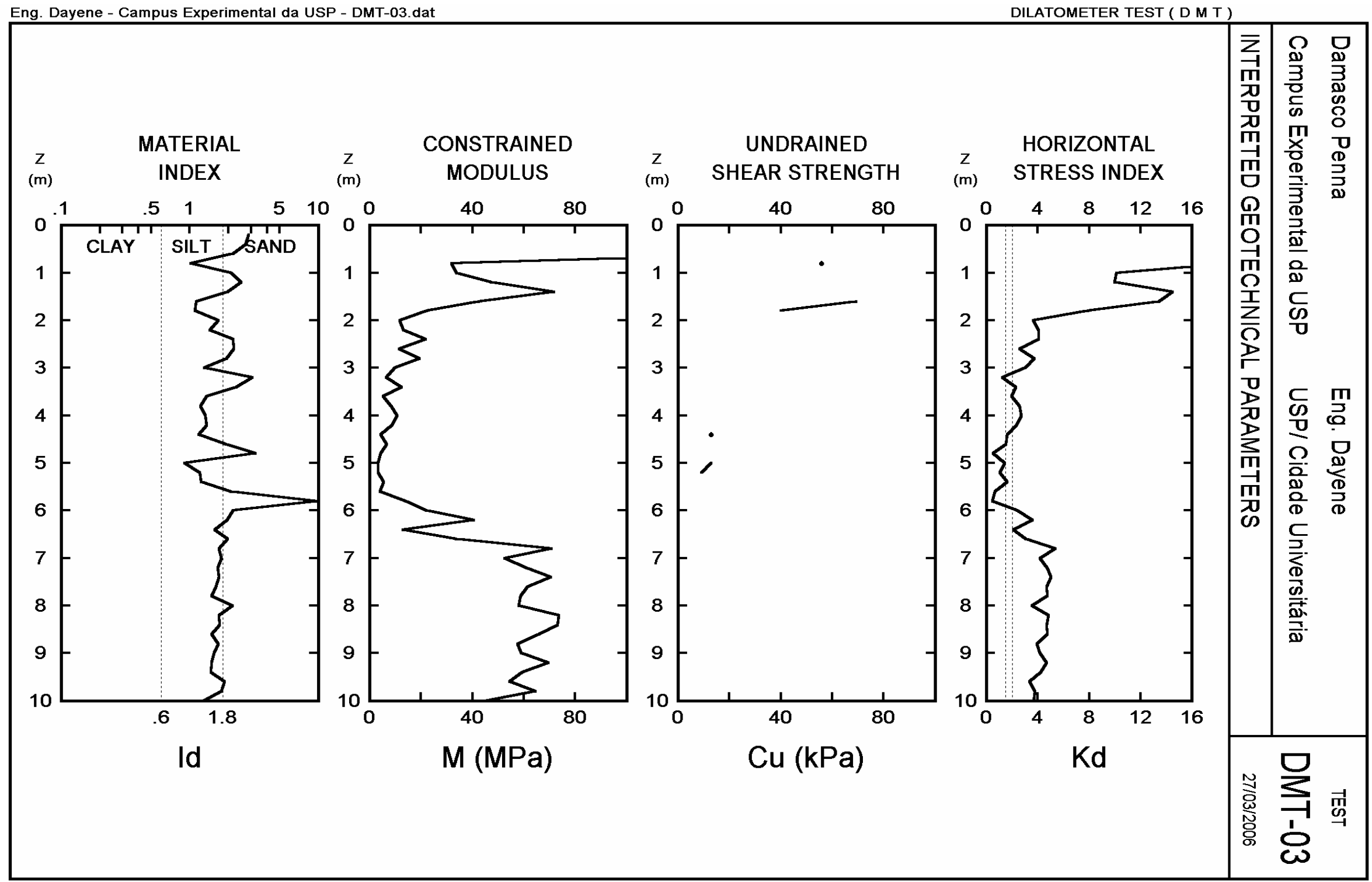




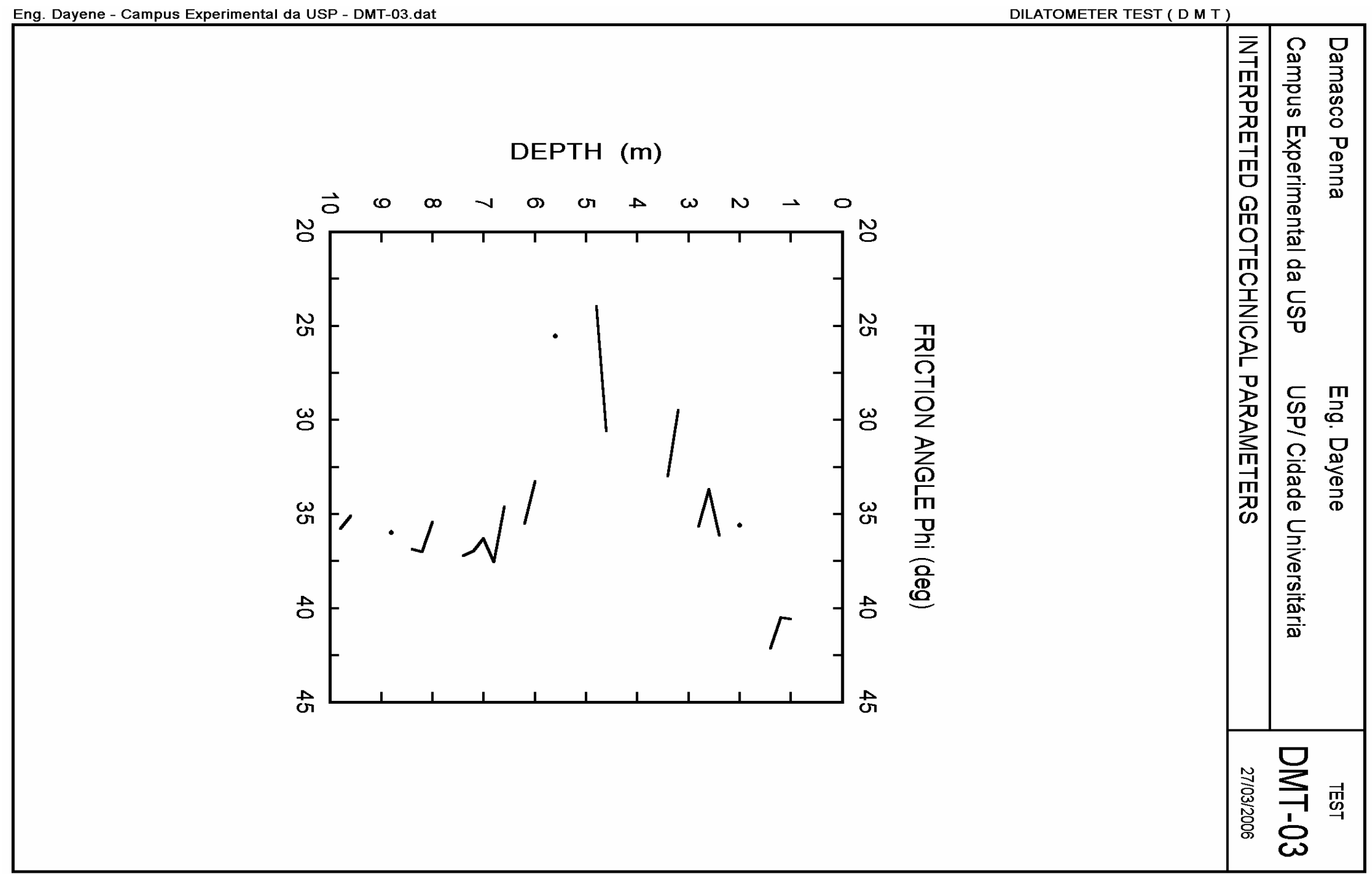




\begin{tabular}{|c|c|c|c|}
\hline DMT-03 & \multirow{3}{*}{$\begin{array}{l}\text { LEGEND } \\
\mathrm{z}=\text { Depth Below Ground Level } \\
\text { P0, P1, P2 = Corrected A, B,C readings } \\
\text { Id = Material Index } \\
\text { Ed = Dilatometer modulus } \\
\text { Ud = Pore Press. Index = (P2-UO) / (PO-UO) } \\
\text { Garma = Bulk unit weight } \\
\text { Sigma' = Effective overb. stress } \\
\text { UO = Pore pressure }\end{array}$} & \multirow{3}{*}{$\begin{array}{l}\text { INTERPRETED PARAMETERS } \\
\text { Phi = Safe floor value of Friction Angle } \\
\text { Ko = In situ earth press. coeff. } \\
\text { M = Constrained modulus (at Sigma') } \\
\mathrm{Cu}=\text { Undrained shear strength } \\
\text { OCr = Overconsolidation ratio } \\
\text { (OCR = "relative OCR"- generally } \\
\text { realistic. If accurate independent OCR } \\
\text { available, apply suitable OCR Factor) }\end{array}$} & \multirow{3}{*}{$\begin{array}{l}\text { SOUNDING PARAMETERS } \\
\text { DeltaA }=12 \mathrm{kPa} \\
\text { DeltaB }=58 \mathrm{kPa} \\
\text { GammaTop }=17.0 \mathrm{kN} / \mathrm{m}^{\wedge} 3 \\
\text { FactorEd }=34.7 \\
\mathrm{Zm}=0.0 \mathrm{kPa} \\
\mathrm{Zabs}=102.15 \mathrm{~m} \\
\mathrm{Zw}>\mathrm{zfinal}\end{array}$} \\
\hline $\begin{array}{l}\text { 27/03/2006Eng. Dayene - Campus } \\
\text { Experimental da USP - DMT-03.dat }\end{array}$ & & & \\
\hline $\begin{array}{l}\text { Damasco Penna } \\
\text { Eng. Dayene } \\
\text { Campus Experimental da USP } \\
\text { USP/ Cidade Universitária }\end{array}$ & & & \\
\hline
\end{tabular}

Water Level below end of sounding

Reduction formulae according to Marchetti, ASCE Geot.Jnl.Mar. 1980, Vol.109, 299-321; Phi according to TC16 ISSMGE, 2001

\begin{tabular}{|c|c|c|c|c|c|c|c|c|c|c|c|c|c|c|c|c|c|c|c|}
\hline$\underset{(m)}{Z}$ & $\underset{(\mathrm{kPa})}{\mathrm{A}}$ & $\underset{(\mathrm{kPa})}{\mathrm{B}}$ & $\underset{(\mathrm{kPa})}{\mathrm{C}}$ & $\begin{array}{l}\mathrm{PO} \\
(\mathrm{kPa})\end{array}$ & $\begin{array}{l}\mathrm{P} 1 \\
\text { (kPa) }\end{array}$ & $\begin{array}{l}\mathrm{P2} \\
\text { (kPa) }\end{array}$ & $\begin{array}{c}\text { Gamma } \\
\left(\mathrm{kN} / \mathrm{m}^{\wedge} 3\right)\end{array}$ & $\begin{array}{l}\text { Sigma' } \\
\text { (kPa) }\end{array}$ & $\begin{array}{c}\mathrm{UO} \\
(\mathrm{kPa})\end{array}$ & Id & $\mathrm{Kd}$ & $\begin{array}{c}E d \\
(\mathrm{MPa})\end{array}$ & Ud & Ko & Ocr & $\begin{array}{l}\text { Phi } \\
\text { (Deg) }\end{array}$ & $\begin{array}{c}\mathrm{M} \\
(\mathrm{MPa})\end{array}$ & $\underset{(\mathrm{kPa})}{\mathrm{Cu}}$ & $\begin{array}{l}\text { DMT-03 } \\
\text { DESCRIPTION }\end{array}$ \\
\hline 0.2 & 410 & 1500 & & 371 & 1442 & & 18.6 & 3 & 0 & 2.89 & $>99.9$ & 37.2 & & & & & 173.9 & & SILTY SAND \\
\hline 0.4 & 350 & 1250 & & 321 & 1192 & & 18.6 & 7 & 0 & 2.72 & 45.0 & 30.2 & & & & 46 & 118.6 & & SILTY SAND \\
\hline 0.6 & 540 & 1650 & & 500 & 1592 & & 19.6 & 11 & 0 & 2.18 & 46.1 & 37.9 & & & & 46 & 149.5 & & SILTY SAND \\
\hline 0.8 & 290 & 640 & & 288 & 582 & & 16.7 & 15 & 0 & 1.02 & 19.5 & 10.2 & & 2.7 & 35.0 & & 31.9 & 56 & SILT \\
\hline $\begin{array}{l}1.0 \\
1.0\end{array}$ & 190 & 630 & & 184 & 572 & & $\begin{array}{l}17.7 \\
17.7\end{array}$ & 18 & 0 & 2.12 & 10.1 & 13.5 & & 2.1 & US. & 41 & 33.9 & 50 & SILTY SAND \\
\hline 1.2 & 230 & 820 & & 216 & 762 & & 18.6 & 22 & 0 & 2.53 & 10.0 & 18.9 & & & & 40 & 47.3 & & SILTY SAND \\
\hline 1.4 & 390 & 1150 & & 368 & 1092 & & 18.6 & 25 & 0 & 1.97 & 14.5 & 25.1 & & & & 42 & 71.7 & & SILTY SAND \\
\hline 1.6 & 400 & 890 & & 391 & 832 & & 17.7 & 29 & 0 & 1.13 & 13.4 & 15.3 & & 2.2 & 19.6 & & 42.5 & 69 & SILT \\
\hline $\begin{array}{l}1.8 \\
1.8\end{array}$ & 260 & 600 & & 259 & 542 & & 16.7 & 33 & 0 & 1.10 & 7.9 & 9.8 & & 1.6 & 8.6 & & 22.3 & 40 & SILT \\
\hline 2.0 & 130 & 410 & & 132 & 352 & & 16.7 & 36 & 0 & 1.68 & 3.7 & 7.7 & & & & 36 & 11.8 & & SANDY SILT \\
\hline 2.2 & 160 & 450 & & 161 & 392 & & 16.7 & 39 & 0 & 1.43 & 4.1 & 8.0 & & & & & 13.1 & & SANDY SILT \\
\hline 2.4 & 180 & 610 & & 174 & 552 & & 17.7 & 43 & 0 & 2.17 & 4.1 & 13.1 & & & & 36 & 21.9 & & SILTY SAND \\
\hline 2.6 & 120 & 440 & & 120 & 382 & & 17.7 & 46 & 0 & 2.20 & 2.6 & 9.1 & & & & 34 & 11.4 & & SILTY SAND \\
\hline 2.8 & 190 & 600 & & 185 & 542 & & 17.7 & 50 & 0 & 1.93 & 3.7 & 12.4 & & & & 36 & 19.5 & & SILTY SAND \\
\hline 3.0 & 160 & 430 & & 162 & 372 & & 16.7 & 53 & 0 & 1.30 & 3.0 & 7.3 & & & & & 9.7 & & SANDY SILT \\
\hline 3.2 & 70 & 350 & & 71 & 292 & & 16.7 & 57 & 0 & 3.08 & 1.3 & 7.7 & & & & 29 & 6.5 & & SILTY SAND \\
\hline 3.4 & 140 & 510 & & 137 & 452 & & 17.7 & 60 & 0 & 2.30 & 2.3 & 10.9 & & & & 33 & 12.6 & & SILTY SAND \\
\hline 3.6 & 120 & 350 & & 124 & 292 & & 15.7 & 63 & 0 & 1.35 & 2.0 & 5.8 & & & & & 5.3 & & SANDY SILT \\
\hline 3.8 & 170 & 440 & & 172 & 382 & & 16.7 & 67 & 0 & 1.22 & 2.6 & 7.3 & & & & & 8.5 & & SANDY SILT \\
\hline 4.0 & 190 & 500 & & 190 & 442 & & 16.7 & 70 & 0 & 1.33 & 2.7 & 8.7 & & & & & 10.7 & & SANDY SILT \\
\hline 4.2 & 170 & 460 & & 171 & 402 & & 16.7 & 73 & 0 & 1.35 & 2.3 & 8.0 & & & & & 8.7 & & SANDY SILT \\
\hline 4.4 & 120 & 330 & & 125 & 272 & & 15.7 & 77 & 0 & 1.18 & 1.6 & 5.1 & & 0.44 & $<0.8$ & & 4.3 & 13 & SILT \\
\hline 4.6 & 120 & 410 & & 121 & 352 & & 17.7 & 80 & 0 & 1.91 & 1.5 & 8.0 & & & & 31 & 6.8 & & SILTY SAND \\
\hline 4.8 & 40 & 250 & & 45 & 192 & & 16.7 & 83 & 0 & 3.27 & 0.5 & 5.1 & & & & 24 & 4.3 & & SILTY SAND \\
\hline 5.0 & 120 & 300 & & 127 & 242 & & 15.7 & 87 & 0 & 0.91 & 1.5 & 4.0 & & 0.39 & $<0.8$ & & 3.4 & 13 & SIIT \\
\hline 5.2 & 90 & 270 & & 96 & 212 & & 15.7 & 90 & 0 & 1.20 & 1.1 & 4.0 & & $<0.3$ & $<0.8$ & & 3.4 & 9 & SILT \\
\hline
\end{tabular}




\begin{tabular}{|c|c|c|c|c|c|c|c|c|c|c|c|c|c|c|c|c|c|c|c|}
\hline 5.4 & 150 & 400 & & 153 & 342 & & 16.7 & 93 & 0 & 1.24 & 1.6 & 6.6 & & & & & 5.6 & & SANDY SILT \\
\hline 5.6 & 60 & 260 & & 66 & 202 & & 16.7 & 96 & 0 & 2.08 & 0.7 & 4.7 & & & & 26 & 4.0 & & SILTY SAND \\
\hline 5.8 & 60 & 590 & & 49 & 532 & & 16.7 & 100 & 0 & 9.86 & 0.5 & 16.8 & & & & & 14.2 & & SAND \\
\hline 6.0 & 260 & 840 & & 247 & 782 & & 18.6 & 103 & 0 & 2.17 & 2.4 & 18.6 & & & & 33 & 22.0 & & SILTY SAND \\
\hline 6.2 & 410 & 1200 & & 386 & 1142 & & 18.6 & 107 & 0 & 1.96 & 3.6 & 26.2 & & & & 36 & 40.6 & & SILTY SAND \\
\hline 6.4 & 240 & 660 & & 235 & 602 & & 16.7 & 110 & 0 & 1.57 & 2.1 & 12.8 & & & & & 12.9 & & SANDY SILT \\
\hline 6.6 & 370 & 1100 & & 349 & 1042 & & 18.6 & 114 & 0 & 1.99 & 3.1 & 24.0 & & & & 35 & 33.6 & & SILTY SAND \\
\hline 6.8 & 670 & 1760 & & 631 & 1702 & & 19.1 & 117 & 0 & 1.70 & 5.4 & 37.2 & & & & 38 & 70.9 & & SANDY SILT \\
\hline 7.0 & 540 & 1470 & & 509 & 1412 & & 19.1 & 121 & 0 & 1.77 & 4.2 & 31.3 & & & & 36 & 52.5 & & SANDY SILT \\
\hline 7.2 & 630 & 1640 & & 595 & $\begin{array}{l}1412 \\
1582\end{array}$ & & 19.1 & 125 & 0 & 1.66 & $\begin{array}{l}4.2 \\
4.8\end{array}$ & 34.2 & & & & 37 & 61.3 & & SANDY SILT \\
\hline 7.4 & 690 & 1810 & & 649 & 1752 & & 19.1 & 129 & 0 & 1.70 & 5.0 & 38.3 & & & & 37 & 70.7 & & SANDY SILT \\
\hline 7.6 & 660 & 1680 & & 624 & 1622 & & 19.1 & 133 & 0 & 1.60 & 4.7 & 34.6 & & & & & 61.5 & & SANDY SILT \\
\hline 7.8 & 680 & 1660 & & 646 & 1602 & & 19.1 & 137 & 0 & 1.48 & 4.7 & 33.2 & & & & & 58.9 & & SANDY SILT \\
\hline 8.0 & 540 & 1640 & & 501 & 1582 & & 19.6 & 140 & 0 & 2.16 & 3.6 & 37.5 & & & & 35 & 58.1 & & SILTY SAND \\
\hline 8.2 & 740 & 1930 & & 696 & 1872 & & 19.1 & 144 & 0 & 1.69 & 4.8 & 40.8 & & & & 37 & 73.6 & & SANDY SILT \\
\hline 8.4 & 740 & 1940 & & 695 & 1882 & & 19.1 & 148 & 0 & 1.71 & 4.7 & 41.2 & & & & 37 & 73.3 & & SANDY SILT \\
\hline 8.6 & 760 & 1850 & & 721 & 1792 & & 19.1 & 152 & 0 & 1.49 & 4.7 & 37.2 & & & & & 66.1 & & SANDY SILT \\
\hline$\underset{(\mathrm{m})}{\mathrm{z}}$ & $\underset{(\mathrm{kPa})}{\mathrm{A}}$ & $\underset{(\mathrm{kPa})}{\mathrm{B}}$ & $\underset{(\mathrm{kPa})}{\mathrm{C}}$ & $\begin{array}{l}\mathrm{PO} \\
\text { (kPa) }\end{array}$ & $\begin{array}{l}\mathrm{P} 1 \\
\text { (kPa) }\end{array}$ & $\begin{array}{l}\mathrm{P} 2 \\
\text { (kPa) }\end{array}$ & $\begin{array}{c}\text { Gamma } \\
\left(\mathrm{kN} / \mathrm{m}^{\wedge} 3\right)\end{array}$ & $\begin{array}{l}\text { Sigma' } \\
\text { (kPa) }\end{array}$ & $\begin{array}{c}\mathrm{UO} \\
(\mathrm{kPa})\end{array}$ & Id & $\mathrm{Kd}$ & $\begin{array}{r}\mathrm{Ed} \\
(\mathrm{MPa})\end{array}$ & Ud & Kо & Ocr & $\begin{array}{l}\text { Phi } \\
\text { (Deg) }\end{array}$ & $\underset{(\mathrm{MPa})}{\mathrm{M}}$ & $\underset{(\mathrm{kPa})}{\mathrm{Cu}}$ & $\begin{array}{l}\text { DMT-03 } \\
\text { DESCRIPTION }\end{array}$ \\
\hline 8.8 & 650 & 1700 & & 613 & 1642 & & 19.1 & 156 & 0 & 1.68 & 3.9 & 35.7 & & & & 36 & 57.5 & & SANDY SILT \\
\hline 9.0 & 700 & 1750 & & 663 & 1692 & & 19.1 & 160 & 0 & 1.55 & 4.2 & 35.7 & & & & & 59.1 & & SANDY SILT \\
\hline 9.2 & 810 & 1960 & & 768 & 1902 & & 19.1 & 163 & 0 & 1.48 & 4.7 & 39.3 & & & & & 69.6 & & SANDY SILT \\
\hline 9.4 & 740 & 1790 & & 703 & 1732 & & 19.1 & 167 & 0 & 1.46 & 4.2 & 35.7 & & & & & 59.3 & & SANDY SILT \\
\hline & 610 & 1700 & & 571 & 1642 & & 19.6 & 171 & 0 & 1.88 & 3.3 & 37.2 & & & & 35 & 54.5 & & SILTY SAND \\
\hline 9.8 & 710 & 1900 & & 666 & 1842 & & 19.1 & 175 & 0 & 1.77 & 3.8 & 40.8 & & & & 36 & 64.6 & & SANDY SILT \\
\hline 10.0 & 690 & 1570 & & 661 & 1512 & & 19.1 & 179 & 0 & 1.29 & 3.7 & 29.5 & & & & & 45.0 & & SANDY SILT \\
\hline
\end{tabular}




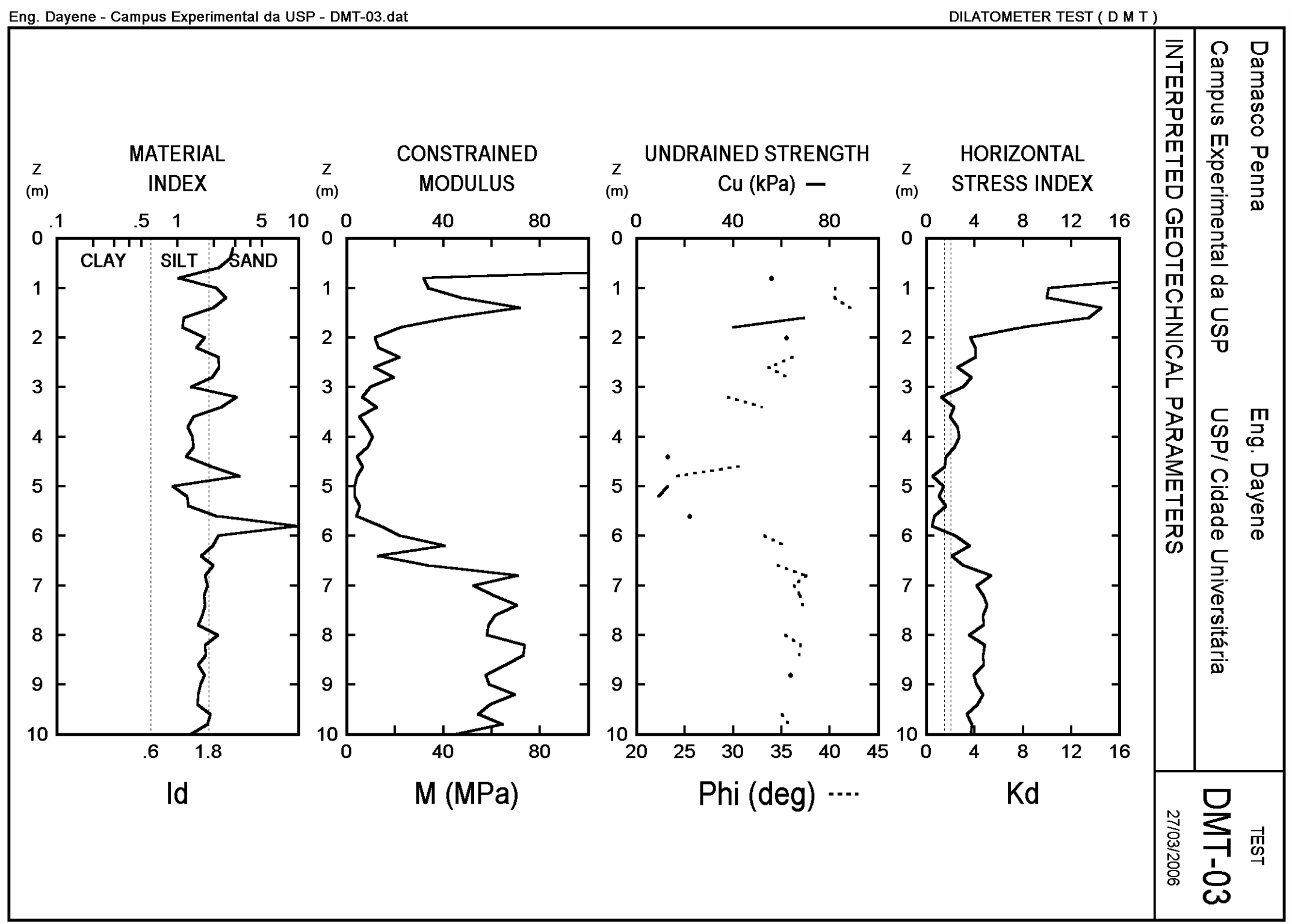

